
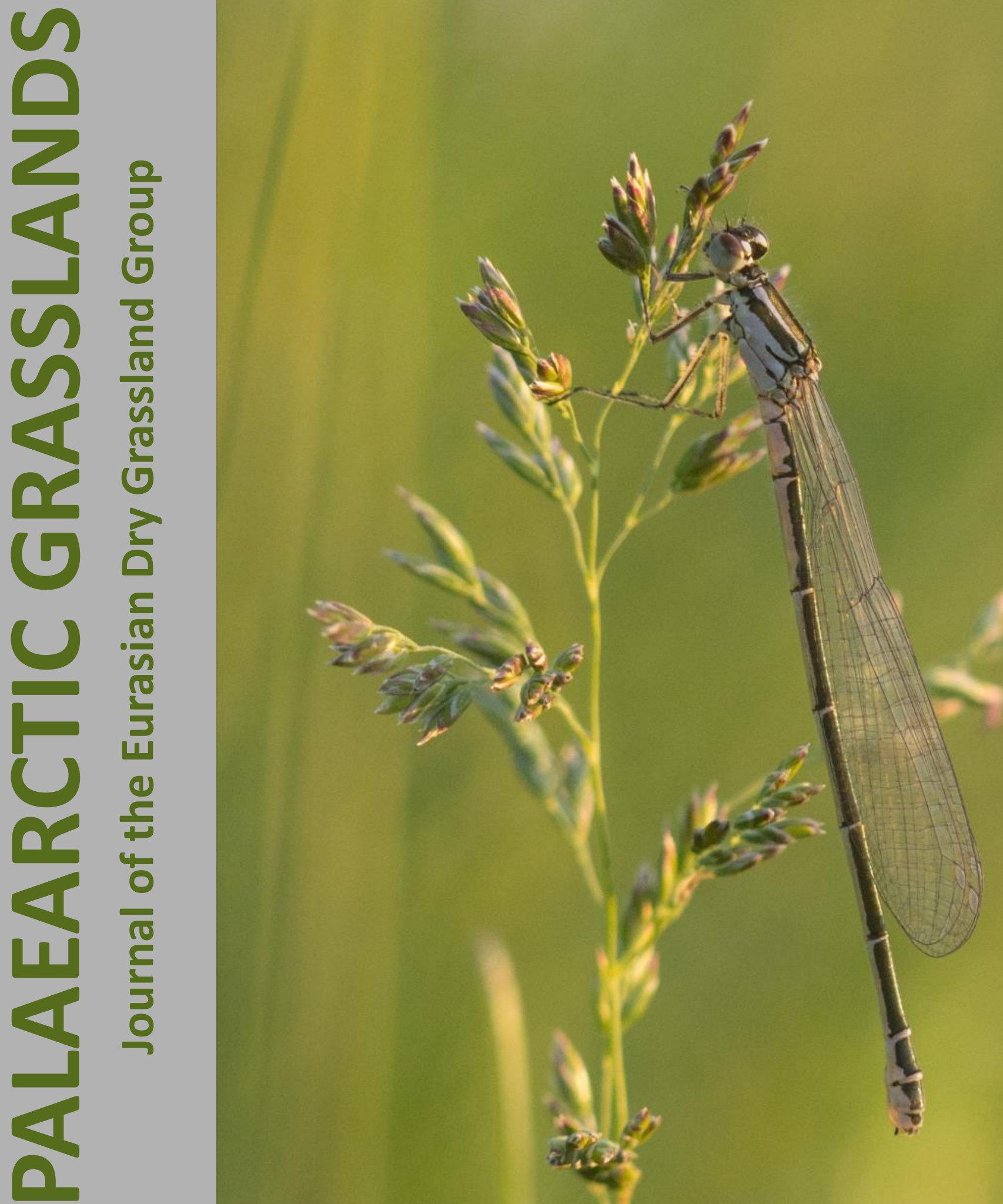


\section{Table of Contents}

Editorial

News

Aleksanyan et al.: Biodiversity of dry grasslands in Armenia: First results from the 13th EDGG Field Workshop in Armenia

Hilpold et al.: Proposal of a standardized EDGG surveying methodology for orthopteroid insects

Photo Stories

Glimpses of a Grassland

Best Shots on "Managing grasslands"

Short Contributions

Recent Publications of our Mem105 bers

Forthcoming Events

\section{Palaearctic Grasslands}

ISSN 2627-9827

DOI 10.21570/EDGG.PG46

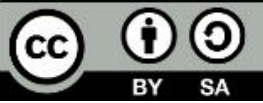

Palaearctic Grasslands, formerly published under the names Bulletin of the European Dry Grassland Group (Issues 1-26) and Bulletin of the Eurasian Dry Grassland Group (Issues 27-36) is the journal of the Eurasian Dry Grassland Group (EDGG). It usually appears in four issues per year. Palaearctic Grasslands publishes news and announcements of EDGG, its projects, related organisations and its members. At the same time it serves as outlet for scientific articles and photo contributions.

Palaearctic Grasslands is sent to all EDGG members and, together with all previous issues, it is also freely available at http://edgg.org/publications/bulletin.

All content (text, photos, figures) in Palaearctic Grasslands is open access and available under the Creative Commons license CC-BY-SA 4.0 that allow to re-use it provided proper attribution is made to the originators ("BY") and the new item is licensed in the same way ("SA" = "share alike").

Scientific articles (Research Articles, Reviews, Forum Articles, Scientific Reports) should be submitted to Jürgen Dengler (juergen.dengler@uni-bayreuth.de), following the Author Guidelines updated in Palaearctic Grasslands 45: 4. They are subject to editorial review, with one member of the Editorial Board serving as Scientific Editor and deciding about acceptance, necessary revisions or rejection.

All other text contributions (News, Announcements, Short Contributions, Book Reviews, Glimpses of a Grassland...) should be submitted to Anna Kuzemko (anyameadow.ak@gmail.com) AND Idoia Biurrun (idoia.biurrun@ehu.es). Please check a current issue of Palaearctic Grasslands for the format and style. Deadline for submission to the next issue is 15 September 2020

Photo and art contributions (for general illustrative purposes with captions; proposals for Photo Stories; contributions to Photo and Art Competition) should be submitted to our Photo Editor Rocco Labadessa (rocco.labadessa@gmail.com). Deadline for submissions to the next Photo Competition on "Home grasslands" is 15 September 2020.

Contributions to the section "Recent Publications of our Members" should be sent to Iwona Dembicz (i.dembicz@gmail.com) and those for "Forthcoming Events" to Alla Aleksanyan (alla.alexanyan@gmail.com).

Photos included in submissions have always to be delivered in two forms, embedded in the document and as separate jpg (or tiff) files with sufficient resolution for printing (i.e. not less than $1 \mathrm{MB}$ ).

Palaearctic Grasslands is published by EDGG c/o Prof. Dr. Jürgen Dengler, Plant Ecology, BayCEER, University of Bayreuth, Universitätsstr. 30, 85447 Bayreuth, Germany.

\section{Editorial Board}

CHIEF EDITOR:

Anna Kuzemko, Ukraine

DEPUTY CHIEF EDITORS:

Idoia Biurrun, Spain

Jürgen Dengler, Switzerland

EDITORAL BOARD:

Alla Aleksanyan, Armenia

Didem Ambarlı, Turkey

Dolores Byrne, Ireland

Iwona Dembicz, Poland

Edy Fantinato, Italy

Magdalena Firganek-Fulcher, UK

Paul Goriup, UK

Riccardo Guarino, Italy

Richard Jefferson, UK

Gwyn Jones, UK
Rocco Labadessa, Italy

Frank Yonghong Li, China

Ashley Lyons, UK

Lorna Marcham, UK

Jim Martin, Ireland

James Moran, Ireland

Jalil Noroozi, Austria

Arkadiusz Nowak, Poland

Salza Palpurina, Bulgaria

Nina Polchaninova, Ukraine

Solvita Rūsiṇa, Latvia

Stuart Smith, UK

Laura Sutcliffe, Germany

Péter Török, Hungary

Atushi Ushimaru, Japan

Orsolya Valkó, Hungary

Stephen Venn, Finland 


\section{Editorial}

Dear readers,

These are difficult times all around the world, where the Coronavirus pandemic is hitting hard and bringing pain and sorrow. The Palaearctic region has hopefully overcome the worst period, and now it is the time for all of us to restart our lives and projects, weep for the dead, and take care of the most vulnerable people. But we should not forget that this has not finished yet, and that in many parts of the World the pandemic is very active. Our hearts and minds are now with the people in those countries.

Many of us were not able to start our fieldwork for our projects in spring, we could not even go for a walk in the nature. Who knows, maybe some of you are still in this situation. When you are confined at home is when you most miss enjoying nature, specially in spring when the colours of flowers delight our eyes, and the air is full of the sounds of insects and the songs of birds. Several members of the Editorial Board of Palaearctic Grasslands realized that this was a common feeling among grassland researchers and conservationists, and decided to start a new section in our journal joining short contributions devoted to our favourite grasslands or places.

This new section is named "A Glimpse of a Grassland". In this issue, we present 12 glimpses from all over the Palaearctic, from the Basque Country (northern Spain) in the west, to the Russian Far East, from Sicily in the south, to Finland in the north. We hope that these glimpses will bring you the diversity and beauty of Palaearctic grasslands, and that what started as a kind of consolation during the Pandemic will continue in future issues of Palaearctic Grasslands. All of you are invited to show us your beloved grasslands and their biota with such short glimpses.

Although we could not go out to the countryside, we were working hard in our homes, and of course this issue also brings contributions from our regular sections, such as two nice Photo Stories. I would also like to highlight the Scientific Report on the 13th EDGG Field Workshop in Armenia, which may serve as some kind of consolation for the postponement of the 14th Field Workshop in Eastern Ukraine to 2021. Actually, the pandemic has damaged many EDGG activities, and both the Field Workshop in Ukraine and the Eurasian Grassland Conference in Tolosa have been postponed to 2021, as you can read in our News section.

Last but not least, this issue includes an outstanding scientific report introducing a standardized methodology for the sampling of orthopteran insects, which is fully compatible with the EDGG sampling methodology. This is a very useful paper that will probably be a keystone in zoological sampling and in general in the study of the biological community of grasslands.

I wish all of you to stay healthy and keep working in our beloved grasslands, and I hope that you will enjoy reading this issue, created in the middle of the pandemic. And of course, I wish that we can meet as soon as possible, be it in the field or in a meeting.

Idoia Biurrun, Deputy Chief Editor

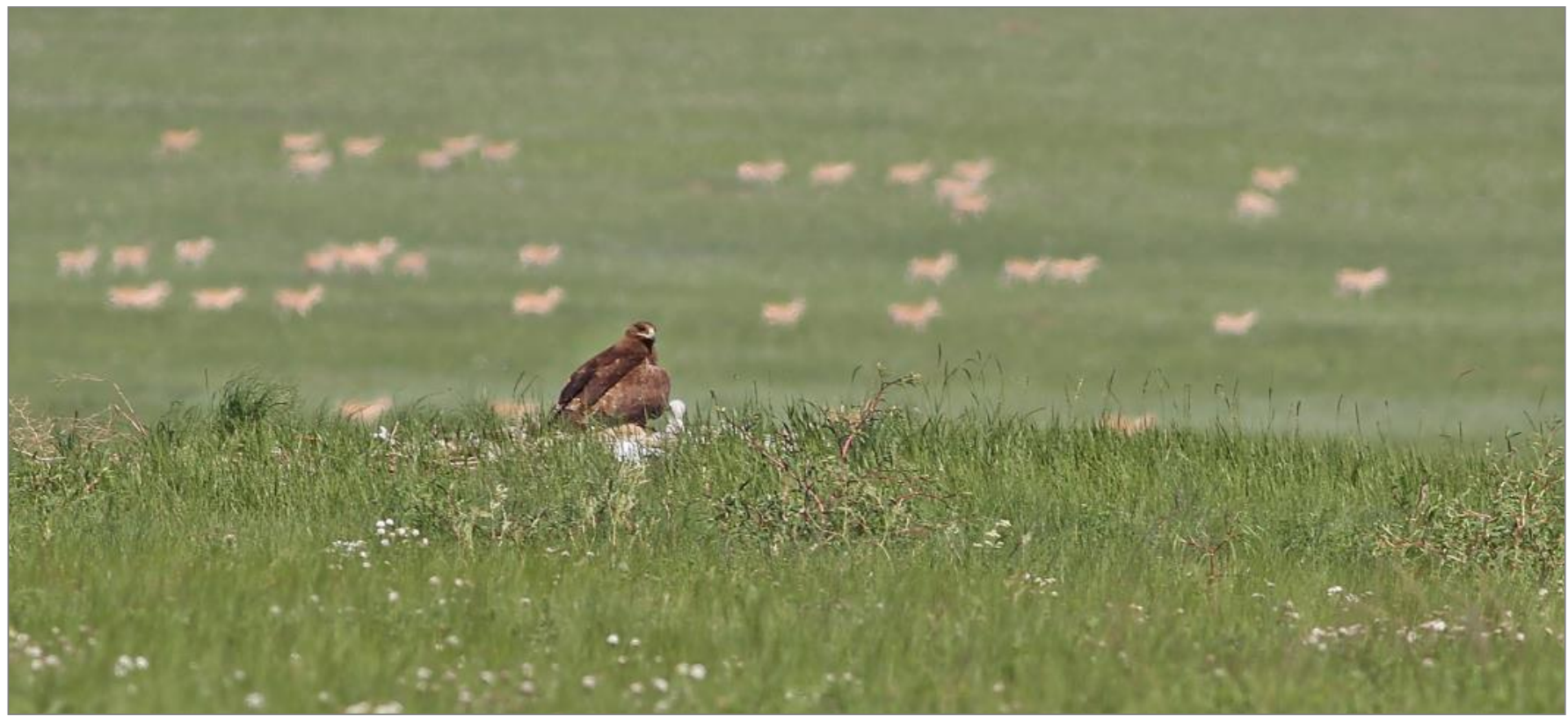




\section{News}

\section{EDGG Field Workshops postponed}

Due to the Coronavirus pandemic, the EDGG Executive Committee, in accordance with the local organizers, decided to postpone the 14th Field Workshop in Ukraine to 2021. Therefore, the schedule for next years' Field Workshop announced in PG 45 (p. 4) has been rearranged, after consultation with all the organizers:

15th EDGG Field Workshop in South Tyrol, hosted by Andras Hilpold and team, has been postponed to summer 2022.

\section{Postponing EDGG conferences}

This year we planned to have our annual conference in Tolosa, Spain and announced the second call for the conference after the Covid-19 pandemic had begun. Due to the severity of the pandemic, the local organizing committee (Idoia Biurrun, Itziar García-Mijangos, Javier Loidi, Juan Antonio Campos, Isabel Salcedo, Peter B. Pearman, Asun Berastegi), in consultation with the EDGG Executive Committee, decided to postpone the conference until 2021. There were two main reasons for our decision: Firstly, even if the pandemic will hopefully be over shortly, still travel limitations and risks related to the second wave are expected. We did not want to put our participants at risk by making them travel long distances and gathering several people around the Palearctic in one big event. Secondly, as of $20^{\text {th }}$ June, there are still Coronapositive cases and losses; we realized that we may run 16th EDGG Field Workshop in Picos de Europa, hosted by Amparo Mora and team, has been postponed to summer 2023.

Exact dates of the 14th Field Workshop in Ukraine, organized by Denys Vynokurov and team, will be announced in early autumn, on our website, media and in Palaearctic Grasslands.

EDGG Executive Committee

out of time for the organization even if the pandemic would be over in July. Registered participants were informed immediately about the postponement and their fees repaid.

The conference will be held with the same theme, sessions and a similar schedule next year. Detailed information on dates and registration will be announced on the EDGG website, as well as in Palaearctic Grasslands, during autumn 2020. We hope that our keynote speakers and participants will be able to join us and we will welcome all of you in Tolosa. Consequently, the conference planned to be organized by Peter Török and his colleagues next year in Hungary, has been postponed until 2022. We hope to meet in healthy days!

EDGG Executive Committee

\section{EDGG website: New pages and functionalities}

We have two new pages devoted to the special features of EDGG: Under the Publications in the main menu at the top, you can find the page of the Ongoing Special Features and the page presenting Past Special Features of the EDGG. The purpose of the first one is to attract attention for planned special features and provide detailed information about the planned journals, editors, outlines, submission information and deadlines. We encourage all grassland researchers to visit this site regularly and plan the submission of an abstract! In the Past Special Features page, we checked and updated all paper links. Finally, we also moved Publications from our Members page to the submenu of the Publications. The aim of this page is to present a list of recent and past publications about Palearctic grasslands. In this page, the publication information provided by our members are listed under different topics and then chronologically. We intend to make this page as comprehensive as possible. Therefore, please send us references of your publications.

EDGG Executive Committee 


\section{vegsciblog.org: \\ Palaearctic Grasslands is now also part of the official blog of the IAVS journals}

The Vegetation Science Blog is the official blog of the IAVS journals and hitherto published news from Journal of Vegetation Science, Applied Vegetation Science, Vegetation Classification and Survey and the IAVS Bulletin. From now on, also Palaearctic Grasslands will use this opportunity to announce news and increase the visibility of the journal and the individual articles. The Chief Editor Team, like the chief editors of the other journals, will announce the publication of new issues and inform about important editorial news.

Moreover, authors of peer-reviewed articles in Palaearctic Grasslands have the possibility to publicize their paper upon publication via a blog. Four types of contributions are possible:

- Behind the Paper - a longer post describing what was happening behind the scenes of your research, possibly written in a rather informal way, and including several photographs or figures.

- Plain Language Summary - a short (up to 500 words) summary written in plain English, describing your research in everyday language which is understandable also to the non-research audience and including 1-2 illustrative photographs or figures.

- Video summary - if you have prepared the presentation of your research (for a past or future conference meeting, university seminar, working group meeting), you may record a short (up to 10-15 minutes) commented video with the slide presentation.

- Linking to elsewhere - if you already wrote a post about your paper for another blog or media, we may publish a short announcement (with photograph or figure) advertising the paper and including the link to that post.

Further details can be found at https://vegsciblog.org/ author-guidelines/. You can submit your contribution when your article in PG is published via submission to the blog editors David Zeleny, Viktoria Wagner and Peter Minchin at editor@vegsciblog.org.

You can subscribe to the blog of all five journals at: https:// vegsciblog.org/

Jürgen Dengler, Wädenswil, Switzerland (juergen.dengler@uni-bayreuth.de)

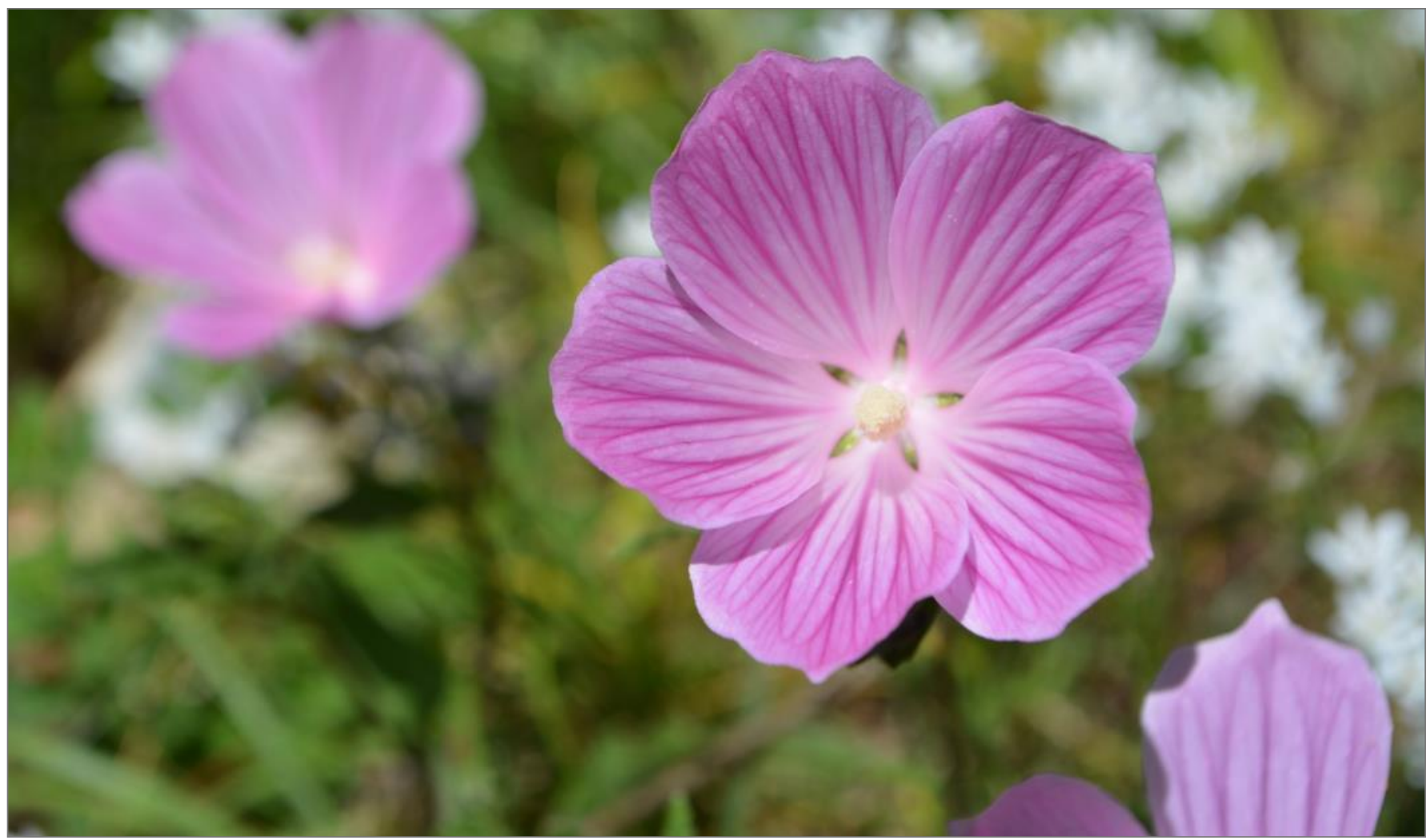




\section{T-shirt competiton results}

We are pleased to inform you about the results of the first EDGG T-shirt motif competition, announced in issue 43 of Palaearctic Grasslands.

Prior to the extended deadline, we received seven EDGG Tshirt motif proposals. Many thanks to all the authors!!!

The proposals were evaluated by a jury of eight members, consisting of Alla Aleksanyan, Didem Ambarlı, Idoia Biurrun,

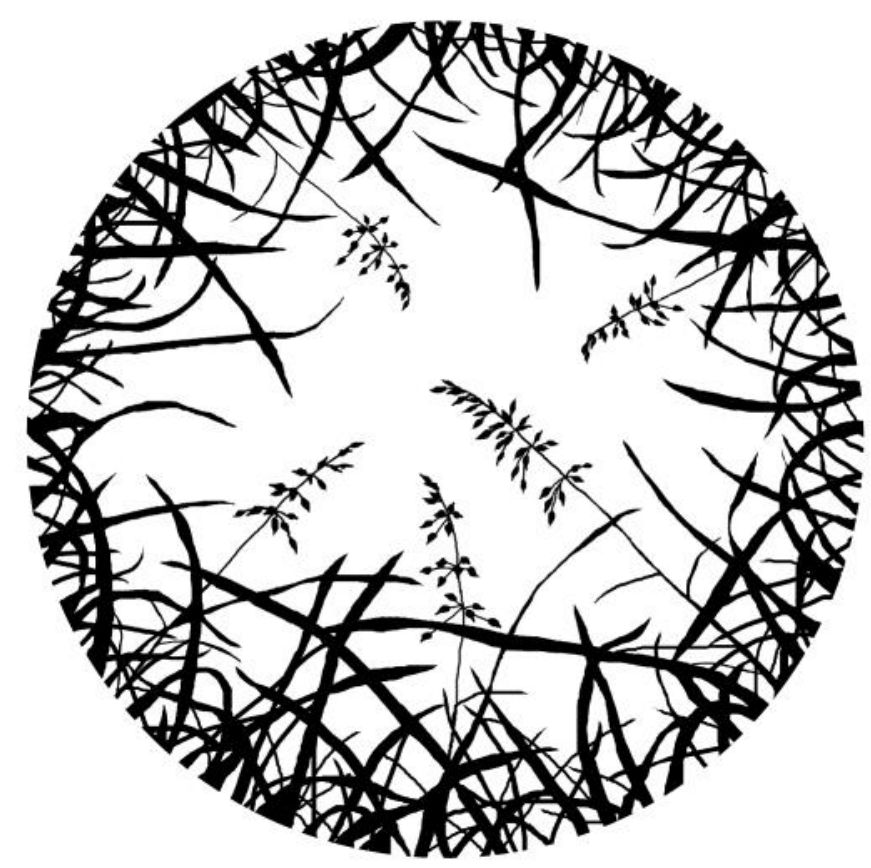

The best motif ( $1^{\text {st }}$ place) will be used to create the firstever EDGG T-shirt, which then, among others, will be available for purchase at the EDGG events in 2021. Note that the final T-shirt might slightly differ from this design,
Iwona Dembicz, Riccardo Guarino, Monika Janišová, Stephen Venn \& Denys Vynokurov. The jury did not only rank the proposals according to their suitability and aesthetics, but also collected ideas for possible further improvement of each motif.

Here are the three motives with the highest scores - congratulations to the winners:

2nd place-motif by Rocco Labadessa

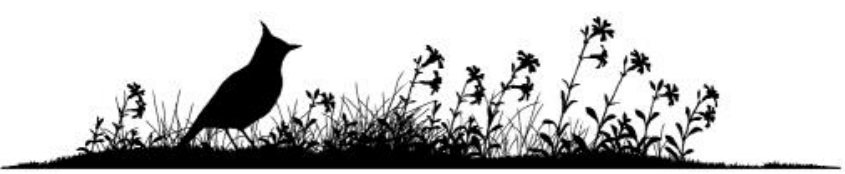

3rd place-motif by Anna Kuzemko
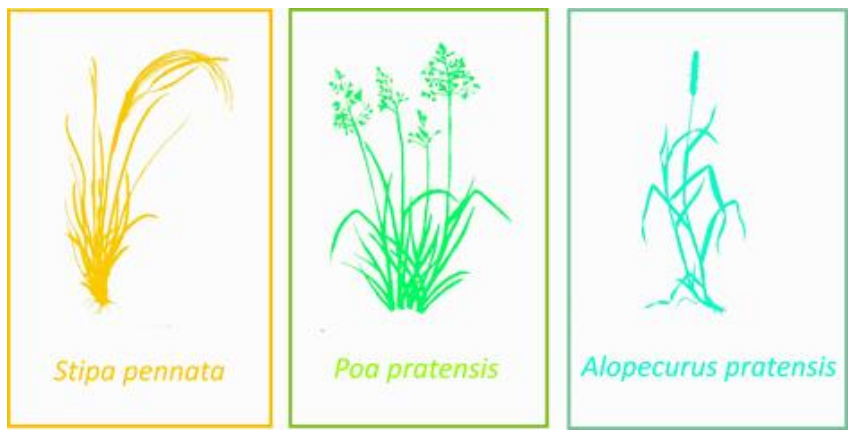

as the jury, together with the artists, might implement some modifications.

Iwona Dembicz, Warsaw, Poland i.dembicz@gmail.com 


\section{Call for the new Photo Competition "Home grasslands" and Photo Story}

The call of the current Photo Competition is dedicated to the theme "Home grasslands", which has been inspired by the period of lockdown. We are looking for photographs focused on those remnants of grassland vegetation that resist in the cities where we live or work, either in contrast or in harmony with the surrounding human society.

You are invited to send up to three high-quality photographs within the competition theme (full size JPEG or TIFF images, at least $300 \mathrm{dpi}$ ) together with captions giving a short title or description (a short text to explain the meaning or a story beyond the shot) and information on the subject (species name, date, place name).

The selection will be made by a jury of at least five members from the Editorial Board of the journal. The three best shots will be awarded with full space in the next issue, but we reserve the right to use further submitted materials for illustrative purposes in other parts of the issue.

If you feel you can contribute with your shots, don't be shy! Everyone can join the competition!
Contributions for the Photo Story section are always welcome. Photo Story is an open space where members can submit their own photo collection on a certain grasslandrelated topic of their choice. High-quality photos should be provided together with their captions (at least species names or landscape description), a brief text and possibly other graphical elements (like a map or a drawing). The selection of photos should fit for 3-10 pages and the proponents should already propose a preliminary layout (in PDF or MS Word format), which will be finally typeset by Editors. As an example, you may take a look at the Photo Stories published in previous PG issues.

If you want to contribute to these sections, or if you simply want to help us enriching the aspect of the journal, please submit your photos together with required information to Rocco (rocco.labadessa@gmail.com).

Deadline for photo submissions is $\mathbf{1 5}$ September 2020!

Rocco Labadessa, Bari, Italy rocco.labadessa@gmail.com

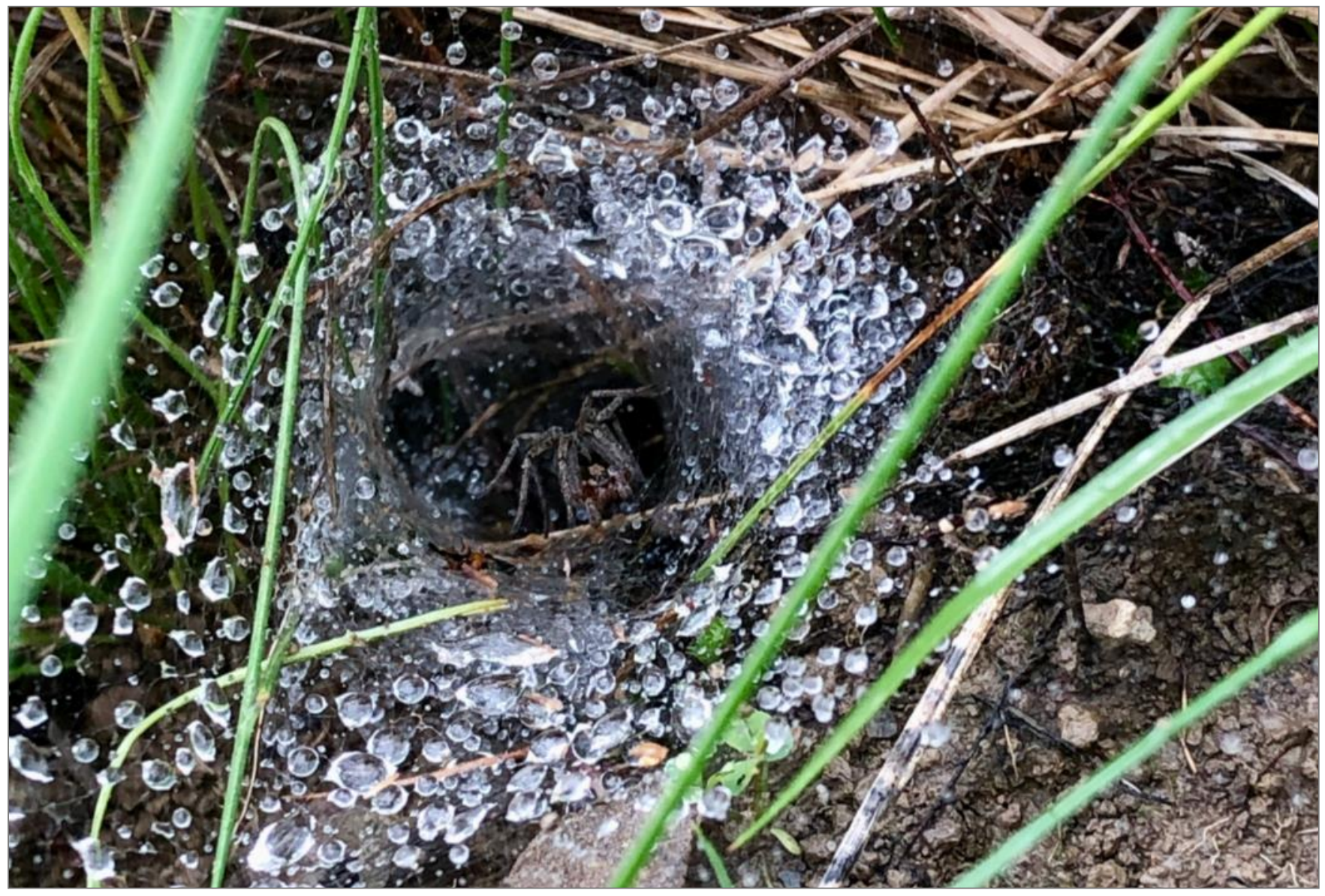

Luxurious, but for some dangerous house of Agelena sp., Nova Sedlica village, Romania. Photo: M. Janišová. 


\section{EDGG Publication}

EDGG and Vegetation Classification and Survey (VCS) are inviting proposals for a Special Collection on Classification of grasslands and other open vegetation types in the Palaearctic

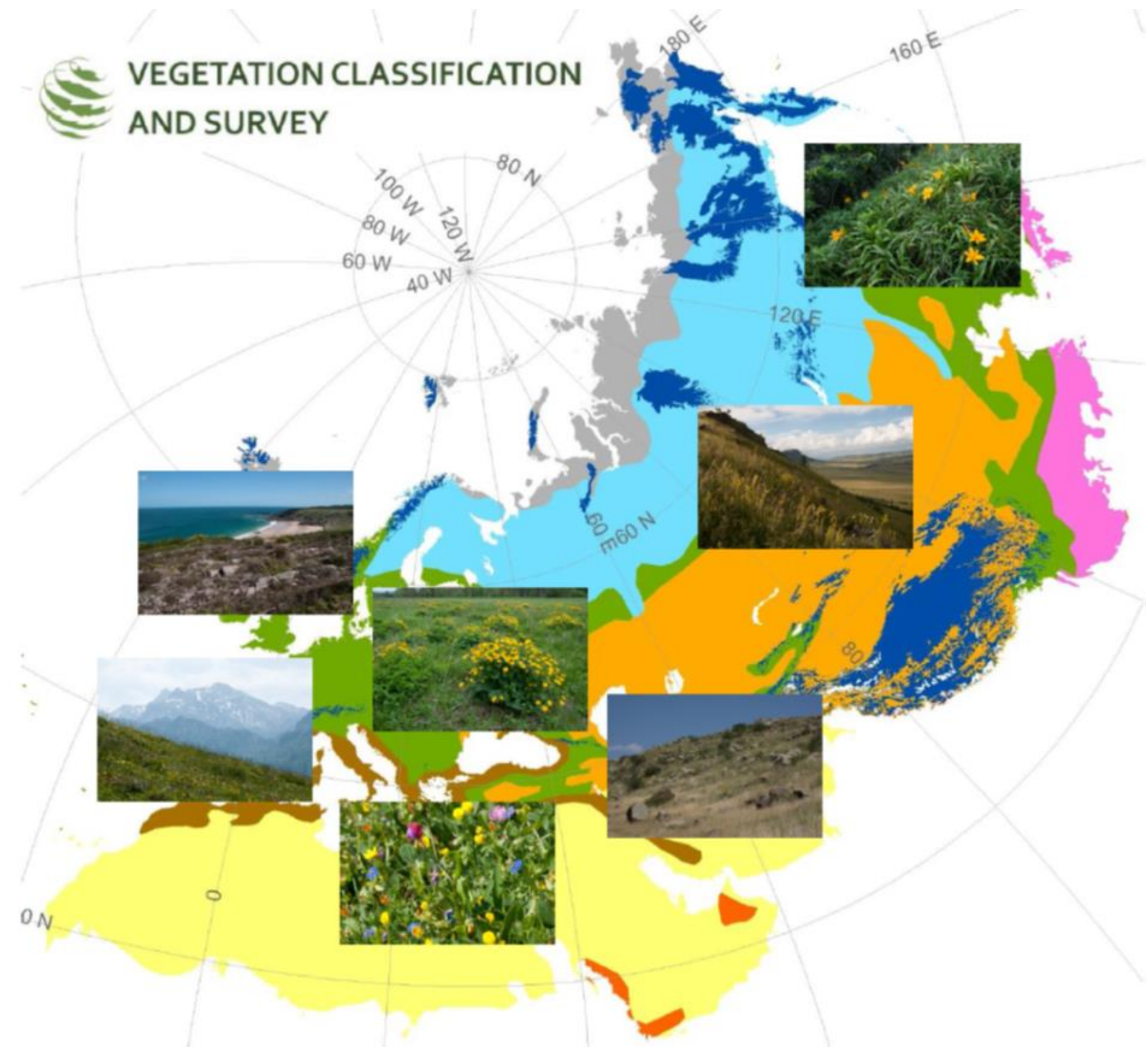


Journal: VCS is the new gold open access journal of the International Association for Vegetation Science (IAVS), started in May 2020. It is devoted to vegetation classification with any methodological approach and at any organisational scale. There is no limit to the length of articles as long as it is justified by the content. For more information, see https:// vCs.pensoft.net/. Note that as gold open access journal, VCS has article processing charges (APCs), but for submissions in 2020 these are substantially reduced thanks to financial support from IAVS, and further reductions apply, among others, for IAVS members and first authors with financial constraints (see https://vcs.pensoft.net/about\#ArticleProcessing-Charges).

Editors: Idoia Biurrun (ES), Jürgen Dengler $(\mathrm{CH})$, Monika Janišová (SK) \& Arkadiusz Nowak (PL)

Outline: Palaearctic grasslands in the broad sense comprise a large diversity of vegetation types, many of them of high conservation concern. Sound classification systems of Palaearctic grasslands and other open habitats are needed as reference systems for conservation and research. On the one hand, large national and continental vegetation-plot databases in combination with new classification methods allow developing plot-based classification systems that are consistent over large spatial extents, thus overcoming the idiosyncrasies of the multitude of previous regional classification systems. On the other hand, there are still many regions in the Palaearctic with diverse grassland vegetation that lack any plot-based classification system.

For this Special Collection in collaboration with the IAVS Working Group Eurasian Dry Grassland Group (EDGG; www.edgg.org), we invite classification papers dealing with Palaearctic grasslands sensu lato, i.e. any natural and seminatural vegetation type that is dominated by graminoids, forbs, dwarf shrubs, bryophytes or lichens. This Special Collection builds on two previous Special Features organised by some of the current editors in other IAVS-associated journals (Dengler et al. 2013; Janišová et al. 2016) and thus aims to reflect the advancement in knowledge since then. While we particularly appreciate broad-scale syntheses of grassland types over larger areas, we also accept regional studies from understudied regions. Methodological and conceptual studies as well as nomenclatural revisions of syntaxa are also possible. While the focus of the Special Collection is on plot-based classification, we are open to consider Forum papers that elaborate on higher level typologies, such as biomes, sub-biomes, formations or degrees of naturalness. Particularly appreciated are studies that demonstrate how sound grassland typologies can serve as useful tools in conservation, e.g. in red-list assessments.

\section{Procedure and deadlines:}

- Until 31 July 2020 (extended deadline): Send your proposal (preliminary title, authors, preliminary abstract, expected submission time) to juergen.dengler@unibayreuth.de.

- Between 31 July and 10 August 2020 the Special Collection Editors will evaluate the proposed contributions regularly and invite or decline them (i.e. those who submit earlier can also expect an earlier decision).

- Until 31 December 2020: Submission of invited contributions (exceptionally, later submissions might still be included in the Special Collection, but keep in mind that for submissions from 1 January 2021 onwards higher APCs apply)

- Submitted articles undergo a regular peer-review with one of the four editors as Subject Editor.

- After acceptance, each article will be published without delay.

- Approx. mid-2021: Together with the last article, the Special Collection Editors will publish an Editorial that sets the included articles in context.

We look forward to your proposals!

\section{References:}

Dengler, J., Bergmeier, E., Willner, W. \& Chytrý, M. 2013. Towards a consistent classification of European grasslands. Applied Vegetation Science 16: 518-520.

Janišová, M., Dengler, J. \& Willner, W. 2016. Classification of Palaearctic grasslands. Phytocoenologia 46: 233-239.

Idoia Biurrun, Jürgen Dengler, Monika Janišová \& Arkadiusz Nowak 


\section{EDGG Publication}

\section{Encyclopedia of the World's Biomes published with 13 EDGG chapters included}

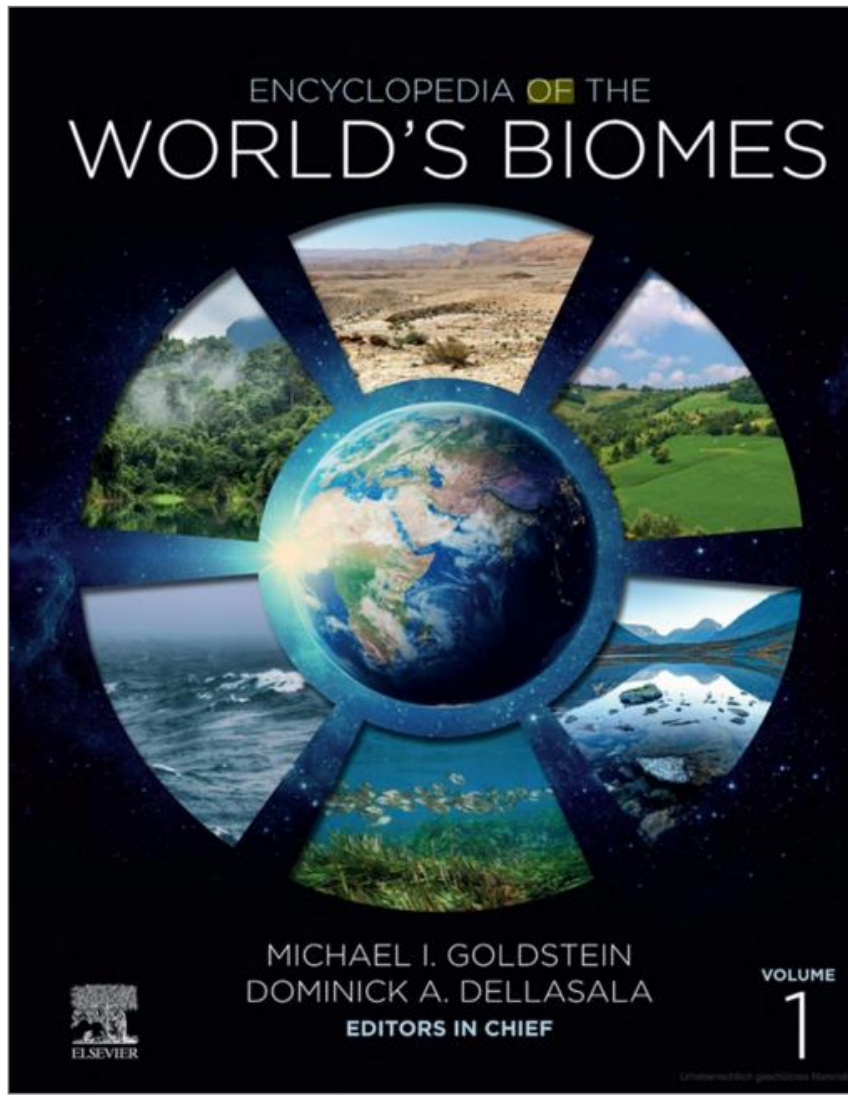

On 18 June 2020, the Encyclopedia of the World's Biomes was published. This is a unique, five-volume reference work that provides a global synthesis of biomes and habitats, their biota, their threat and conservation. In total, the Encyclopedia comprises 3,500 pages and is so expensive that likely only rich libraries will be able to buy it. We EDGG Special Issue Coordinators organised 13 chapters by multiauthor teams comprised of EDGG members typically coming from different countries. Together the EDGG chapters account for nearly 200 pages in Volume 3. This treatment is even more comprehensive and detailed than the EDGG chapters in the global grassland book by Squires et al. (2018). The EDGG chapters all have a similar structure to facilitate comparisons. For the first time, not only grasslands, but also shrublands have been covered in an EDGG publication. If you are interested in a specific chapter, but do not wish to buy the whole Encyclopedia, you might contact the corresponding authors and ask them for a pdf (see e-mail contacts below).

\section{Content}

Dengler, J., Biurrun, I., Boch, S., Dembicz, I. \& Török, P. 2020. Grasslands of the Palaearctic biogeographic realm: introduction and synthesis. In: Goldstein, M.I., DellaSala, D.A. \& DiPaolo, D.A. (eds.) Encyclopedia of the world's biomes. Volume 3: Forests - trees of life. Grasslands and shrublands - sea of plants, pp. 617-637. Elsevier, Amsterdam, NL. [juergen.dengler@uni-bayreuth.de]

Guarino, R., Vrahnakis, M., Rodríguez-Rojo, M.P., Giuga, L. \& Pasta, S. 2020. Grasslands and shrublands of the Mediterranean region. In: Goldstein, M.I., DellaSala, D.A. \& DiPaolo, D.A. (eds.) Encyclopedia of the world's biomes. Volume 3: Forests - trees of life. Grasslands and shrublands - sea of plants, pp. 638-655. Elsevier, Amsterdam, NL. [guarinotro@hotmail.com]

Loidi, J., de Blust, G., Campos, J.A., Haveman, R. \& Janssen, J. 2020. Heathlands of temperate and boreal Europe. In: Goldstein, M.I., DellaSala, D.A. \& DiPaolo, D.A. (eds.) Encyclopedia of the world's biomes. Volume 3: Forests trees of life. Grasslands and shrublands - sea of plants, pp. 656-668. Elsevier, Amsterdam, NL. [javier.loidi@ehu.es]

Loidi, J., Campos, J.A., Haveman, R. \& Janssen, J. 2020. Shrublands of temperate Europe. In: Goldstein, M.I., DellaSala, D.A. \& DiPaolo, D.A. (eds.) Encyclopedia of the world's biomes. Volume 3: Forests - trees of life. Grasslands and shrublands - sea of plants, pp. 669-677. Elsevier, Amsterdam, NL. [javier.loidi@ehu.es]

Boch, S., Biurrun, I. \& Rodwell, J. 2020. Grasslands of Western Europe. In: Goldstein, M.I., DellaSala, D.A. \& DiPaolo, D.A. (eds.) Encyclopedia of the world's biomes. Volume 3: Forests - trees of life. Grasslands and shrublands - sea of plants, pp. 678-688. Elsevier, Amsterdam, NL. [steffen.boch@wsl.ch]

Dengler, J., Birge, T., Bruun, H.H., Rašomavičius, V., Rūsiṇa, S. \& Sickel, H. 2020. Grasslands of Northern Europe and the Baltic States. In: Goldstein, M.I., DellaSala, D.A. \& DiPaolo, D.A. (eds.) Encyclopedia of the world's biomes. Volume 3: Forests - trees of life. Grasslands and shrublands - sea of plants, pp. 689-702. Elsevier, Amsterdam, NL. [juergen.dengler@uni-bayreuth.de]

Török, P., Dembicz, I., Dajić Stevanović, Z. \& Kuzemko, A. 2020. Grasslands of Eastern Europe. In: Goldstein, M.I., 
DellaSala, D.A. \& DiPaolo, D.A. (eds.) Encyclopedia of the world's biomes. Volume 3: Forests - trees of life. Grasslands and shrublands - sea of plants, pp. 703-713. Elsevier, Amsterdam, NL. [molinia@gmail.com]

Ambarlı, D., Naqinezhad, A. \& Aleksanyan, A. 2020. Grasslands and shrublands of the Middle East and the Caucasus. G. In: Goldstein, M.I., DellaSala, D.A. \& DiPaolo, D.A. (eds.) Encyclopedia of the world's biomes. Volume 3: Forests - trees of life. Grasslands and shrublands - sea of plants, pp. 714-724. Elsevier, Amsterdam, NL. [didem.ambarli@gmail.com]

Tishkov, A., Belonovskaya, E., Smelansky, I.E., Titova, S., Trofimov, I. \& Trofimova, L. 2020. Temperate grasslands and shrublands of Russia. In: Goldstein, M.I., DellaSala, D.A. \& DiPaolo, D.A. (eds.) Encyclopedia of the world's biomes. Volume 3: Forests - trees of life. Grasslands and shrublands - sea of plants, pp. 725-749. Elsevier, Amsterdam, NL. [tishkov@biodat.ru]

Wagner, V., Bragina, T.M., Nowak, A., Smelansky, I.E. \& Vanselow, K.A. 2020. Grasslands and shrublands of Kazakhstan and Middle Asia. In: Goldstein, M.I., DellaSala, D.A. \& DiPaolo, D.A. (eds.) Encyclopedia of the world's biomes. Volume 3: Forests - trees of life. Grasslands and shrublands - sea of plants, pp. 750-758. Elsevier, Amsterdam, NL. [viktoria.wagner@ualberta.ca]

Pfeiffer, M., Dulamsuren, C. \& Wesche, K. 2020. Grasslands and shrublands of Mogolia. In: Goldstein, M.I., DellaSala,
D.A. \& DiPaolo, D.A. (eds.) Encyclopedia of the world's biomes. Volume 3: Forests - trees of life. Grasslands and shrublands - sea of plants, pp. 759-772. Elsevier, Amsterdam, NL. [martin.pfeiffer@uni-bayreuth.de]

Li, F.Y., Jäschke, Y., Guo, K. \& Wesche, K. 2020. Grasslands of China. In: Goldstein, M.I., DellaSala, D.A. \& DiPaolo, D.A. (eds.) Encyclopedia of the world's biomes. Volume 3: Forests - trees of life. Grasslands and shrublands - sea of plants, pp. 773-784. Elsevier, Amsterdam, NL. [lifyhong@126.com]

Ushimaru, A., Uchida, K., Ikegami, M. \& Suka, T. 2020. Grasslands and shrublands of Japan. In: Goldstein, M.I., DellaSala, D.A. \& DiPaolo, D.A. (eds.) Encyclopedia of the world's biomes. Volume 3: Forests - trees of life. Grasslands and shrublands - sea of plants, pp. 785-799. Elsevier, Amsterdam, NL. [ushimaru@kobe-u.ac.jp]

\section{Reference}

Squires, V.R., Dengler, J., Feng, H. \& Hua, L. (eds.) 2018. Grasslands of the world: diversity, management and conservation. CRC Press, Boca Raton, US.

Jürgen Dengler, Wädenswil, Switzerland (juergen.dengler@uni-bayreuth.de)

Péter Török, Debrecen, Hungary (molinia@gmail.com)

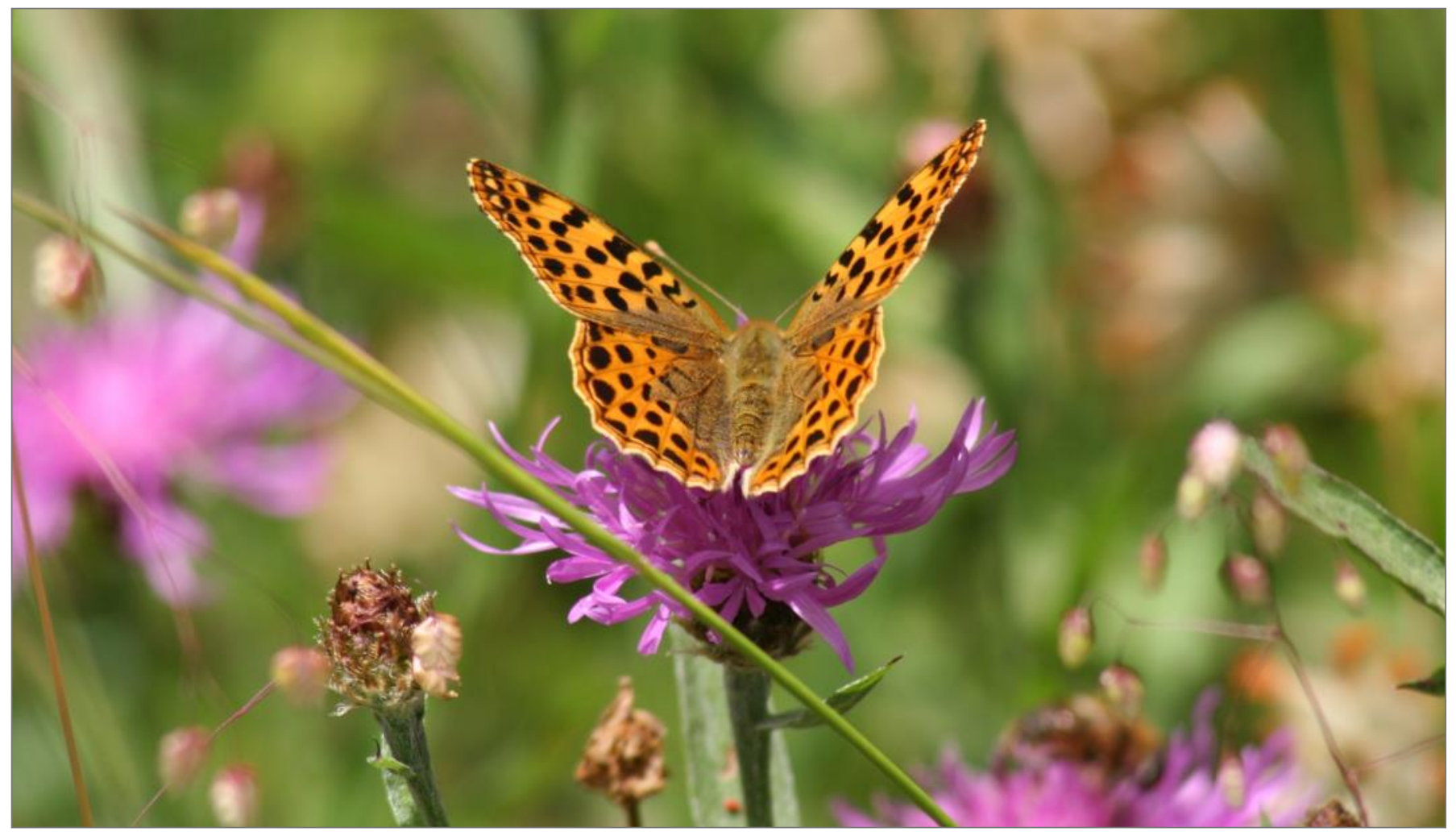

Issoria lathonia on Centaurea jacea in Balmberg, Solothurn, Switzerland. Photo: M. Buchler. 


\title{
Biodiversity of dry grasslands in Armenia: First results from the 13th EDGG Field Workshop in Armenia
}

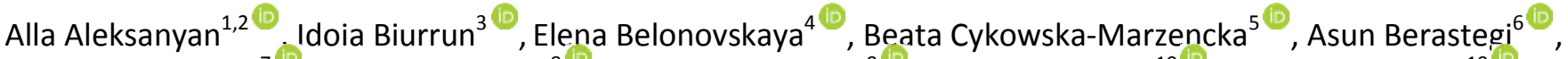

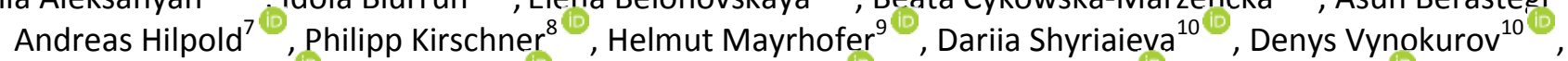 \\ Thomas Becker $^{11}$, Ute Becker ${ }^{12}$. Iwona Dembicz ${ }^{13,14}$, George Fayvush ${ }^{10}$, Dieter Frank ${ }^{15}$. Martin

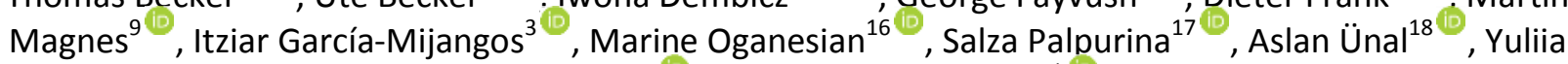 \\ Vasheniak $^{19}$ \& Jürgen Dengler ${ }^{13,20,21^{*} \mathbb{C}}$
}

\begin{abstract}
${ }^{1}$ Department of Geobotany and Plant Eco-Physiology, Institute of Botany after A.L. Takhtajyan, NAS RA, Acharyan 1, 0040, Yerevan, Armenia; alla.alexanyan@gmail.com; gfayvush@yahoo.com

${ }^{2}$ Chair of Biology and Biotechnology, Armenian National Agrarian University, Teryan 74, 0009, Yerevan, Armenia

${ }^{3}$ Department of Plant Biology and Ecology, University of the Basque Country UPV/EHU, P.O. Box 644, 48080 Bilbao, Spain; idoia.biurrun@ehu.es; itziar.garcia@ehu.es

${ }^{4}$ Department of Biogeography, Institute of Geography, Russian Academy of Sciences, Staromonetny per. 29, 119017 Moscow, Russia; ebelonovskaya.0709@gmail.com

${ }^{5}$ Department of Mycology, W. Szafer Institute of Botany, Polish Academy of Sciences, Lubicz 46, 31-512 Kraków, Poland; b.cykowska@botany.pl

${ }^{6}$ Department of Biodiversity, Environmental Management of Navarre, Padre Adoain 219 Bajo, 31015 Pamplona, Spain; aberastg@gan-nik.es

${ }^{7}$ Institute for Alpine Environment, Drususallee 1/VialeDruso 1, 39100 Bozen -Bolzano, Italy; andreas.hilpold@eurac.edu

${ }^{8}$ Department of Botany, University of Innsbruck, Sternwartestraße 15, Innsbruck, Austria; philipp.kirschner@gmail.com

${ }^{9}$ Division of Plant Sciences, Institute of Biology, Karl-Franzens-University of Graz, Holteigasse 6, 8010 Graz, Austria; helmut.mayrhofer@uni-graz.at; martin.magnes@uni-graz.at

${ }^{10}$ Geobotany and Ecology Department, M.G. Kholodny Institute of Botany, NAS of Ukraine, Tereshchenkivska str. 2, 01601 Kyiv, Ukraine; darshyr@gmail.com; denys.vynokurov@gmail.com

${ }^{11}$ Department of Geobotany, University of Trier, Behringstr. 21, 54296 Trier, Germany; beckerth@uni-trier.de
\end{abstract}

${ }^{12}$ Green School in the Botanic Garden, Johannes Gutenberg University Mainz, Anselm-Franz-von-Bentzel-Weg 9 b, 55128 Mainz, Germany; beckeru@uni-mainz.de

${ }^{13}$ Vegetation Ecology, Institute of Natural Resource Sciences (IUNR), Zurich University of Applied Sciences (ZHAW), Grüentalstr. 14, 8820 Wädenswil, Switzerland; i.dembicz@gmail.com; juergen.dengler@uni-bayreuth.de

${ }^{14}$ Department of Plant Ecology and Environmental Conservation, Faculty of Biology, University of Warsaw, ul. Zwirki I Wigury 101, 02-089 Warsaw, Poland

${ }^{15}$ Saxony-Anhalt Environment Agency, Reideburger Str. 47, Halle 06116, Germany; dieter.frank@lau.mlu.sachsen-anhalt.de

${ }^{16}$ Department of Taxonomy and Geography of Higher Plants, Institute of Botany aft. A.L. Takhtajyan, NAS RA, Acharyan 1, 0040, Yerevan, Armenia; oganesianm@yahoo.com

${ }^{17}$ National Museum of Natural History, 1 Tsar Osvoboditel Blvd, 1000 Sofia, Bulgaria; salza.palpurina@gmail.com

${ }^{18}$ Am Schießrain 10 , 79219 Staufen, Germany; auenal@mail.ru

${ }^{19}$ Department of Biology, Chemistry and Biotechnologies, Vasyl' Stus Donetsk National University, 600-richya str. 21021, Vinnytsia, 21, Ukraine; arrhenatherum@gmail.com

${ }^{20}$ Plant Ecology, Bayreuth Center of Ecology and Environmental Research (BayCEER), Universitätsstr. 30, 95447 Bayreuth, Germany

${ }^{21}$ German Centre for Integrative Biodiversity Research (iDiv) Halle-JenaLeipzig, DeutscherPlatz 5e, 04103 Leipzig, Germany

*) corresponding author

Palaearctic Grasslands 46 (2020): 12-51

Abstract: The $13^{\text {th }}$ EDGG Field Workshop was conducted from the 26 June to 6 July 2019 in Armenia. The Field Workshop had two main aims: (a) to analyse the biodiversity patterns of the Armenian grasslands across multiple taxonomic groups and grain sizes, and (b) to study the syntaxonomic position of these grasslands in a general European context. We conducted our sampling in 16 sites that ensured good geographical coverage across the country. In total, we sampled 29 EDGG Biodiversity Plots (nested-plot series of 0.0001 to $100 \mathrm{~m}^{2}$ ) and 53 additional $10-\mathrm{m}^{2}$ plots. Data of orthopteroid insects (Orthoptera and Mantodea) were recorded in $42100-\mathrm{m}^{2}$ plots. We found mean total species richness values of the vegetation of 7.5 species in $0.01 \mathrm{~m}^{2}, 31.9$ species in $1 \mathrm{~m}^{2}$ and 51.3 species in $10 \mathrm{~m}^{2}$. The richest grasslands for vascular plants were meso-xeric grasslands with up to 35 species in $0.1 \mathrm{~m}^{2}$ and 80 in $10 \mathrm{~m}^{2}$. Maximum orthopteroid richness in $100 \mathrm{~m}^{2}$ was 14 . Syntaxonomically, the majority of stands appear to belong to the class Festuco-Brometea, with the orders Brachypodietalia pinnati (meso-xeric), Festucetalia valesiacae (xeric, non-rocky) and an unknown order of rocky dry grasslands. By contrast, the thorn-cushion communities (probably Onobrychidetea cornutae), the scree communities and the dry grasslands of lower elevations rich in annuals and chamaephytes (probably largely Astragalo-Brometea), do not fit to any vegetation class described in Europe. We found two species new to Armenia - the moss Syntrichia papillosissima and the lichen Aspicilia hispida. Our data demonstrate that Armenia is 
one of the Palaearctic hotspots of fine grain plant diversity. Both diversity patterns and syntaxonomy warrant in-depth studies, which are now possible with our comprehensive dataset.

Keywords: Armenia; biodiversity; bryophyte, dry grassland; lichen; Mantodea; nested plot; Orthoptera; species richness; syntaxonomy; vascular plant.

Nomenclature: Euro+Med (2020) for vascular plants, Hill et al. (2006) for mosses, Söderström et al. (2016) for liverworts, Nimis et al. (2018) for lichens and Heller et al. (2016) for orthopteroid insects.

Abbreviations: EDGG = Eurasian Dry Grassland Group.

Submitted: 9 June 2020; first decision: 10 June 2020; accepted: 16 June 2020

Scientific Editor: Riccardo Guarino

Linguistic Editor: Richard Jefferson

\section{Introduction}

Palaearctic grasslands are known for their outstanding biodiversity in many taxonomic groups (Dengler et al. 2014; 2020a). For vascular plants, most of the world records of species richness at fine spatial grains across any habitat type worldwide come from Palaearctic semi-dry grasslands, but bryophytes, lichens and many invertebrate groups can also be quite diverse (Dengler et al. 2020a). Despite numerous studies, there is still no conclusive knowledge as to which factors are mainly responsible for this fine-grain diversity and why, in some regions, exceptionally rich grasslands occur and in others not (Dengler et al. 2014).

Armenia is known to have diverse grasslands (Fayvush \& Aleksanyan 2016; Dengler et al. 2019; Ambarlı et al. 2020) and a very rich vascular plant flora. However, detailed data on fine-grain plant diversity are lacking and, as such, this would be valuable for pan-Palaearctic studies of patterns and drivers of grassland diversity, such as Dengler et al. (2020c). While Armenia has a typology of habitats (Fayvush \& Aleksanyan 2016), there are only few phytosociological studies from the country. Therefore, its community types cannot readily be aligned with the well-established syntaxonomic system of Europe (Mucina et al. 2016). Due to a lack of vegetation-lot data, Armenian vegetation has not been included in the broad-scale consistent classification of Palaearctic dry grasslands, either with supervised (Schaminée et al. 2016) or semi-supervised methods (Willner et al. 2017).

Since 2009, the Eurasian Dry Grassland Group (EDGG) has been conducting annual Field Workshops, with the main aim of obtaining high-quality biodiversity data of grassland vegetation in Palaearctic areas that have been undersampled in the past (Dengler et al. 2019). Sampling is conducted with a standardised multi-scale method (Dengler et al. 2016a; based on Dengler 2009). Using data from these expeditions, a series of regional studies on phytosociological classification have been developed (Dengler et al. 2012; Pedashenko et al. 2013; Kuzemko et al. 2014). Studies of patterns and drivers of plant diversity (Turtureanu et al. 2014; Kuzemko et al. 2016; Polyakova et al. 2016) and also comparative overviews on mean and maximum richness values of Palaearctic grasslands have been obtained from these data (Dengler et al. 2016b). All the multi-scale vegeta- tion plot data produced in the EDGG Field Workshops have been incorporated into the "GrassPlot" database of EDGG (Dengler et al. 2018; Biurrun et al. 2019) to facilitate their utilization for scientific studies. Several ongoing projects related to alpha and beta diversity are taking advantage of this, including a study on species-area relationships in Palaeartic grasslands (Dengler et al. 2020c). While vascular plants, bryophytes and lichens are the principal objective of the EDGG Field Workshops, specialists in other taxonomic groups such as spiders (Biurrun et al. 2014) and leafhoppers (Filibeck et al. 2018), have taken part in some expeditions. This interdisciplinary collaboration has been translated into some specific publications (Polchaninova et al. 2018).

In 2019, EDGG organised two Field Workshops: the 12th in Switzerland (Dengler et al. 2020b), which continued the survey of central dry valleys of the Alps started in Austria by the $11^{\text {th }}$ Field Workshop (Magnes et al. 2020), and the 13th in Armenia. The latter was conducted from the 26 June to the 6 July 2019, and this was the second time that EDGG conducted a Field Workshop in Asia, the other being based in Khakassia, Russia (see Polyakova et al. 2016). The main aims of the workshop were (a) to analyse the biodiversity patterns of the Armenian grasslands across multiple taxonomic groups and grain sizes and (b) to study the syntaxonomic position of these grasslands within the Palaearctic context. In this paper, we present some initial findings concerning the species diversity and composition of vascular plants, bryophytes, lichens and orthopteroid insects of these grasslands. Moreover, we have also provided some visual impressions with photographs of the Armenian grasslands, their diversity and biota.

\section{The 13th EDGG Field Workshop}

Nineteen scientists from nine countries (Armenia, Austria, Bulgaria, Germany, Italy, Russia, Spain, Switzerland and Ukraine) participated in the Field Workshop. Most of them were botanists, but two zoologists specialized in orthopteroid insects also joined the Field Workshop (Fig. 1). Subsequently, two cryptogam specialists helped with the determination of bryophytes and lichens.

Based on several pre-excursions, our Armenian hosts selected an itinerary that covered a wide variety of dry grassland types in Armenia (Fig. 2, Table 1). We sampled plots in five 


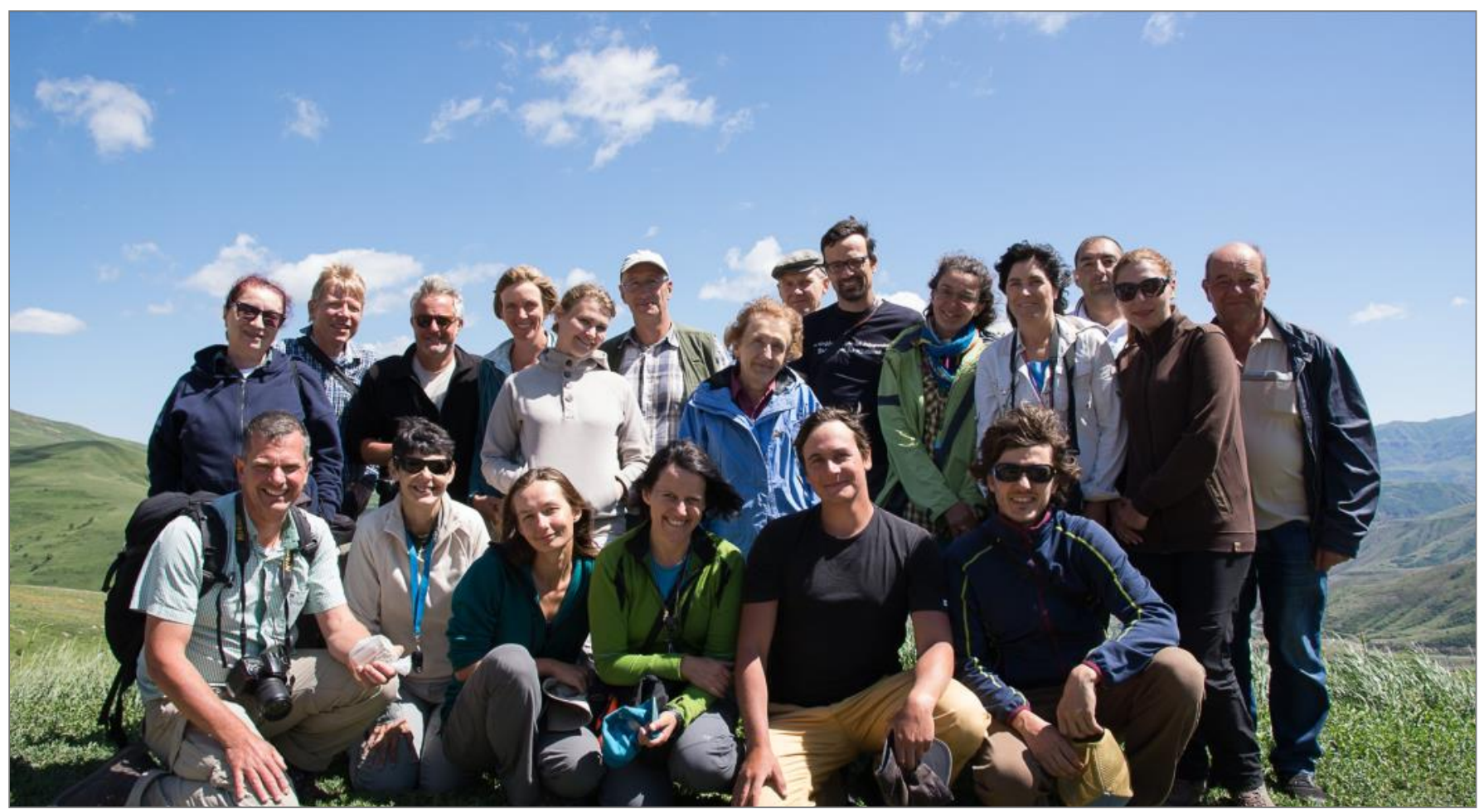

Fig. 1. Group photo at the Selim Pass on 2 July 2019.

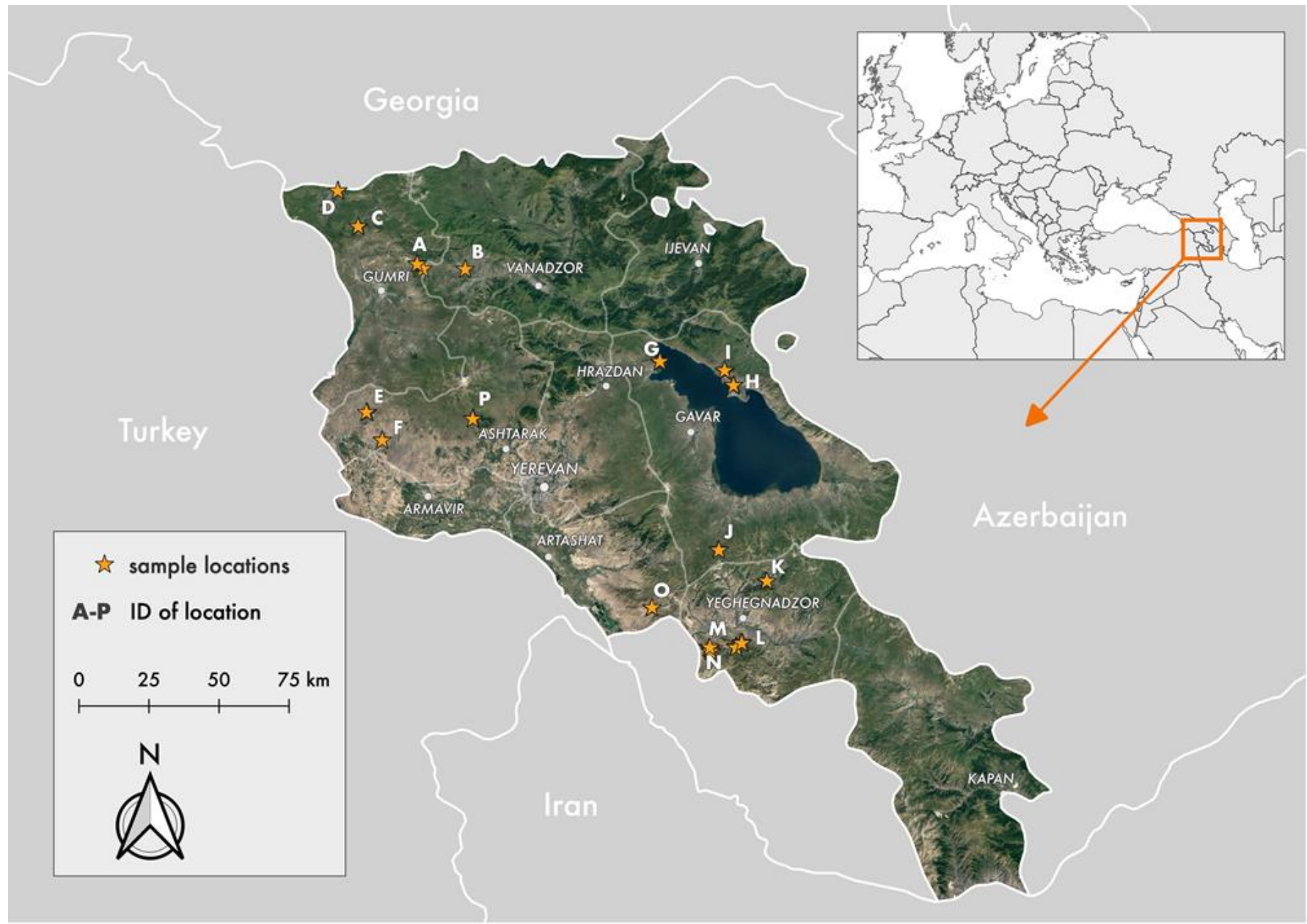

Fig. 2. Sites sampled during the 13th EDGG Field Workshop in Armenia. Further information on the sites is provided in Table 1. The selected sites were distributed from 39.66 to $44.00^{\circ} \mathrm{N}, 40.88$ to $45.43^{\circ} \mathrm{E}$, and at 1338 to $2400 \mathrm{~m}$ a.s.I. Base map: C2020 Google (satellite image) and @Natural Earth (administrative boundaries). 
Table 1. Overview of the grassland sites studied during the $13^{\text {th }}$ EDGG Field Workshop 2019 in Armenia. The location of the sites is shown in Fig. 1.

\begin{tabular}{|c|c|c|c|c|c|c|c|}
\hline $\begin{array}{l}\text { Site } \\
\text { ID }\end{array}$ & Date & $\begin{array}{l}\text { Administrative } \\
\text { region }\end{array}$ & $\begin{array}{l}\text { Floristic } \\
\text { region }\end{array}$ & Site location & $\begin{array}{l}\text { \# biodiversity } \\
\text { plots }\end{array}$ & $\begin{array}{l}\text { \# normal } \\
\text { plots }\end{array}$ & $\begin{array}{l}\text { Total \# of } \\
10-\mathrm{m}^{2} \text { plots }\end{array}$ \\
\hline$A$ & 27 June 2019 & Shirak & Shirak & Jajur pass & 1 & 4 & 6 \\
\hline B & 27 June 2019 & Shirak & Shirak & $\begin{array}{l}\text { Vicinity of Shi- } \\
\text { rakamut village }\end{array}$ & 1 & 3 & 5 \\
\hline c & 28 June 2019 & Shirak & $\begin{array}{l}\text { Verin } \\
\text { Akhuryan }\end{array}$ & $\begin{array}{l}\text { Vicinity of Amasia } \\
\text { town }\end{array}$ & 2 & 2 & 6 \\
\hline D & 28 June 2019 & Shirak & $\begin{array}{l}\text { Verin } \\
\text { Akhuryan }\end{array}$ & $\begin{array}{l}\text { Vicinity of Zo- } \\
\text { rakert village }\end{array}$ & 1 & 4 & 6 \\
\hline $\mathrm{E}$ & 29 June 2019 & Aragatsotn & Shirak & $\begin{array}{l}\text { Vicinity of Tatool } \\
\text { village }\end{array}$ & 2 & 2 & 6 \\
\hline $\mathrm{F}$ & 29 June 2019 & Aragatsotn & Shirak & $\begin{array}{l}\text { Vicinity of } \\
\text { Dashtadem vil- } \\
\text { lage }\end{array}$ & 1 & 5 & 7 \\
\hline G & 30 June 2019 & Gegharkunik & Sevan & $\begin{array}{l}\text { Vicinity of Sevan } \\
\text { town }\end{array}$ & 3 & 0 & 6 \\
\hline $\mathrm{H}$ & 01 July 2019 & Gegharkunik & Areguni & Ardanish & 1 & 5 & 7 \\
\hline I & 01 July 2019 & Gegharkunik & Areguni & Shorja & 2 & 2 & 6 \\
\hline J & 02 July 2019 & Gegharkunik & Darelegis & Selim pass & 3 & 2 & 8 \\
\hline $\mathrm{K}$ & 02 July 2019 & Vayots dzor & Darelegis & Hermon & 0 & 3 & 3 \\
\hline $\mathrm{L}$ & 03 July 2019 & Vayots dzor & Darelegis & $\begin{array}{l}\text { Vicinity of Gnishik } \\
\text { village }\end{array}$ & 5 & 6 & 16 \\
\hline M & 04 July 2019 & Vayots dzor & Darelegis & $\begin{array}{l}\text { Between Khachik } \\
\text { and Areni villages }\end{array}$ & 2 & 4 & 8 \\
\hline$N$ & 04 July 2019 & Vayots dzor & Darelegis & $\begin{array}{l}\text { Vicinity of Kha- } \\
\text { chik village }\end{array}$ & 2 & 6 & 10 \\
\hline $\mathrm{O}$ & 05 July 2019 & Ararat & Yerevan & $\begin{array}{l}\text { Vicinity of } \\
\text { Tigranashen vil- } \\
\text { lage }\end{array}$ & 2 & 2 & 6 \\
\hline$P$ & 06 July 2019 & Aragatsotn & Aparan & $\begin{array}{l}\text { Near Amberd } \\
\text { fortress }\end{array}$ & 1 & 3 & 5 \\
\hline
\end{tabular}

administrative regions and this included seven of the 12 floristic regions of the country (Tamanyan \& Fayvush 2009): Verin Akhuryan, Shirak, Sevan, Areguni, Aparan, Yerevan and Darelegis. Our itinerary comprised two national parks (Arpi Lake and Sevan) and the Gnishik Community-Managed Protected Area.

Over ten days, we collected vascular plant, bryophyte and lichen data in 29 EDGG Biodiversity Plots (= nested-plot series of 0.0001 to $100 \mathrm{~m}^{2}$; see Dengler et al. 2016a and Fig. 3) and 53 additional $10-\mathrm{m}^{2}$ plots. Orthopteroid insects were sampled in $42100-\mathrm{m}^{2}$ (28 EDGG Biodiversity Plots and 14 enlarged $10-\mathrm{m}^{2}$-vegetation plots; for method, see Hilpold et al. 2020). After the Field Workshop, a set of soil parameters were determined in the laboratory from mixed soil samples that were collected in the field from the uppermost $15 \mathrm{~cm}$ of the soil. The identification of bryophytes and lichens has been completed. However, determination of vascular plants is still ongoing and, therefore, minor modifications to the richness data might be required in the future.

\section{Preliminary results and discussion}

\section{Site conditions and vegetation structure}

Our sampling covered an elevational gradient from 1338 to $2400 \mathrm{~m}$ a.s.l. (Table 2). Thus, only the lowest areas and the alpine grasslands were not sampled, the former due to the season already being too advanced. The alpine grasslands were visited on the last day (see Appendix) but not sampled. Dry grasslands occurred in all aspects, from South to North, from nearly flat areas to steep slopes (Table 2). The majority of soils were skeletal (on average more than $40 \%$ cover of rocks, stones and gravel on the surface) and rather shallow with a mean soil depth of less than $20 \mathrm{~cm}$ (Table 2). Soil reaction was mostly alkaline, with only a few soils having a $\mathrm{pH}$ below 7 (Table 2).

\section{Composition of the vegetation}

The most frequent graminoids were Dactylis glomerata (31.2\%), Poa bulbosa (31.2\%), Elytrigia intermedia (20.7\%), 


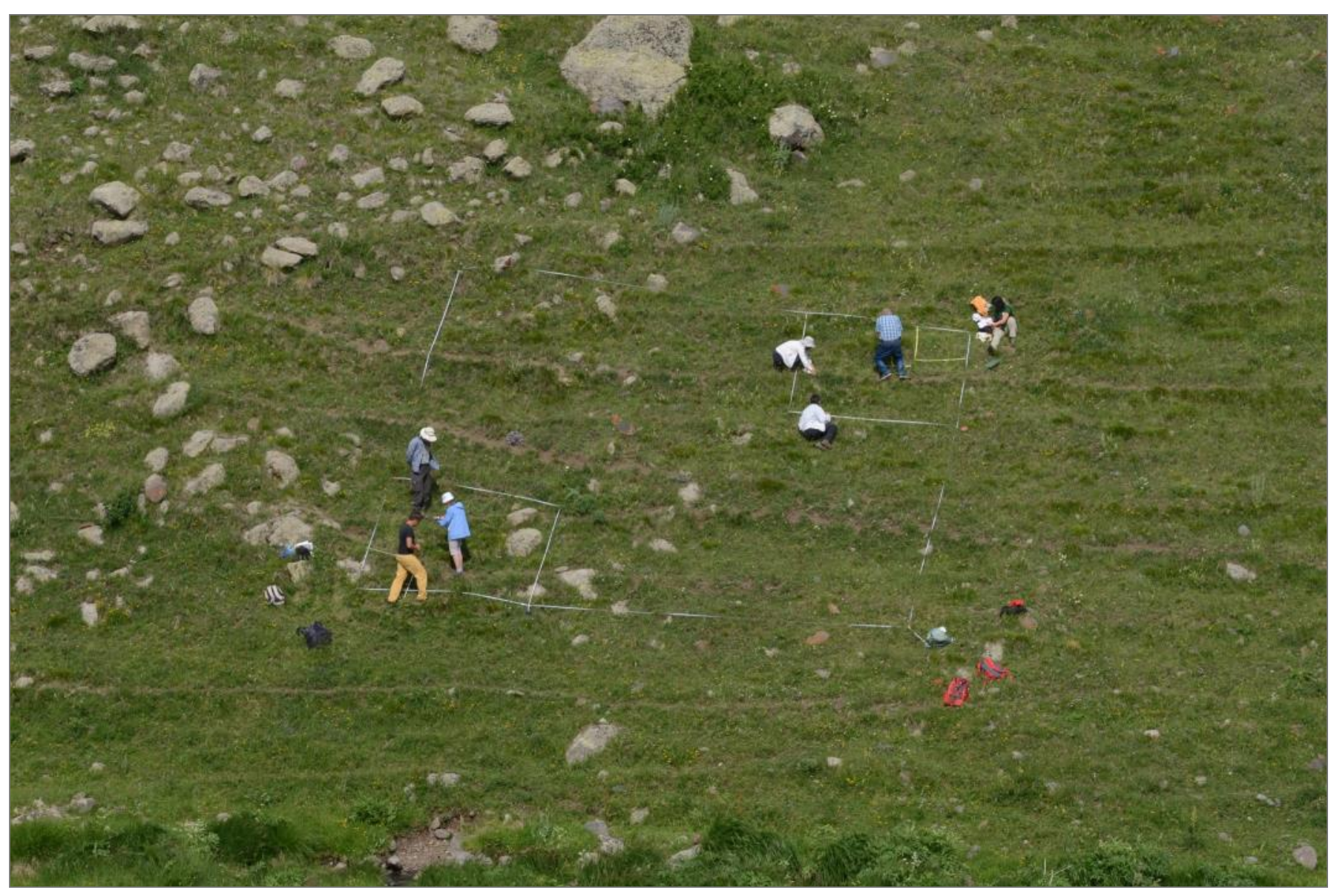

Fig. 3. Sampling the EDGG Biodiversity Plot No. 5 in the vicinity of Zorakert village. Photo: T. Becker.

Poa angustifolia (17.7\%), Koeleria macrantha (14.4\%) and Phleum phleoides $(14.4 \%)$, i.e. all species that are widespread in the xerothermic regions of the Western Palaearctic. We found 14 taxa of Stipa, with S. capillata (8.8\%) and S. pulcherrima (8.4\%) being the most frequent ones. Apart from the common Central and Eastern European species such as S. capillata, S. lessingiana, S. pennata, S. pulcherrima and $S$. tirsa, we also found Caucasian and Minor Asian ones, such as S. sareptana subsp. anisotricha, S. arabica, S. araxensis, S. canescens, S. hohenackeriana, S. ehrenbergiana and others. The narrow-leaved fescue species were mainly represented by Festuca valesiaca (13.5\%), but additionally, also rare occurrences of $F$. stricta subsp. sulcata, $F$. brunnescens and $F$. woronowii. The most widespread forbs were Galium verum (36.0\%), Medicago sativa agg. (34.0\%), Teucrium capitatum (28.1\%), Thymus kotschyanus (27.7\%), Stachys recta (24.4\%), Scutellaria orientalis (with various subspecies: $20.2 \%)$, Convolvulus lineatus (19.1\%), Lotus corniculatus (18.8\%) and Scabiosa bipinnata (17.0\%). While our samples still need final confirmation, it appears that we recorded for the first time from Armenia (see Euro+Med 2020), Festuca stricta subsp. sulcata (= S. rupicola; in regional keys seemingly included in the polymorphic $F$. brunnescens) and Rhinanthus angustifolius (quite widespread but according to the key in the Armenian flora one would determine it as $R$. minor).
In the Armenian dry grasslands we investigated, 43 moss taxa were found. Among them, ground mosses of the Pottiaceae family predominated, especially Syntrichia ruralis var. ruralis, S. ruralis var. ruraliformis and Weissia brachycarpa. On areas of bare ground and plant debris, common mosses such as Bryum argenteum, B. caespiticium, B. capillare, Ceratodon purpureus, Hypnum cupressiforme and Pohlia nutans frequently occurred. On more alkaline sites, typical mosses of base-rich grasslands were found: Abietinella abietina, Campyliadelphus chrysophyllus, Encalypta vulgaris, Homalothecium lutescens, Rhytidium rugosum. On rocky ground (gravel, stones and the margins of rocks) Grimmia laevigata, G. pulvinata, and Schistidium crassipilum were noted. During our study, only one species of liverwort was found, namely Lophocolea heterophylla. The moss species Syntrichia papillosissima (Pottiaceae) was found new for Armenia.

Lichens were generally rare in the dry grasslands of Armenia, with Collema spp. div. (12.3\%), Placidium spp. div. (2.3\%), Aspicilia hispida (syn. Agrestia hispida, Circinaria hispida, Sphaerothallia hispida) (2.3\%) and Cladonia foliacea (1.9\%) being the most frequent taxa. Most remarkable were the records of the small manna lichen (Aspicilia hispida) from three Biodiversity Plots (AM08, AM16, AM32) in sites B and $O$ (see Table 1), which is new for Armenia. The thallus 
Table 2. Overview of site, soil and structural parameters of the conditions found in the $11110-\mathrm{m}^{2}$ plots. Soil chemical variables refer to a mixed sample of the uppermost $15 \mathrm{~cm}$; "standard height herb layer" refers to the "disc method" of Dengler et al. (2016a).

\begin{tabular}{|c|c|c|c|c|}
\hline & Min. & Max. & Mean & SD \\
\hline \multicolumn{5}{|l|}{ Location } \\
\hline Latitude $\left[{ }^{\circ}\right]$ & 39.66 & 41.10 & 40.23 & 0.50 \\
\hline Longitude $\left[{ }^{\circ}\right]$ & 43.40 & 45.43 & 44.73 & 0.66 \\
\hline Elevation [m a.s.I.] & 1338 & 2400 & 1931 & 251 \\
\hline \multicolumn{5}{|l|}{ Topography } \\
\hline Southing & -1.00 & 1.00 & 0.08 & 0.67 \\
\hline Inclination $\left[{ }^{\circ}\right]$ & 4 & 53 & 21 & 12 \\
\hline Microrelief (maximum) [cm] & 2 & 72 & 13 & 11 \\
\hline \multicolumn{5}{|l|}{ Soil physical } \\
\hline Cover stones and rocks [\%] & 0 & 70 & 12 & 14 \\
\hline Cover gravel [\%] & 0 & 99 & 28 & 28 \\
\hline Cover fine soil [\%] & 1 & 100 & 61 & 32 \\
\hline Soil depth mean $[\mathrm{cm}]$ & 2.3 & 100.0 & 18.6 & 15.6 \\
\hline Soil depth SD [cm] & 0.0 & 35.0 & 6.5 & 5.2 \\
\hline Soil depth CV [\%] & 0 & 135 & 43 & 25 \\
\hline \multicolumn{5}{|l|}{ Soil chemical } \\
\hline $\mathrm{pH}\left(\mathrm{H}_{2} \mathrm{O}\right)$ & 5.90 & 8.10 & 7.35 & 0.60 \\
\hline Electrical conductivity $\left[\mu \mathrm{S} \mathrm{cm}^{-1}\right]$ & 100 & 780 & 277 & 147 \\
\hline Organic C [\%] & 0.60 & 6.81 & 3.82 & 1.50 \\
\hline Humus [\%] & 1.03 & 11.74 & 6.58 & 2.58 \\
\hline $\mathrm{N}[\%]$ & 0.05 & 0.92 & 0.43 & 0.19 \\
\hline $\mathrm{C} / \mathrm{N}$ & 5.1 & 15.1 & 9.4 & 2.4 \\
\hline \multicolumn{5}{|l|}{ Vegetation cover } \\
\hline Total vegetation cover [\%] & 20 & 95 & 67 & 19 \\
\hline Cover shrub layer [\%] & 0 & 11 & 0 & 2 \\
\hline Cover herb layer [\%] & 20 & 95 & 66 & 19 \\
\hline Cover cryptogam layer [\%] & 0 & 80 & 3 & 9 \\
\hline Cover litter [\%] & 0 & 100 & 28 & 30 \\
\hline Cover dead wood [\%] & 0 & 1 & 0 & 0 \\
\hline \multicolumn{5}{|l|}{ Vegetation height } \\
\hline Maximum height shrub layer & NA & 173 & 9 & 29 \\
\hline Maximum height herb layer & 24 & 150 & 75 & 22 \\
\hline Standard height herb layer & 4 & 57 & 15 & 8 \\
\hline Standard height herb layer SD & 1 & 25 & 7 & 5 \\
\hline
\end{tabular}

of this species forms tiny, bushy, more or less Cladonia-like branches with black apices at the tip of branchlets. It initially grows on soil and later becomes vagrant. Vagrant forms accumulate in wind-deposited drifts (Sohrabi et al. 2013). The species is rare in Europe and is only known from the most continental parts of the Iberian Peninsula, the maritime Alps of France, the western Alps of Piemonte in Italy, the Parnassus mountain in Greece and the Crimean Peninsula. It is more widely distributed in the steppes of the Near East, Middle and Central Asia (Nimis 2016; Sohrabi et al. 2013).

\section{Diversity of the vegetation}

Mean total richness of the vegetation increases from 2.0 species in $1 \mathrm{~cm}^{2}$ via 31.9 species in $1 \mathrm{~m}^{2}$ to 51.3 species in $10 \mathrm{~m}^{2}$ (Table 3). Data for the $100-\mathrm{m}^{2}$ plots have yet to be fully analysed, but the raw data suggest that our richest plot (Fig. 4) contains approximately 145 species, of which 130 are vascular plants. Bryophytes and lichens mostly not only had very low cover with $3 \%$ on average (Table 3 ), but they also contributed only a rather small fraction to the total richness of the dry grasslands, decreasing from about $10 \%$ in the smallest grain sizes to only $5 \%$ in $10 \mathrm{~m}^{2}$. Accordingly, mean vascular plant species richness values were only slightly lower than that of the total vegetation (Table 3). Maximum values for vascular plant species richness were 7 in $1 \mathrm{~cm}^{2}, 51$ in $1 \mathrm{~m}^{2}$ and 80 in $10 \mathrm{~m}^{2}$. Particularly high values of vascular plants were, without exception, a feature of the meso-xeric grasslands, such as the example shown in Fig. 4.

While the richness values for non-vascular species and the contribution of these groups to overall richness of the vegetation were below average for Palaearctic grasslands (Dengler et al. 2016a), the small-scale diversity of vascular plants was outstanding. With a mean of 48.7 vascular plant species in $10 \mathrm{~m}^{2}$, the values were only minimally below those in Transylvania (49.7), which is the record for the EDGG Field Workshops held to date (Dengler et al. 2016a). By contrast, values were much lower in other Field Workshop areas that included xeric valleys and high mountains, such as Navarre (41.9; see Dengler et al. 2016a) and the central-alpine valleys of Switzerland (28.9; Dengler et al. 2020b). This extreme fine-grain vascular plant species richness in the Armenian dry grasslands is all the more astonishing as plots sampled in meso-xeric grasslands were only a relatively small fraction of the total. As is the case all over the Palaearctic (Dengler et al. 2020a), the Armenian mesoxeric (basiphilous) grasslands were by far the richest type. With up to 80 vascular plant species in $10 \mathrm{~m}^{2}$, they exceed the maxima known in most regions of the Palaearctic. Only from Eastern Europe (98 species) and Western Europe (86 species) have higher maxima been reported, but taking into account our small sample size, one can assume that equally rich plots could also be found in Armenia. Also 35 vascular plants in $0.1 \mathrm{~m}^{2}$ (Table 3 ) is only slightly below the Palaearctic (and world) record of 43 (Wilson et al. 2012; Dengler et al. 2020a). 
Table 3. Overview of scale-dependent species richness of vascular plants, terricolous bryophytes and lichens in Armenian dry grasslands using the shoot presence method. The data for vascular plants are preliminary as the determination of herbarium specimens has not been yet finalised. However, for grain sizes below $100 \mathrm{~m}^{\mathbf{2}}$ only minor changes are now likely. Species richness values for vascular plants and complete vegetation in the $100-\mathrm{m}^{2}$ plots are not provided here because they may change substantially once the alignment of plant nomenclature between the subplot series of the two corners is completed.

\begin{tabular}{llllllllll}
\hline & & \multicolumn{2}{c}{ Total richness } & \multicolumn{2}{c}{ Vascular plants } & \multicolumn{2}{l}{ Bryophytes } & & \multicolumn{2}{c}{ Lichens } \\
Area $\left[\mathbf{m}^{2}\right]$ & $\boldsymbol{n}$ & Mean & Range & Mean & Range & Mean & Range & Mean & Range \\
\hline 0.0001 & 58 & 2.0 & $0-10$ & 1.8 & $0-7$ & 0.2 & $0-3$ & 0.0 & $0-0$ \\
0.001 & 58 & 3.4 & $0-12$ & 3.1 & $0-9$ & 0.3 & $0-4$ & 0.1 & $0-2$ \\
0.01 & 58 & 7.5 & $2-24$ & 6.7 & $2-22$ & 0.6 & $0-7$ & 0.1 & $0-3$ \\
0.1 & 58 & 16.6 & $7-35$ & 15.4 & $6-35$ & 0.9 & $0-7$ & 0.3 & $0-3$ \\
1 & 58 & 31.9 & $15-56$ & 29.6 & $15-51$ & 1.9 & $0-11$ & 0.4 & $0-3$ \\
10 & 111 & 51.3 & $22-91$ & 48.7 & $22-80$ & 1.9 & $0-11$ & 0.6 & $0-5$ \\
100 & 29 & NA & NA & NA & NA & 3.8 & $0-12$ & 1.3 & $0-7$ \\
\hline
\end{tabular}

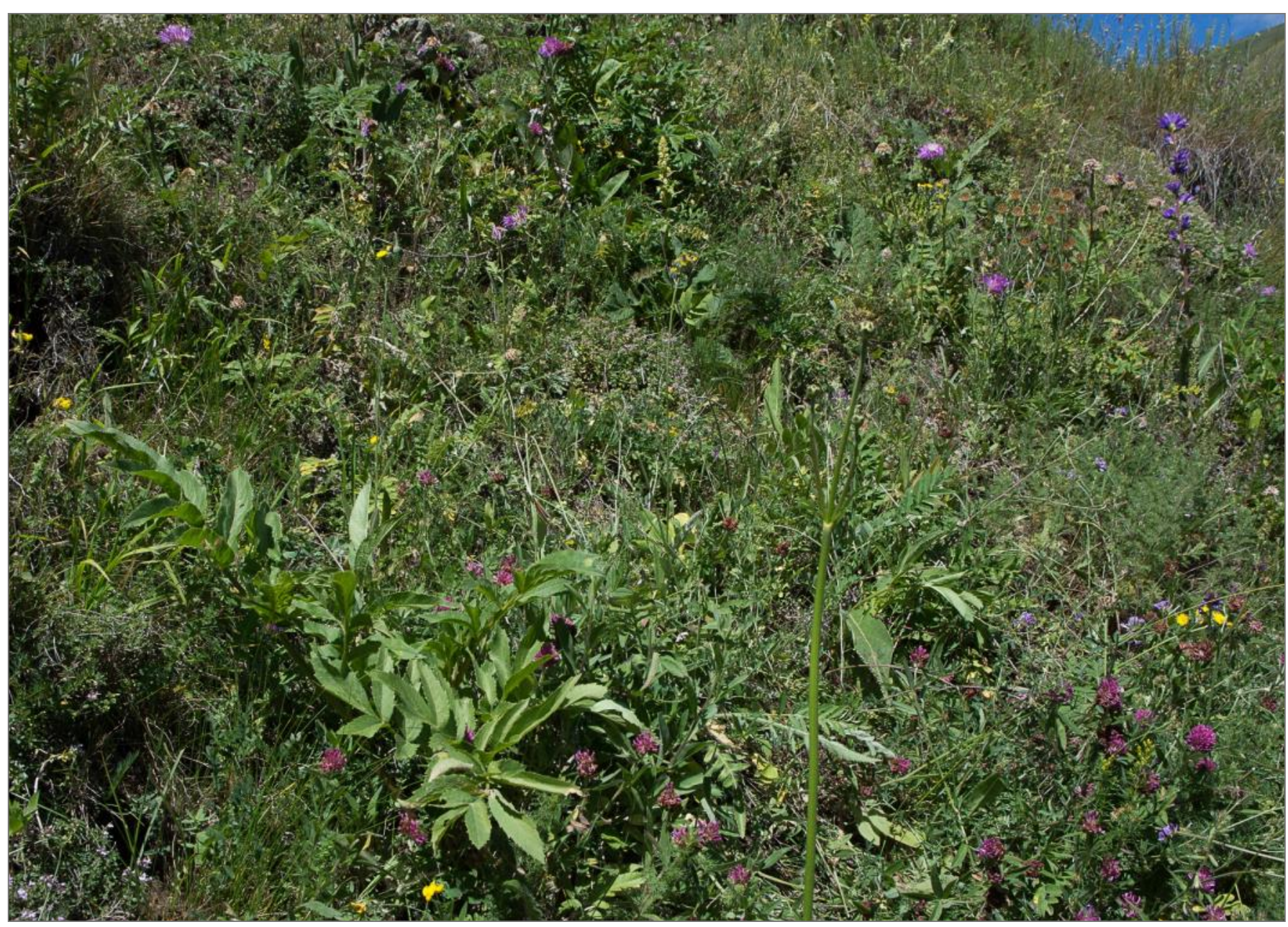

Fig. 4. The most species-rich plot at $10 \mathrm{~m}^{2}$ and $100 \mathrm{~m}^{2}$ recorded during the 13th EDGG Field Workshop, a meso-xeric grassland in Ardanish (site H, Biodiversity Plot AM22), with 91 species in $10 \mathrm{~m}^{2}$ (among them 80 vascular plants) and approx. 145 species (among them approx. 130 vascular plants) in $100 \mathrm{~m}^{2}$ (raw number: 159 species; final number not yet fixed as a cross-check of species determination between subplots is incomplete). Typical species visible in the photo include Trifolium alpestre (red), Psephellus dealbatus (pink), Campanula glomerata (blue), Lotus corniculatus (yellow) and Cephalaria gigantea (non-flowering tall forb in the foreground). Photo: J. Dengler. 


\section{Vegetation types and syntaxonomy}

In the absence of a syntaxonomic overview of Armenia and prior to proper classification of the relevés, we can provide only a brief characterisation of the main vegetation types encountered among the dry grasslands of the country:

Widespread across all study regions (except the lowest elevations), we found meso-xeric grasslands, xeric grasslands and rocky grasslands, all three often juxtaposed, but on slopes with different aspects and rockiness (Figs. 5 and 6). These three main types were floristically and physiognomically clearly distinct, as well as in their colour during sampling time (Fig. 5). Given their dominating species (see in section "Composition of the vegetation" above), all three types probably should be included in the class FestucoBrometea, which comprises the basiphilous dry grasslands dominated by perennial species in Europe (see Mucina et al. 2016). In the case of the meso-xeric and xeric types, the high floristic similarity to stands in Eastern and Eastern Central Europe suggests that they might be included in the widespread orders Brachypodietalia pinnati and Festucetalia valesiacae, respectively (see Mucina et al. 2016), but in both cases probably in a vicariant alliance of the Caucasus.
This finding is particularly interesting (and possibly for many readers astonishing) in the case of the Brachypodietalia pinnati. However, by overlaying distribution maps of diagnostic species of this order, Dengler (2003) already predicted an isolated outpost of this order in the Caucasus. By contrast, the rocky dry grasslands apparently do not belong to any of the described orders (Stipo pulcherrimae-Festucetalia pallentis, Thymo cretacei-Hyssopetalia cretacei, Scorzoneretalia villosae in the sense of Mucina et al. 2016) and thus might represent a new order.

The other three main physiognomic-ecological types (Fig. 7) might largely belong to other classes than the FestucoBrometea. The thorn-cushion communities of Iran and neighbouring countries have been described as Onobrychidetea cornutae and the scree communities might partly belong to the class Prangetea ulopterae (see Ambarlı et al. 2017), partly perhaps still to the Festuco-Brometea (e.g. Fig. 7C). Xeric grasslands with Minor-Asian species, such as Astracantha microcephala, Dianthus crinitus, Helichrysum plicatum, Leontodon asperrimus, Taeniatherum caput-medusae subsp. crinitum, Stipa holosericea are classified within the class Astragalo-Brometea which represents

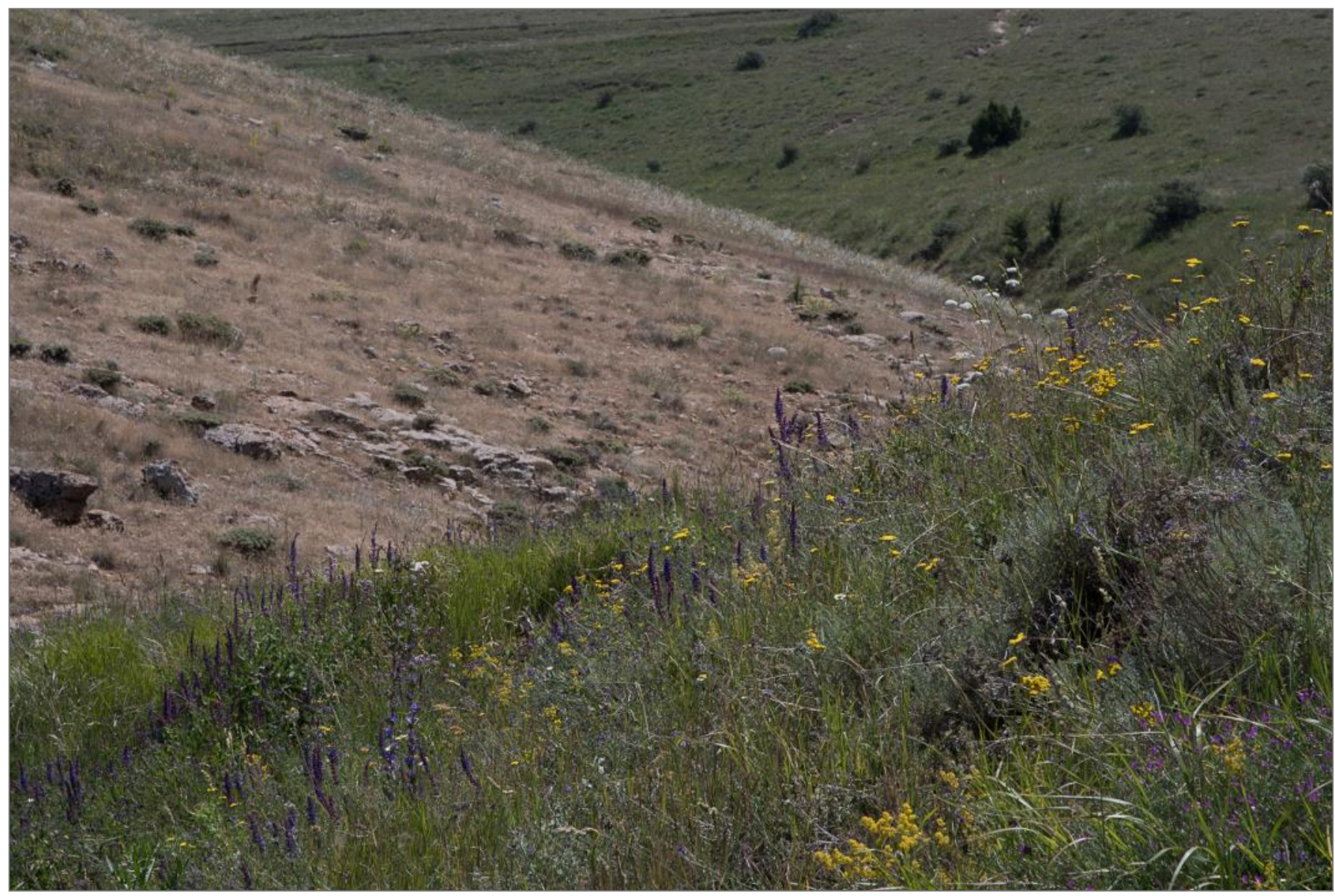

Fig. 5. South-facing (left) and north-facing (right) slopes were often inhabited by contrasting plant communities, i.e. xeric vs. meso-xeric types, with their distinct flora as here in site M. Photo: J. Dengler. 

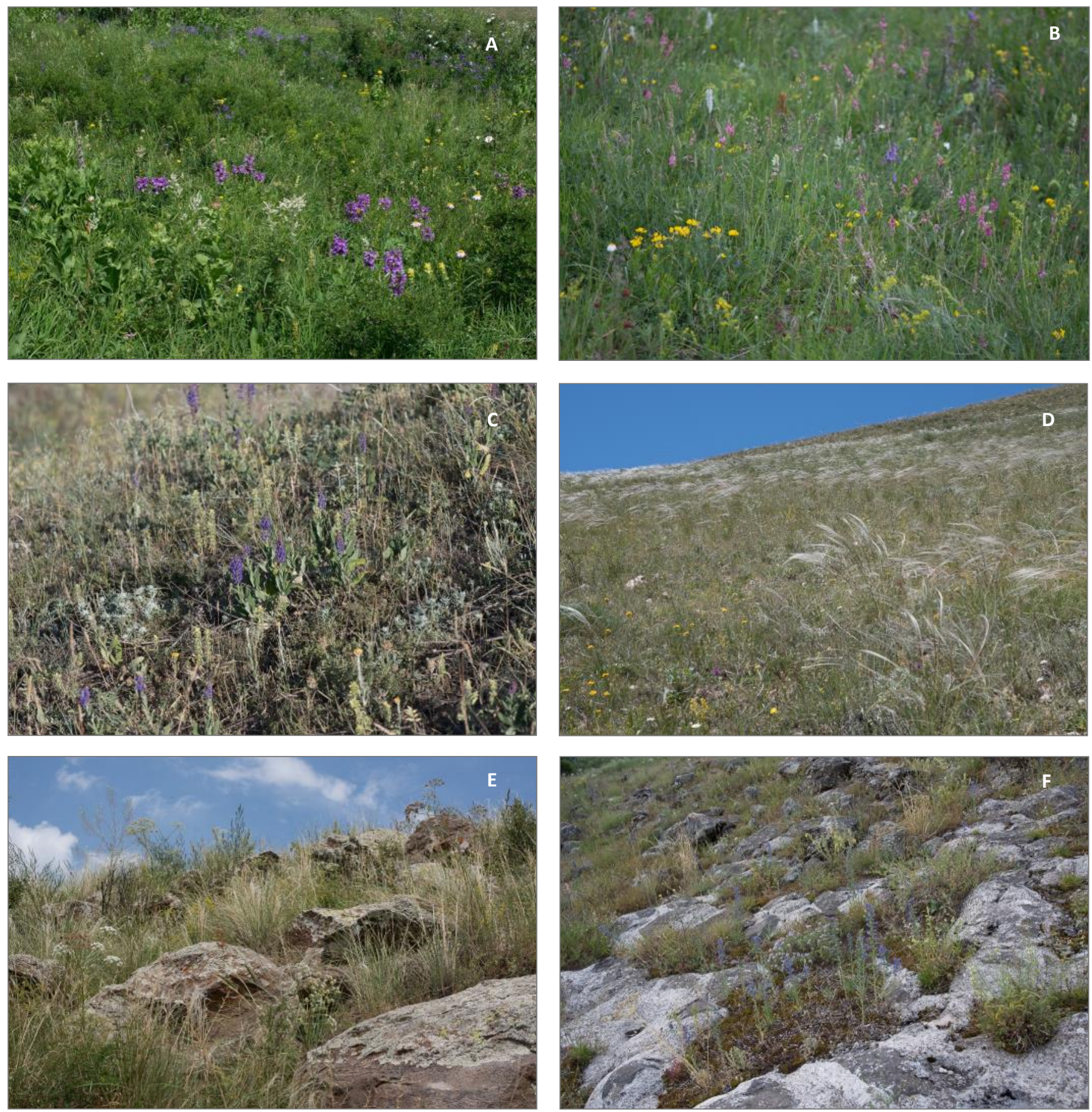

Fig. 6. Examples I of main vegetation types sampled during the EDGG Field Workshop in Armenia. (A) and (B): meso-xeric grasslands sometimes had many Caucasus-specific species as Stachys macrantha, Polygonum alpinum and Rhinanthus cf. angustifolius in site C (A), sometimes had a species composition almost identical to stands in Eastern Central Europe, with Campanula sibirica, Plantago media, Briza media and Onobrychis transcaucasica in site G (B). (C) and (D): xeric grasslands on deeper soils occurred in various types as (C) with Koeleria macrantha, Salvia nemorosa and Teucrium capitatum in site B or (D) with Stipa spp. in site L. (E) and (F): rocky grassland also occurred in various types as (E) in site E or (F) with Echium vulgare in site G. Photos: J. Dengler. 

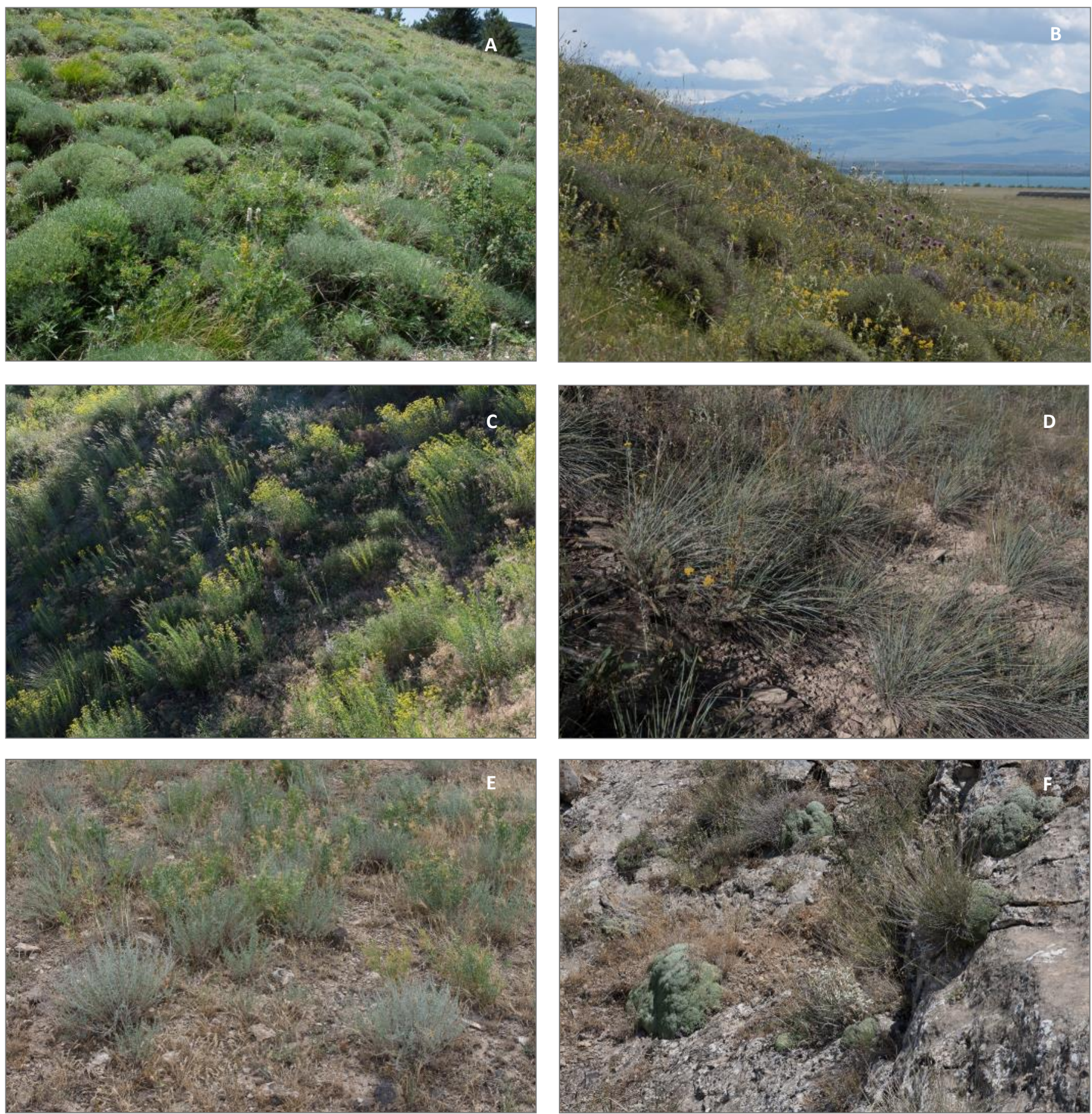

Fig. 7. Examples II of main vegetation types sampled during the EDGG Field Workshop in Armenia. (A) and (B): Thorncushion communities typically also contained grassland elements as (A) with Onobrychis cornuta, Asphodeline taurica and Carex humilis in site A or (B) with Onobrychis cornuta, Stipa pulcherrima and Galium verum in site I. (C) and (D): Xerothermic scree communities were diverse and contained many Caucasus-specific species as (C) with Michauxia laevigata and Euphorbia sequieriana in site $K$ or (D) with Stipa araxensis in site L. (E) and (F): Dry grasslands of the lower elevations were rich in annuals and dwarf shrubs as (E) with Artemisia fragrans, Taeniatherum caput-medusae subsp. crinitum and Aegilops cylindrica in site F or (F) with Gypsophila aretioides, Helianthemum ledifolium and Chardinia orientalis in site O. Photos: J. Dengler. 
Iranian and Anatolian steppes (Kenar et al. 2020). Whether all xeric grasslands of the lower elevations, rich in annuals and dwarf shrubs and containing Irano-Turanian elements, should be included in Astragalo-Brometea, is still an open question that needs further elaboration.

\section{Composition and diversity of the orthopteroid insects}

During the $13^{\text {th }}$ EDGG Field Workshop in Armenia, we were able to test a new, standardized method to survey orthopteroid insects (Hilpold et al. 2020). Within the group "orthopteroid insects" we considered grasshoppers (Caelifera), bush and field crickets (Ensifera) and mantids (Mantodea). In summary, this method is conducted on the full extent of the EDGG biodiversity plots and combines sweep-netting along a transect and an exhaustive species search. This combination enables the surveyor to assess both absolute and relative species abundance, and also provides a representative picture of the total species richness.

We applied and tested the method on 42 EDGG vegetation survey plots (14 "normal plots", 28 EDGG Biodiversity Plots). By doing so, a total of approximately 40 species of orthopteroid insects have been identified so far, while additional species that have been collected await identification. We observed a maximum of 14 species per $100 \mathrm{~m}^{2}$ in the vicinity of the village of Gnishik, which is situated within a landscape that consists of dry pastures, hay meadows and shrubland (see day 8 in the Photo Diary in the Appendix). Orthopteroid insects were present in all the sampled plots with the lowest species number of 3 species per $100 \mathrm{~m}^{2}$ plot. Among these species, we found many characteristic elements of mesic grasslands of the western Palaearctic, for example Stauroderus scalaris and Chorthippus apricarius species that also occur in Central and Western Europe. In addition, we found widespread Eurasian steppe elements that are limited to isolated dry habitats in Central Europe, such as Omocestus petraeus and Stenobothrus nigromaculatus. Also, Mediterranean elements, such as Tylopsis liliifolia and Platycleis affinis were frequently recorded. The group of species that was biogeographically most inter-

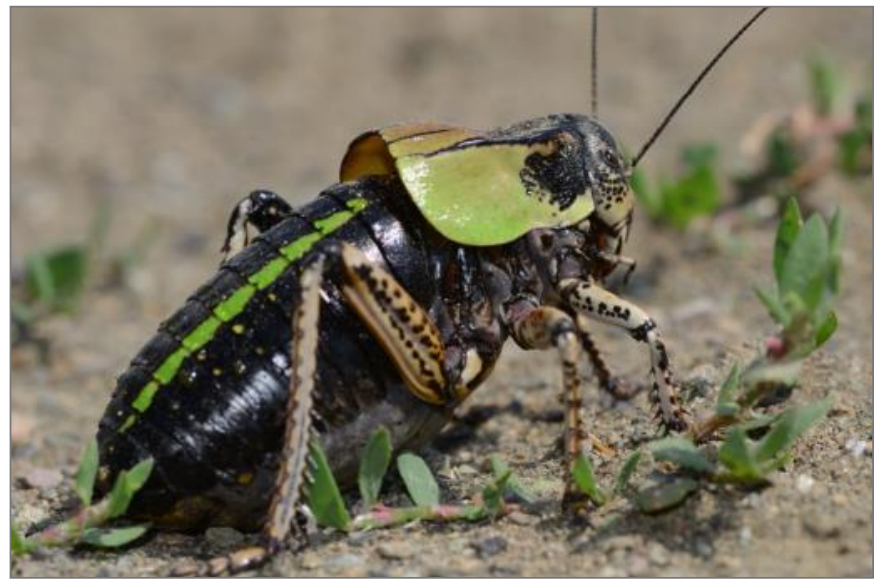

esting to the authors comprised species that have their main distribution in Southwestern Asia, such as Notostaurus anatolicus, Psorodonotus sp., Paradrymadusa sp. or Ramburiella turcomana. Finally, a small number of species were recorded that are endemic to the Caucasus and TransCaucasus area, for example Euchorthippus transcaucasicus and Bradyporus dilatatus (Fig. 8-left), the latter, a huge cricket exceeding $5 \mathrm{~cm}$ in length. The latter was one of the orthopterological highlights of the field workshop and was present in large numbers in the meso-xeric grasslands of Lake Arpi National Park.

For the authors, the excursion was a unique chance to get an impression of the diverse Orthoptera fauna of the TransCaucasus, and to acquire familiarity with many new species of grasshoppers and bush crickets. However, species identification was not always straightforward. The identification key we mainly relied on was qualitatively very good, but comprised the Orthoptera fauna of the whole former Soviet Union and dates back to 1951 (Bei-Bienko \& Mishchenko 1964). This lack of recent, and more region-specific taxonomic literature became challenging at times, mostly when we encountered genera that appear rather exotic to the Central European orthopterologist. This was for example the case for several species belonging to the Pamphagidae, a family that is uncommon in Central Europe. These very attractive grasshoppers were another orthopterological highlight of the Field Workshop (Fig. 8-right).

\section{Conclusions and outlook}

The 13th EDGG Field Workshop provided the participants with a wonderful insight into the diversity of the dry grasslands of Armenia. In addition, and for the first time, standardised and comprehensive biodiversity sampling of four important grassland taxa (vascular plants, bryophytes, lichens, orthopteroid insects) have been undertaken in this country. Meanwhile, data have been entered, soils have been analysed and bryophytes, lichens, Orthoptera and Festuca samples have been determined. Thus, all that remains to be completed is the identification of vascular

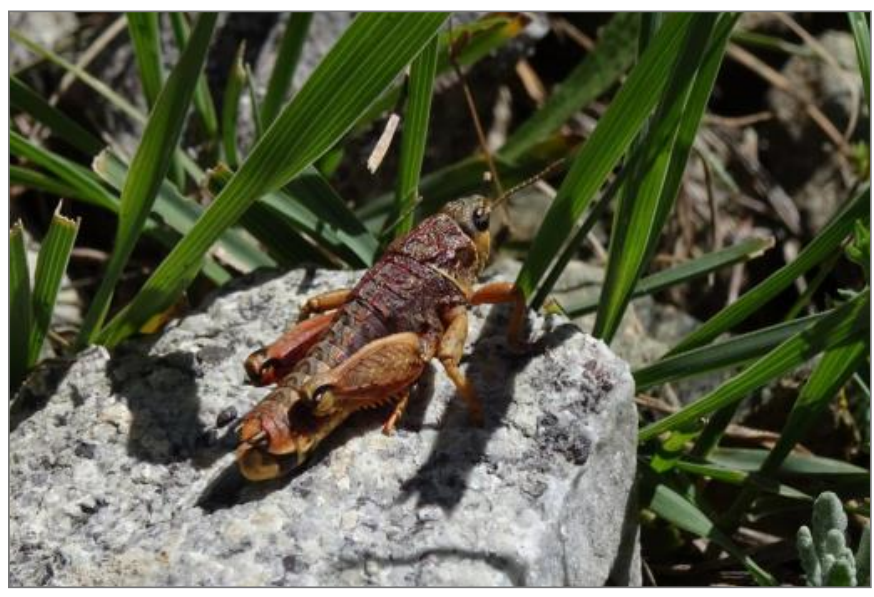

Fig. 8. Two Orthoptera species that are particularly interesting from a European perspective. Left: Bradyporus dilatatus at Lake Arpi National Park, the largest Orthoptera species found during the Field Workshop in Armenia. Photo: T. Becker. Right: Pamphagidae sp. Photo: P. Kirschner. 
plants. The current incomplete data have already provided several valuable insights, including:

First records from Armenia of two species of cryptogams (Syntrichia papillosissima and Aspicilia hispida) and possibly two more vascular plant species.

Very high fine-grain species richness of vascular plants, only slightly below the current world records (despite our relatively small sample size). Armenia can in this respect now be mentioned together with well-known places in Transylvania and the White Carpathians as a global hotspot.

Dominant vegetation types seem to fit into the European class Festuco-Brometea and here into the orders Brachypodietalia pinnati, Festucetalia valesiacae and probably a new order of Caucasian rocky grasslands.

By contrast, the other vegetation types (thorn cushion communities, scree vegetation and dry grasslands of lower elevations rich in annuals and chamaephytes) do not fit into any of the European classes.

The new method for sampling orthopteroid insects (Hilpold et al. 2020) designed to be conducted in conjunction with EDGG Biodiversity Plots of vegetation (Dengler et al. 2016a) proved to be efficient and informative.

As next steps, we plan to finalise the determination of the sampled vascular plants and Mantodea species. Then we aim to prepare at least two papers dealing with (a) the combined analysis of the scale- and taxon-dependent biodiversity patterns and their drivers and (b) the syntaxonomy of the Armenian dry grasslands in a Palaearctic context. Meanwhile, the plots sampled during the expedition have already been fed into the GrassPlot database (Dengler et al. 2018; Biurrun et al. 2019) and will, from now on, provide highquality biodiversity data for macroecological studies such as Dengler et al. (2020c). In conclusion, the Field Workshop has contributed to filling important information gaps both in biodiversity analyses and syntaxonomy both from a national and from a Palaearctic perspective.

\section{Author contributions}

A.A. organised the Field Workshop together with G.F. and M.O., while J.D. and I.B. led the writing of the text. D.V. and E.B. compiled the Photo Diary. All authors, except B.C.-M., I.D. and H.M., were involved in the field sampling. P.K and A.H. sampled the orthopteroid insects and wrote the corresponding section. B.C.-M. H.M. and I.D. determined bryophytes, lichens and Festuca species, respectively, and wrote the corresponding sections. A.B. contributed to the Introduction, D.V. to the text on Stipa and syntaxonomy, and D.S. prepared the map. A.B., D.S and I.V. entered the data and I.B and I.D. contributed to "data cleaning". Many authors contributed photos (see captions). All authors read and approved the manuscript.

\section{Acknowledgments}

We are grateful to the IAVS and EDGG for providing travel grants to some participants and the administration of the Institute of Botany after A.L. Takhtajyan of the National Academy of Science of the Republic of Armenia for support in the organization of the Field Workshop. We are grateful to Richard Jefferson for fast and thorough linguistic editing.

\section{References}

Ambarlı, D., Vrahnakis, V., Burrascano, S., Naqinezhad, A. \& Pulido, M. 2017. Grasslands in the Mediterranean Basin and the Middle East. In: Squires, V.R., Dengler, J., Feng, H. \& Hua, L. (eds.) Grassland of the world: diversity, management and conservation, pp. 89-112. CRC Press, Boca Raton, US.

Ambarlı, D., Naqinezhad, A. \& Aleksanyan, A. 2020. Grasslands and shrublands of the Middle East and the Caucasus. In: Goldstein, M.I. \& DellaSala, D.A. (eds.) Encyclopedia of the world's biomes, pp. 714-724. Elsevier, Amsterdam, NL.

Bei-Bienko, G. \& Mishchenko, L.L. 1964. Locusts and grasshoppers of the U.S.S.R. and adjacent countries (English edition). National Science Foundation, Washington D.C., US.

Biurrun, I., García-Mijangos, I., Berastegi, A., Ambarlı, D., Dembicz, I., Filibeck, G., Jandt, U., Janišová, M., Jaunatre, R., (...) \& Dengler, J. 2014. Diversity of dry grasslands in Navarre (Spain). Experiences from the $7^{\text {th }}$ EDGG Field Workshop, 15-24 June 2014. Bulletin of the European Dry Grassland Group 24/25: 421.

Biurrun, I., Burrascano, S., Dembicz, I., Guarino, R., Kapfer, J., Pielech, R., García-Mijangos, I., Wagner, V., Palpurina, S., (...) \& Dengler, J. 2019. GrassPlot v. 2.00 - first update on the database of multi-scale plant diversity in Palaearctic grasslands. Palaearctic Grasslands 44: 26-47.

Dengler, J. 2003. Entwicklung und Bewertung neuer Ansätze in der Pflanzensoziologie unter besonderer Berücksichtigung der Vegetationsklassifikation. Archiv naturwissenschaftlicher Dissertationen 14: 1-297.

Dengler, J. 2009. A flexible multi-scale approach for standardised recording of plant species richness patterns. Ecological Indicators 9: 1169-1178.

Dengler, J., Becker, T., Ruprecht, E., Szabó, A., Becker, U., Beldean, M., Biţă-Nicolae, C., Dolnik, C., Goia, I., (...) \& Uğurlu, E. 2012. Festuco-Brometea communities of the Transylvanian Plateau (Romania) - a preliminary overview on syntaxonomy, ecology, and biodiversity. Tuexenia 32: 319-359.

Dengler, J., Janišová, M., Török, P. \& Wellstein, C. 2014. Biodiversity of Palaearctic grasslands: a synthesis. Agriculture, Ecosystems \& Environment 182: 1-14.

Dengler, J., Boch, S., Filibeck, G., Chiarucci, A., Dembicz, I., Guarino, R., Henneberg, B., Janišová, M., Marcenò, C., (...) \& Biurrun, I. 2016a. Assessing plant diversity and composition in grasslands across spatial scales: the standardised EDGG sampling methodology. Bulletin of the Eurasian Grassland Group 32: 13-30.

Dengler, J., Biurrun, I., Apostolova, I., Baumann, E., Becker, T., Berastegi, A., Boch, S., Cancellieri, L., Dembicz, I., (...) \& Weiser, F. 2016b. Scale-dependent plant diversity in Palaearctic grasslands: a comparative overview. Bulletin of the Eurasian Dry Grassland Group 31: 12-26. 
Dengler, J., Wagner. V., Dembicz, I., García-Mijangos, I., Naqinezhad, A., Boch, S. Chiarucci, A., Conradi, T., Filibeck, G., (...) \& Biurrun, I. 2018. GrassPlot - a database of multi-scale plant diversity in Palaearctic grasslands. Phytocoenologia 48: 331-347.

Dengler, J., Gehler, J., Aleksanyan, A., Fayvush, G. \& Biurrun, I. 2019. EDGG Field Workshops 2019 - the international research expeditions to study grassland diversity across multiple scales and taxa: Call for participation. Palaearctic Grasslands 41: 922.

Dengler, J., Biurrun, I., Boch, S., Dembicz, I. \& Török, P. 2020a. Grasslands of the Palaearctic biogeographic realm: introduction and synthesis. In: Goldstein, M.I. \& DellaSala, D.A. (eds.) Encyclopedia of the world's biomes, pp. 617-637. Elsevier, Amsterdam, NL.

Dengler, J., Guarino, R., Moyisyenko, I., Vynokurov, D., Boch, S., Cykowska-Marzencka, B., Babbi, M., Catalano, C., Eggenberg, S., (...) \& Dembicz, I. 2020b. On the trails of Josias BraunBlanquet II: First Results from the $12^{\text {th }}$ EDGG Field Workshop studying the dry grasslands of the inneralpine dry valleys of Switzerland. Palaearctic Grasslands 45: 59-88.

Dengler, J., Matthews, T.J., Steinbauer, M.J., Wolfrum, S., Boch, S., Chiarucci, A., Conradi, T., Dembicz, I., Marcenò, C., (...) \& Biurrun, I. 2020c. Species-area relationships in continuous vegetation: Evidence from Palaearctic grasslands. Journal of Biogeography 47: 72-86.

Euro+Med 2020. Euro+Med PlantBase - the information resource for Euro-Mediterranean plant diversity. URL: http:// ww2.bgbm.org/EuroPlusMed/ [accessed on 9 June 2020].

Fayvush, G. \& Aleksanyan, A. 2016. Habitats of Armenia. Institute of Botany NAS RA, Yerevan, AM.

Filibeck, G., Cancellieri, L., Sperandii, M.G., Belonovskaya, E., Sobolev, N., Tsarevskaya, N., Becker, T., Berastegi, A., Bückle, C. (...) \& Biurrun, I. 2018. Biodiversity patterns of dry grasslands in the Central Apennines (Italy) along a precipitation gradient: experiences from the 10th EDGG Field Workshop. Bulletin of the Eurasian Grassland Group 36: 25-41.

Heller, K-G., Bohn, H., Haas, F., Willemse, F. \& de Jong, Y. 2016. Fauna Europaea - Orthopteroid orders. Biodiversity Data Journal 4: e8905.

Hill, M.O., Bell, N., Bruggeman-Nannenga, M.A., Brugués, M., Cano, M.J., Enroth, J., Flatberg, K.K., Frahm, J.-P., Gallego, M.T., (...) \& Söderström, L. 2006. An annotated ckecklist of the mosses of Europe and Macaronesia. Journal of Bryology 28: 198267.

Hilpold, A., Kirschner, P. \& Dengler, J. 2020. Proposal of a standardized EDGG surveying methodology for orthopteroid insects. Palaearctic Grasslands 46: 52-57.

Kenar, N., Şekerciler, F. \& Çoban, S. 2020. The phytosociology, ecology, and plant diversity of new plant communities in Central Anatolia (Turkey). Hacquetia 19: 1-22.

Kuzemko, A., Becker, T., Didukh, Y.P., Ardelean, I.V., Becker, U., Beldean, M., Dolnik, C., Jeschke, M., Naqinezhad, A., (...) \& Dengler, J. 2014. Dry grassland vegetation of central Podolia (Ukraine) - A preliminary overview of its syntaxonomy, ecology and biodiversity. Tuexenia 34: 391-430.

Kuzemko, A., Steinbauer, M.J., Becker, T., Didukh, Y.P., Dolnik, C., Jeschke, M., Naqinezhad, A., Uğurlu, E., Vassilev, K. \& Dengler, J. 2016. Patterns and drivers of phytodiversity in steppe grasslands of Central Podolia (Ukraine). Biodiversity and Conservation 25: 2233-2250.
Magnes, M., Kirschner, P., Janišová, M., Mayrhofer, H., Berg, C., Mora, A., Afif, E., Willner, W., Belonovoskaya, E., (...) \& Dengler, J. 2020. On the trails of Josias Braun-Blanquet changes in the grasslands of the inneralpine dry valleys during the last 70 years. First results from the 11th EDGG Field Workshop in Austria. Palaearctic Grasslands 45: 34-58.

Mucina, L., Bültmann, H., Dierßen, K., Theurillat, J.-P., Raus, T., Čarni, A., Šumberová, K., Willner, W., Dengler, J., (...) \& Tichý, L. 2016. Vegetation of Europe: Hierarchical floristic classification system of vascular plant, bryophyte, lichen, and algal communities. Applied Vegetation Science 19, Suppl. 1: 3-264.

Nimis, P.L. 2016. The lichens of Italy. A second annotated catalogue. EUT - Edizioni Università di Trieste, Trieste, IT.

Nimis, P.L., Hafellner, J., Roux, C., Clerc, P., Mayrhofer, H., Martellos, S. \& Bilovitz, P.O. 2018. The lichens of the Alps - an annotated checklist. MycoKeys 31: 1-634.

Pedashenko, H., Apostolova, I., Boch, S., Ganeva, A., Janišová, M., Sopotlieva, D., Todorova, S., Ünal, A., Vassilev, K., (...) \& Dengler, J. 2013. Dry grasslands of NW Bulgarian mountains: first insights into diversity, ecology and syntaxonomy. Tuexenia 33: 309-346.

Polchaninova, N., García-Mijangos, I., Berastegi, A., Dengler, J. \& Biurrun, I. 2018. New data on the spider fauna (Araneae) of Navarre, Spain: results from the 7th EDGG Field Workshop. Arachnology Letters 56: 17-23.

Polyakova, M.A., Dembicz, I., Becker, T., Becker, U., Demina, O.N., Ermakov, N., Filibeck, G., Guarino, R., Janišová, M., (...) \& Dengler, J. 2016. Scale- and taxon-dependent patterns of plant diversity in steppes of Khakassia, South Siberia (Russia). Biodiversity and Conservation 25: 2251-2273.

Schaminée, J.H.J., Chytrý, M., Dengler, J., Hennekens, S.M., Janssen, J.A.M., Jiménez-Alfaro, B., Knollová, I., Landucci, F., Marcenò, C., (...) \& Tichý, L. 2016. Development of distribution maps of grassland habitats of EUNIS habitat classification. European Environment Agency [Report EEA/NSS/16/005], Copenhagen, DK.

Söderström, L., Hagborg, A., von Konrat, M., Bartholomew-Began, S., Bell, D., Briscoe, L., Brown, E., Cargill, D.C., Pinheiro da Costa, D., (...) \& Zhu, R.-L. 2016. World checklist of hornworts and liverworts. PhytoKeys 59: 1-821.

Sohrabi, M., Stenroos, S., Myllys, L., Søchting, U., Athi, T. \& Hyvönen, J. 2013. Phylogeny and taxonomy of the 'manna lichens'. Mycological Progress 12: 231-269.

Tamanyan, K.G. \& Fayvush, G.M. 2009. On the problem of floristic regions of Armenia. Flora, Vegetation and Plant Resources of Armenia 17: 73-78.

Turtureanu, P.D., Palpurina, S., Becker, T., Dolnik, C., Ruprecht, E., Sutcliffe, L.M.E., Szabó, A. \& Dengler, J. 2014. Scale- and taxondependent biodiversity patterns of dry grassland vegetation in Transylvania. Agriculture, Ecosystems \& Environment 182: 1524.

Willner, W., Kuzemko, A., Dengler, J., Chytrý, M., Bauer, N., Becker, T., Biţă-Nicolae, C., Botta-Dukát, Z., Čarni, A., (...) \& Janišová, M. 2017. A higher-level classification of the Pannonian and western Pontic steppe grasslands (Central and Eastern Europe). Applied Vegetation Science 20: 143-158.

Wilson, J.B., Peet, R.K., Dengler, J. \& Pärtel, M. 2012. Plant species richness: the world records. Journal of Vegetation Science 23: 796-802. 


\title{
Appendix: Photo diary of the $13^{\text {th }}$ EDGG Field Workshop in Armenia
}

\author{
Compiled by Elena Belonovskaya, Denys Vynokurov and Idoia Biurrun
}

With photos by Elena Belonovskaya, Asun Berastegi, Idoia Biurrun, Jürgen Dengler, Dieter Frank, Itziar GarcíaMijangos, Andreas Hilpold, Philipp Kirschner, Martin Magnes, Salza Palpurina, Dariia Shyriaieva \&

Denys Vynokurov

\section{Day 1 - June 26, Yerevan-Gyumri}

The meeting point for the group was at the Yerevan Botanical Garden. Everyone was very glad to see colleagues again. We started at $3 \mathrm{PM}$ and the outdoor temperature was $40^{\circ} \mathrm{C}$. Our first trip was to Gyumri. We crossed Yerevan city and made our way to the North-West.

During our journey, we had a short unexpected stop near a small village. For most of us it was our first acquaintance with the desert steppe community with Artemisia fragrans, Capparis sicula subsp. herbacea, Taeniatherum caput-medusae subsp. crinitum, etc.

We arrived at Gyumri in the evening and, after checking in the hotel, we went for dinner. We sat outdoors on the terrace and tasted traditional Armenian dinner with several national dishes: dolma, shashlik, apjapsandal and lavash. Then back in the hotel, we assembled our equipment in readiness for our first sampling the next day.
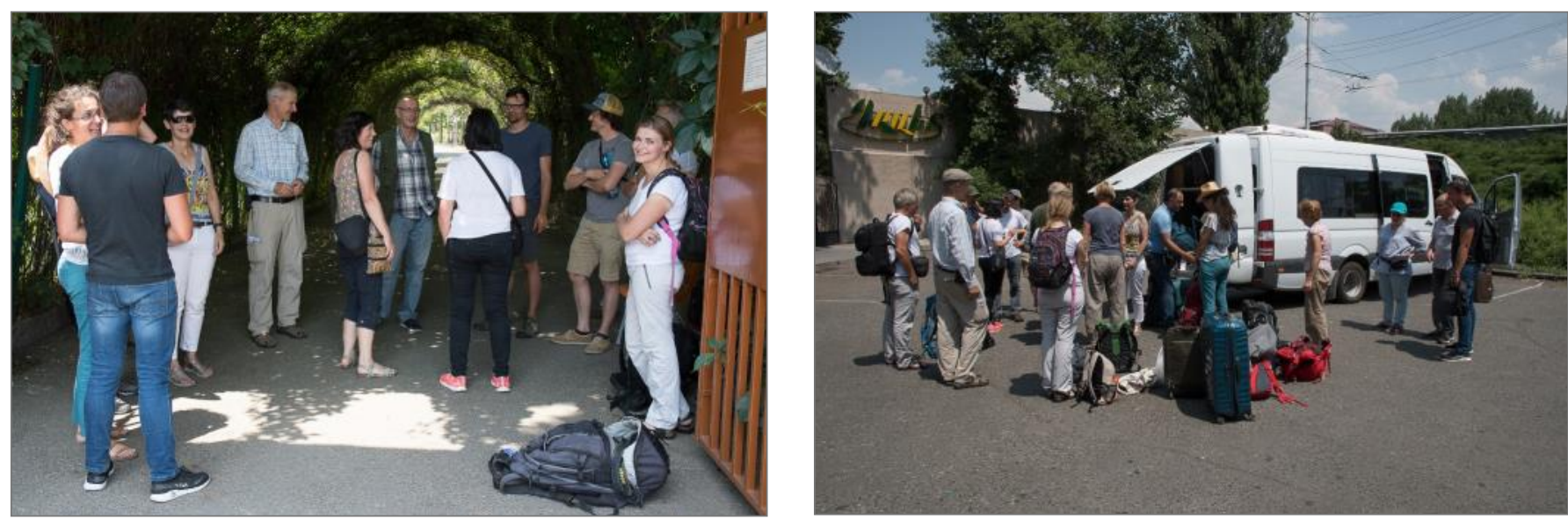

Left: Gathering in the Yerevan Botanical Garden. Right: Our driver Aram loads our luggage into the bus that will take us through Armenia.

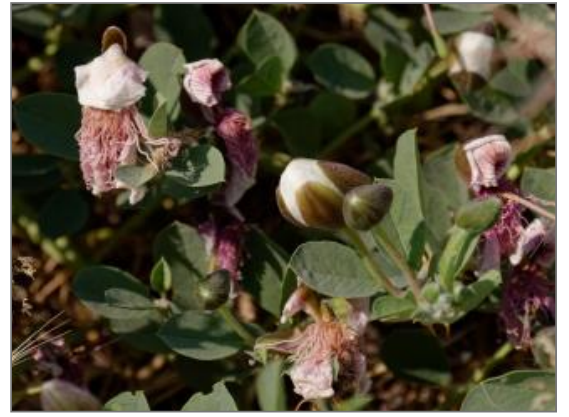

Capparis sicula subsp. herbacea.

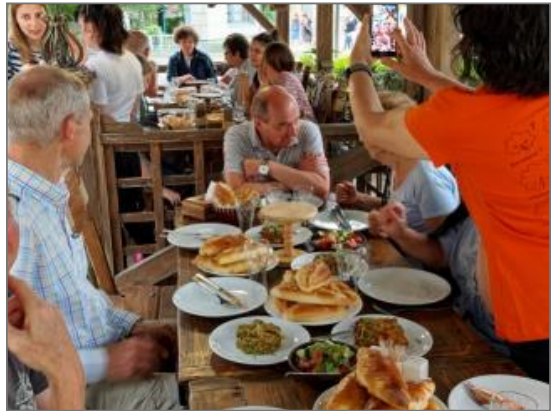

Traditional Armenian dinner.

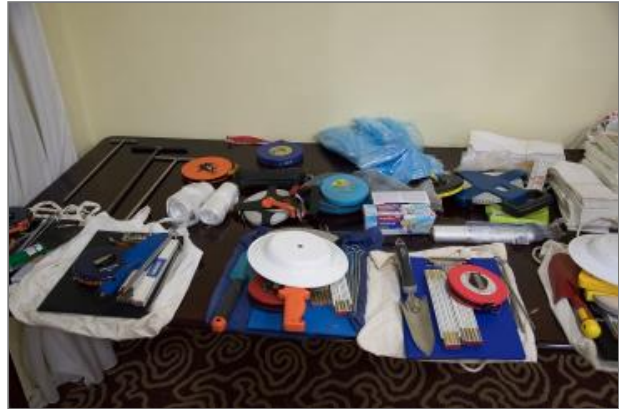

Traditional equipment ready for the next day. 
Day 2 - June 27, Gyumri-Jajur, Jajur-

\section{Shirakamut}

On this day we travelled to the region of Jajur pass. We sampled several plots of the rare thorn cushion and shrub steppe with Onobrychis cornuta, Asphodeline taurica and Prangos ferulacea in a narrow valley with rather steep stony slopes. While we were working, the weather changed rapidly. The sky was becoming more and more cloudy. Nevertheless, we managed to finish our work on the plots, run down the scree slopes and get into the car before the heavy rain began. We drove through the rain and when the sun appeared again, we found a place for a nice picnic lunch near the river under the trees.

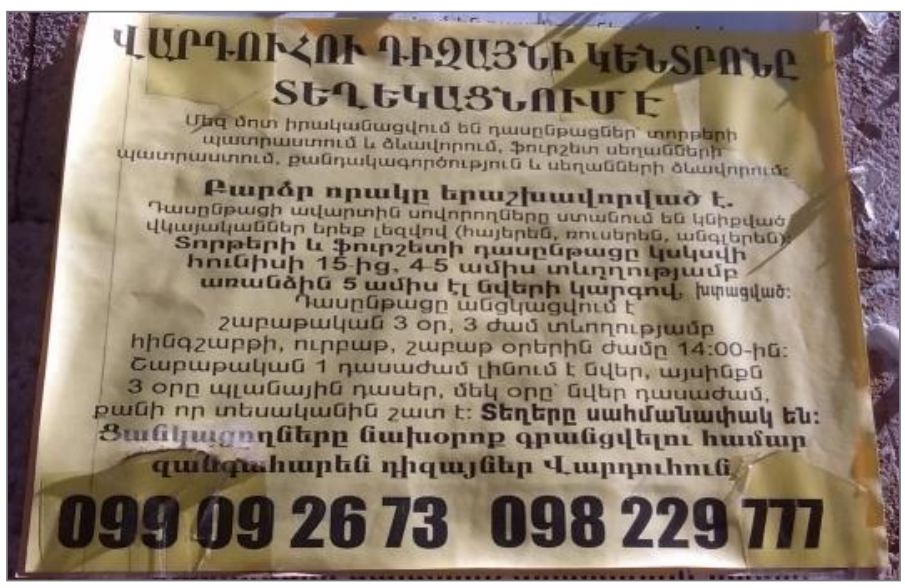

This was our leaflet detailing the sampling instructions.

In the afternoon, we drove eastwards towards the Lory area and stopped near Shirakamut village. This area has a long, well-documented land use history and is known for its Palaeo-and Neolithic settlements. We saw several caves preserved by archaeologists for further researches. We sampled plots of the mountain feather-grass steppes on the relatively flat surfaces. Most of these habitats were previously arable fields. In the evening, we had dinner in the famous fish restaurant "Cherkezi Dzor" where fresh fish was caught from the artificial ponds within the restaurant grounds. Later the same evening, at the hotel, we identified the plants collected during the day.
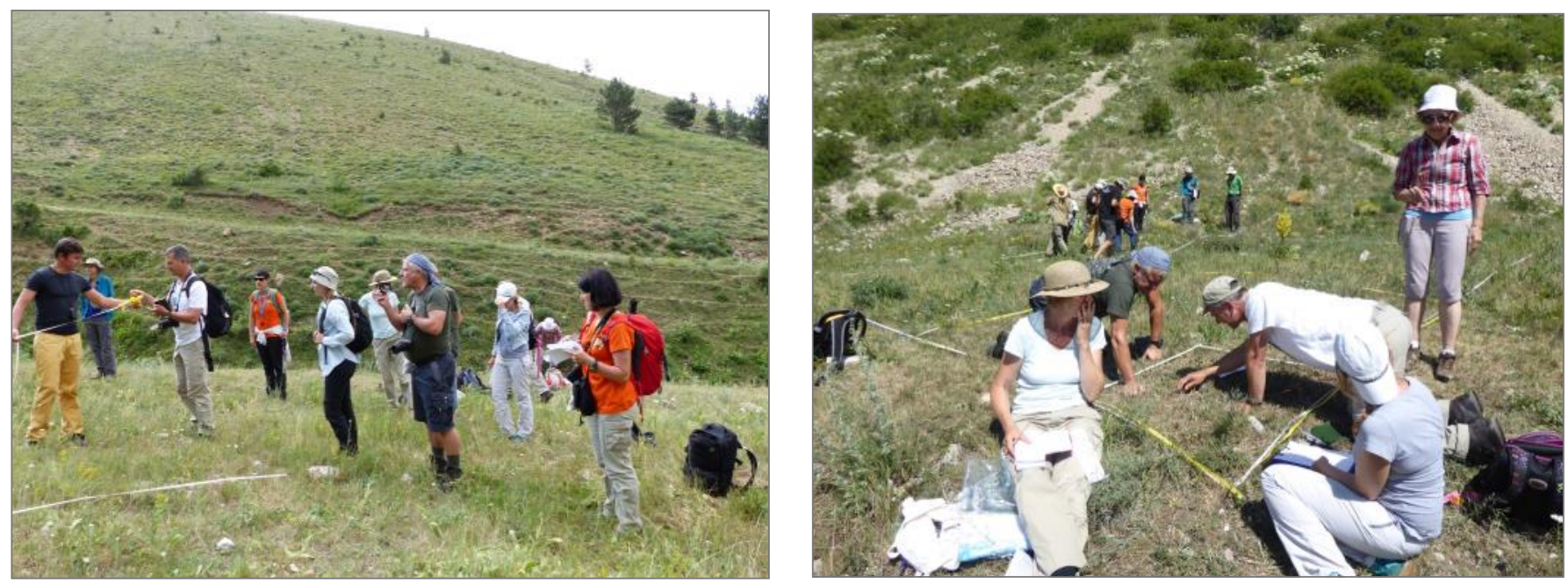

Our first EDGG Biodiversity Plot in Armenia. 

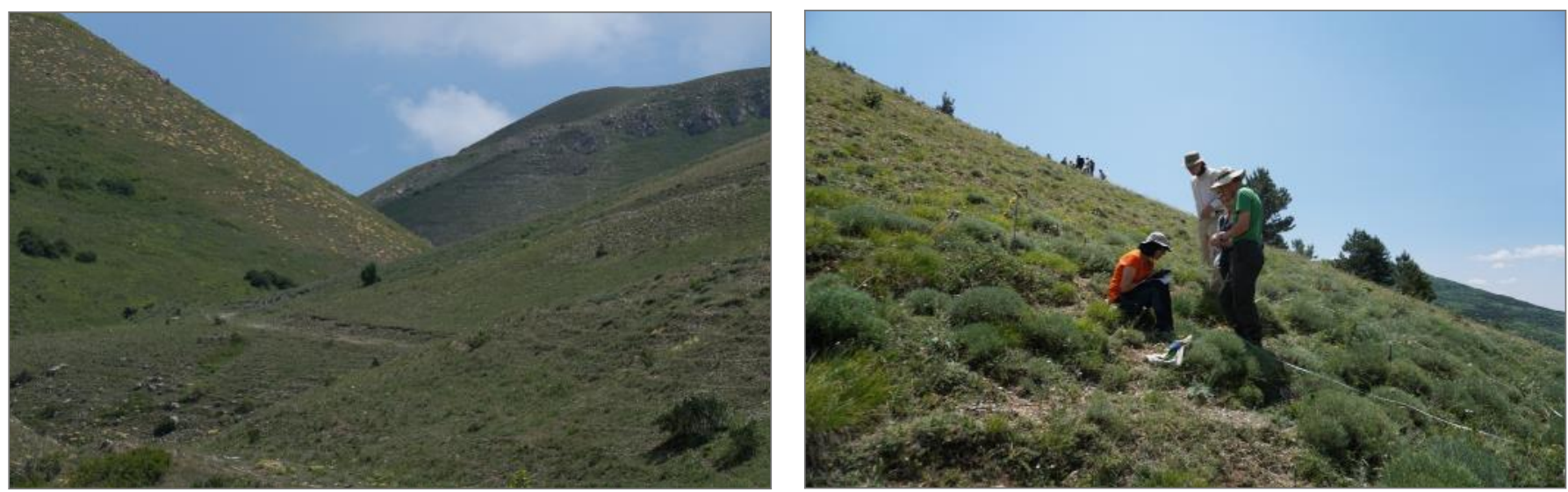

Thorn cushions of Onobrychis cornuta in the Jajur pass.
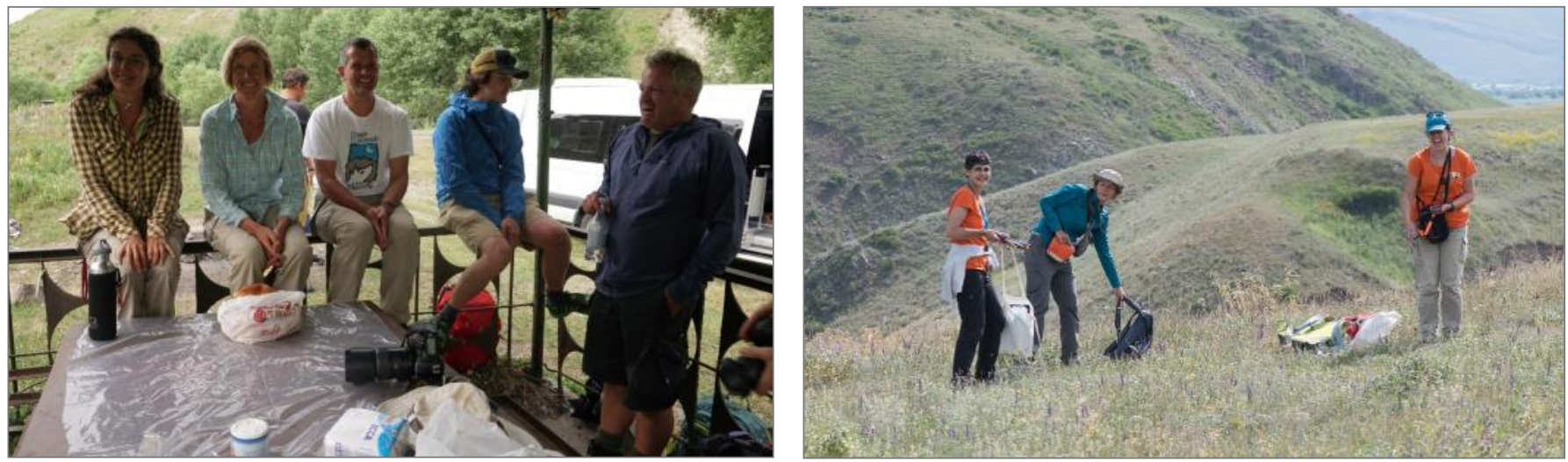

Left: Picnic by the stream. Right: After lunch, we are quite enthusiastic and have the energy to sample more plots.
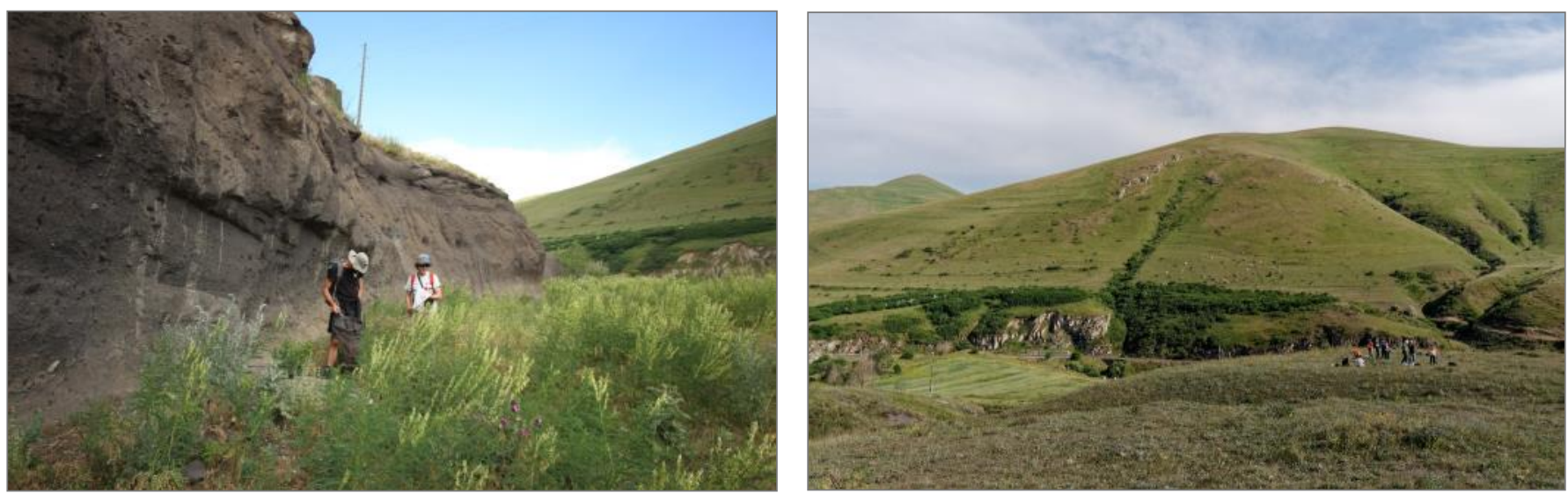

Afternoon work near the Shirakamut village.
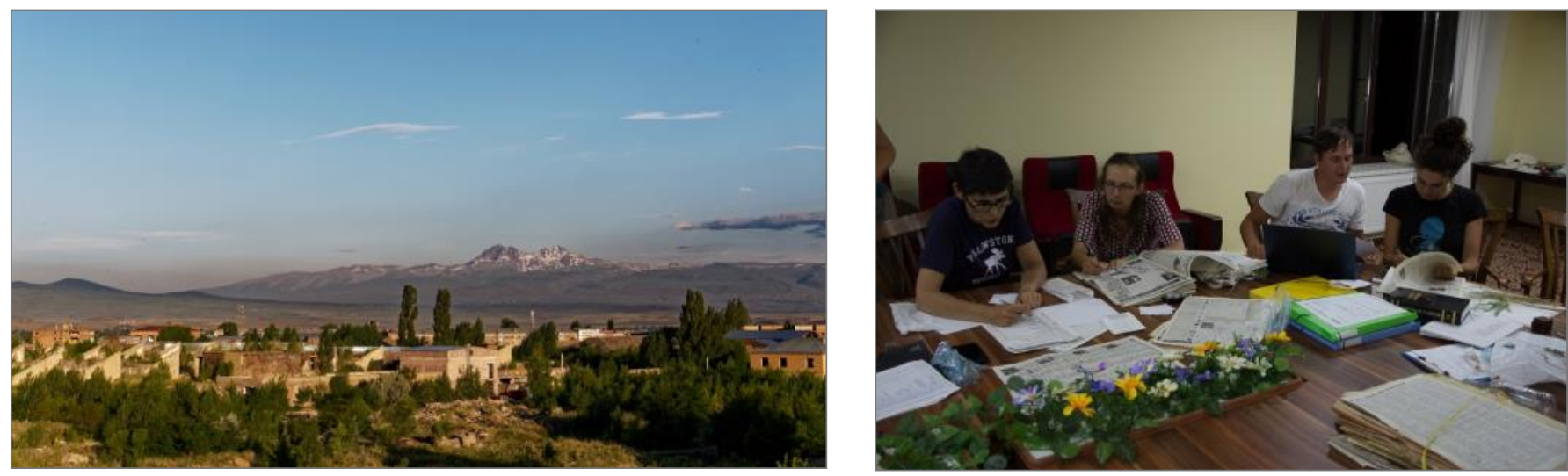

Left: Aragats mountain behind Gyumri city. Right: Plant determination in the evening. 


\section{Day 3 - June 28, Gyumri-Amasia, Amasia-Zorakert}

Early in the morning, our direction was to the North-West, towards the town of Amasia. Our bus drove for a long time and, after crossing the pass, we found ourselves on a flat plateau. We passed villages and rivers in deep canyons and then stopped opposite a partly ruined abandoned settlement. There, we sampled mainly former arable fields. At midday, our picnic was by the roadside ("Roadside Picnic" or "Extraterrestrial Picnic" was the name of a famous novel by the Strugatsky brothers). Sometimes in our Field Workshops we also feel the presence of aliens in our surroundings $(-)$.

Then we drove further for a long time, and near the lake Arpi and Aghvorik village, turned into a valley with a spring near Zorakert village. We crossed the spring and sampled plots on the steep slopes. The weather started to deteriorate. Dark clouds were gathering over us. However, again, we were lucky - we managed to finish our work, return to the bus, and at the moment it started moving, a severe storm with thunder and lightning, rain and hail began.

Late in the evening, we returned to Gyumri. On this evening, we had our dinner in the tavern of Georgian Armenians named "Avlabar" ("Avlabar" is the Armenian quarter in Tbilisi, Georgia) where they serve mainly Georgian dishes: khinkali, lobbio, pkhali.
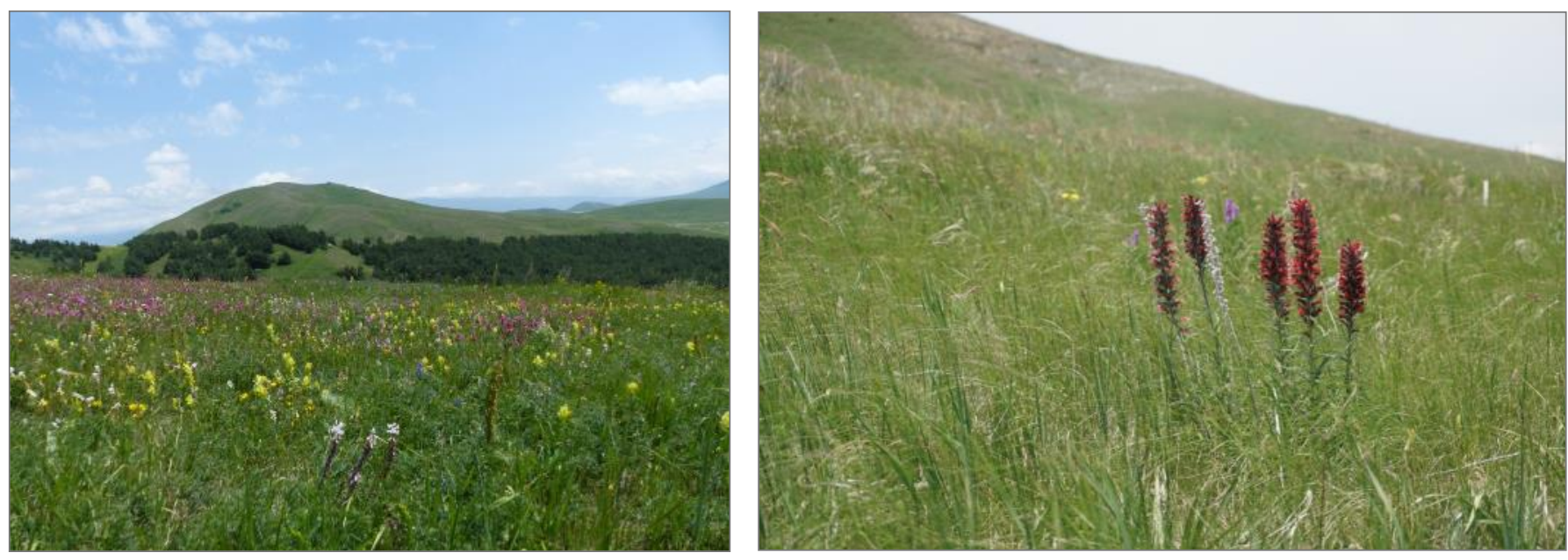

Colourful grasslands and meadow steppe with Stipa tirsa and Pontechium maculatum were the focus of our morning sampling.
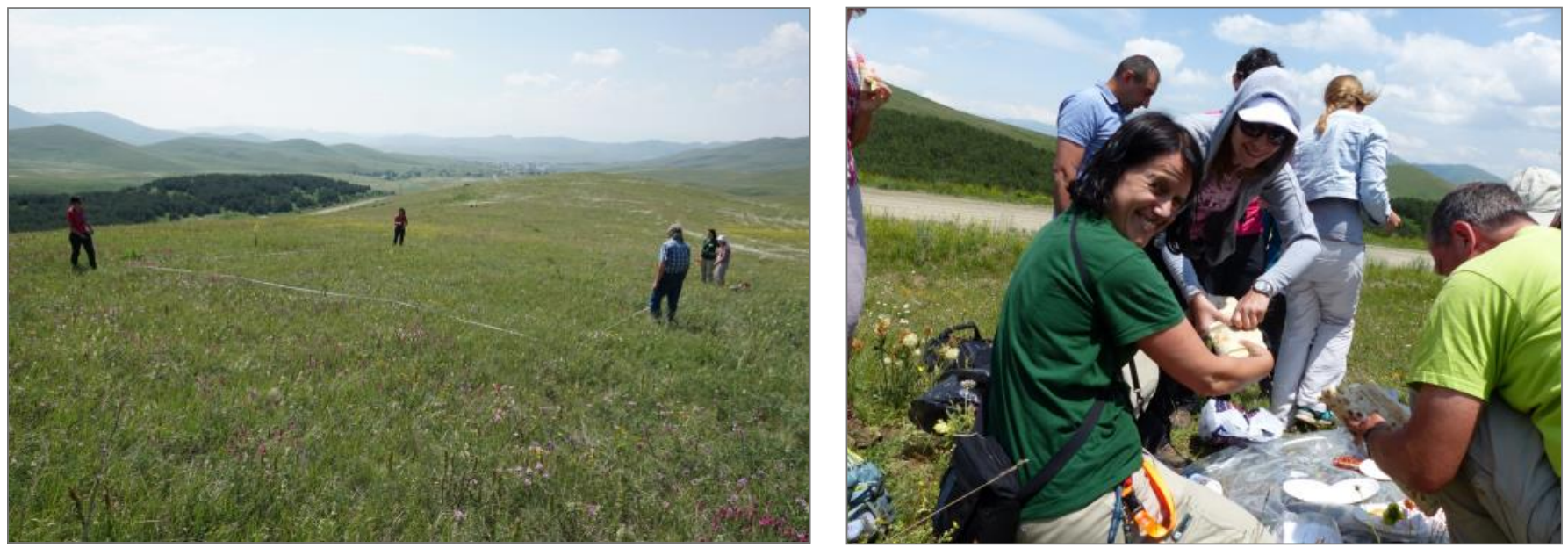

Left: Sampling meadow steppes. Right: Picnic by the roadside with Armenian bread - lavash. 

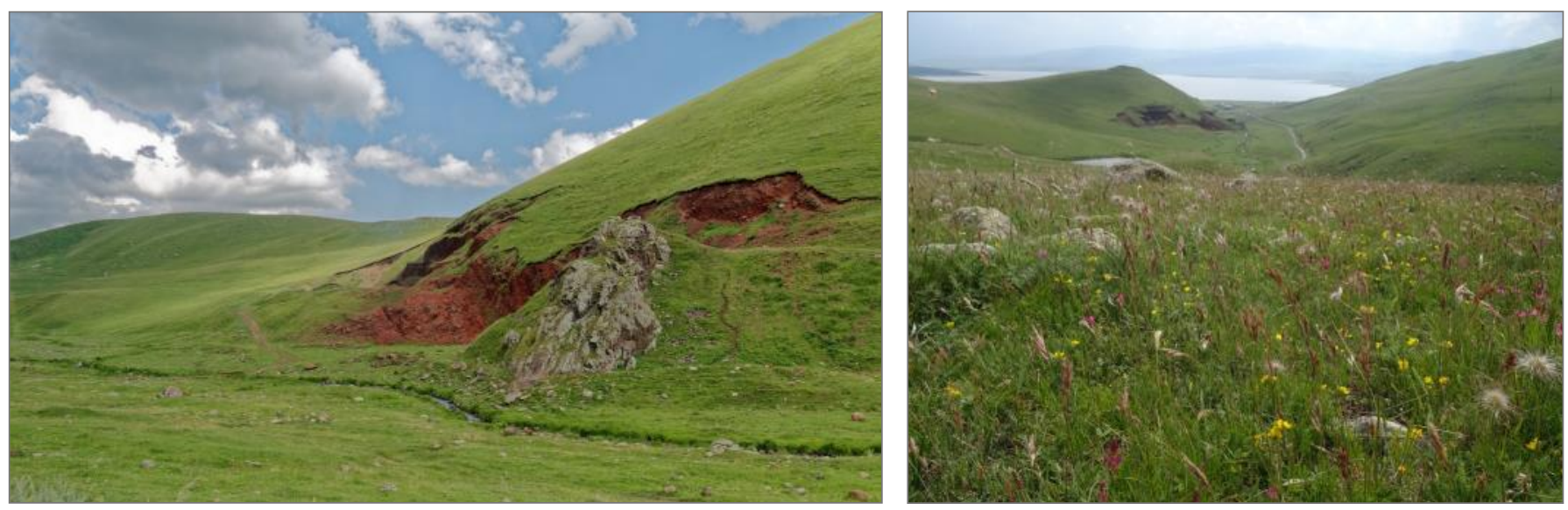

Landscapes of the Lake Arpi National Park.

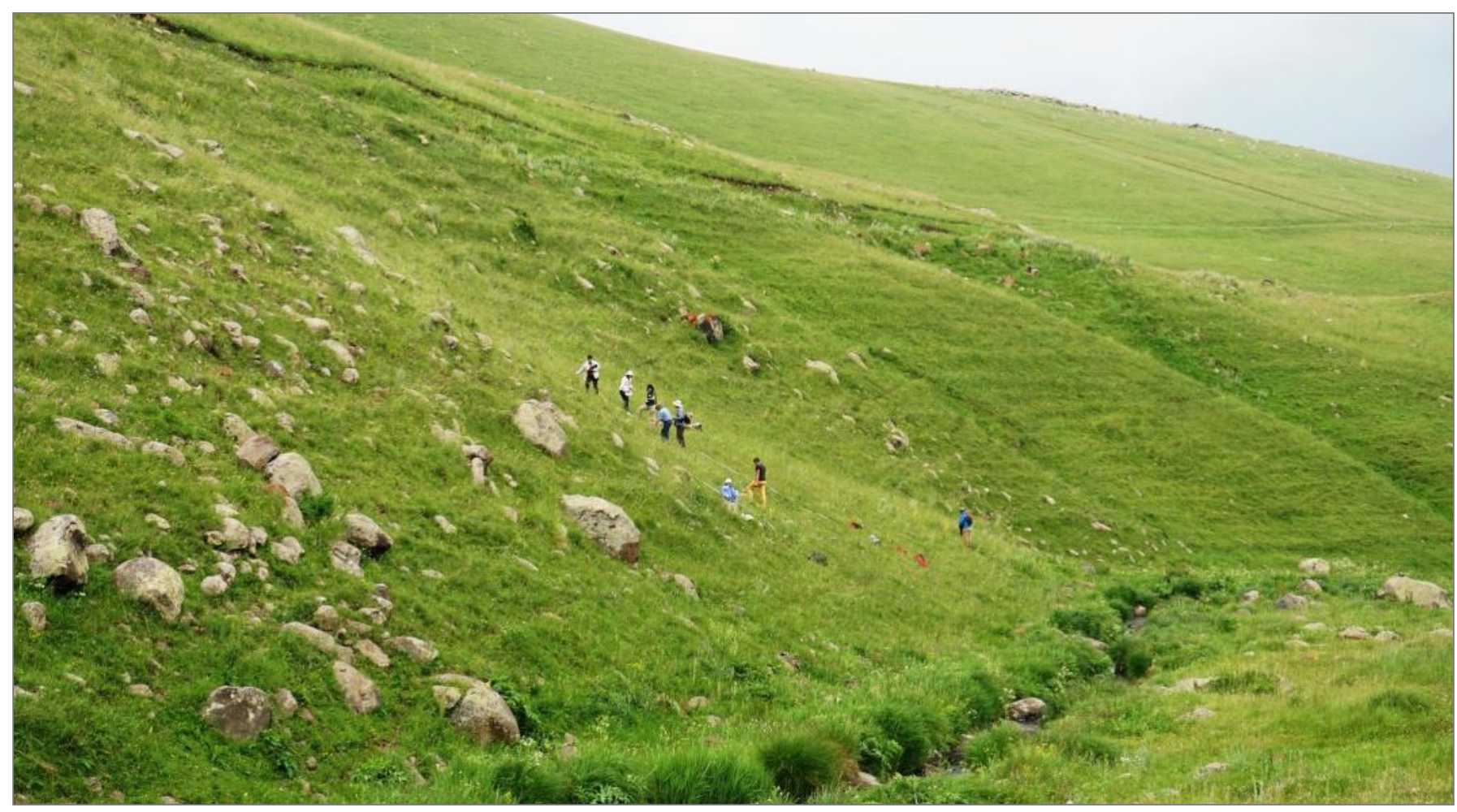

Afternoon sampling in the Lake Arpi National Park, near Zorakert village.
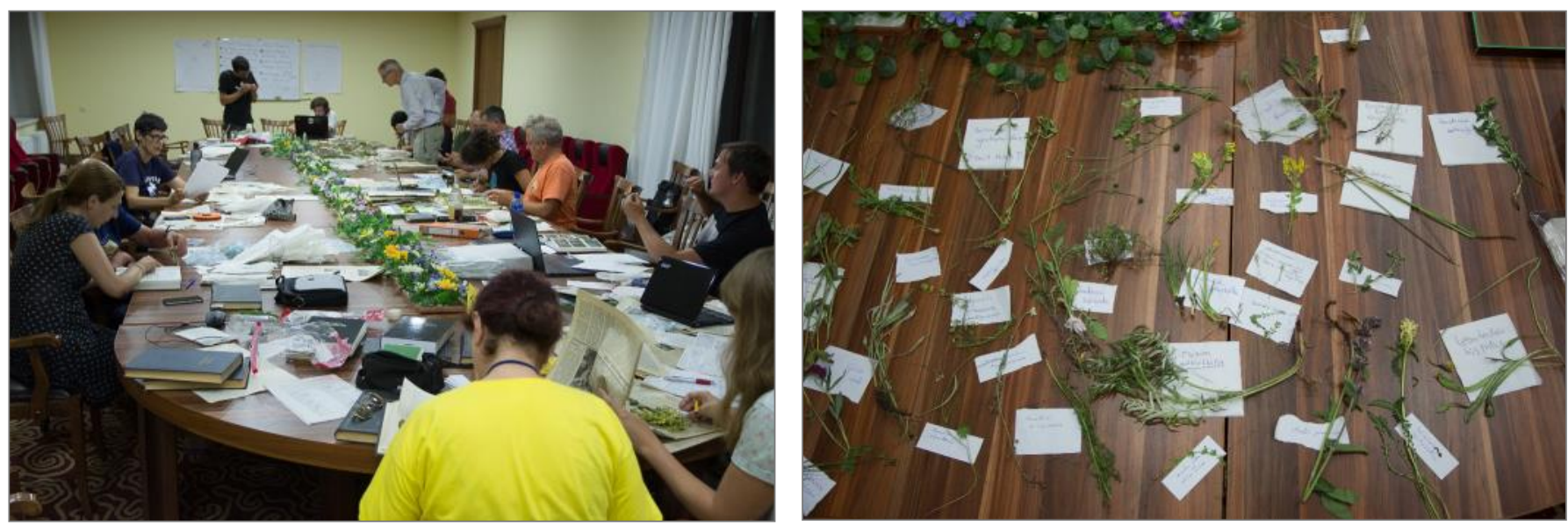

Left: Working moments in the evening. Right: examples of some of the identified plant species. 


\section{Day 4 - June 29, Gyumri-Talin}

In the morning, after breakfast, we made our way to the South, towards Talin town. The bus drove on a flat plateau and far away we saw mountains. We sampled plots in the secondary grasslands restored from former arable fields near Tatool and Dashtadem villages. Some of these steppe grasslands were very dry and we ended up with a large amount of the sharp fruits of grasses in our socks and shoes. As is usual in this region, it became cloudy in the afternoon and, when we were already in the bus, heavy rain began. On the way back to Gyumri, we started learning the song "Garun-Garun" which we had heard in the tavern the day before. We liked this song so much that it became the musical talisman for our team.

On this evening, we had our dinner in the restaurant run by Syrian Armenians "Nor Allepo" which means "New Aleppo". We tasted the delicious western Asian cuisine: hummus, pita, pilaf... Meanwhile in the hotel, that days plant collection was awaiting identification. Our taxonomic work lasted long into the night!
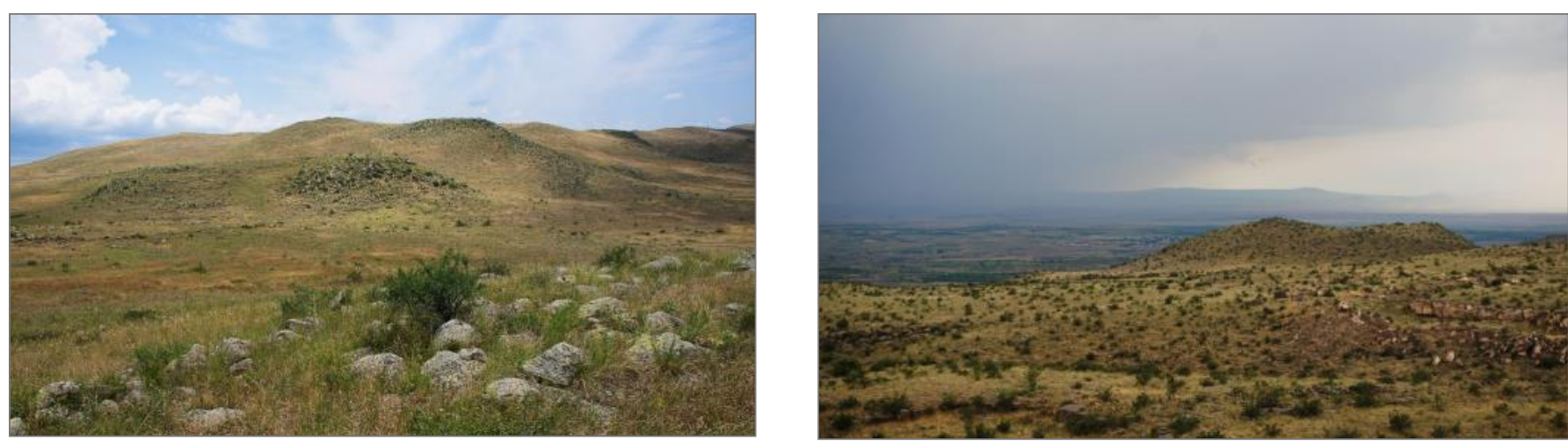

Dry landscape near Talin town.
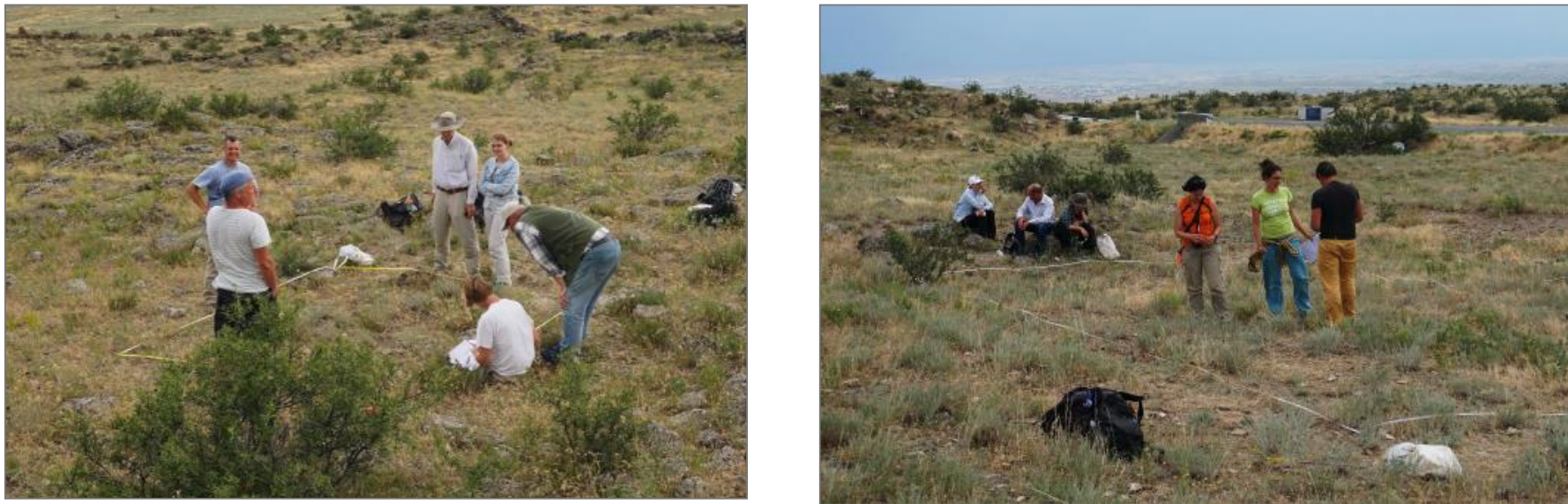

Sampling moments.
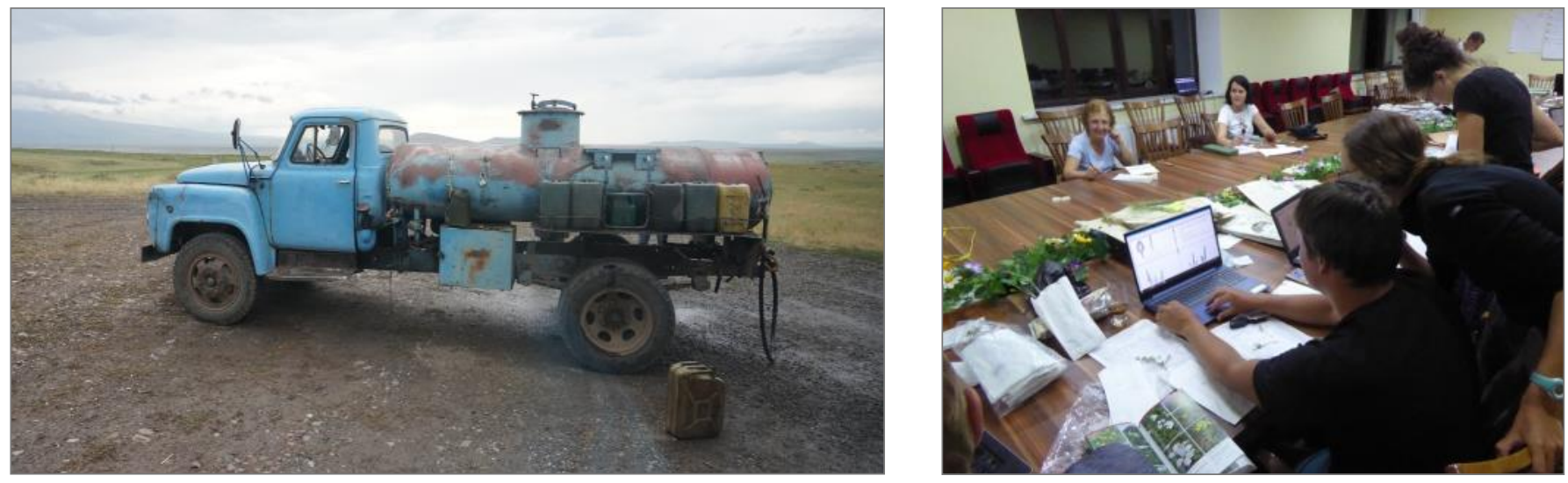

Left: Local gas station on the way back. Right: Plant identification in the evening. 
Day 5 - June 30, Gyumri-Sevan pass, Sevan pass-Sevan town

In the morning, we left hospitable Gyumri and made our way to the East, towards Sevan lake. We passed Spitak town (sadly known for the destructive earthquake), Vanadzor town, several Molokanian villages with Russian names (for example Lermontovo, Fioletovo; Molokans are members of a Russian religious sect), Dilijan town, and reached the Argatsin monastery founded between 11-13th century. Everybody was amazed with the ensemble of the ancient monastery. Of course, as botanists we also enjoyed the visit to the Oriental beech (Fagus orientalis) forest surrounding Argatsin.

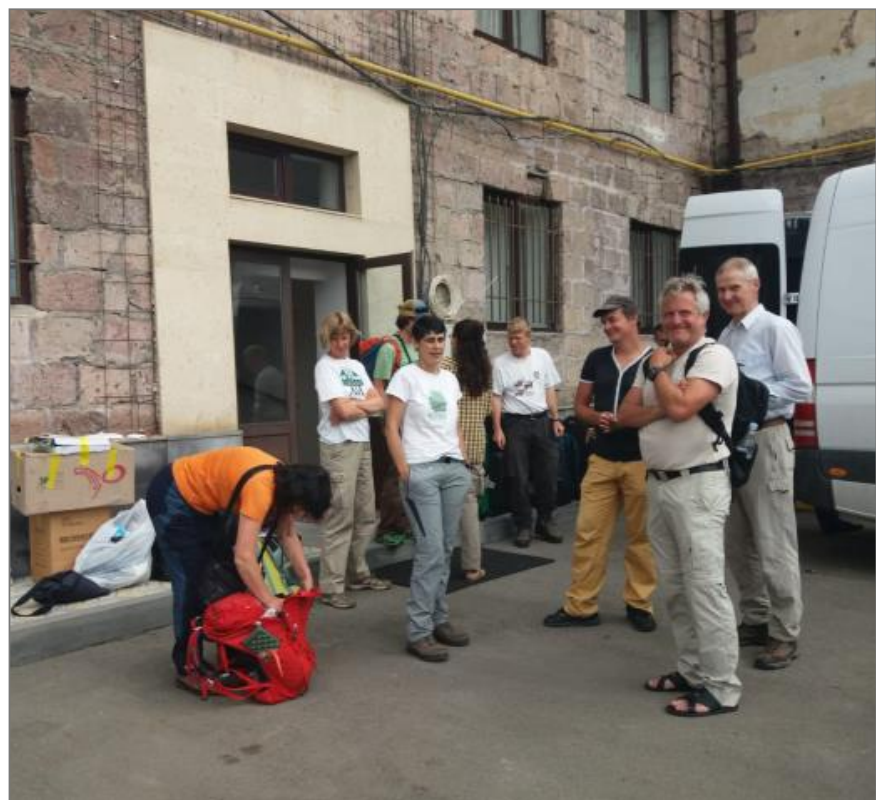

Everyone is packed and ready at Gyumri before we travel to our next accommodation in Sevan.

After sightseeing, we continued on our way, crossed Sevan pass and soon had a first glance at Sevan lake. Upon reaching Sevan town, our first visit was to the Sevan Botanical Garden. This has been maintained and is open to the public only thanks to the enthusiasm of the local specialists. We enjoyed the hospitality of our Sevanian colleagues and had our lunch there. After the lunch, we drank hot tea and coffee served Armenian style. Then, following Armenian tradition, we tried to read out future from the coffee grounds. Of course, they told us that everything would be all right.

Then we sampled plots near Sevan town in front of the Sevanavank monastery. After finishing our sampling, we sat on our bus and as usual, the rain began. For several days, we were due to stay in the "Noyland" resort (Noyland = land of Noy or Noah, whose ark navigated the sea near Ararat in Armenia, according to the Bible). After check-in, we had our dinner in a restaurant on the shore of the lake. The weather at Sevan lake was severe but our dinner was very tasty. We tasted ishkhan (endemic of Sevan - subspecies of brook trout) and various "underfoot exotics": aveluk (Rumex crispus), shushan (Chaerophyllum spp.).

After a heavy dinner and a long working day, nobody objected to putting off plant identification until another time! 

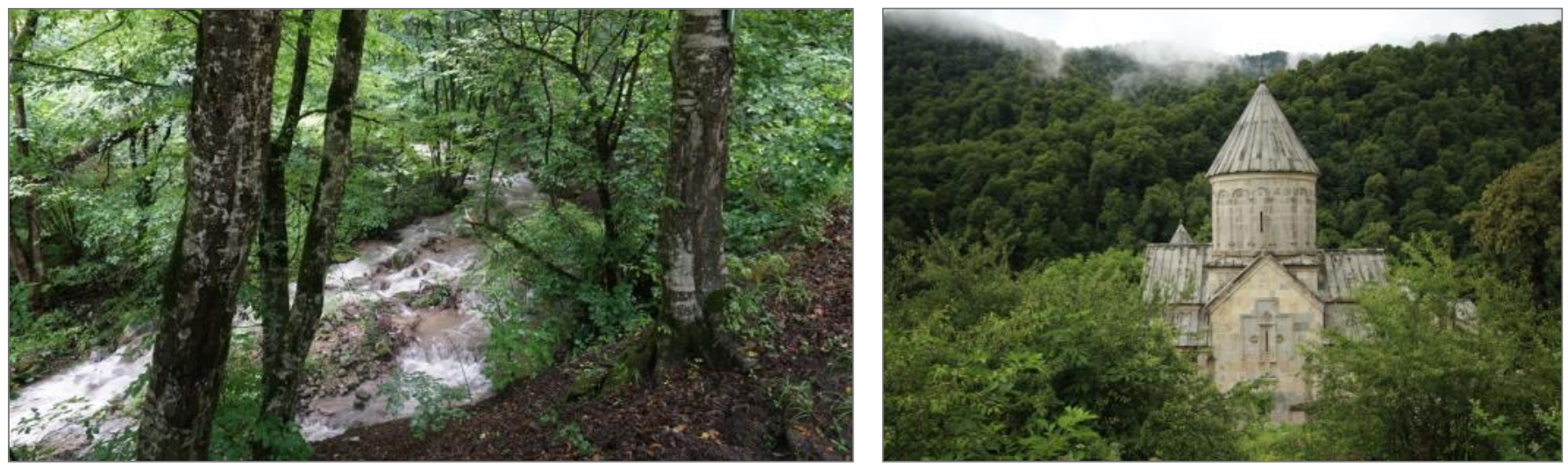

Left: Fagus orientalis forest in the Dilijan National Park. Right: Argatsin monastery.
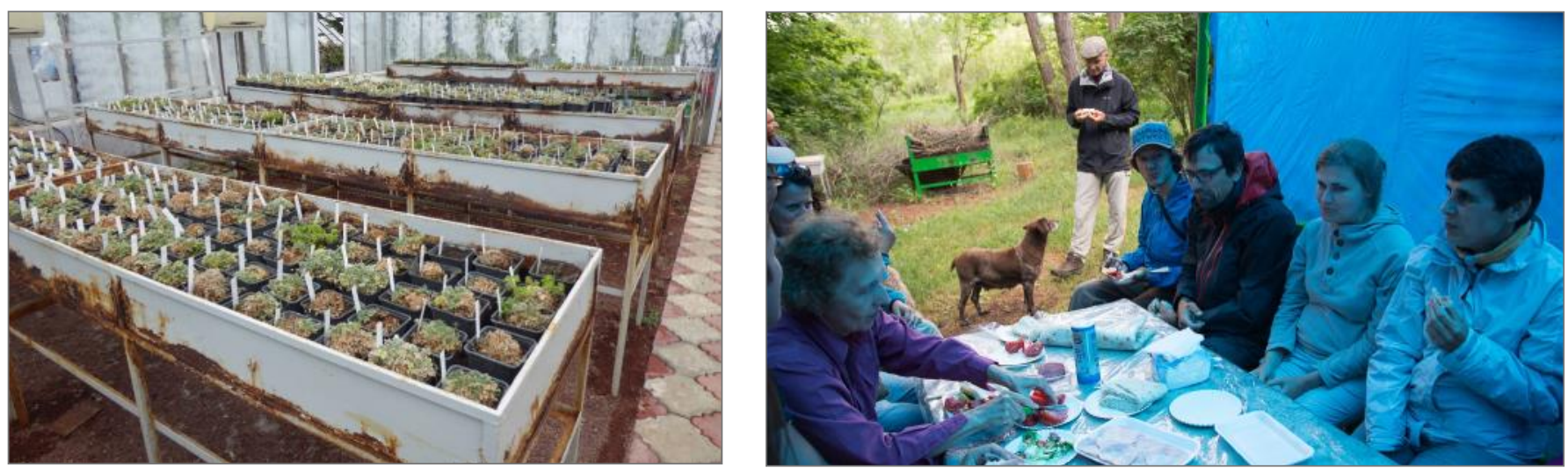

Lunch in the Sevan Botanical Garden.
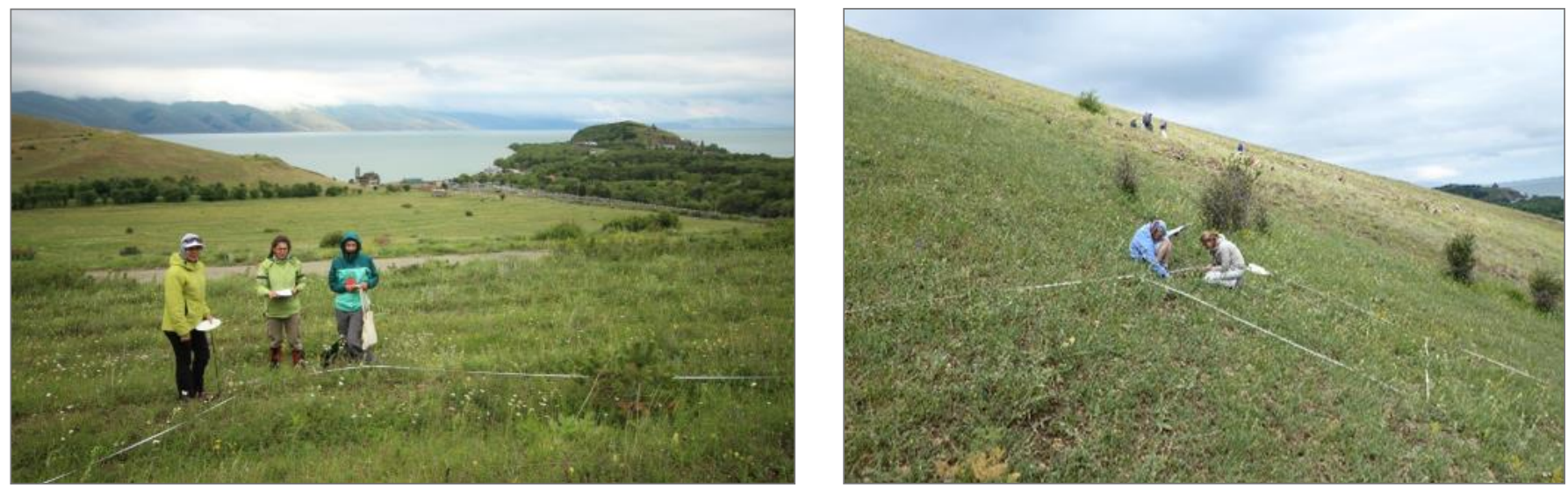

Sampling with a view of the Sevan Lake.
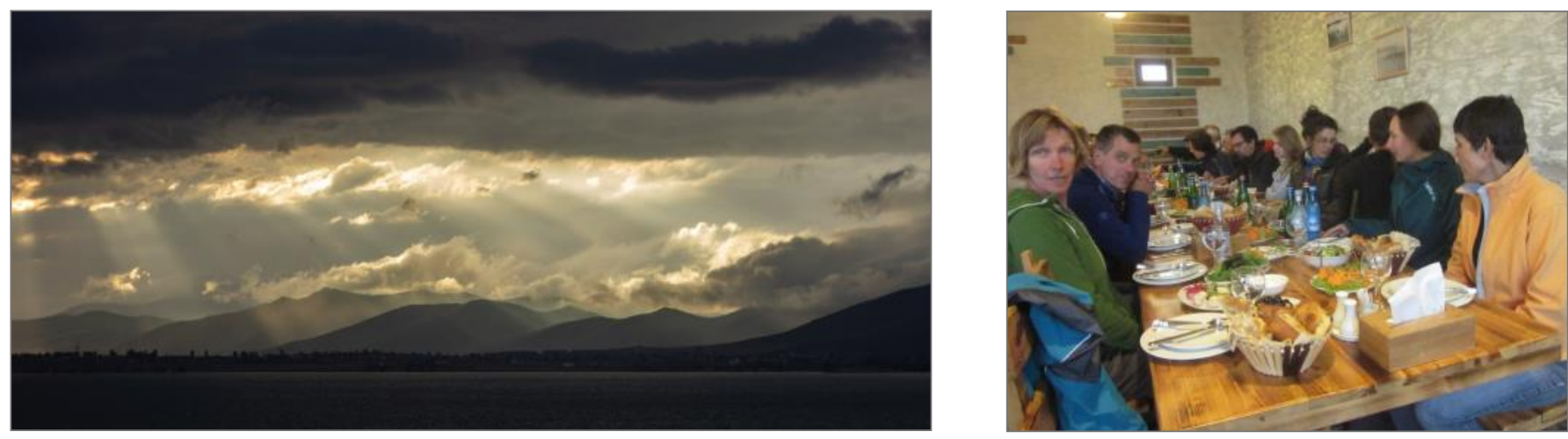

Severe Sevan Lake weather and warm atmosphere. 


\section{Day 6 - July 1, Ardanish peninsula, vicinity of Shorja village}

In the morning the sun shined brightly, Sevan was calm and blue. Some of us had their breakfast in the rooms, and others preferred to have morning tea on the balcony. Some of us - people with spirit - swam in the Sevan.

We went along the northern shore of the lake towards Ardanish peninsula and sampled plots in a very nice valley near Chembarak village. Here we sampled the most species-rich plot in Armenia. After lunch, we moved a little bit and studied tragacanth communities near Shorja village.

After dinner, we continued with the usual business of plant identification, which lasted nearly until early morning, at least for some of us!!
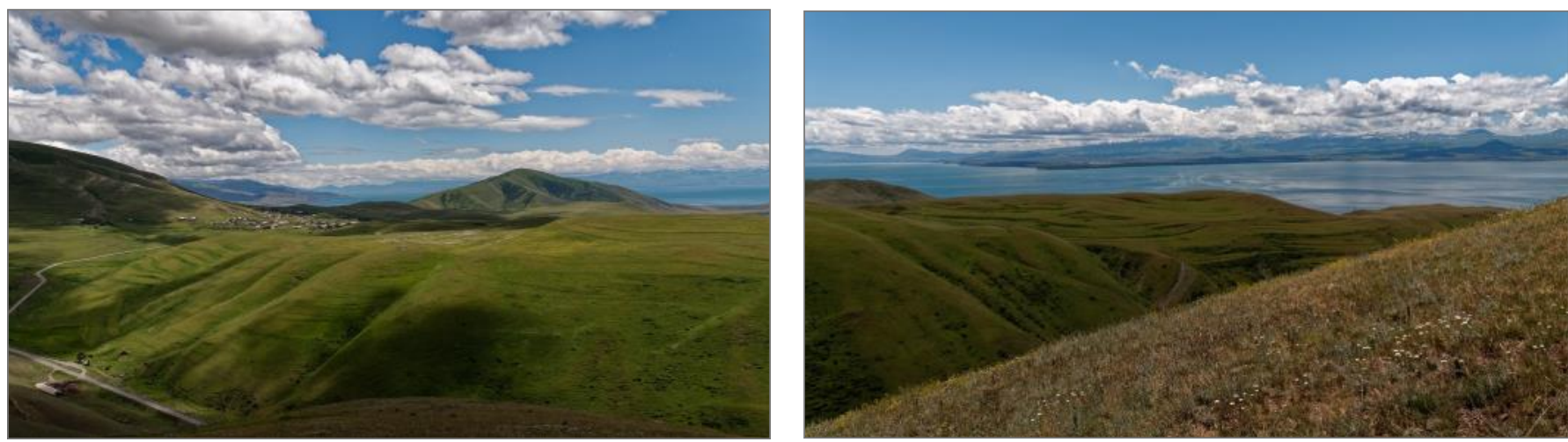

Astonishing view of Sevan Lake.
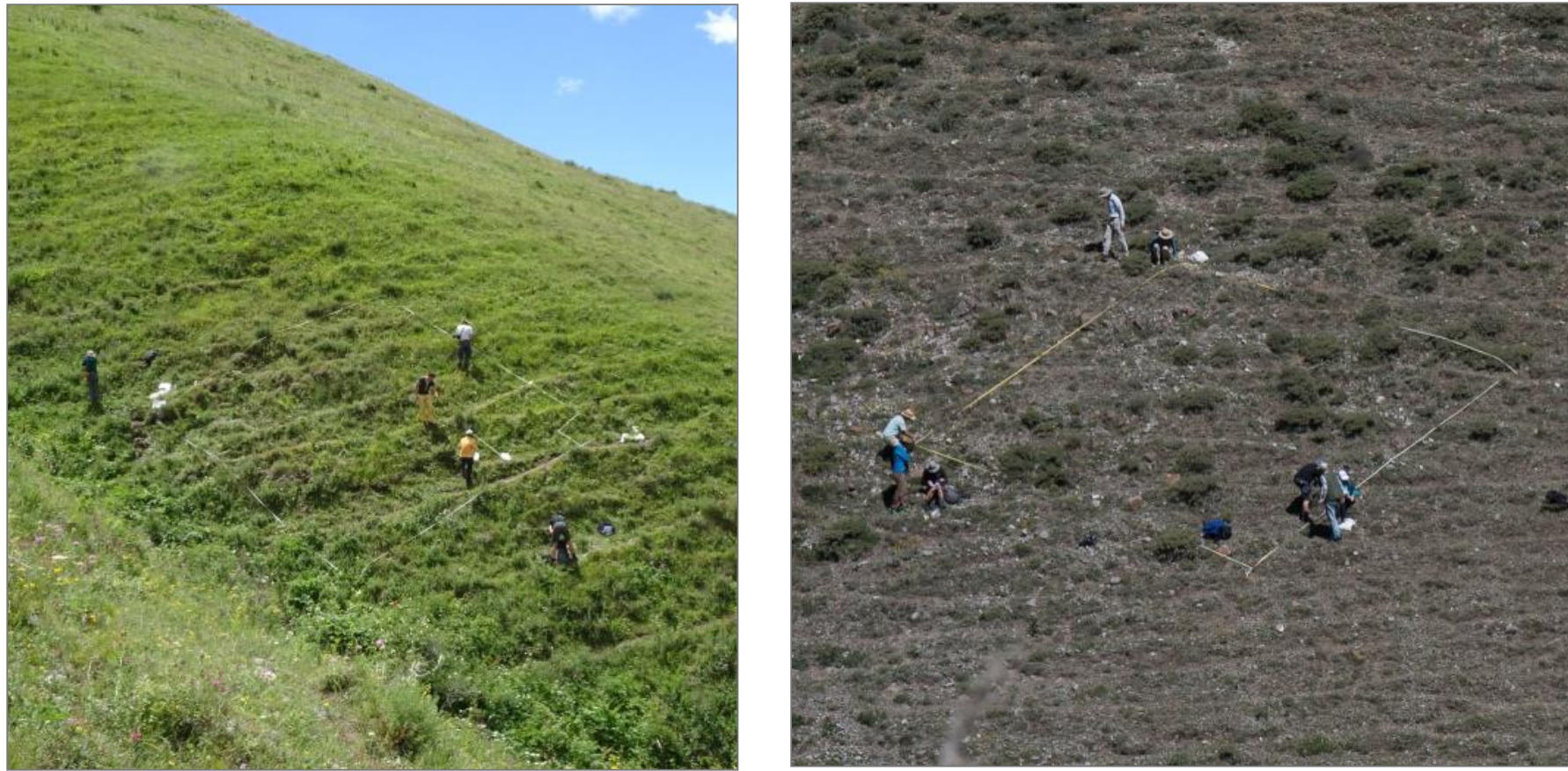

Left: Biodiversity plot in the diverse meso-xeric grassland near Chembarak village, in Ardanish. Right: Sampling of more xeric communities on the opposite slope. 

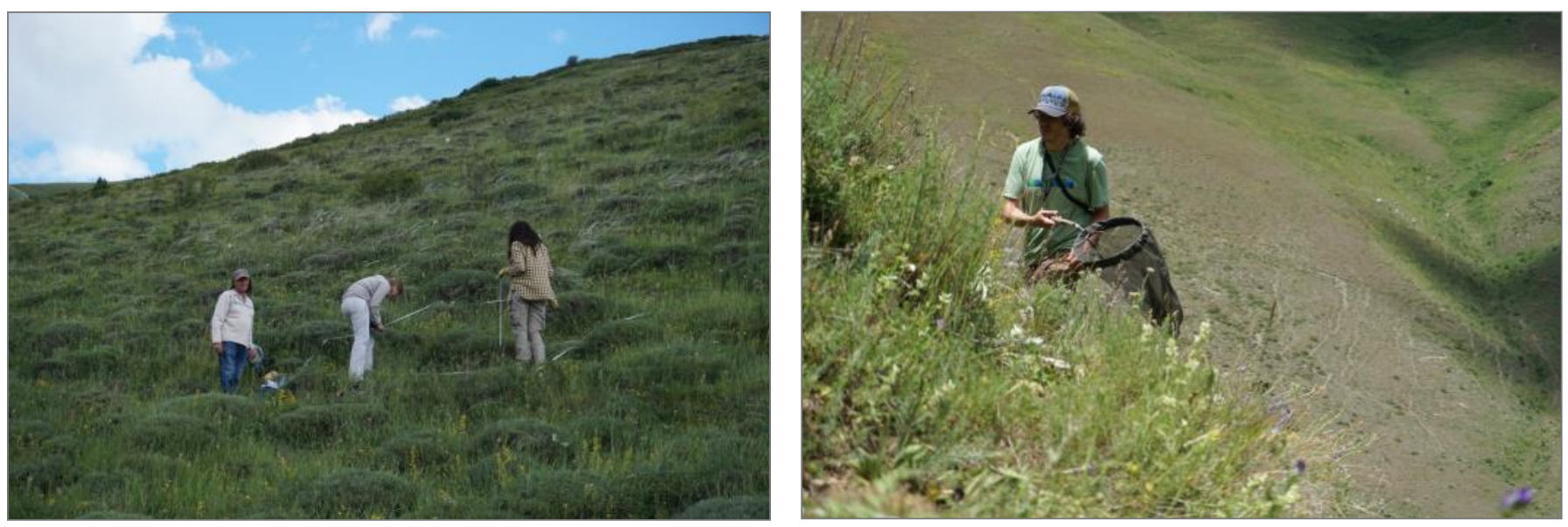

Botanical and zoological sampling.

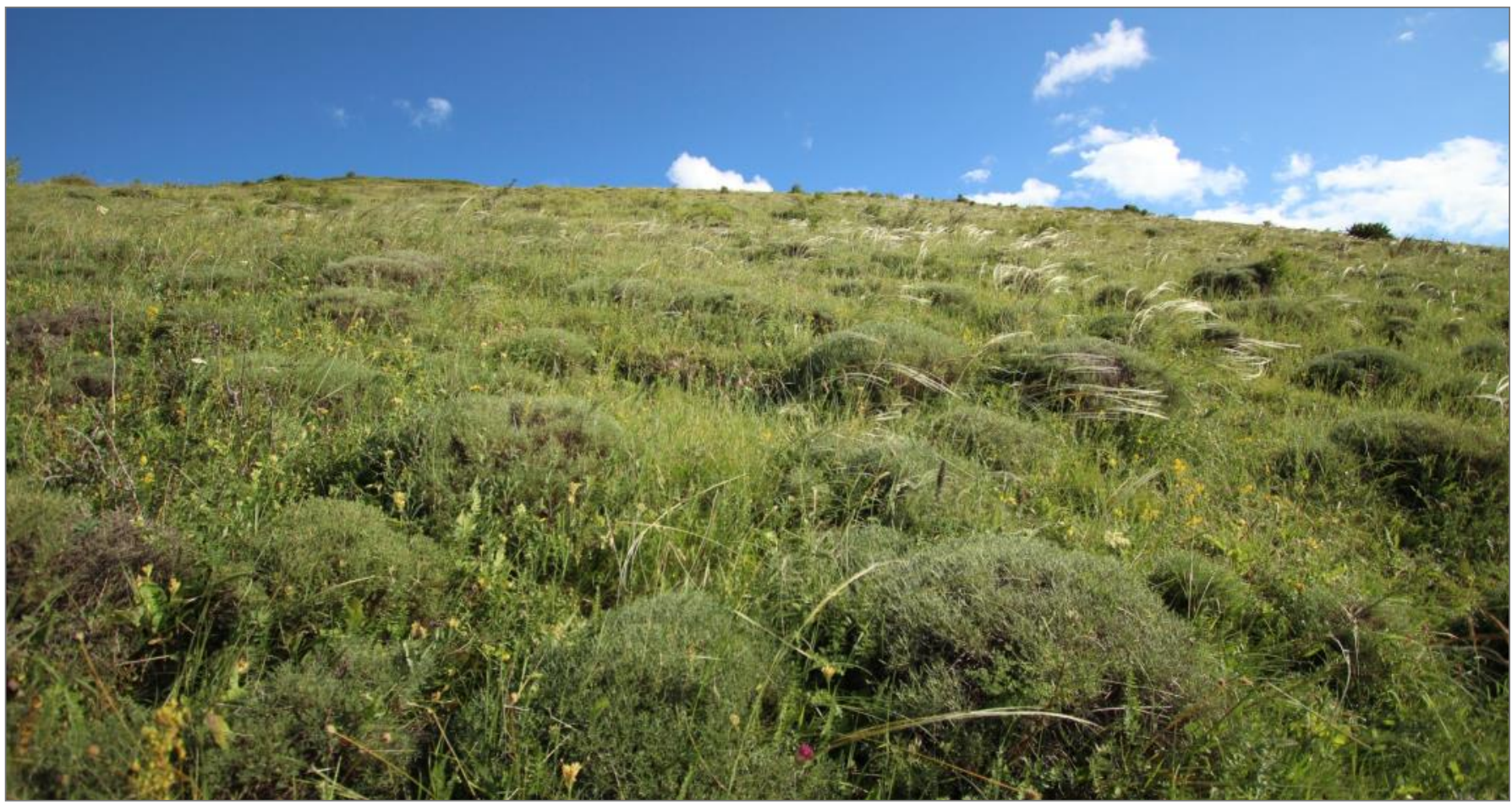

Vegetation with Onobrychis cornuta.
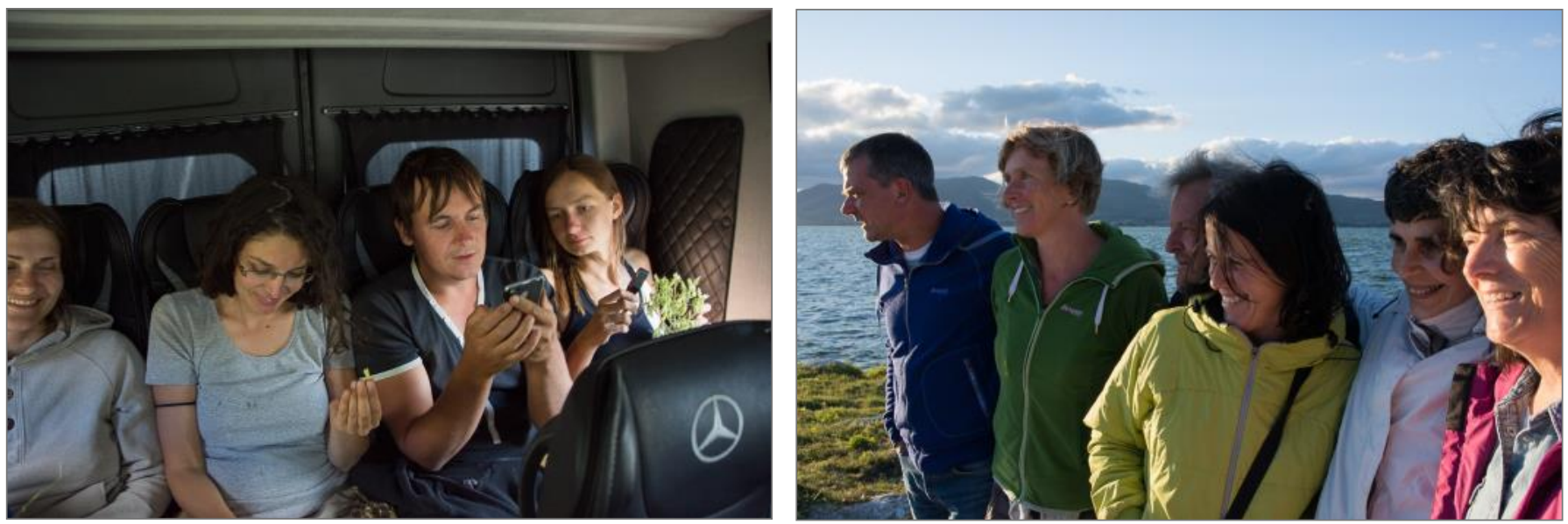

Left: Plant identification has already begun in the car. Right: Photo session before dinner. 


\section{Day 7 - July 2, Sevan-Selim pass-Hermon}

On a sunny morning, we said goodbye to the "Noyland" and drove along the southern shore of the lake. Within two days, we had made a full circle around Sevan. After Chkalovka, we stopped in a fantastic valley with flowering meadows, where we stayed all the morning and sampled several plots. Then we continued our journey and after a while reached the Selim pass. We were delighted with the fantastic view from the pass. There was also an ancient caravanserai. This proves that this road was a part of the Great Silk Road. After some quick sightseeing, we returned to the bus and along the serpentine, came across the fantastic valley.

After a short time, we arrived at the fairy garden of our pension "Lyusi-tour" in Hermon. In the afternoon, we had some free time, which some of us chose to spend sampling on the nearby slope whereas others chose to relax in the swimming pool. After dinner, we gathered in the very comfortable large hall to process the collected soil and plant samples. A short piano concerto brought variety to our work.
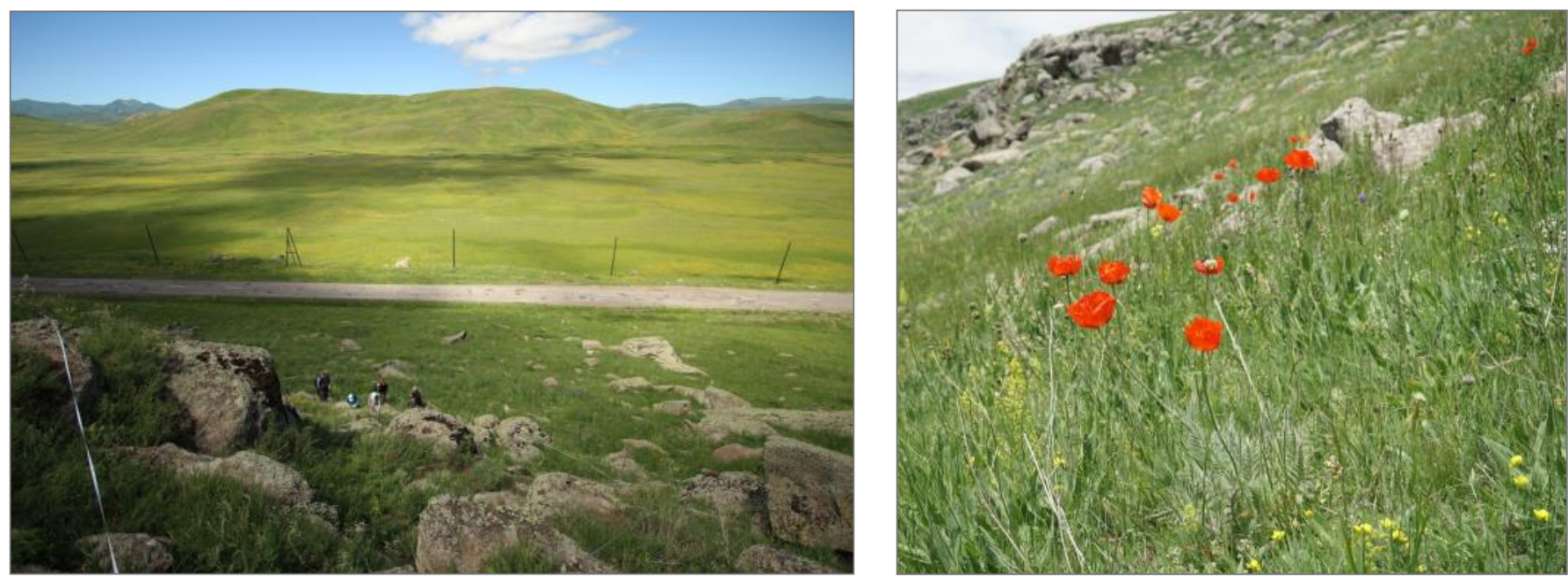

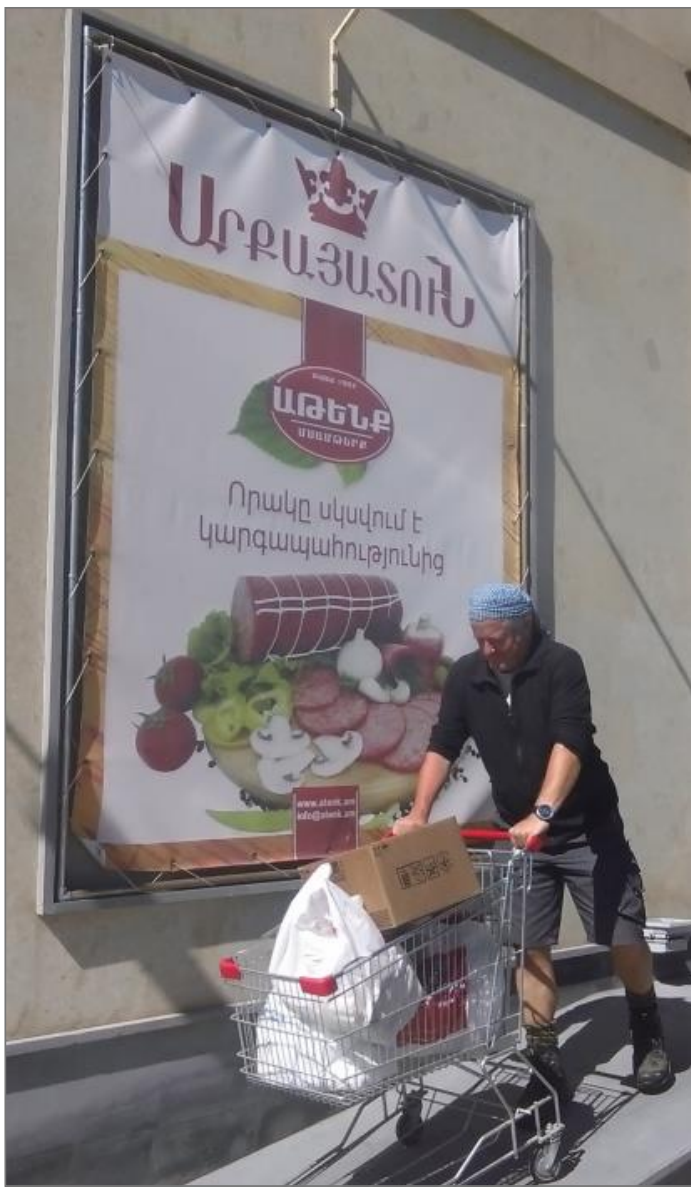

Attracted by the nice advertisement, people took the opportunity to buy a drink for the picnic.

\footnotetext{
Sampling the rocky grasslands with Papaver orientale near Selim pass.
} 


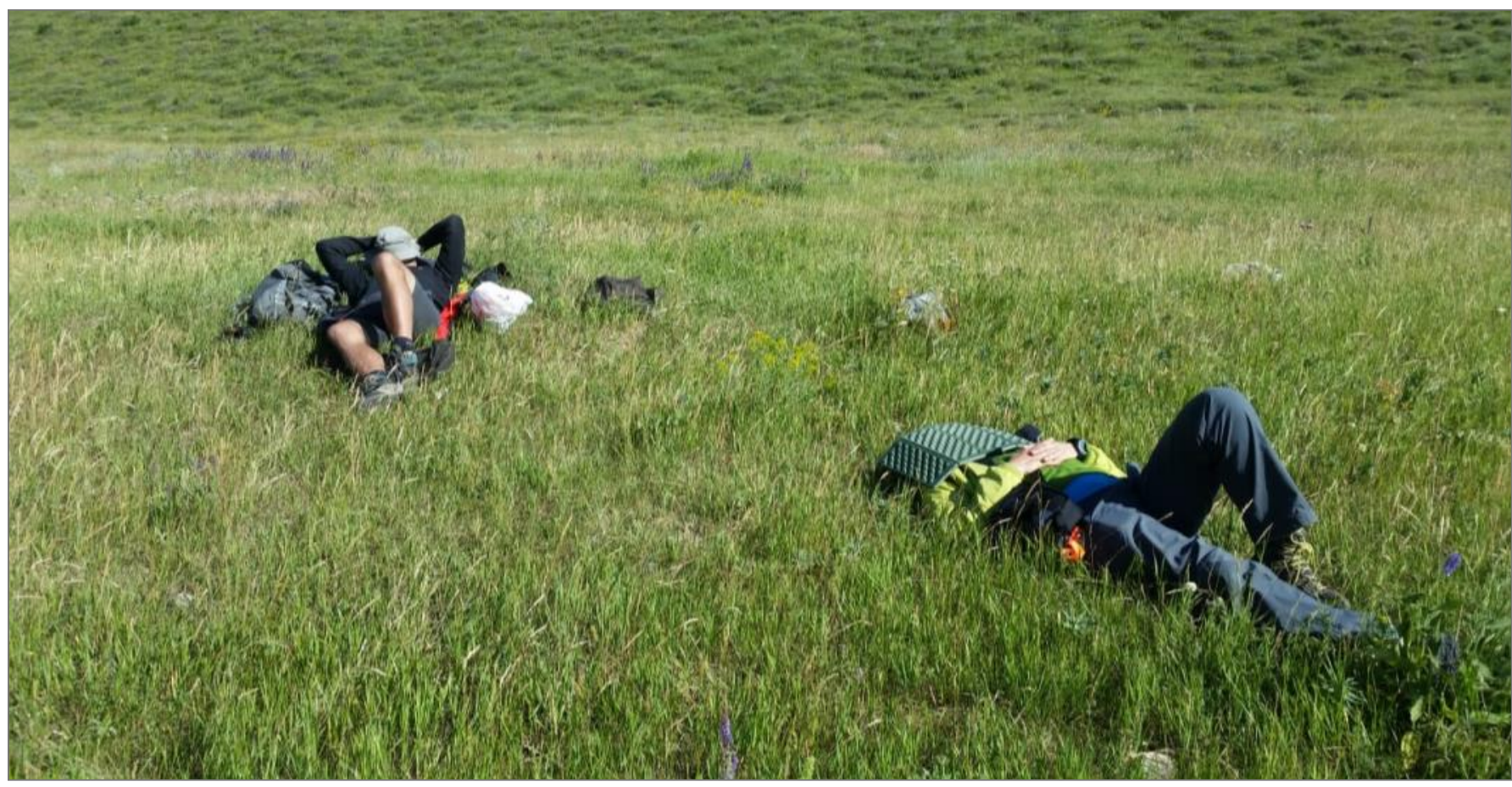

Just in case, resting people hide their faces for posterity $(-)$.
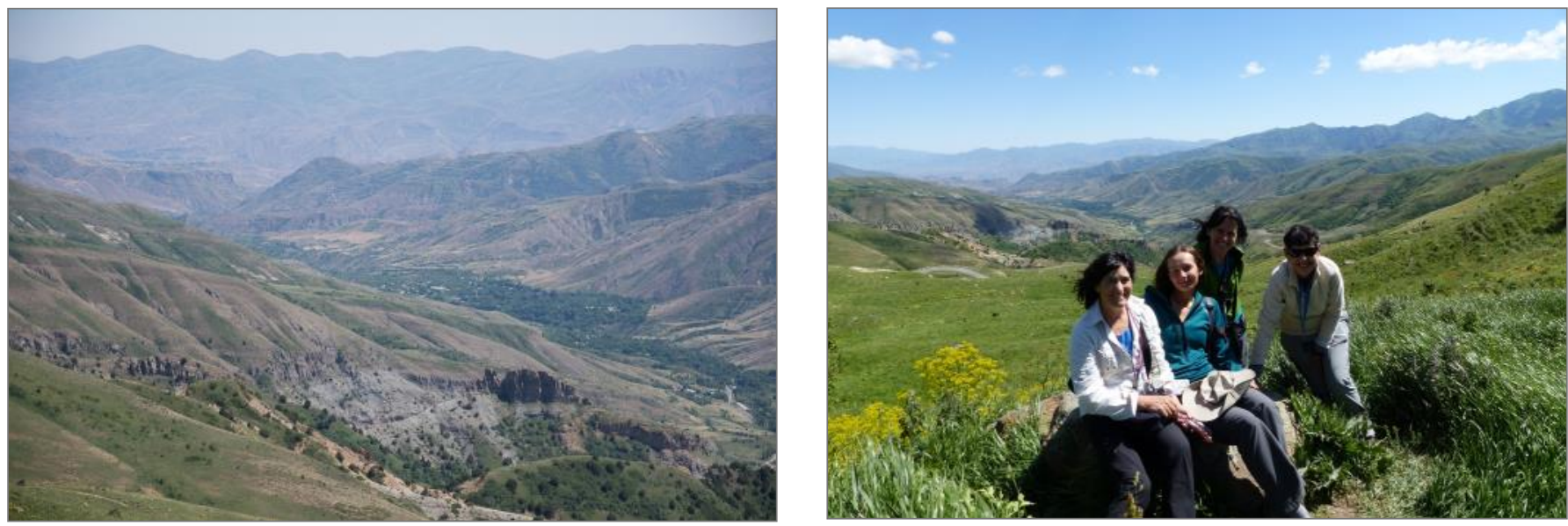

Breathtaking view from the Selim pass.

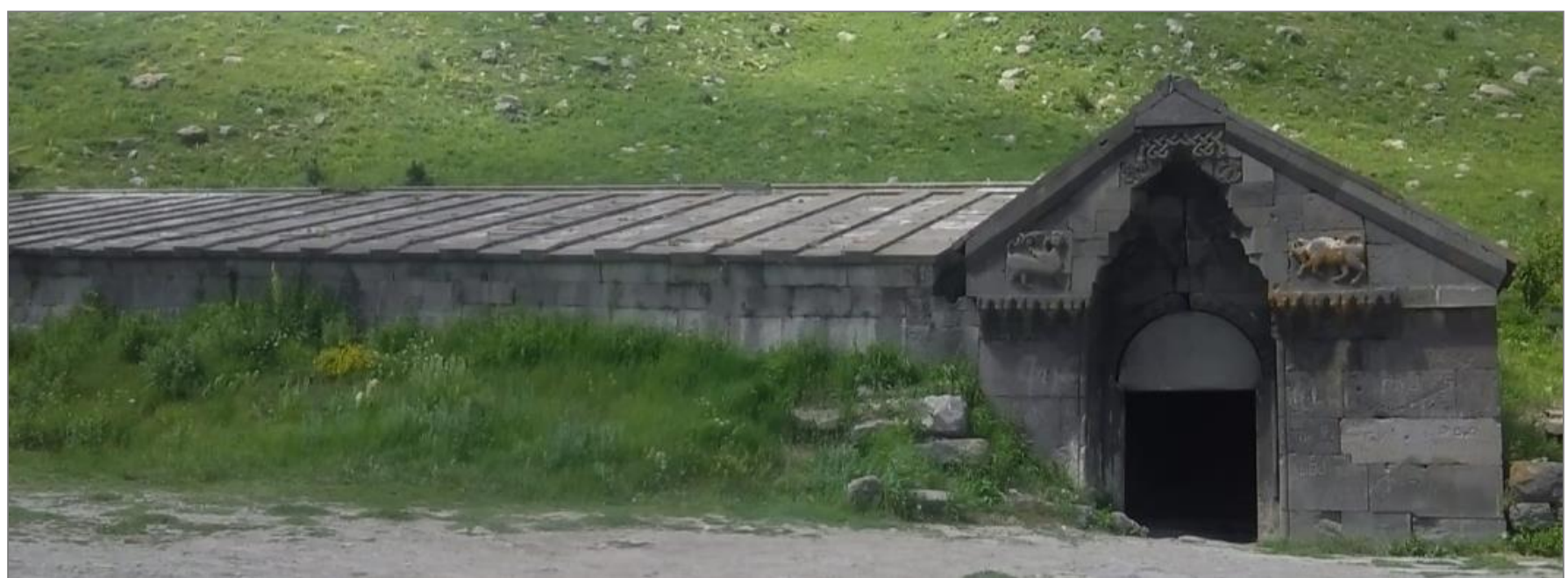



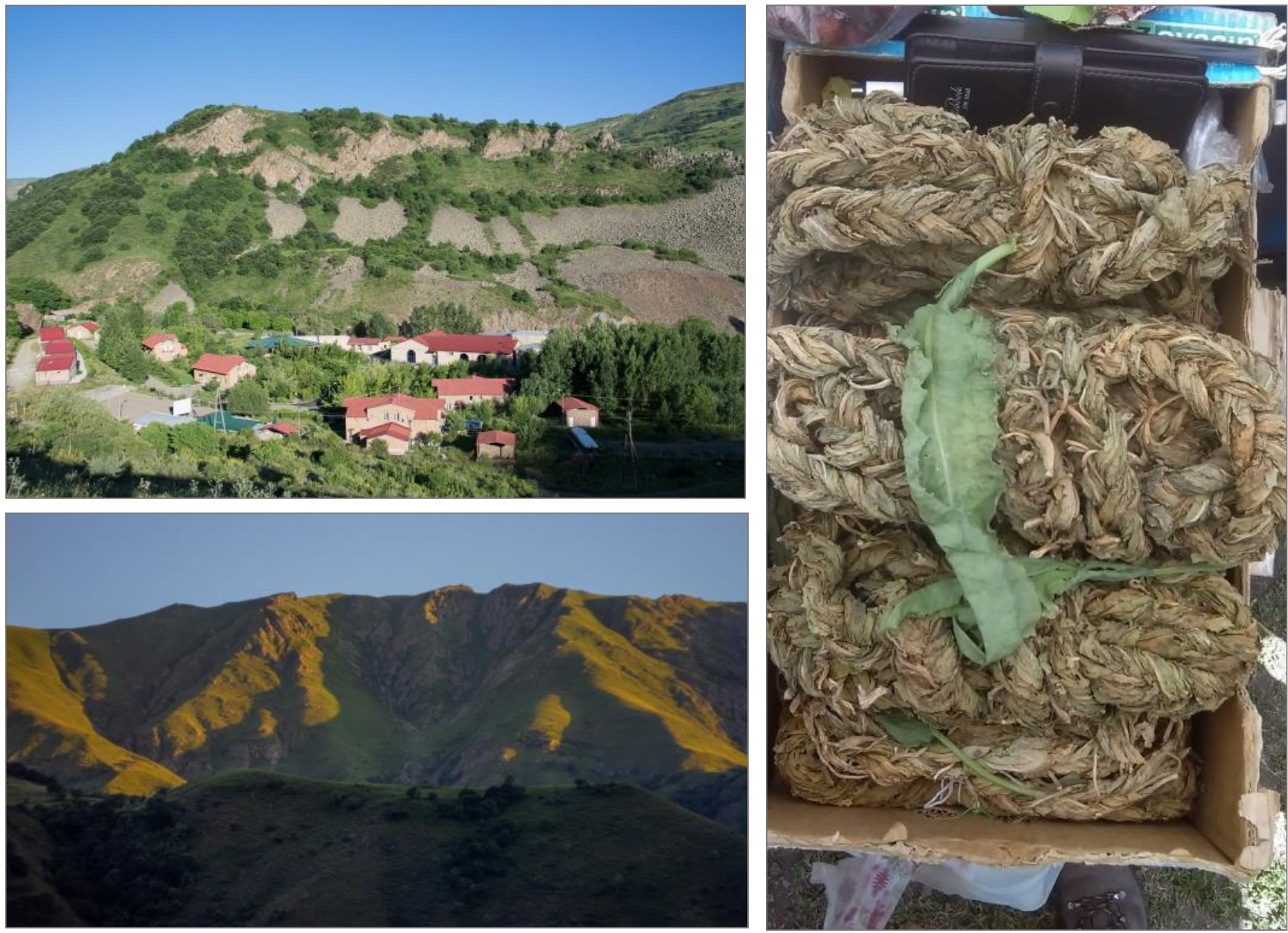

Lyusi-tour - our home for the next two days and the nearby slopes in the Yeghegis valley.

Dried Rumex crispus (aveluk) ready for the soup.
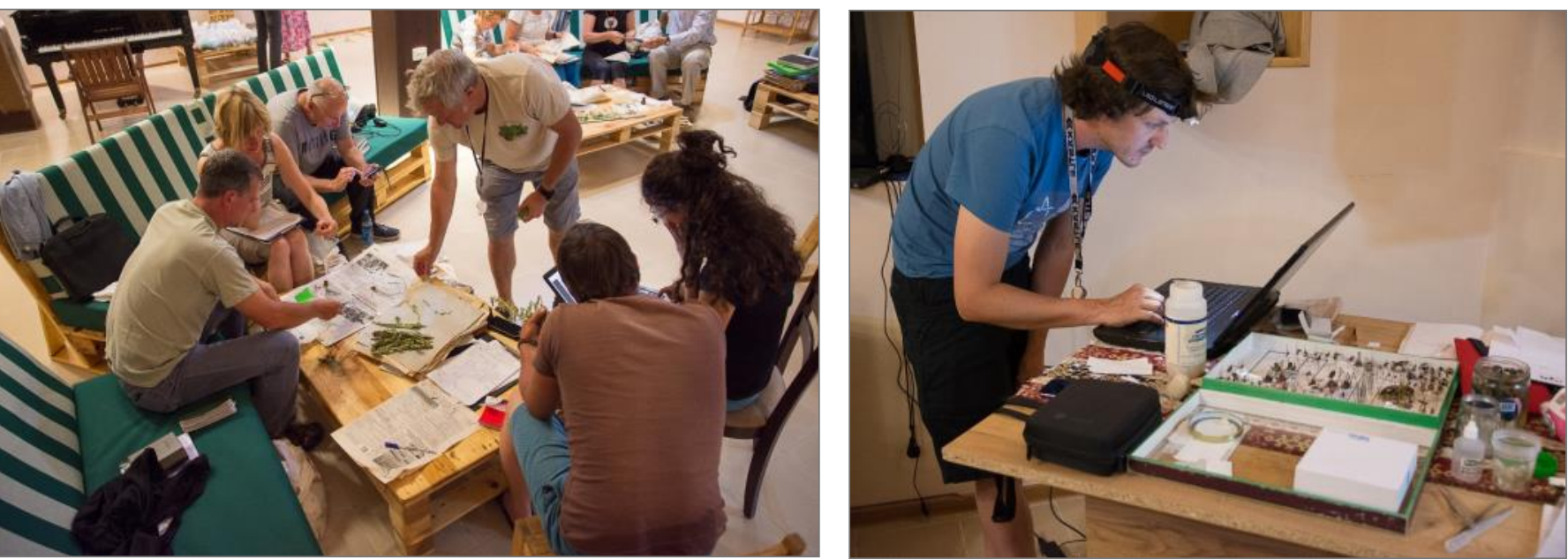

Our evening studies: plant identification (left) and work with orthopterans (right). 


\section{Day 8 - July 3, Yeghegnadzor-Gnishik}

After breakfast, we drove into Yeghegnadzor - a little town with fruit trees in the streets and storks on the roofs. Then our route was to the south to the Gnishik landscape sanctuary. The bus was climbing up to the mountains and the "valley of reeds" (Yeghegnadzor) was left far below. On this day, we sampled plots mainly of hedgehog communities situated on the strongly rugged terrain. Therefore, it was not easy to reach some places with these interesting communities. We had lunch near an old small chapel. In this spot, we had a magnificent view of Mount Ararat. In the evening after dinner, we had a small meeting to organize work after expedition.

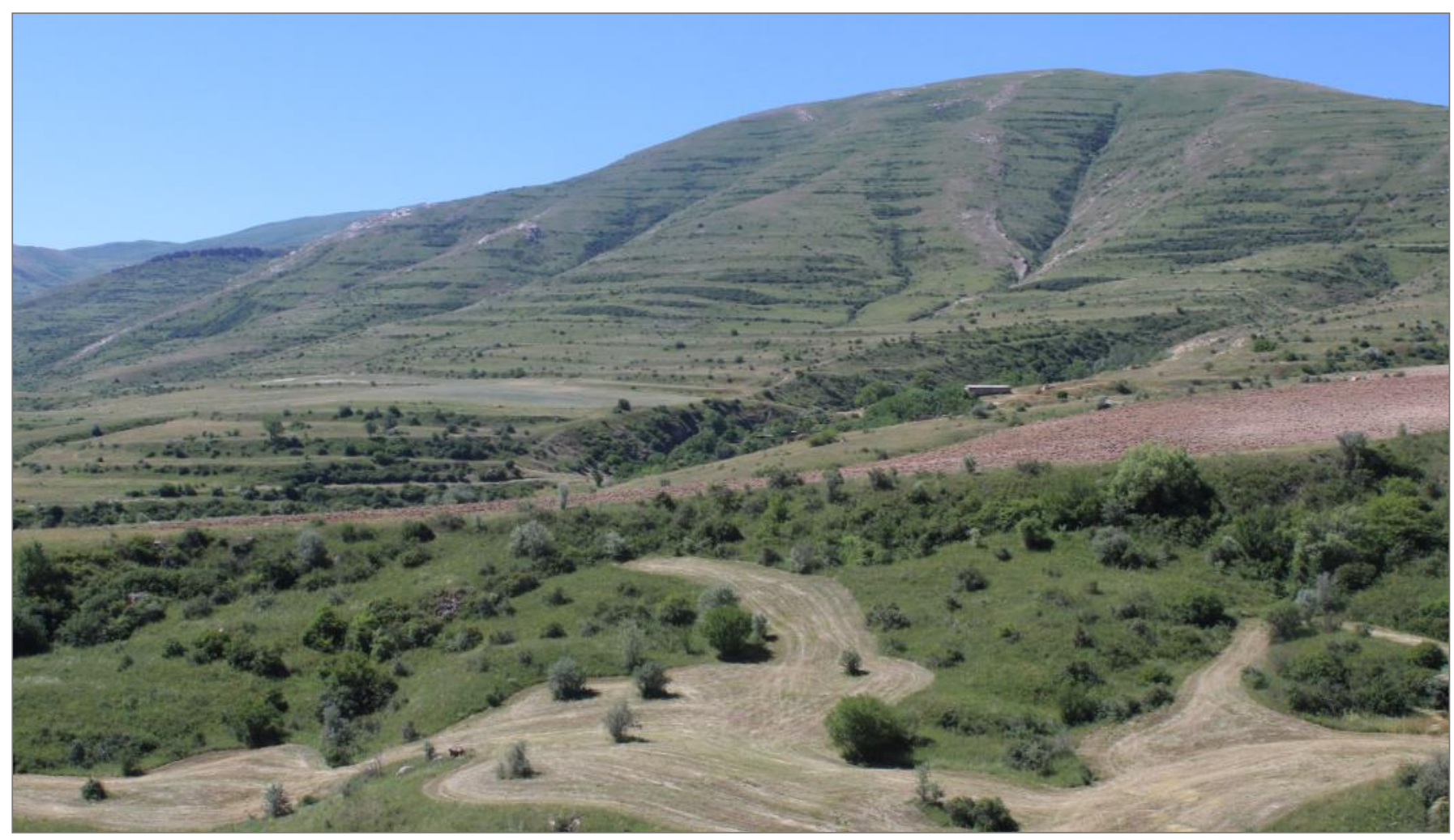

Diverse landscape with the highest orthopteran richness near Gnishik village.
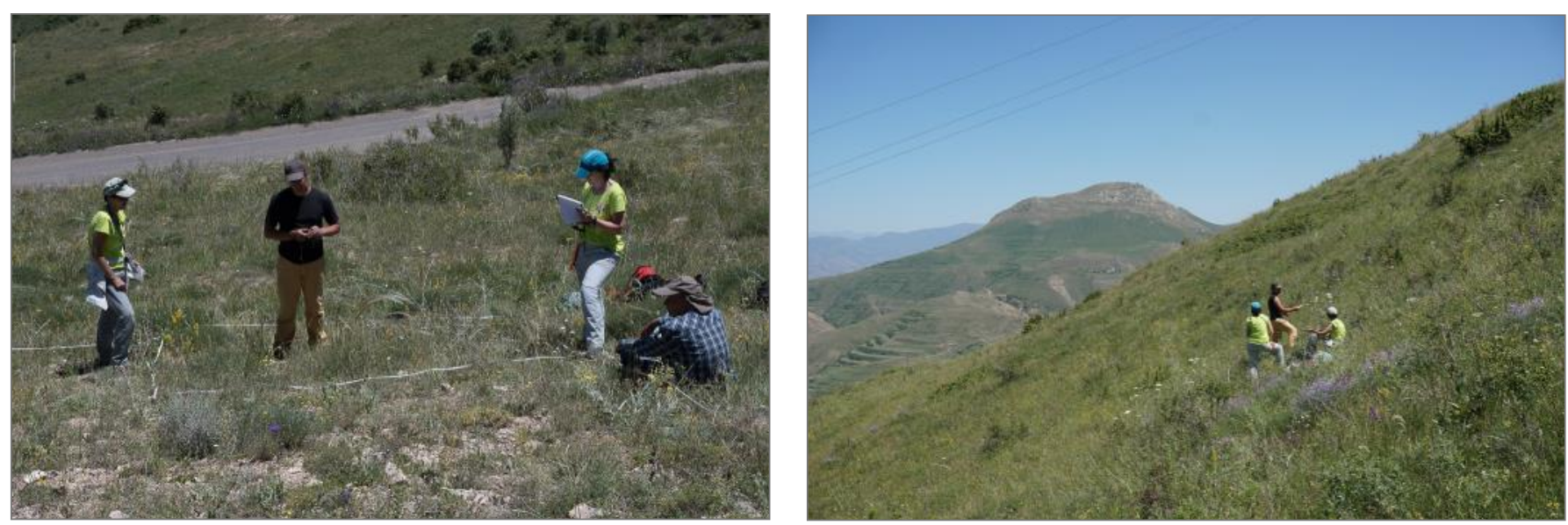

Left: Sampling rocky feather-grass steppes. Right: Sampling a Brachypodietalia pinnati community on the Northern slopes. 


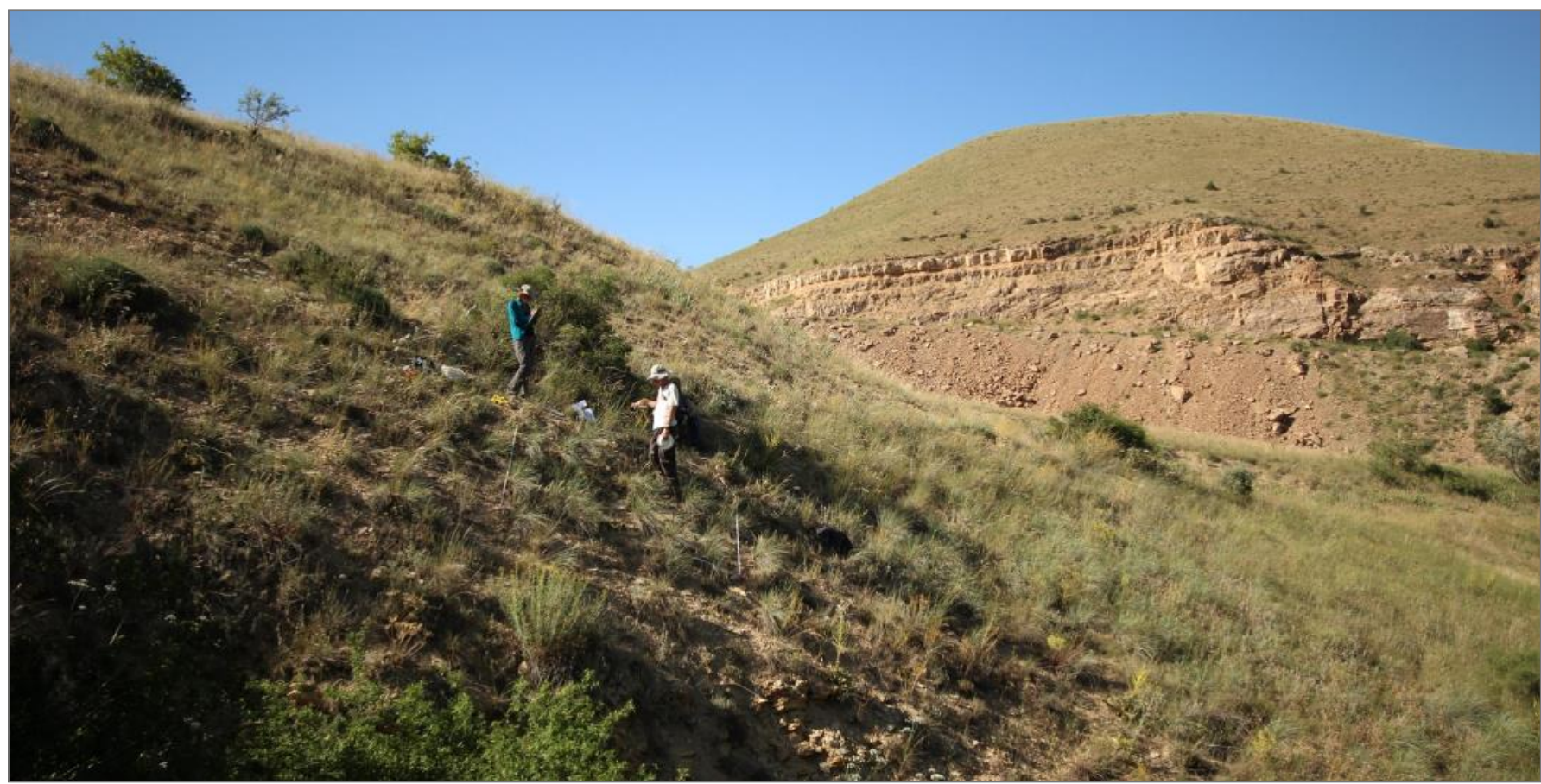

Sampling the Stipa araxensis community.
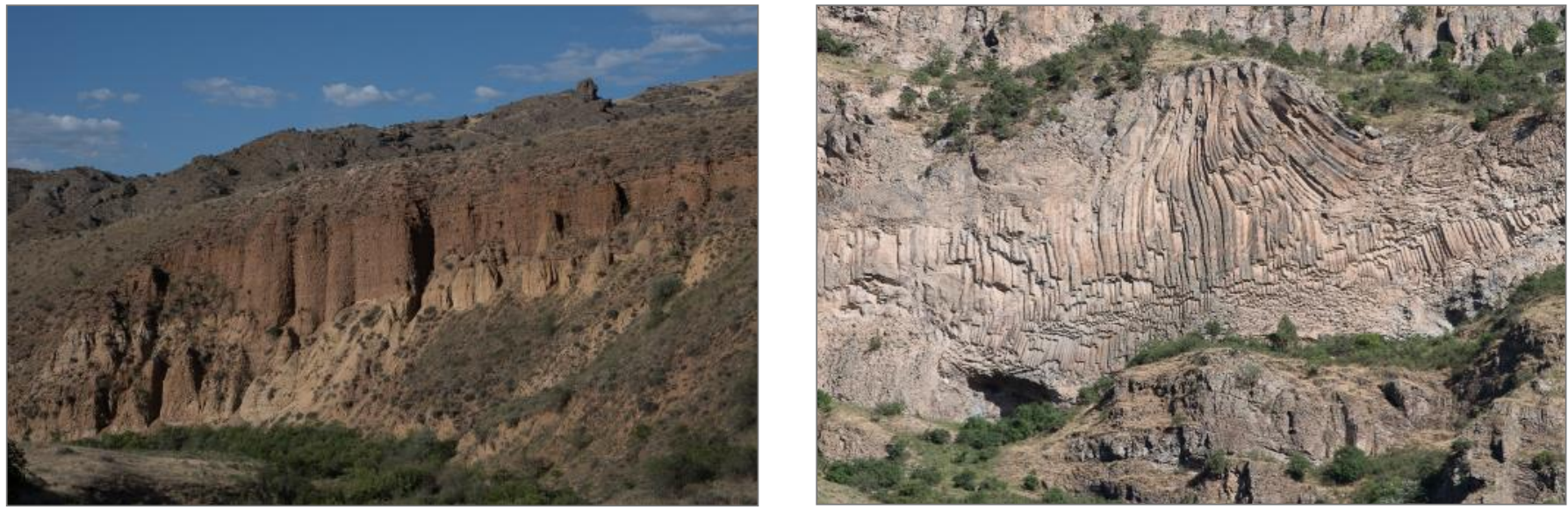

Ancient geological formations.

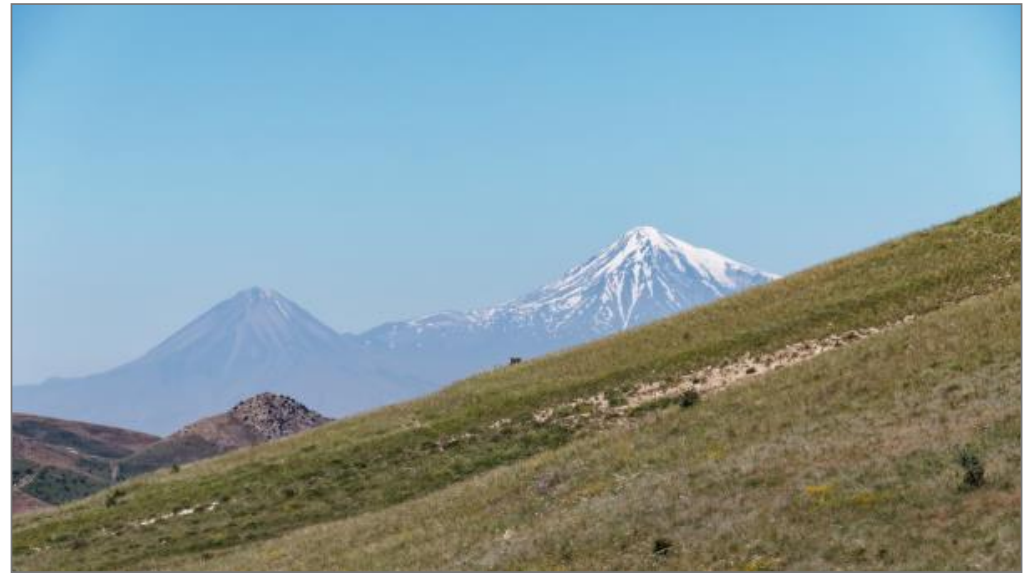

Magnificent Mount Ararat.

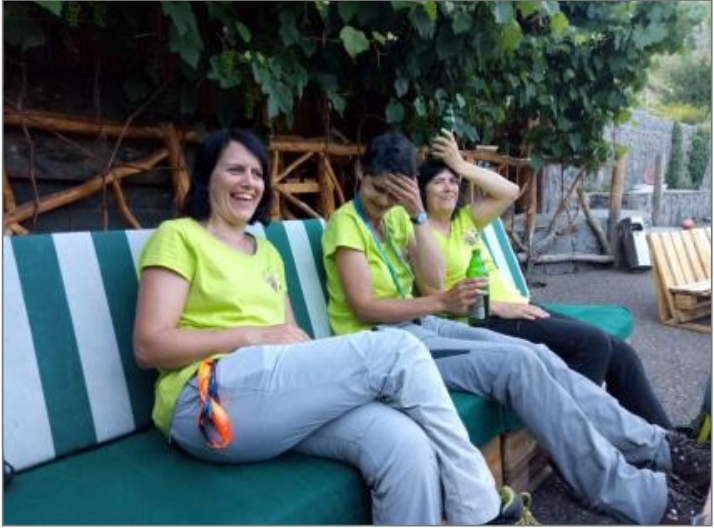

Cold beer is the best for bumps! Itziar recovers after she hit her head on the door of the small chapel in Gnishik. We hope that she did not totally destroy it! 


\section{Day 9 - July 4, Yeghegnadzor-Areni, Areni-Khachik}

On this day our destination was the karst region near the villages of Areni and Khachik. On the dry slopes we sampled plots of thorny cushion communities. The 'hedgehogs' were formed by Onobrochis cornuta, Acantholimon caryophyllaceum and three species of Astracantha. All day long, we worked on the very warm slopes under the open sun. At midday, we gathered near the specially equipped picnic point. We rested a little while near a freshwater spring and under the shade of a tree.
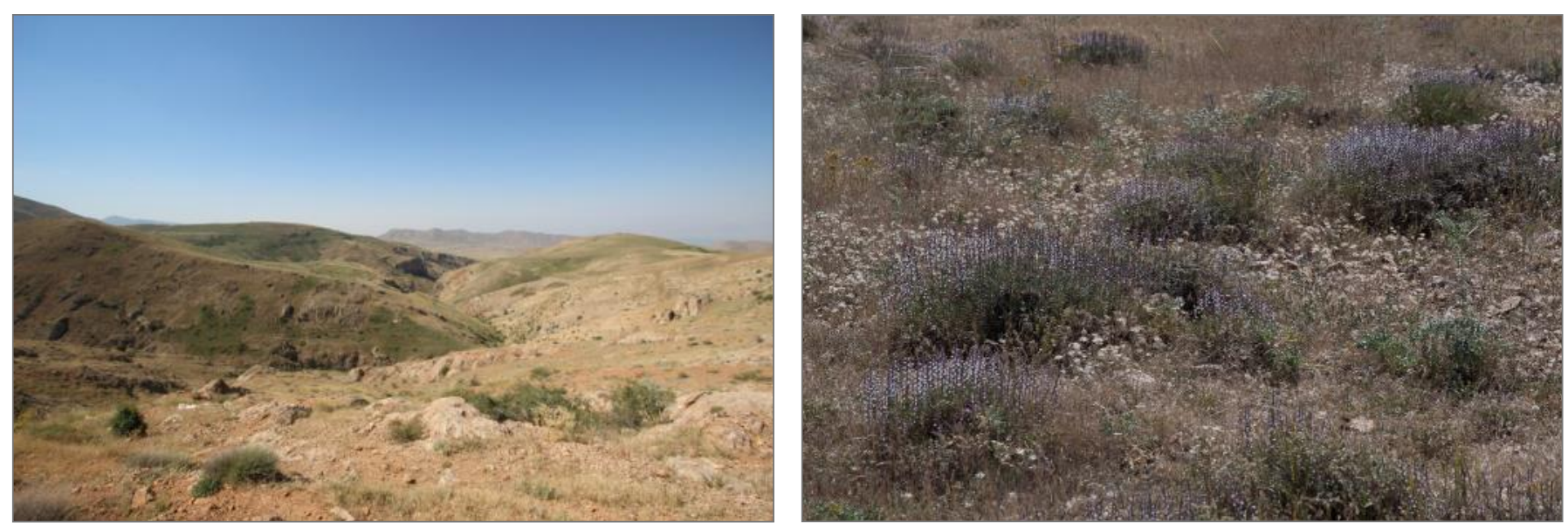

Thorn cushion communities with Acantholimon caryophyllaceum.
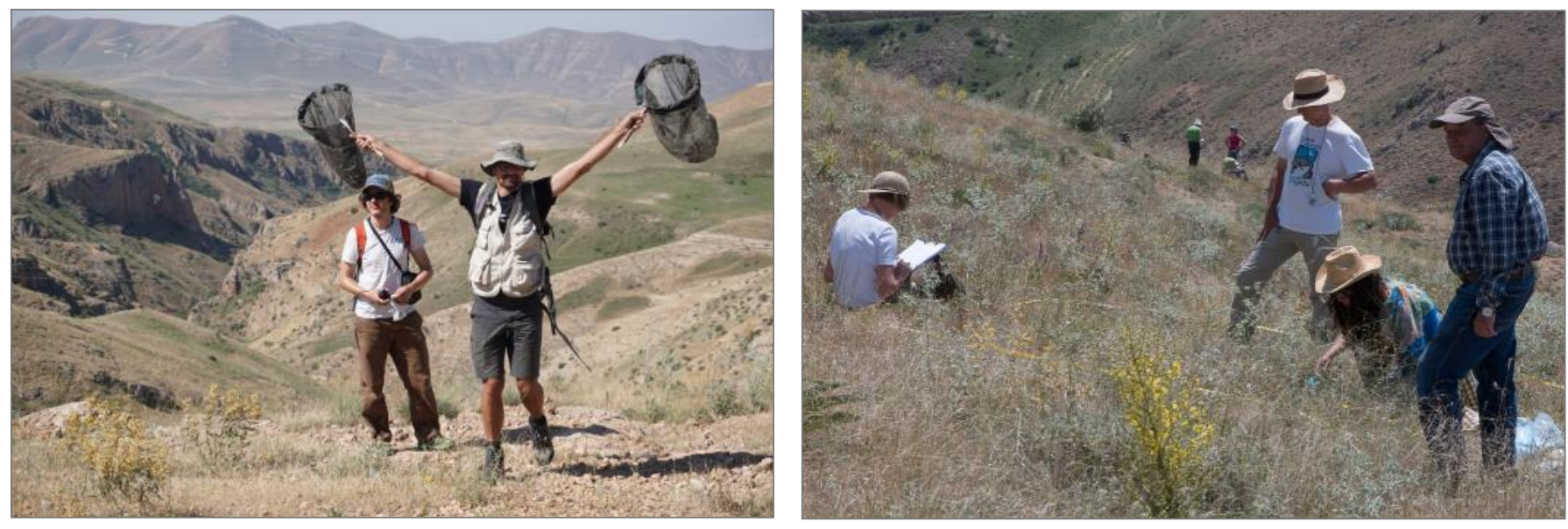

Sampling in progress during the hot day.
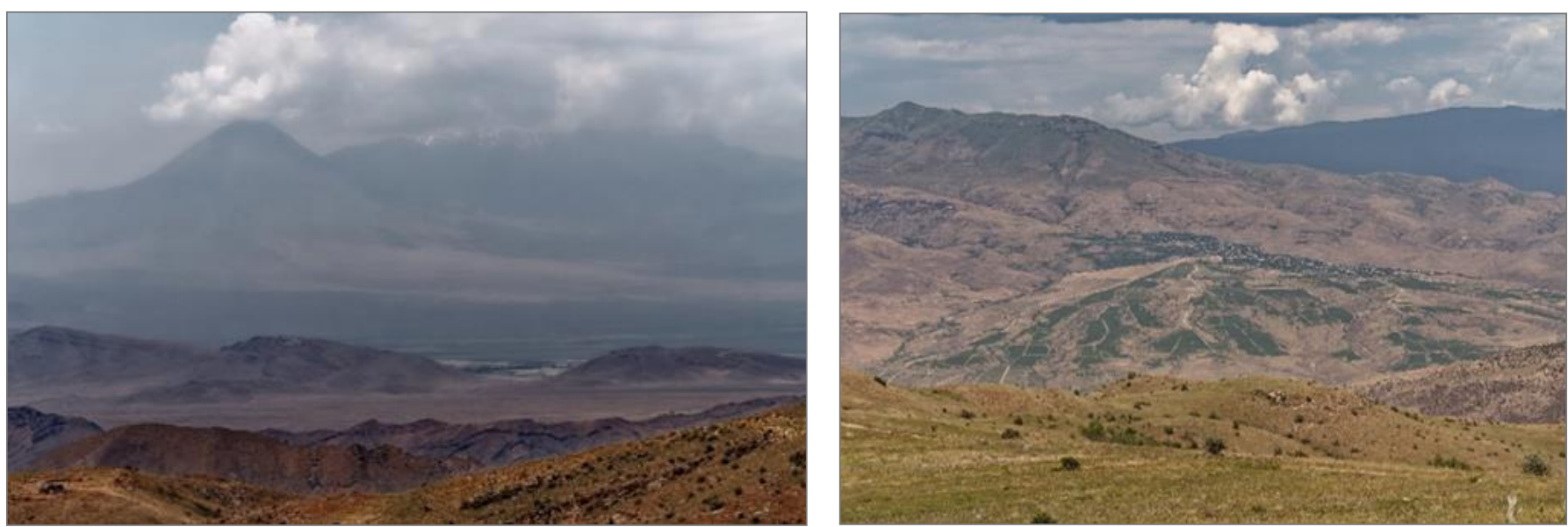

We were surrounded by spectacular mountains. 


\section{Day 10 - July 5, Yeghegnadzor- Tigranashen, Tigranashen-Yerevan}

In the morning, we said good-bye to the corner of paradise where we had lived during the last two days and took the route via the $M-2$ for Yerevan.

On the way, we visited Noravank, a 13-14th century monastery. All of us, with great pleasure, admired its remarkable architecture. Then, we stopped near Areni winery, tasting the wine followed by an excursion to the nearby "bodega". After the excursion, we continued on our way singing our famous song "Garun-Garun".

We stopped near Tigranashen in a rocky place and sampled plots in tragacanthoid communities with the rare Gypsophila aretioides.

In the evening, after checking in the Yerevan hotel, we went to the restaurant for dinner. Before dinner, we strolled along the main streets in the center of Yerevan. There were many people, illuminated streets as well as dancing fountains. Armenians were celebrating the Constitution Day. We also sampled the various attractions and crossed through the fountains' tunnel.

The evening was very nice. We enjoyed the delicious Armenian dishes and also the folk music, songs and dancing.
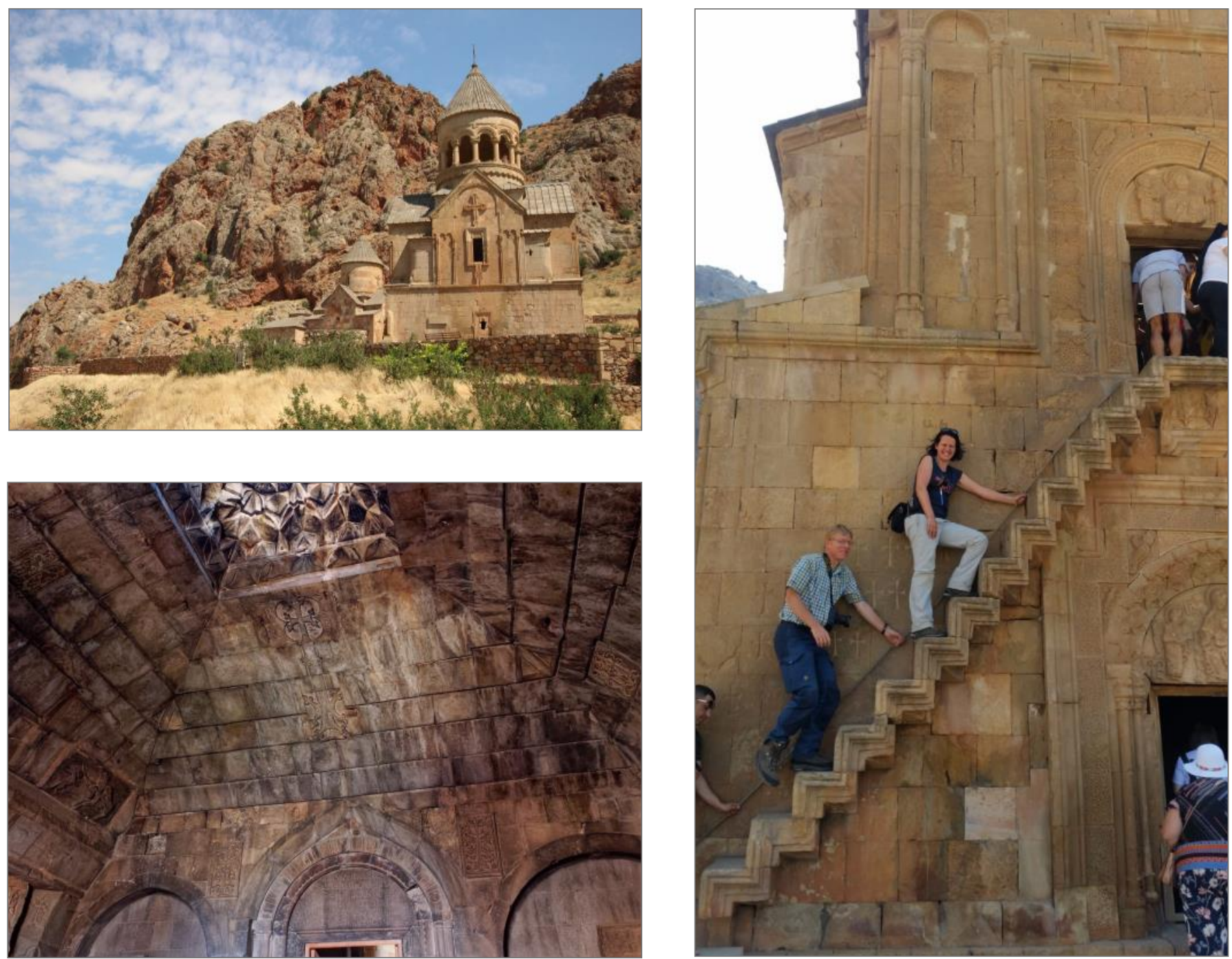

Noravank monastery.

Asun is creating a queue on the steps at Noravank. 

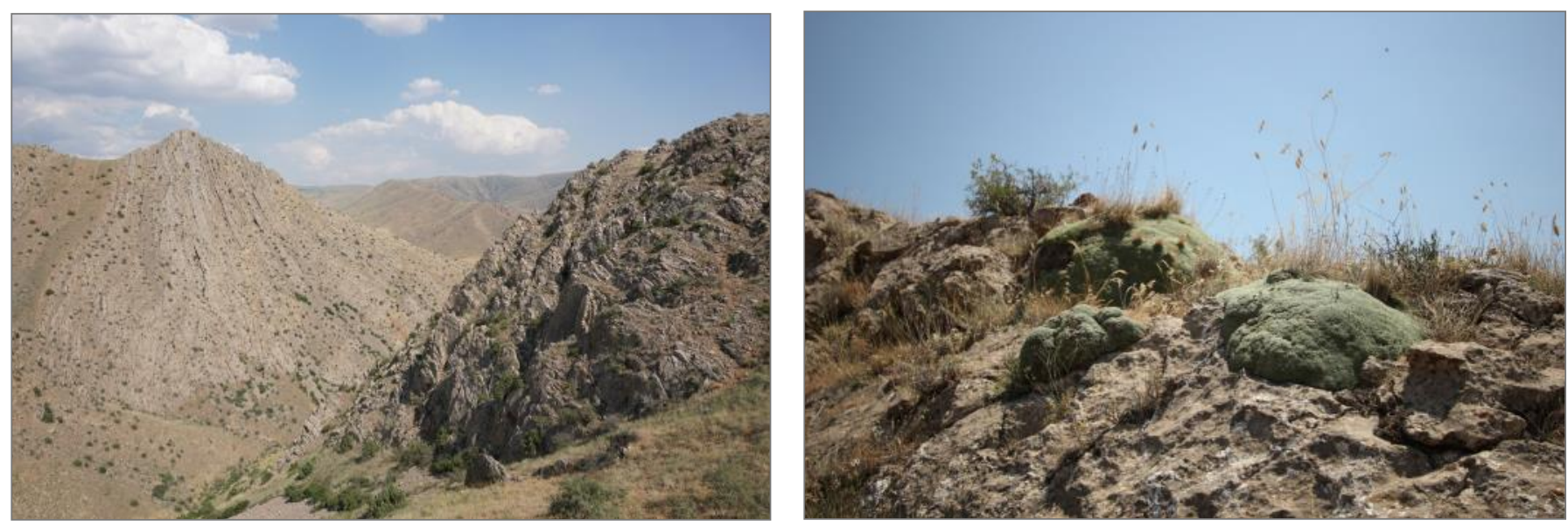

Rocky grasslands with Gypsophila aretioides.
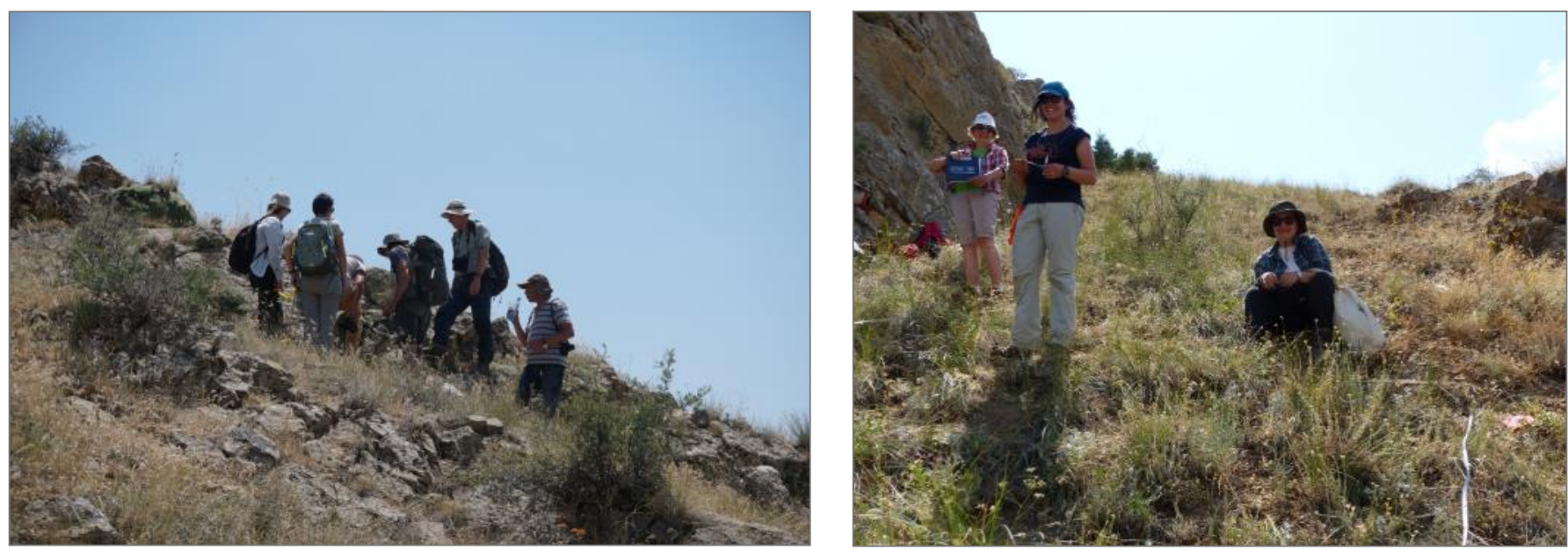

Fieldwork near Tigranashen.
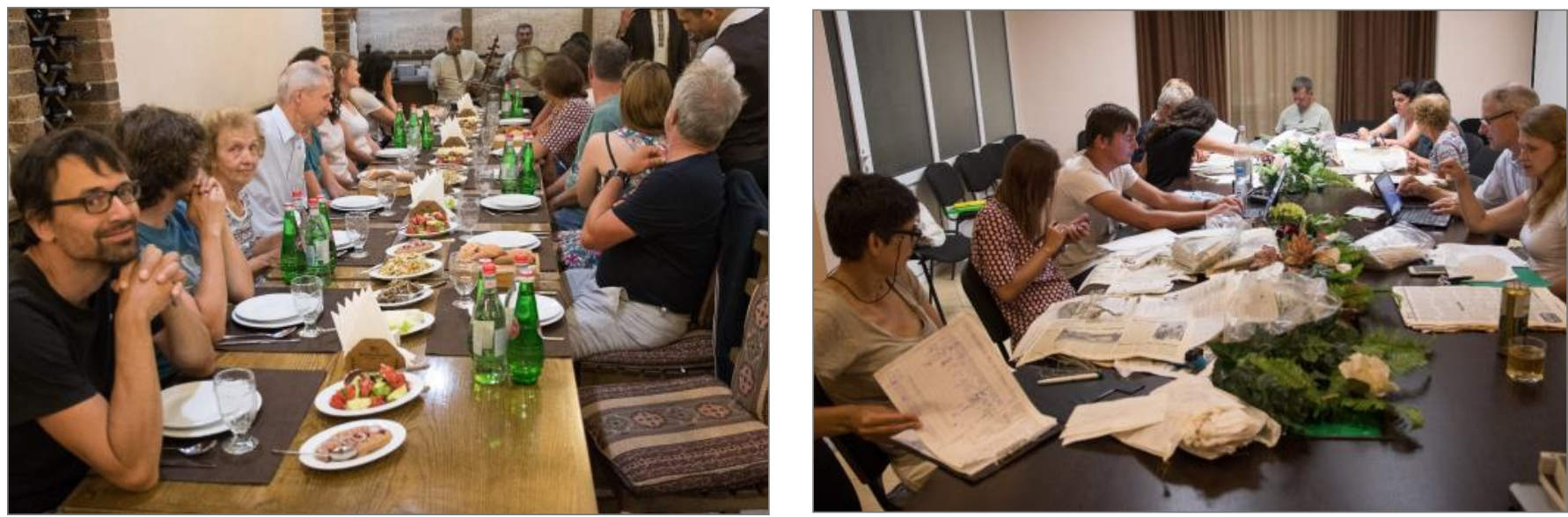

Dining table (left) and working table (right). 


\section{Day 11 - July 6, Yerevan-Kari lake, Kari lake-Amberd fortress}

The last day was devoted to travelling to the Mount Aragats massif. We drove through several small towns: Proshyan, Ashtarak, Byurakan and, at the elevation of 3,300 $\mathrm{m}$ a.s.l., we reached the Aragats Cosmic Ray Station (former Byurokan observatory). Near to the Station, we enjoyed the small Kari Lake, glaciers on the slopes above it and the surrounding colourful alpine meadows.

Then we descended to the subalpine belt and near the 10-13th century Amberd fortress, we sampled plots in the subalpine forb meadows. It was our last sampling of the year and fittingly marked the end of a beautiful and successful expedition. We thanked our Armenian colleagues for organising such an interesting and well-executed Field Workshop. We presented subalpine flowers to Alla, George and Aram.

The farewell party was in the restaurant Yerevan. The firework on the cake celebrated the 10year Jubilee of the EDGG Field Workshops, and successful ending of the $13^{\text {th }}$ Field Workshop in Armenia.
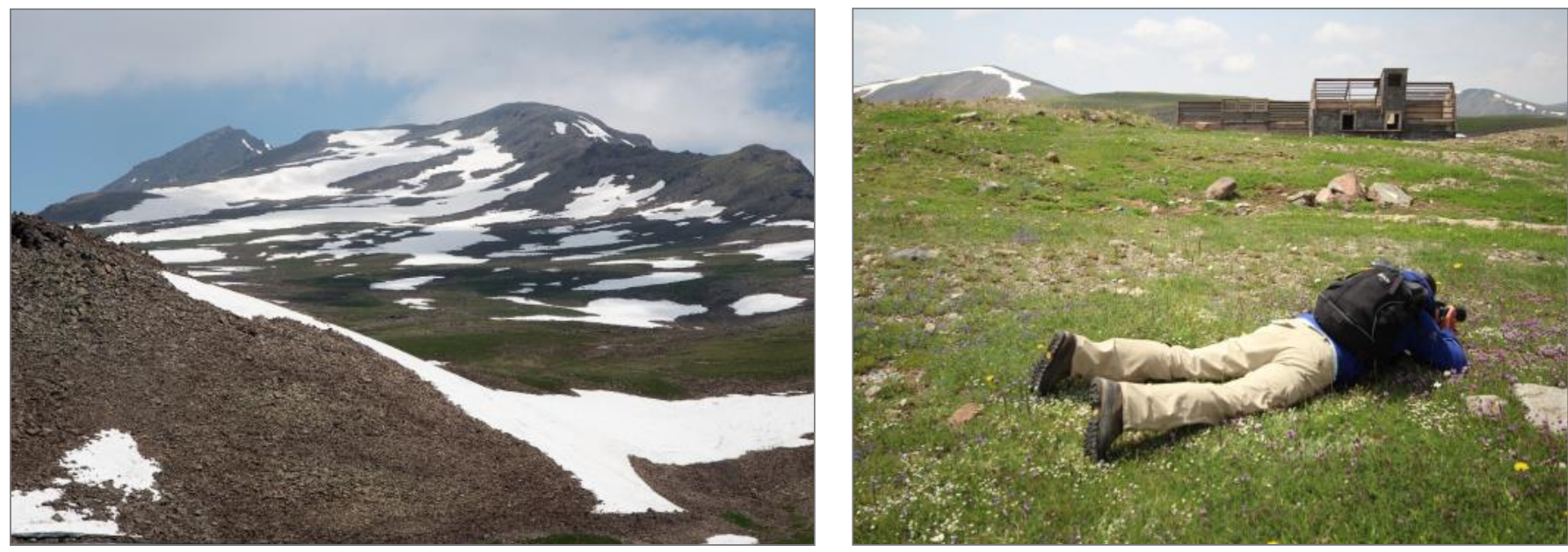

Alpine meadows on Mount Aragats.
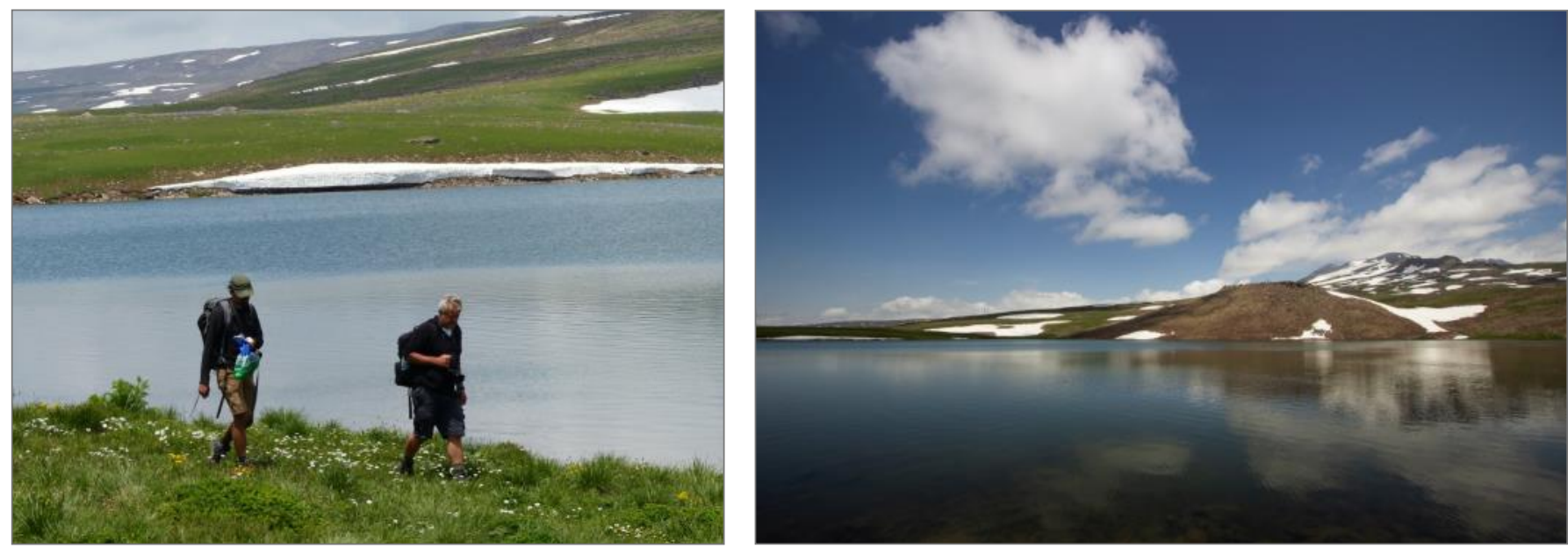

Kari Lake. 

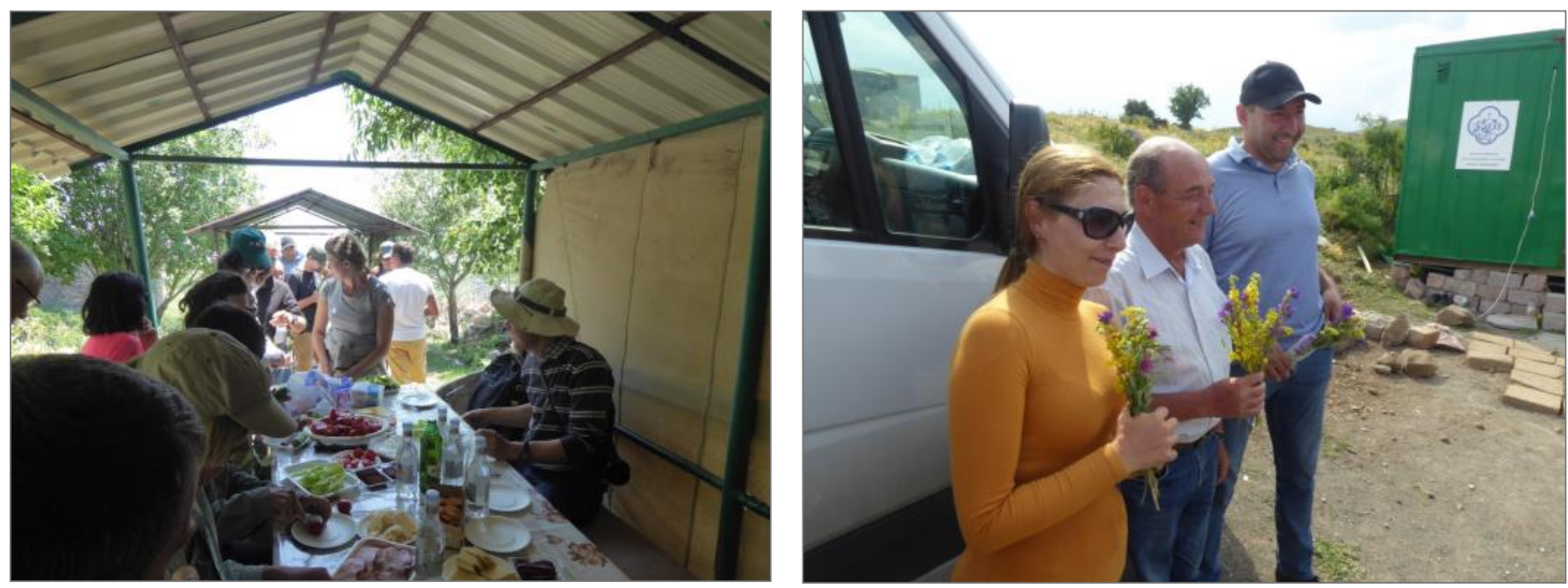

Traditional lunch and our greetings with thanks to Alla, George and Aram.
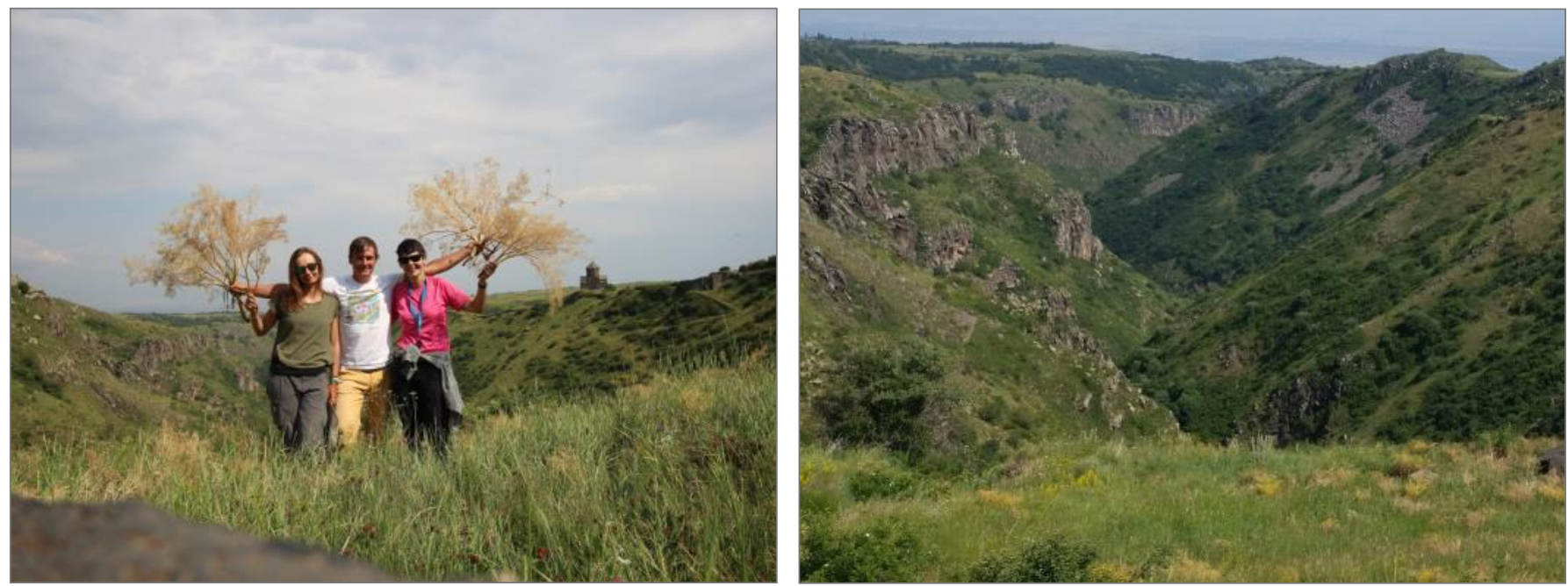

Left: The last sampling of the expedition has just finished and we celebrate with Prangos-fireworks. Right: Gorge near the Amberd fortress.
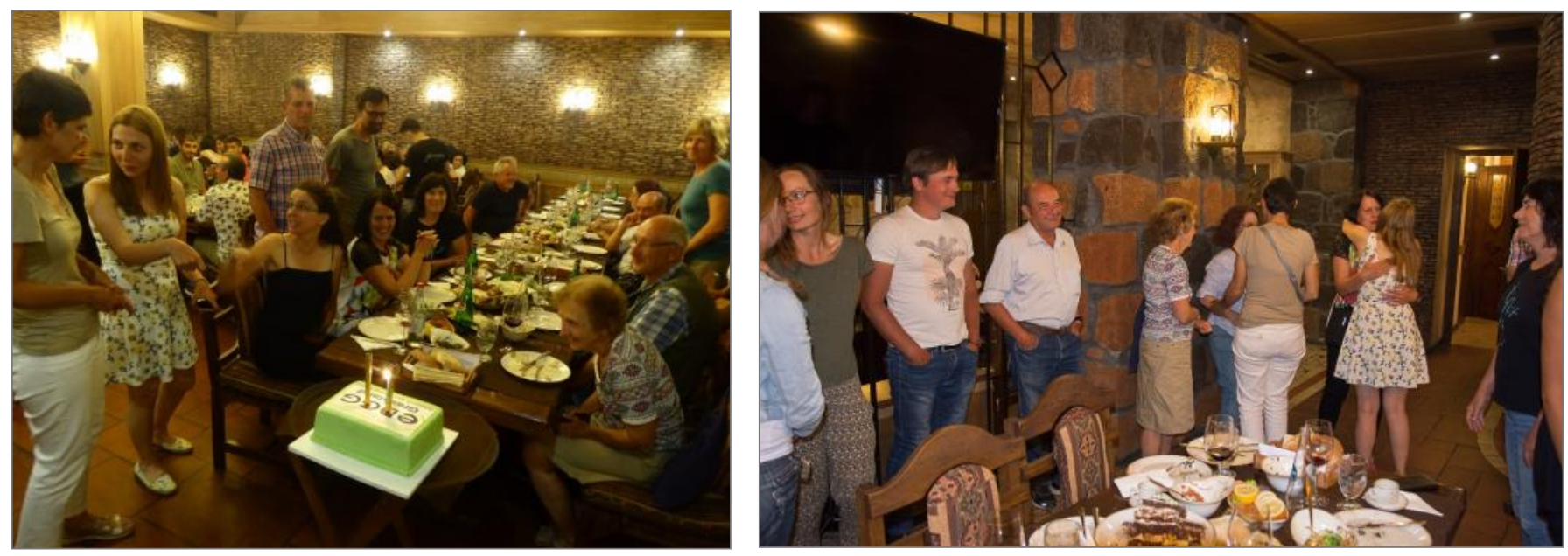

Closing ceremony of the Field Workshop and the farewell words. 


\section{Selected pictures of plants}

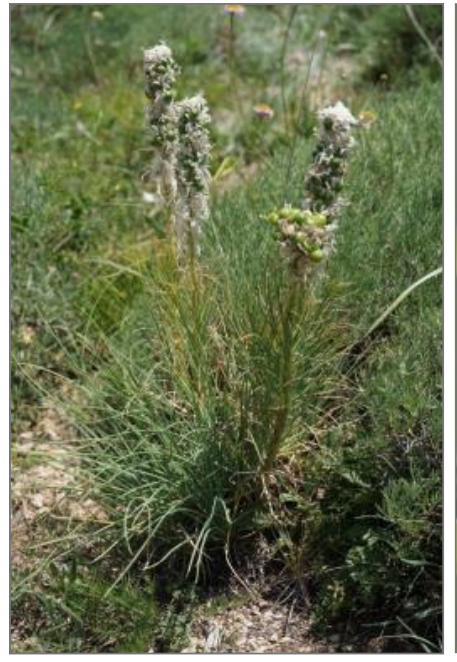

Asphodeline taurica

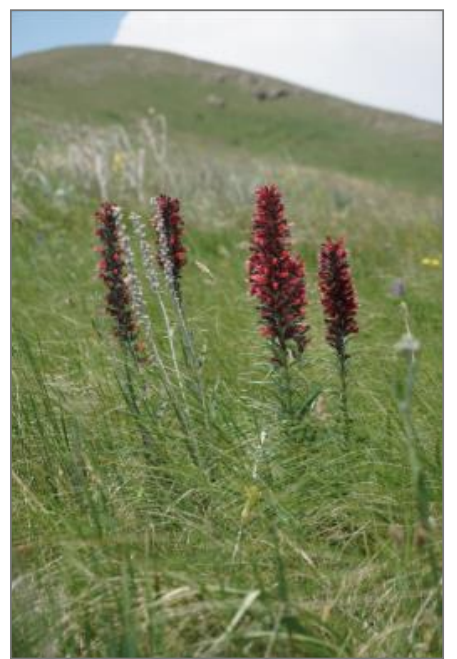

Pontechium maculatum

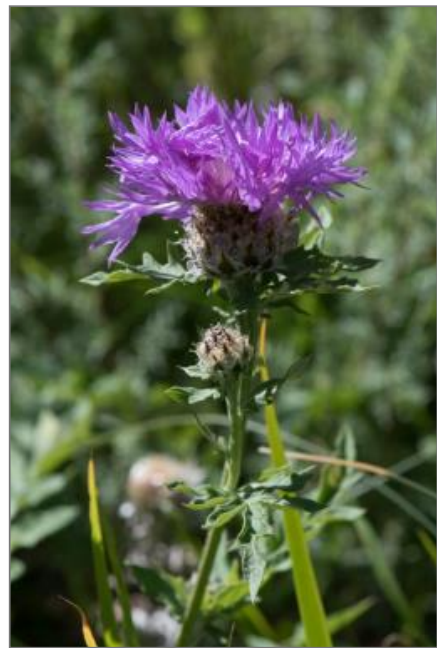

Psephellus dealbatus

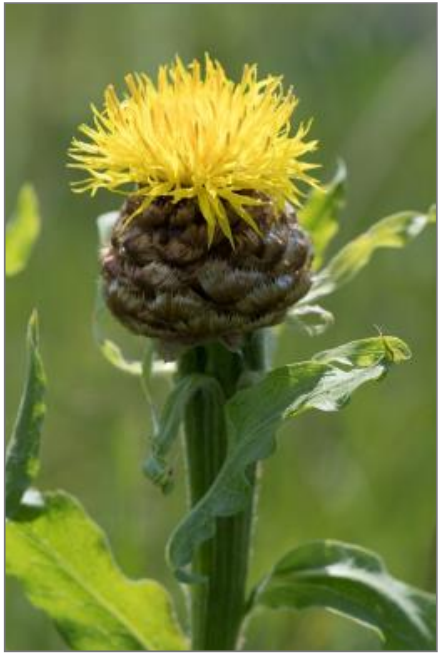

Centaurea macrocephala

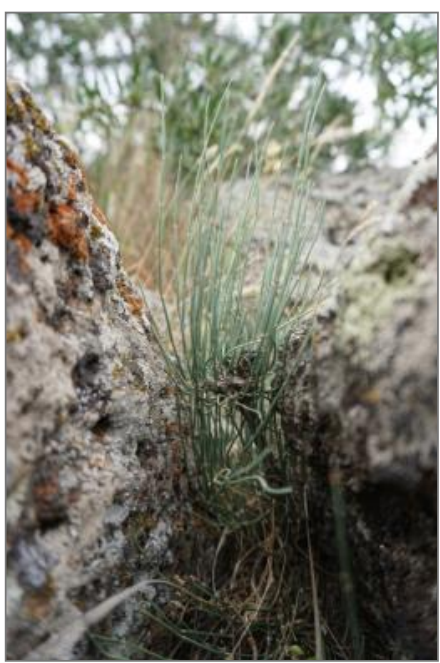

Ephedra major subsp. procera

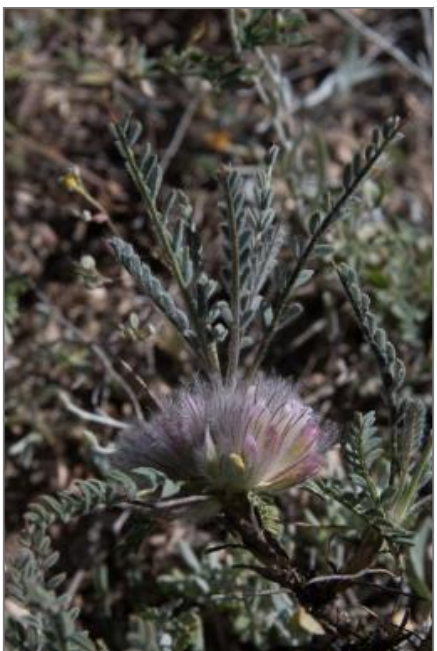

Astracantha vedica

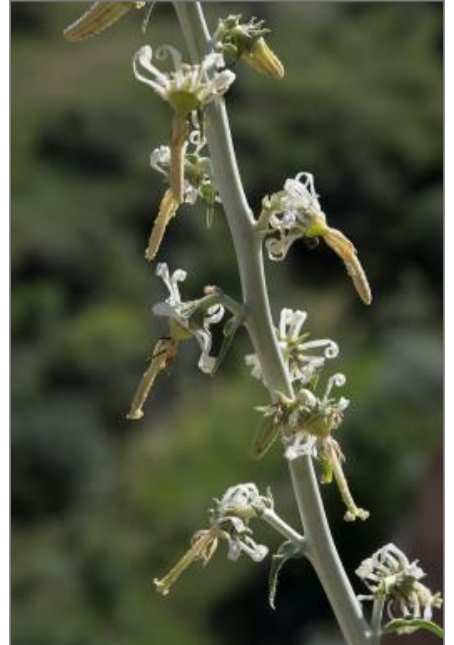

Michauxia laevigata

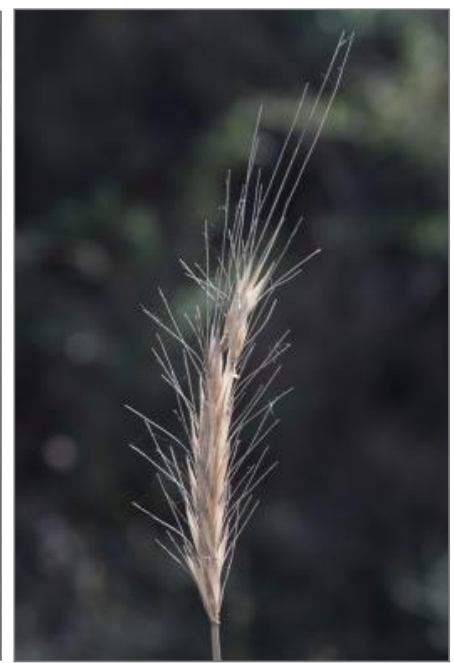

Taeniatherum caput-medusae subsp. crinitum

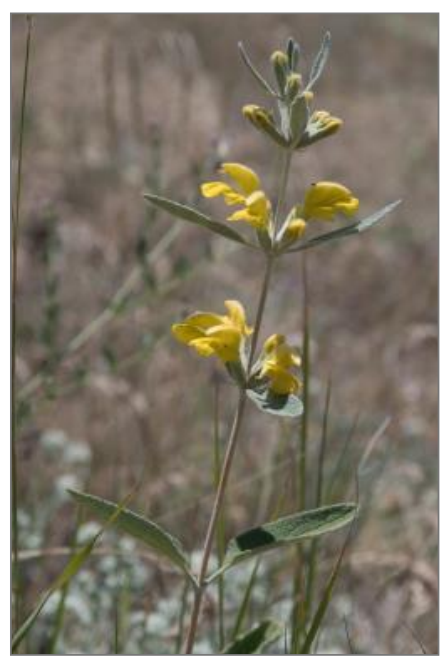

Phlomis orientalis

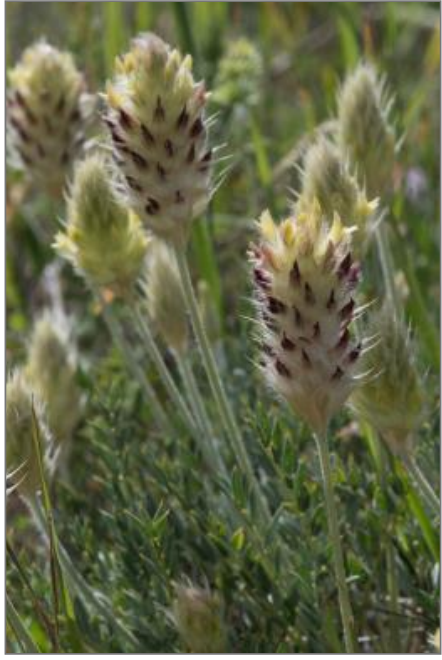

Astragalus lagopoides

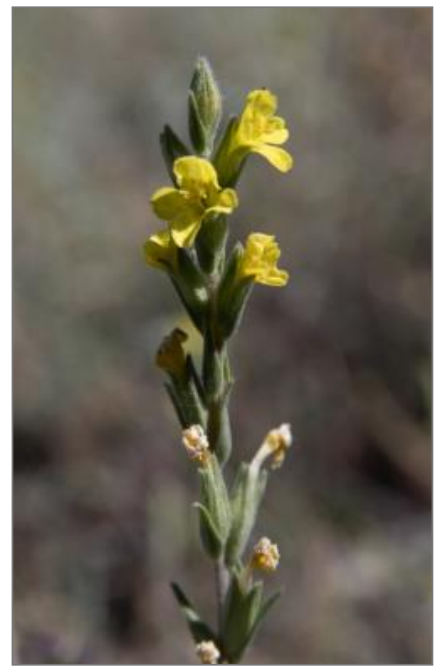

Odontites aucheri

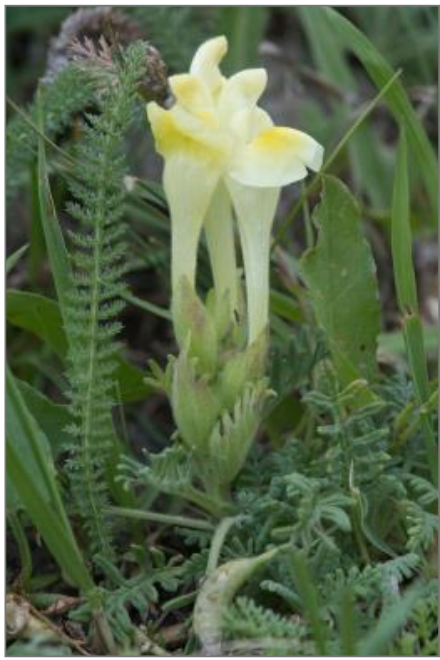

Scutellaria orientalis 


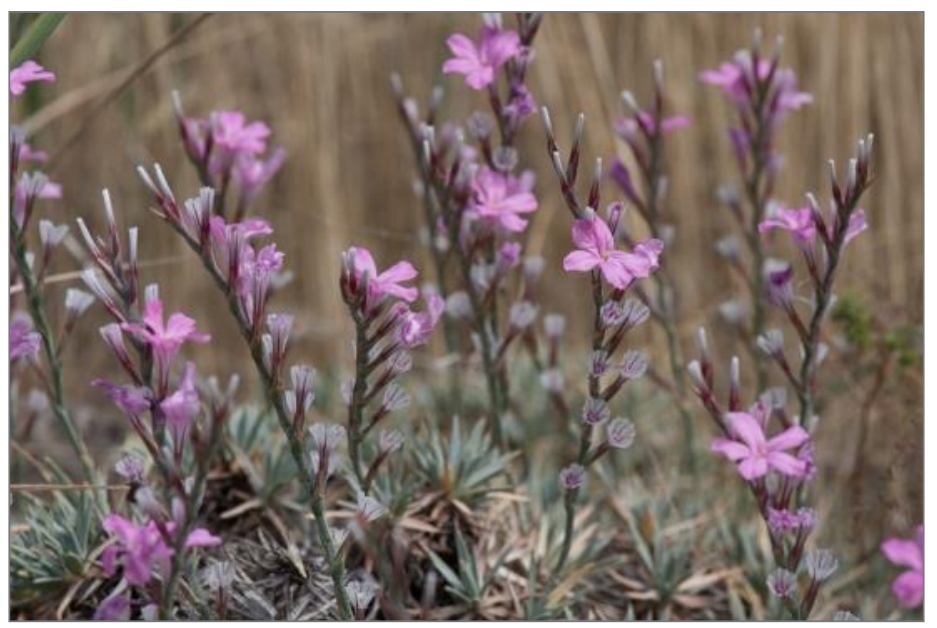

Acantholimon caryophyllaceum

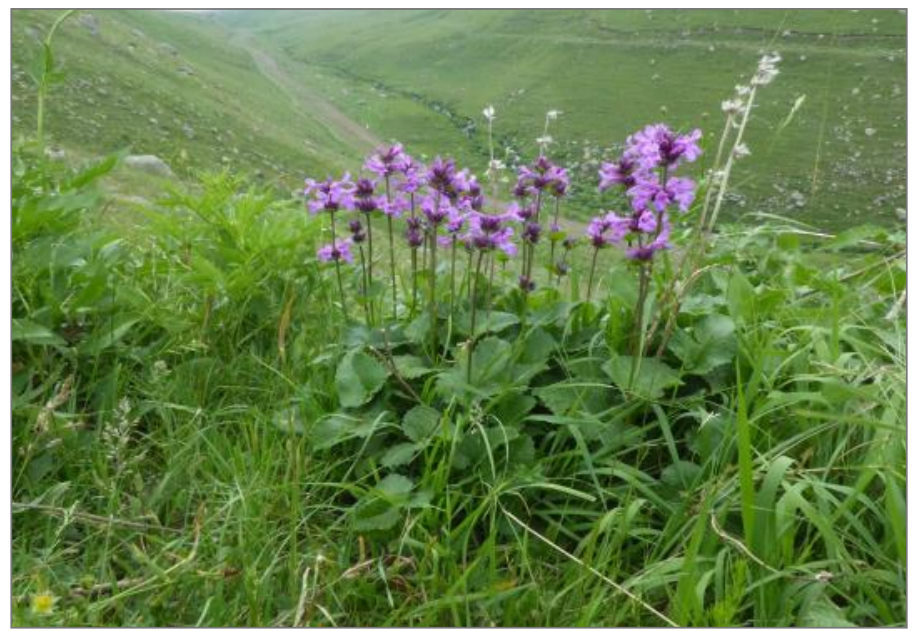

\section{Stachys macrantha}

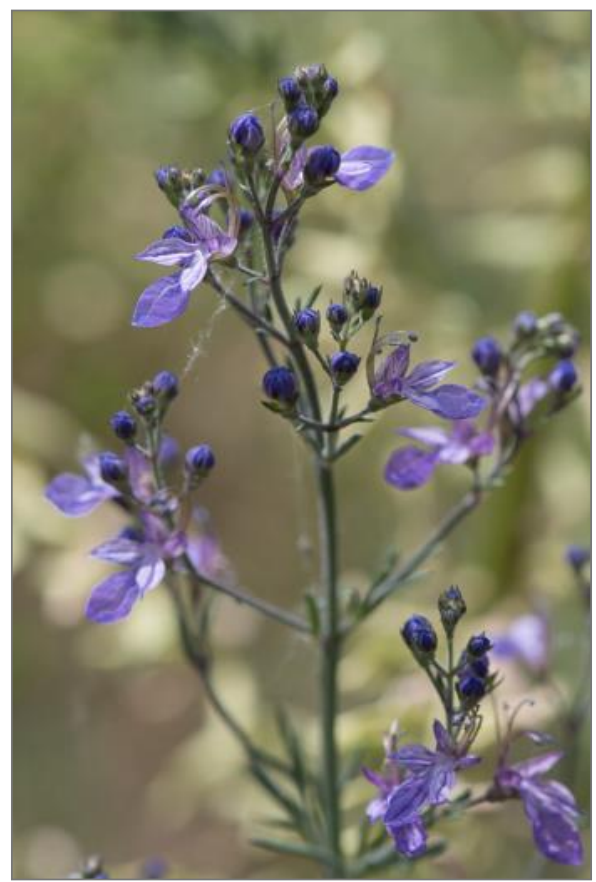

Teucrium orientale

Thalictrum foetidum

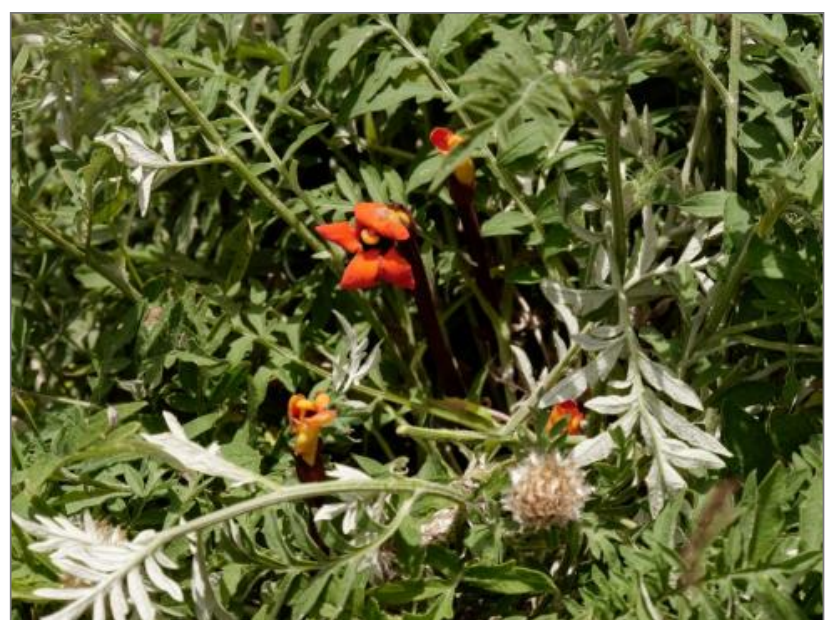

Phelypaea coccinea

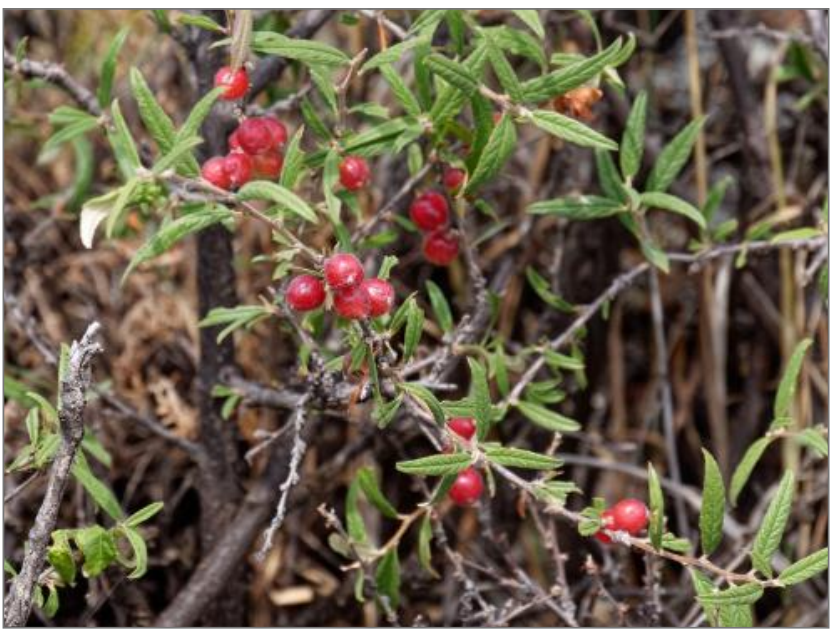

Prunus incana

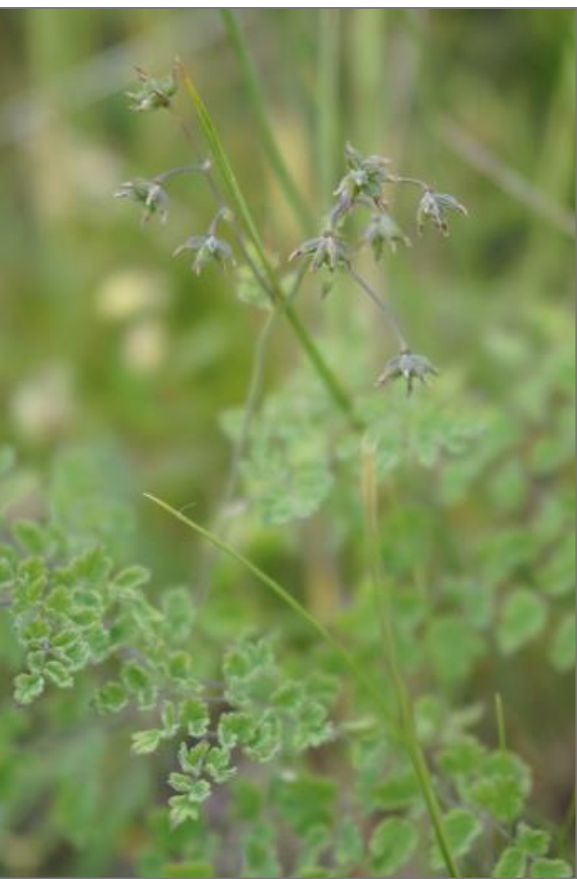

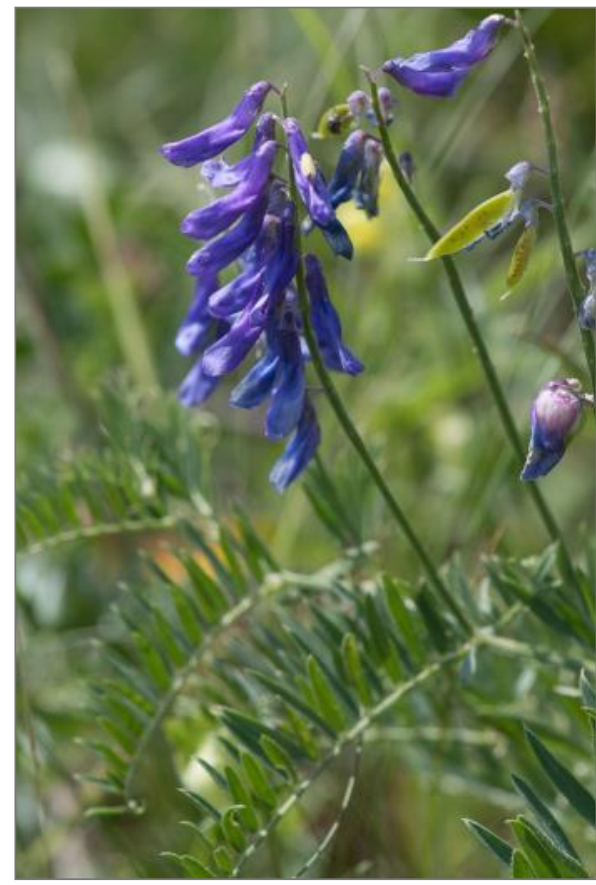

Vicia canescens subsp. variegata 


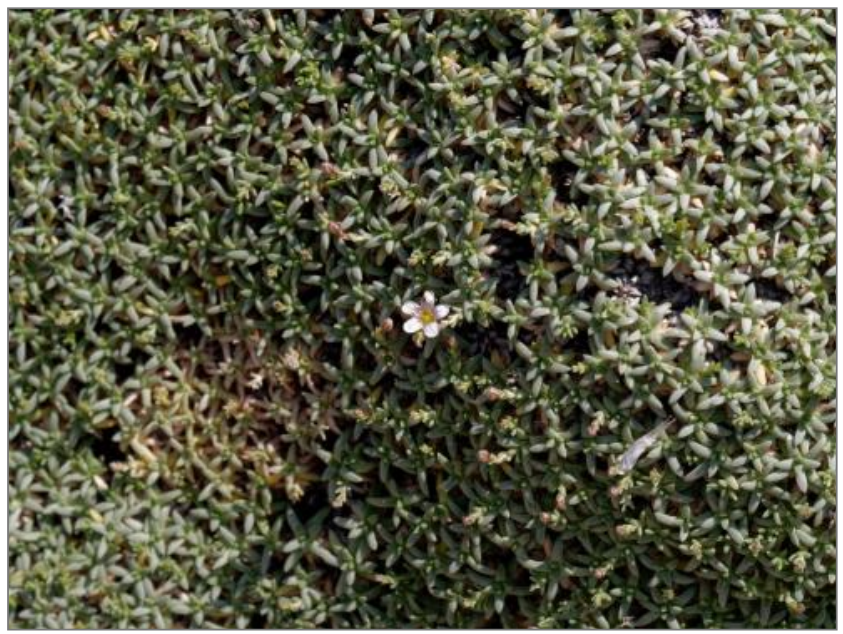

Gypsophila aretioides

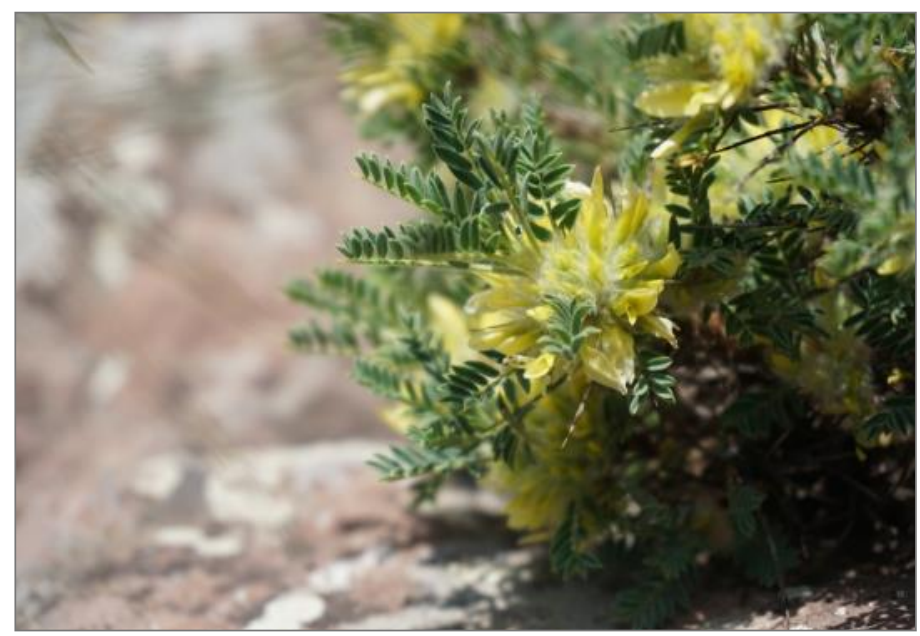

Astracantha microcephala

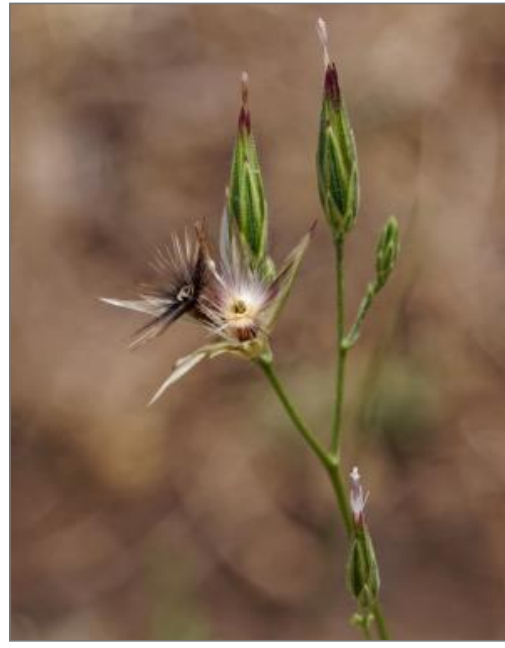

Crupina vulgaris

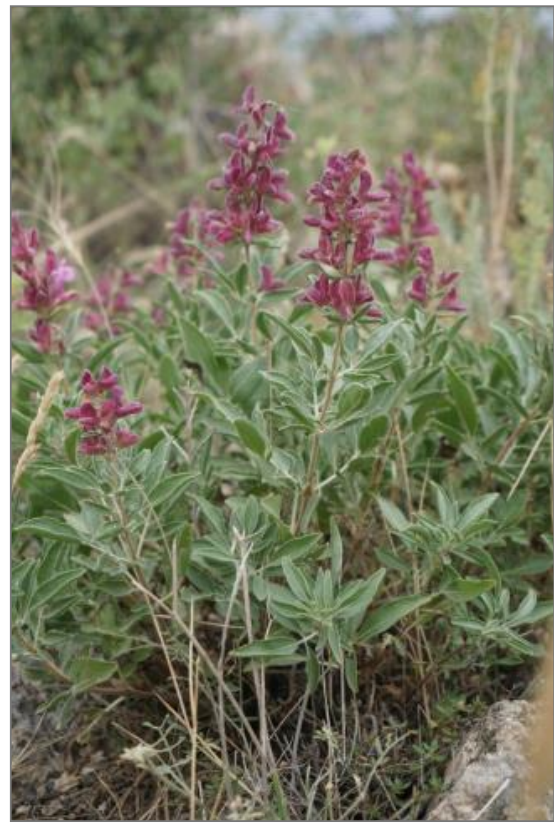

Salvia hydrangea

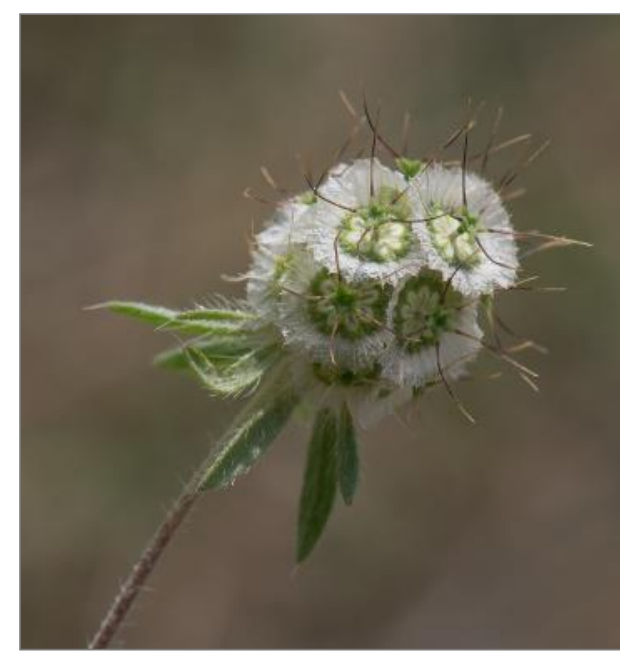

Lomelosia rotata

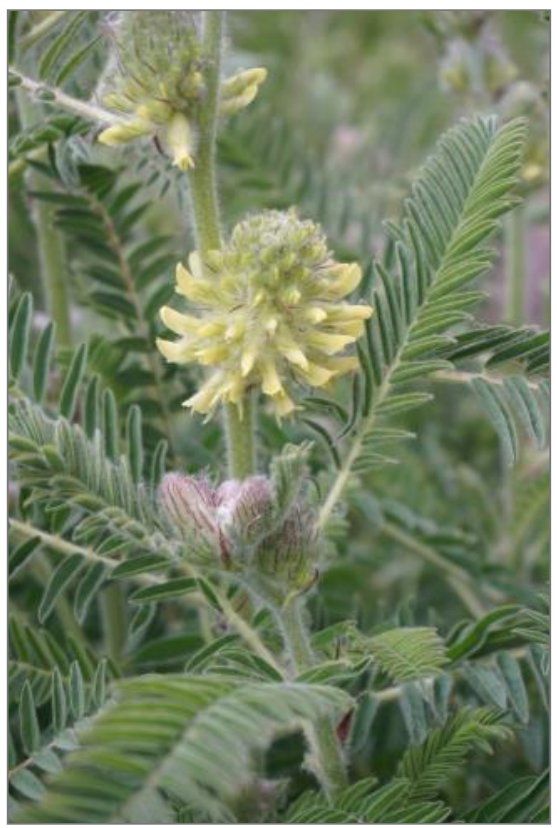

Astragalus alopecurus

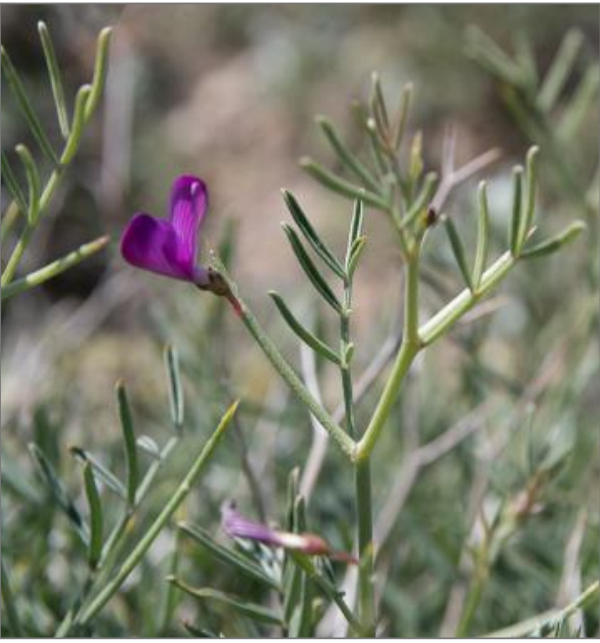

Onobrychis cornuto

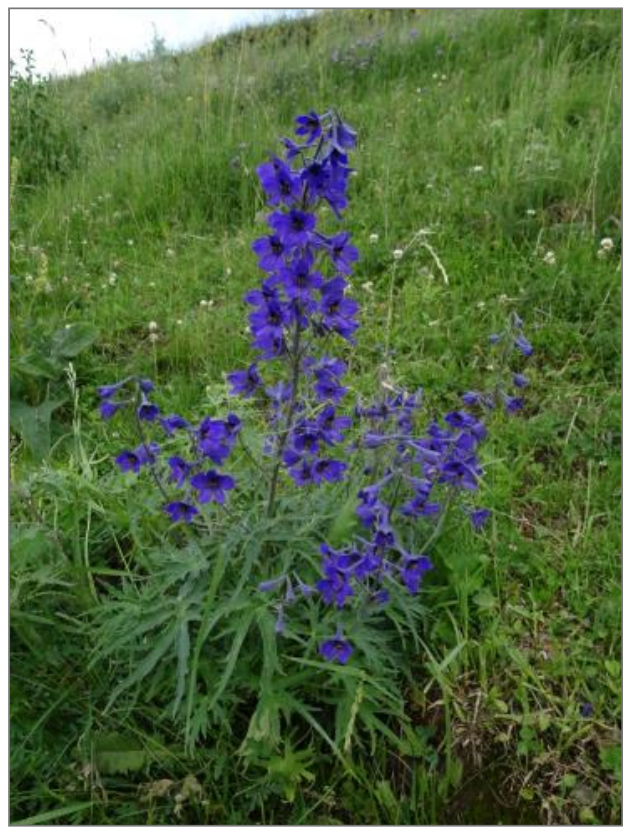

Delphinium buschianum 


\section{Selected pictures of orthopterans}

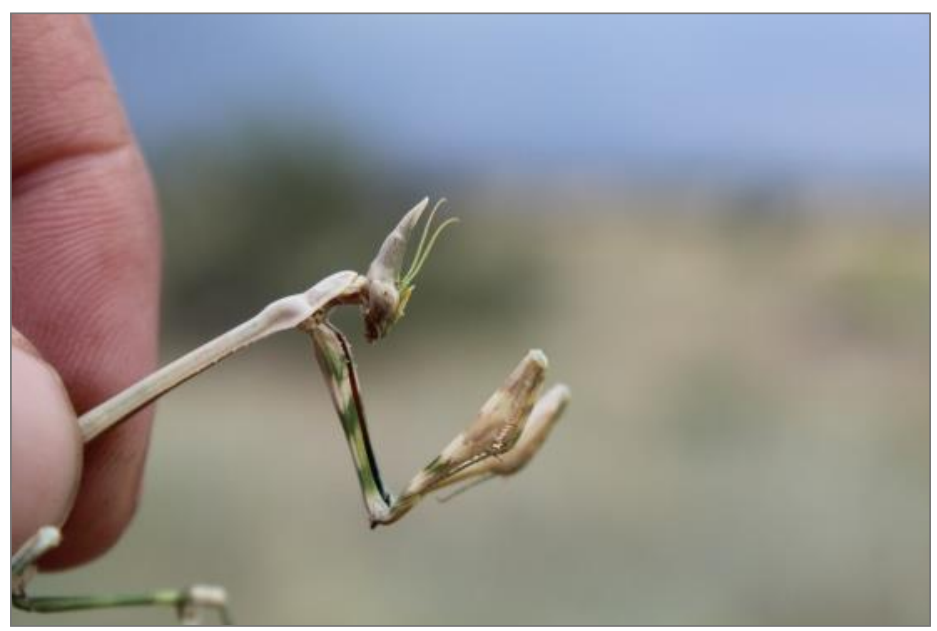

Empusa sp. (Mantodea)

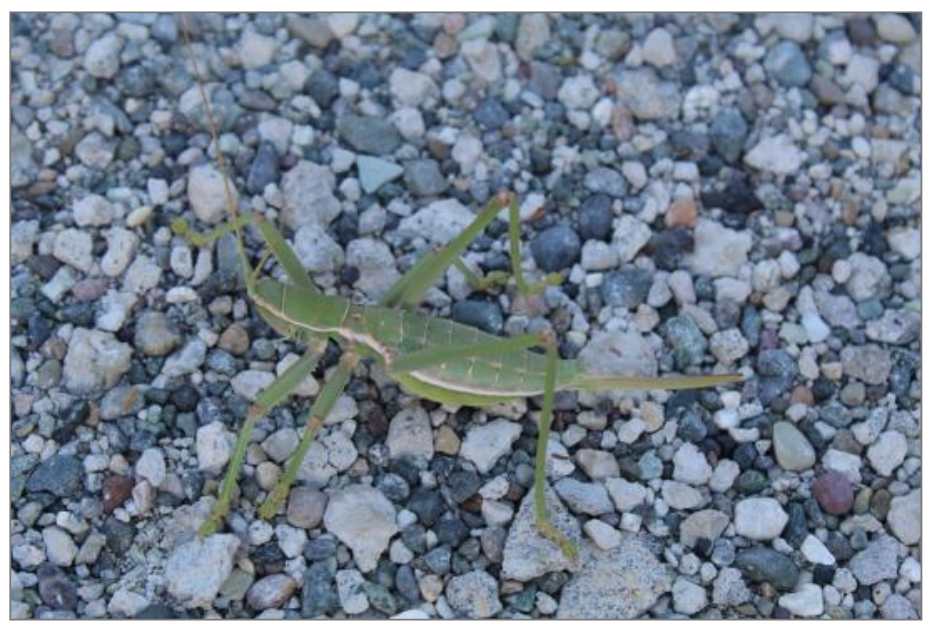

Predatory Bush Cricket (Saga pedo); Saga natoliae, both Ensifera

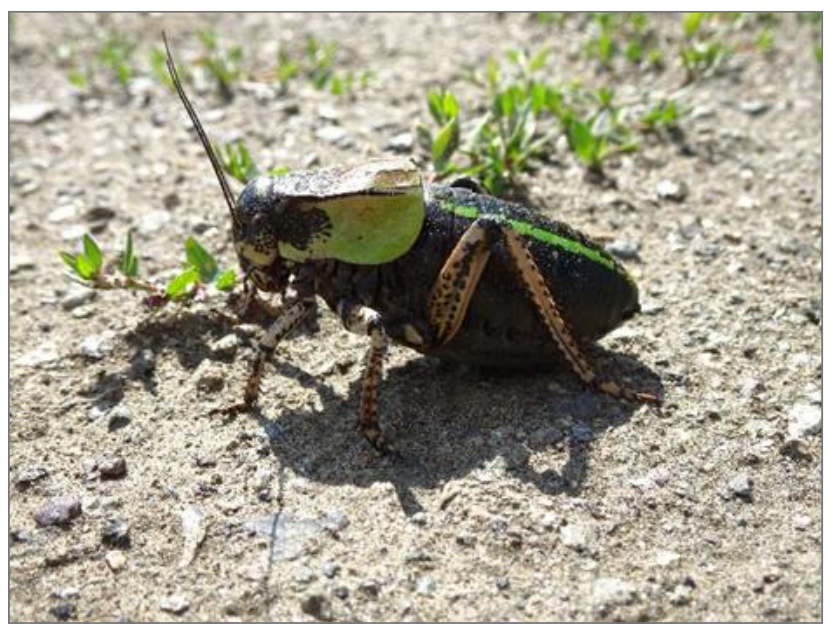

Bradyporus dilatatus group (Ensifera)

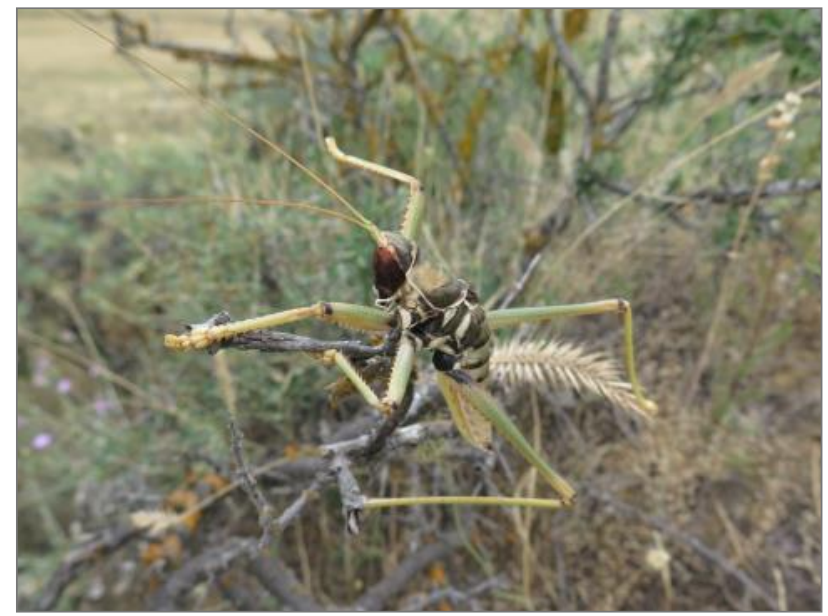

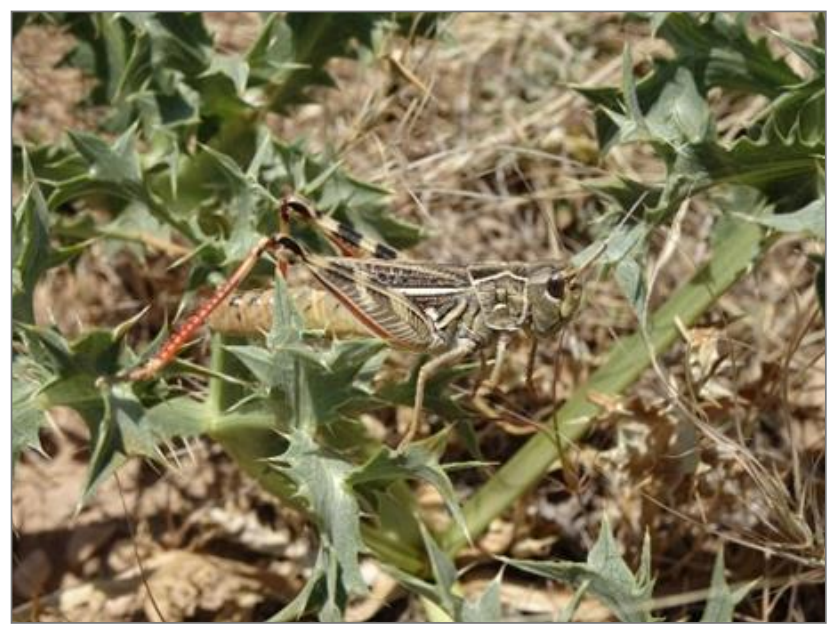

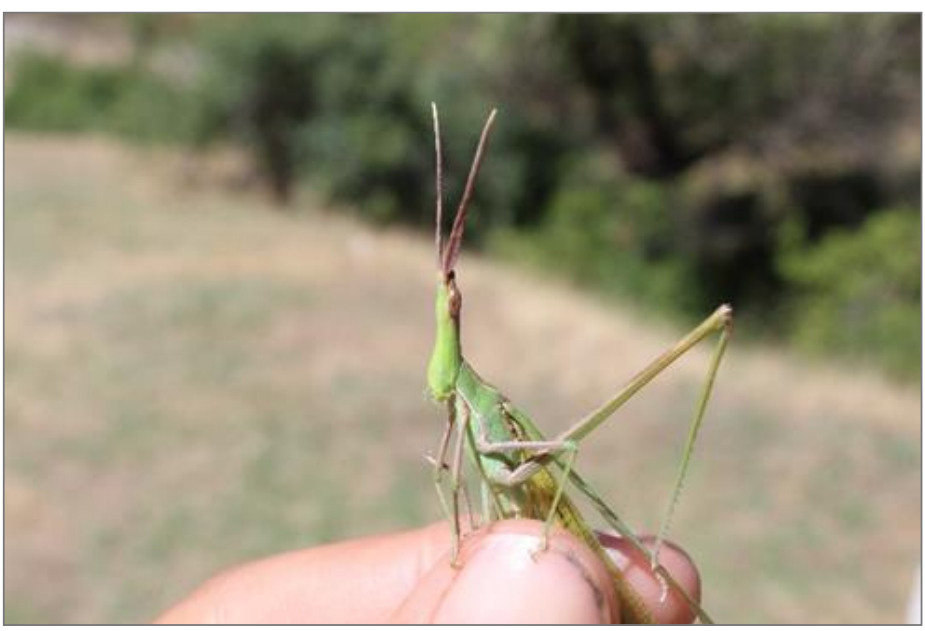

Arcyptera microptera; Cone-headed grasshopper (Acrida sp.), both Caelifera 


\section{Other invertebrates}

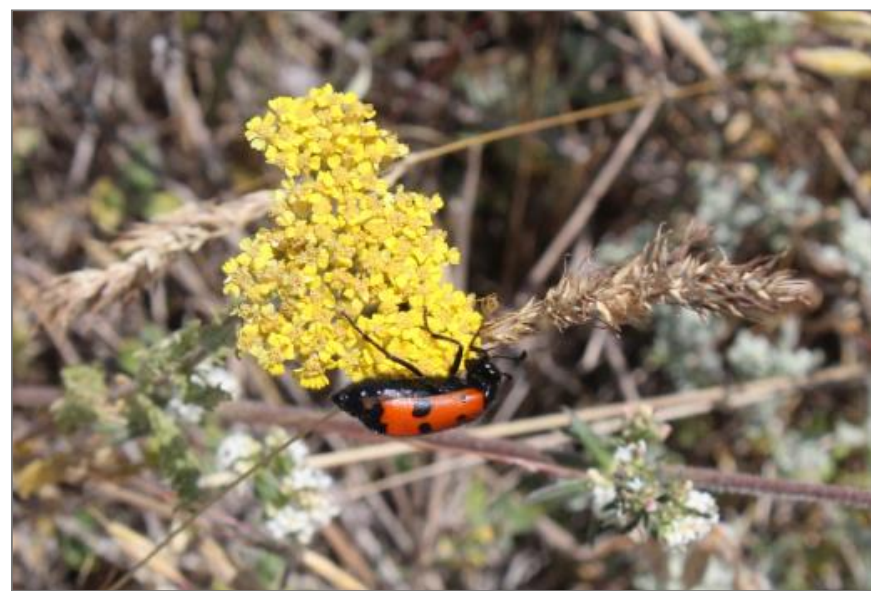

Mylabris sp.

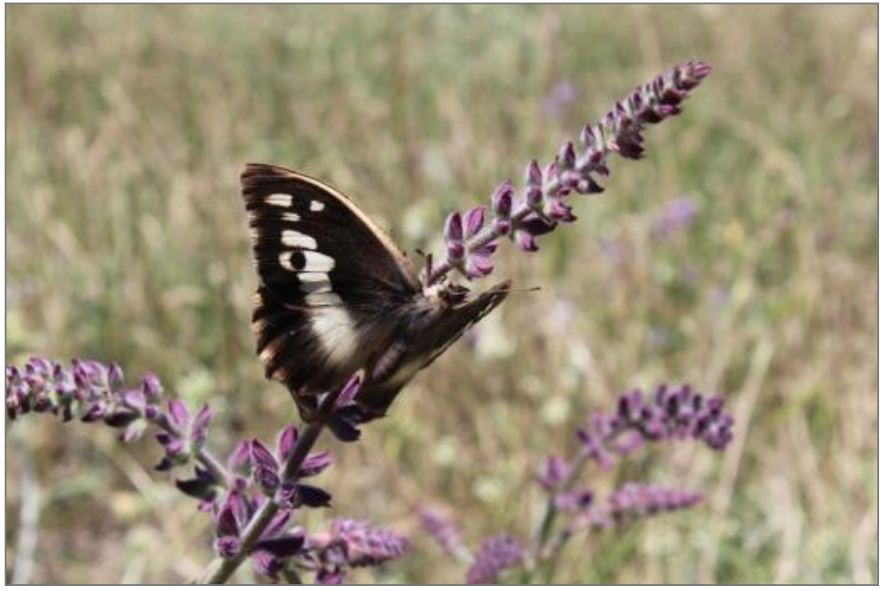

Chazara sp. (Nymphalidae, Lepidoptera)

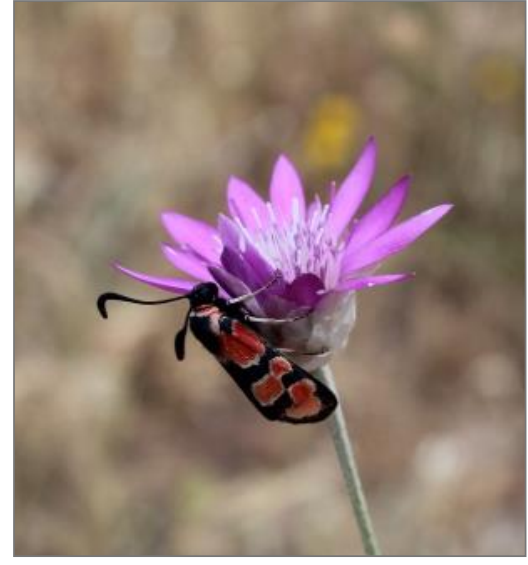

Easter burnet (Zygaena carniolica; Zygaenidae, Lepidoptera)

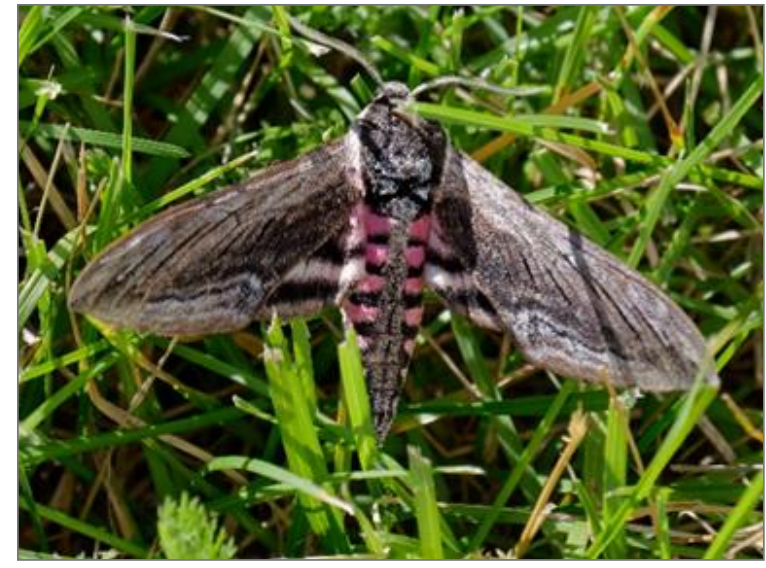

Privet hawk moth (Sphinx ligustri)

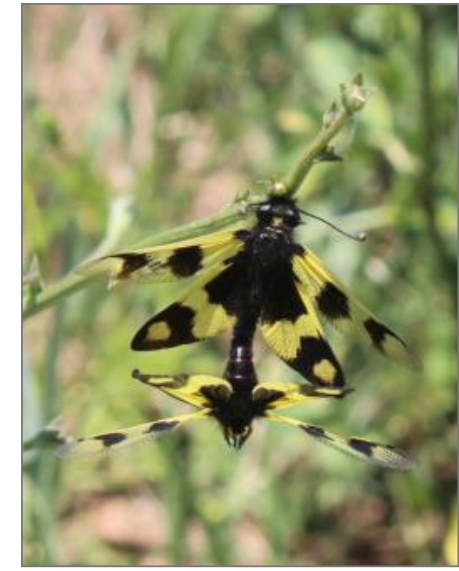

Libelloides macaronius

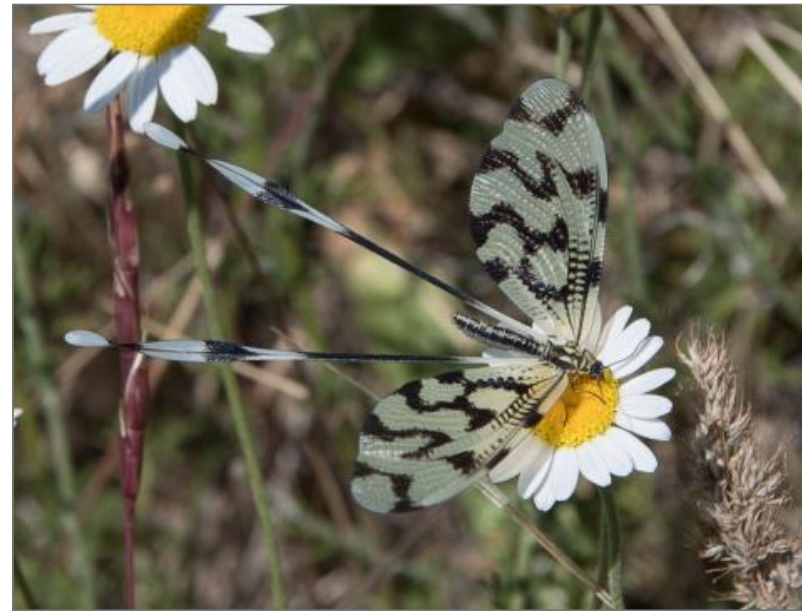

Nemoptera sinuata (both Neuroptera)

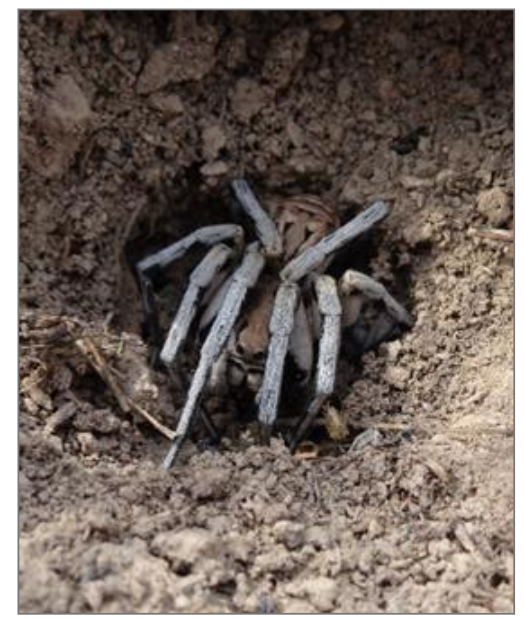

Lycosa praegrandis

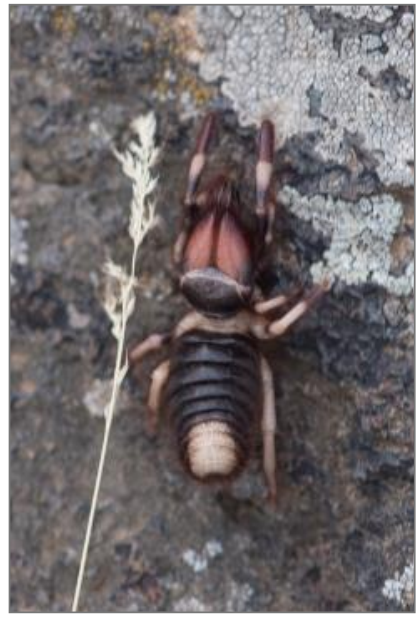

Rhagodes caucasicus (sun spiders / Solifugae) 


\section{Vertebrates}

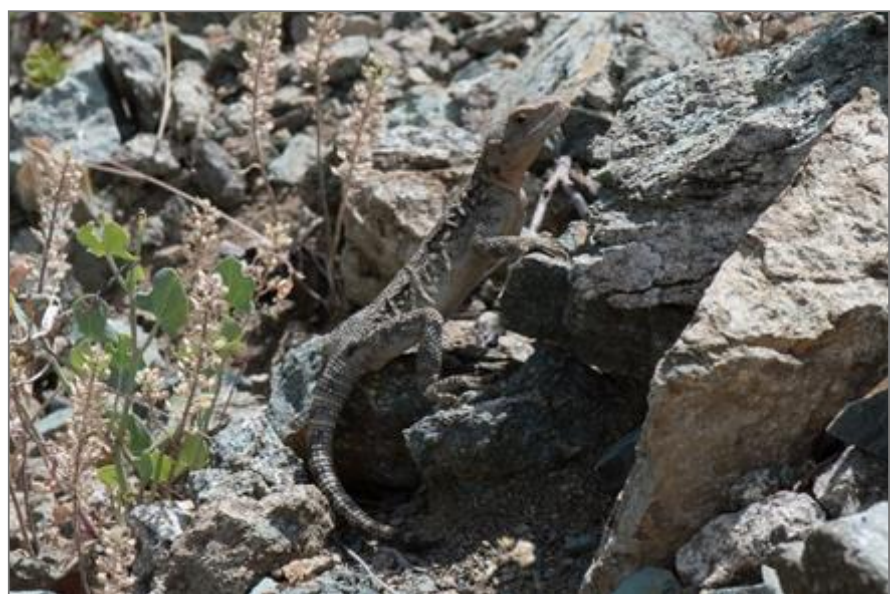

Caucasian agama (Paralaudakia caucasia)

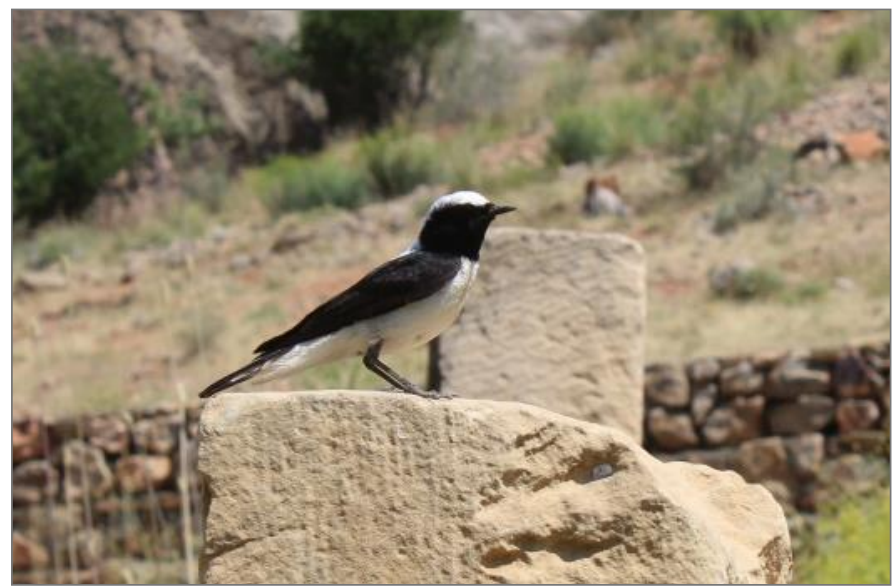

Western black-eared wheatear (Oenanthe hispanica)

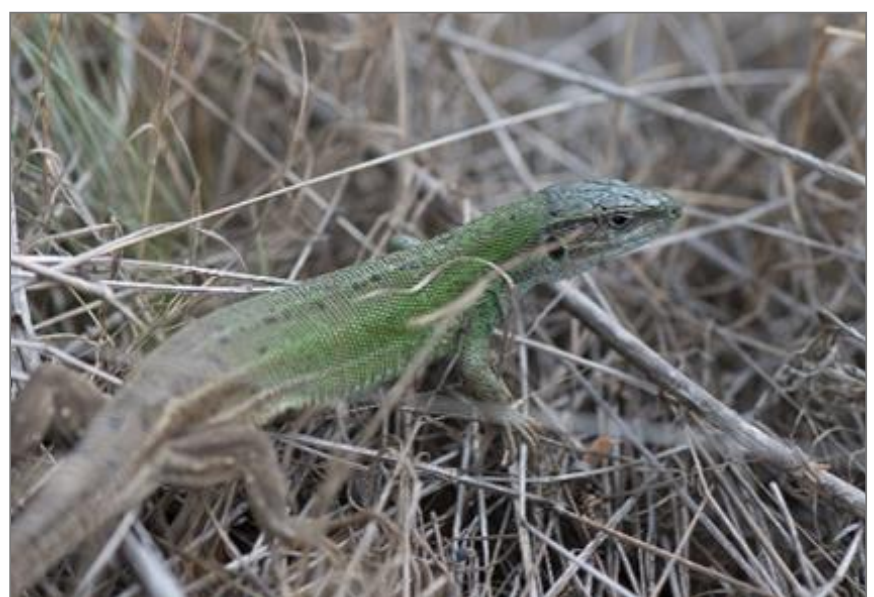

Caucasus emerald lizard (Lacerta strigata)

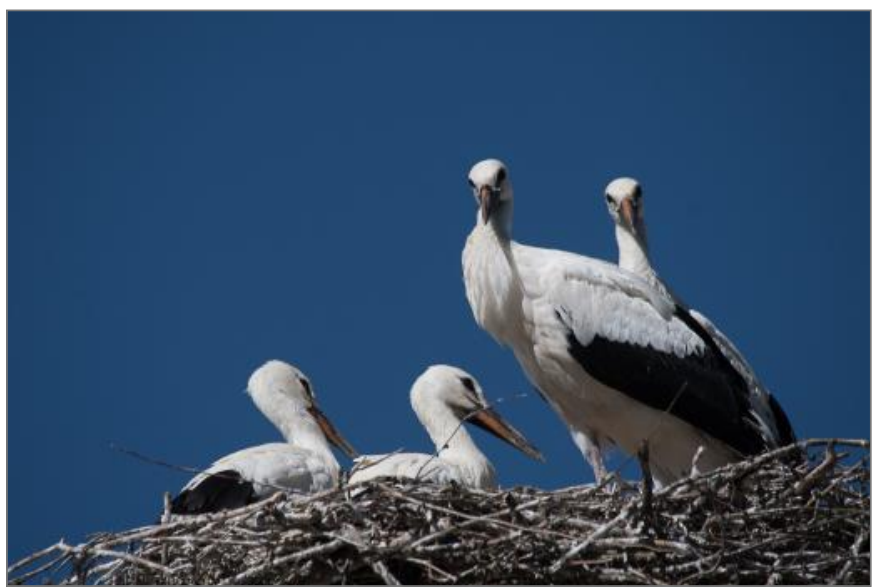

White stork (Ciconia ciconia)

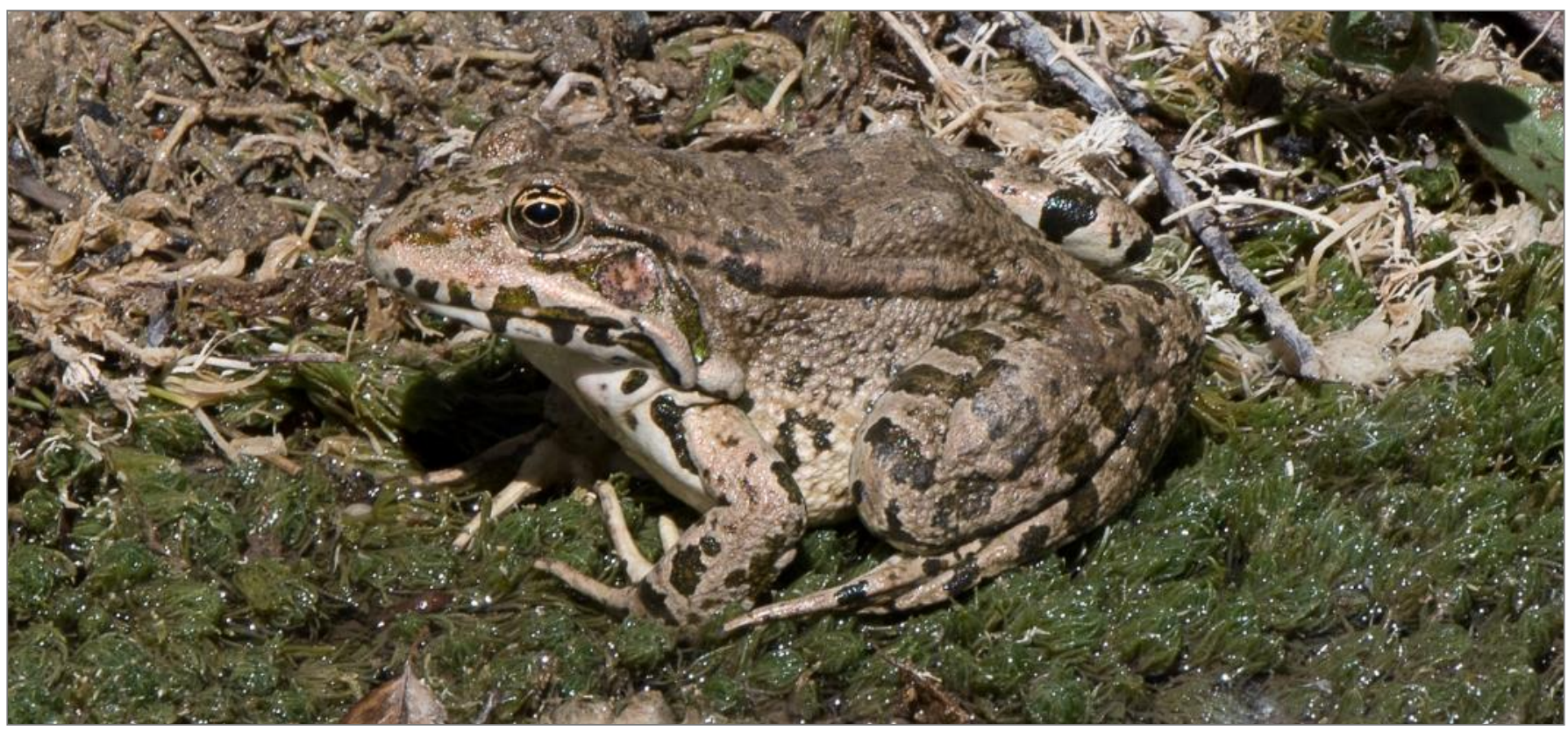




\section{Participants of the $13^{\text {th }}$ EDGG Field Workshop in Armenia}

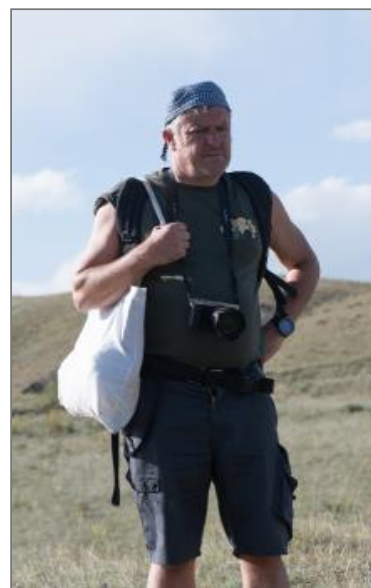

Martin Magnes

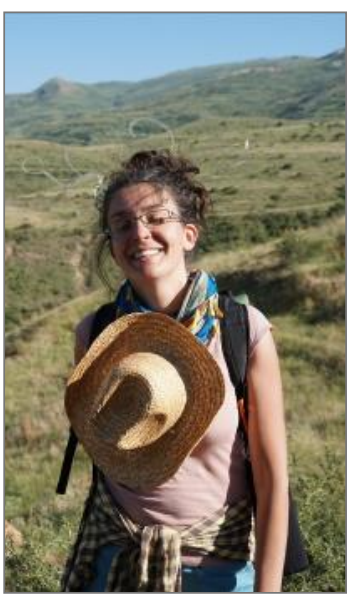

Salza Palpurina

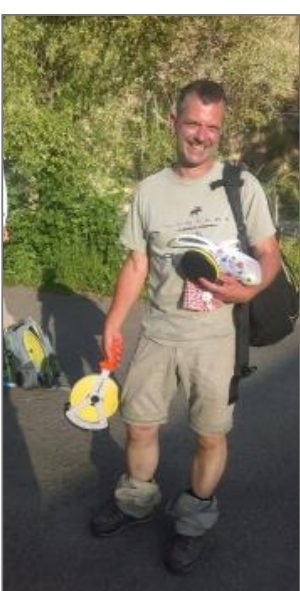

Thomas Becker

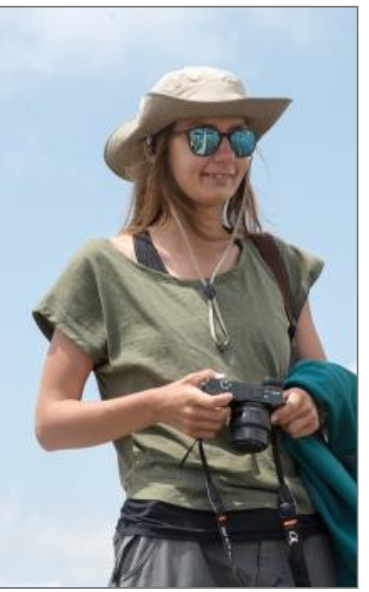

Dariia Shyriaieva

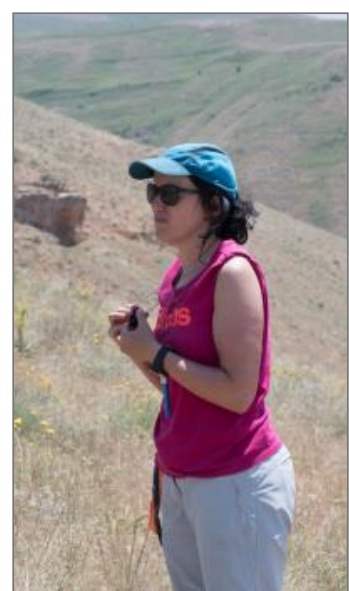

Asun Berastegi

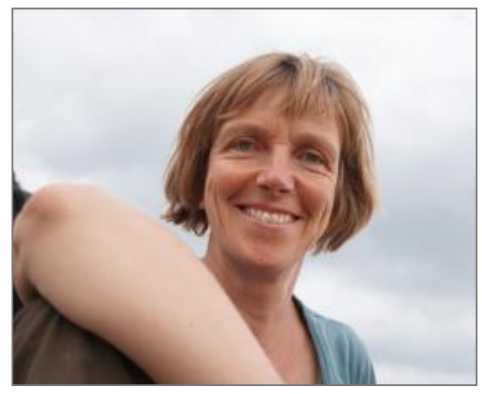

Ute Becker

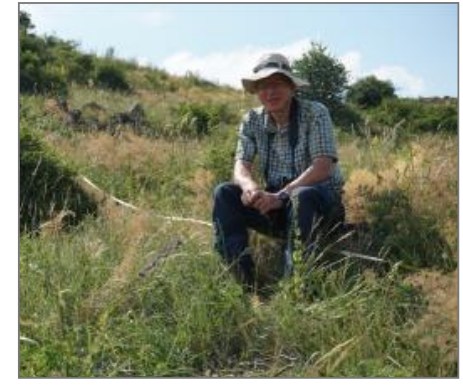

Jürgen Dengler

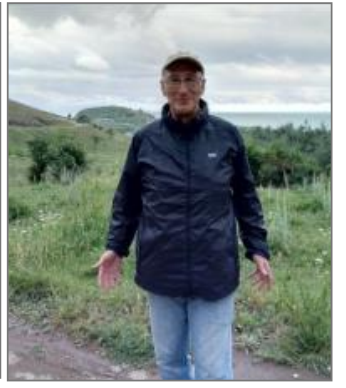

Aslan Unal

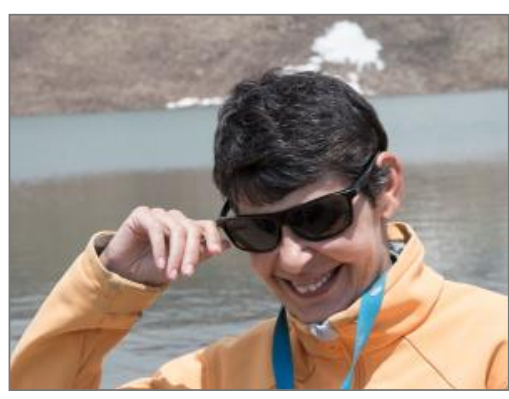

Idoia Biurrun

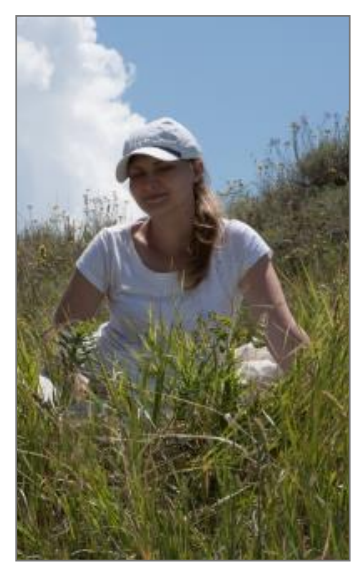

Iuliia Vasheniak

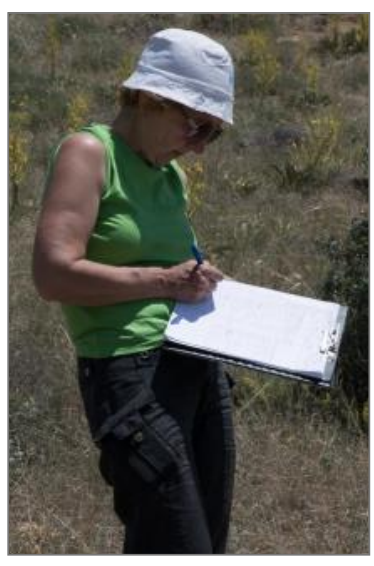

Elena Belonovskaya

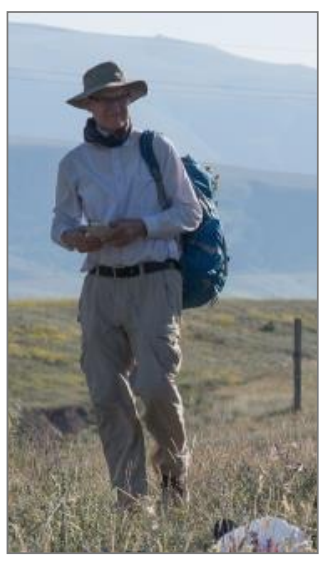

Dieter Frank

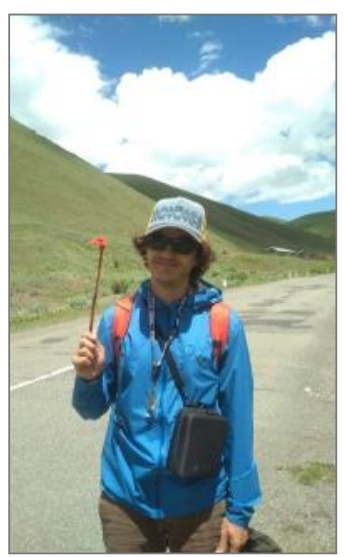

Philipp Kirschner

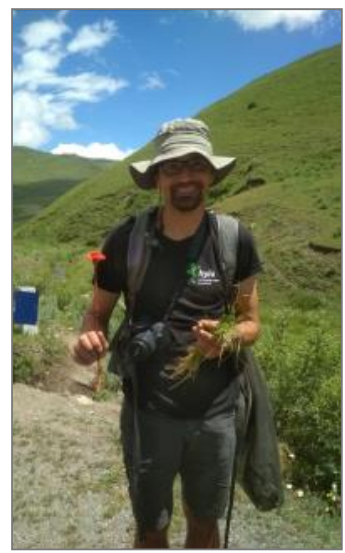

Andreas Hilpold

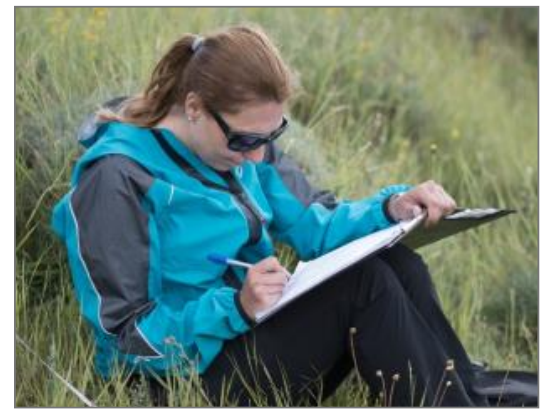

Alla Aleksanyan

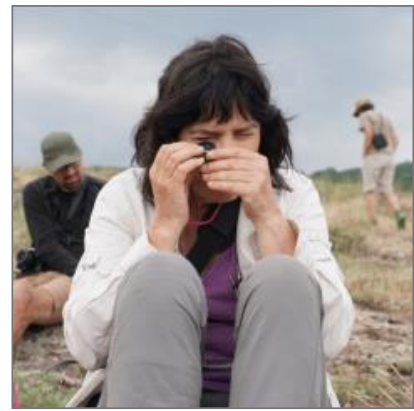

Itziar García-Mijangos

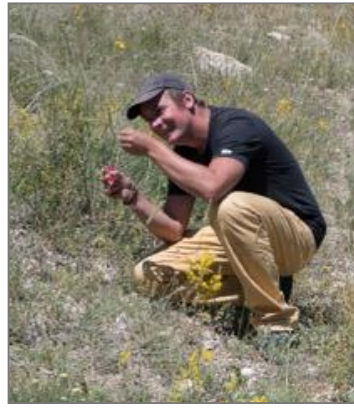

Denys Vynokurov

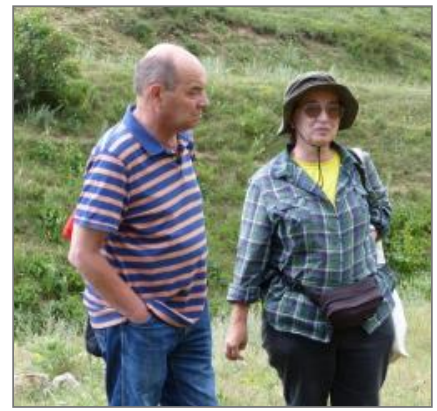

George Fayvush, Marine Oganesian 


\title{
Scientific Report
}

\section{Proposal of a standardized EDGG surveying methodology for orthopteroid insects}

\author{
Andreas Hilpold $^{1 *}$, Philipp Kirschner $^{2}$ \& Jürgen Dengler ${ }^{3,4,5}$
}

\begin{abstract}
${ }^{1}$ Institute for Alpine Environment, Eurac Research, Drususallee/Viale Druso 1, 39100 Bozen/Bolzano, Italy; andreas.hilpold@eurac.edu

${ }^{2}$ Department of Botany, University of Innsbruck, Sternwartestraße 15, 6020 Innsbruck, Austria; philipp.kirschner@gmail.com

${ }^{3}$ Vegetation Ecology, Institute of Natural Resource Sciences (IUNR), Zurich University of Applied Sciences (ZHAW), Grüentalstr. 14, 8820 Wädenswil, Switzerland; juergen.dengler@uni-bayreuth.de
\end{abstract}

\begin{abstract}
${ }^{4}$ Plant Ecology, Bayreuth Center of Ecology and Environmental Research (BayCEER), Universitätsstr. 30, 95447 Bayreuth, Germany

${ }^{5}$ German Centre for Integrative Biodiversity Research (iDiv) Halle-JenaLeipzig, Deutscher Platz 5e, 04103 Leipzig, Germany
\end{abstract}

*) corresponding author

Palaearctic Grasslands 46 (2020): 52-57

Abstract: Orthopteroid insects (Caelifera, Ensifera, Mantodea) are characteristic of grassland ecosystems. They are often key species in grassland food webs, and many species have very specific requirements concerning habitat structure. Thus, orthopteroid insects are valued and widely used indicators in grassland ecology. Here we propose a standardised surveying methodology for orthopteroid insects in EDGG Biodiversity Plots. A variety of methods to survey orthopteroid insects have been used in the past, most of them based on sweep netting along a defined transect. The method proposed here is also based on this principle, but additionally utilises an exhaustive search to capture total species richness and estimate the frequency of the surveyed species. The method can be used in any grassland survey that is based on EDGG Biodiversity Plot and similar sampling designs. It was tested during the EDGG Field Workshop 2019 in Armenia, and has proven its applicability in a wide range of different grassland types.

Keywords: Biodiversity monitoring; bush cricket; EDGG Biodiversity Plot; grasshopper; grassland; mantid; Mantodea; Orthoptera; standardised sampling.

Submitted: 30 May 2020; first decision: 5 June 2020; accepted: 5 June 2020

Scientific Editor: Edy Fantinato

Linguistic Editor: Ashley Lyons

\section{Introduction}

Grasshoppers (Orthoptera: Caelifera), bush crickets (Orthoptera: Ensifera) and mantids (Mantodea), together referred to as "orthopteroid insects" characterise grassland ecosystems like few other arthropod groups. In the Western Palaearctic, grasshoppers occur in all types of grasslands from the salt marshes of the Pannonian depression up to alpine meadows. In most of these ecosystems orthopteroid insects represent the major part of the herbivorous arthropod fauna (Curry 1994) and as such, they play a key role in many grassland food webs (Belovsky \& Slade 2018). Grasshoppers, for example, have a large impact on litter decomposition and nutrient cycling in grasslands and thus can have an effect on plant abundance and plant species composition (Belovsky \& Slade 2000). Most Palaearctic orthopteroid insect species are polyphagous (e.g. grasshoppers are all herbivores) or euryphagous (e.g. bush crickets are often canivorous or omnivorous). Whilst having a generalist diet, many grasshopper and bush cricket species are sensitive to habitat structure and microclimate (Ingrisch \& Köhler 1998; Gardiner \& Dover 2008), which renders them ideal ecological indicators for grassland ecology (Fartmann et al. 2012). Integrating abundance data and species composition has, for example, shown to be useful in assessing succession (e.g. Marini et al. 2009; Fartmann et al. 2012) or disturbance (Bhaskar et al. 2019).

In general, the assessment of orthopteroid insects in biodiversity studies is easy to carry out in comparison to other groups of invertebrates. Orthopteroid insect species can usually be identified in the field by morphological characters and/or species-specific vocalizations (e.g., Coray \& Thorens 2001; Roesti \& Rutschman 2020). Since they have relatively uniform annual cycles, one survey per year is in most cases sufficient to get representative data from a single site.

Here we suggest a survey methodology that can be applied in all kinds of grassland habitats, but may also be suited for 
other kind of open habitats, such as grain fields or vineyards. It is already used in the Biodiversity Monitoring (BDM) South Tyrol, Italy (BMS; https:// biodiversity.eurac.edu). It is based on previous suggestions of Dengler et al. (2016) and Kühnel et al. (2017). It is also particularly suitable in combination with the standardised EDGG multi-scale sampling methodology for vascular plant, bryophyte and lichen diversity (Dengler et al. 2016; 2020). It has been successfully applied in the EDGG Field Workshop in Armenia (Aleksanyan et al. 2020).

\section{Survey design}

Most surveys of orthopteroid insects are done via sweep netting along a transect (Gardiner et al. 2005). Box quadrat sampling, a method in which enclosures are placed onto the patch to be surveyed, has also been used. However, in most instances, these methods produce results that are statistically indiscernible (Gardiner \& Hill 2006). The survey method proposed here is designed to match the size of the EDGG Biodiversity Plots (Dengler et al. 2016). This is to account for habitat heterogeneity, and to enable comparability between both survey methods. We suggest to use the diagonal of EDGG Biodiversity Plots as survey transect $\left(=100 \mathrm{~m}^{2}\right.$ plots $=$ $10 \mathrm{~m} \times 10 \mathrm{~m}=14.14 \mathrm{~m}$ diagonal). By doing so, all parame- ters assessed in the standard EDGG vegetation survey, such as vegetation height, cover of different layers, topographic and soil variables as well as plant community composition (for details, see Dengler et al. 2016) can directly be used as covariates when analysing the animal data. This will enable the detection of orthopteroid insect species that have very specific habitat preferences, such as those that occur on locally confined, small patches of open soil (e.g. Oedipoda caerulescens), or those which are mainly found in shrubs or tall tussocks of herbs such as some bush cricket species (e.g. Polysarcus denticauda).

Dengler et al. (2016), based on the first implementation of Orthoptera sampling in EDGG Biodiversity Plots (see Kühnel et al. 2017), suggested sampling grasshoppers and bush crickets by sweep netting along a transect in the $14.14 \mathrm{~m}$ diagonal of the Biodiversity Plot before the botanical survey. However, according to our experience, such short transects are not sufficient to representatively capture the species richness in the surveyed plots (cf. Kühnel et al. 2017). Whilst such short transects can be sufficient to assess the species richness in dense, mesic grassland types with high grasshopper abundances, they fail to do so in grassland types with low vegetation cover. In such cases, we observed that grasshoppers on bare soil easily escape sweep netting. This has

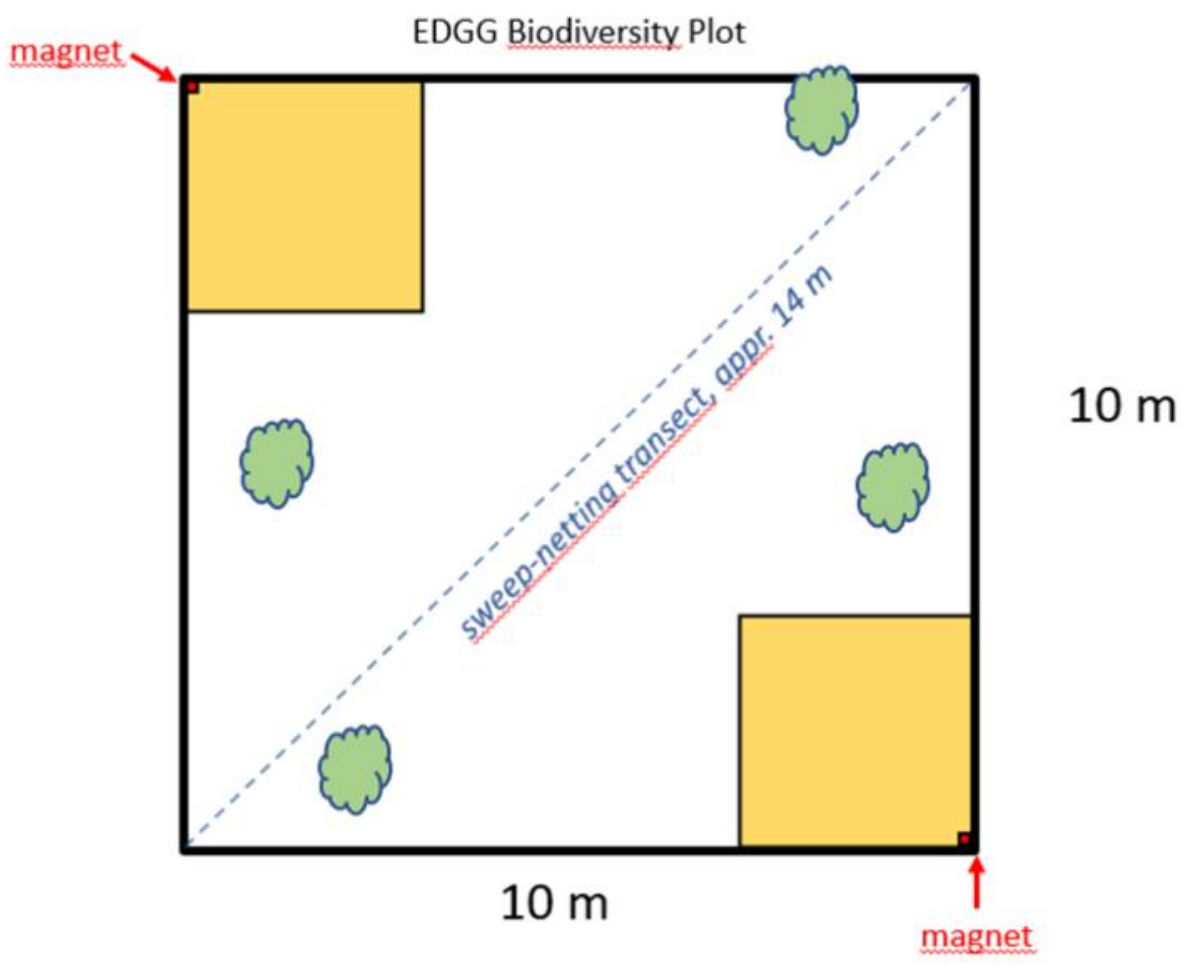

Fig. 1. Scheme for survey of orthopteroid insects. The survey is started by sweep-netting the diagonal transect, follwed by an exhaustive search in the $100 \mathrm{~m}^{2}$ plot. It is important to check shrubs and grass tussocks for Ensifera species and sites with bare ground for certain Caelifera species (e.g. Tetrix spp., Oedipoda spp.). The yellow squares show the $10-\mathrm{m}^{2}$ subplots within the EDGG Biodiversity Plots in which the vegetation surveys are conducted. 
also been shown for other species that tend to dwell e.g. in grass tussocks (Gardiner \& Hill 2006). Whilst selecting a longer transect might be a way to address this problem, such an approach might at the same time render incongruence with the surveyed parameters of the EDGG vegetation plots. Depending on the type of surveyed grassland, increasing the transect length might still be an option. For example, in plots that have a vegetation cover below $50 \%$, a second diagonal could be sampled. Such an approach showed to be efficient in assessing changes in grasshopper community composition in disturbed subtropical grasslands (Bhaskar et al. 2019). Being aware of the advantages and caveats of transect methods, we suggest using a combination of transect sweep netting and exhaustive search as the standardized grasshopper sampling method for EDGG Biodiversity Plots (Fig. 1).

In such an exhaustive search, the grasshopper surveyors should be able to assess the species richness comprehensively within the EDGG biodiversity plot. This should be done via additional sweep net beats and a detailed search by eye within the 100- $\mathrm{m}^{2}$ EDGG biodiversity plot. In an exhaustive search, survey time needs to be standardised, and should, based on our experience, not be longer than 30 minutes. However, it might be shorter, if the surveyor concludes that the grasshopper community of the site is exhaustively assessed (e.g. in sparsely vegetated grassland types). Foremost, this exhaustive search should assure that the full heterogeneity of a plot is assessed, and no species are missed. If there is more than one surveyor, the maximum survey time should be divided by the number of surveyors. Once the species list is complete, a frequency class is assigned to every species (Table 1). The frequency class is based on the number of single animals encountered in the plot. An accurate counting is, especially for abundant species, only possible during the transect survey. An exact counting of individuals within the exhaustive search is prone to double counting and therefore not meaningful.

\section{Phenological issues}

In contrast to many other animal groups, sampling orthopteroid insects is relatively easy. In most cases a single survey in mid-summer, when all species are represented by adult individuals, will be sufficient to assess the full species spec- trum. However, the presence of adults is crucial, as many taxa cannot be determined to species level in their larval stages. Thus, the period in which to survey orthopteroid insects needs to be adapted correspondingly.

In grasslands of the planar to colline belts, the presence of at least some adults can be expected as early as late June or July for most species. In steppe-like grasslands of the montane belt, adults may occur later, i.e. by the end of July (e.g. Chorthippus mollis) (Zuna-Kratky et al. 2017). In subalpine and alpine grasslands, occurrence of adult specimens cannot be expected before the beginning of August. However, a few genera deviate from this pattern: some crickets (e.g. Gryllus campestris) overwinter as subadults and in high summer adults tend to be rare. The same holds true for many groundhoppers (Tetrix spp.), with the ideal sampling period is probably being mid to late July until September. It should be noted that Gryllus and Tetrix can often be identified as larvae, which means that a survey in mid or late summer should cover all grasshopper species.

As emphasized, a single survey between July and September might be sufficient to assess species richness and abundance of orthopteroid insects. However, EDGG grassland plots are frequently surveyed earlier (e.g. June or early July for steppe-like grasslands, May to Mid-July for hay meadows). If a postponement of the vegetation survey to a later period of the year is not possible (due to phenological reasons), we recommend splitting the surveys according to an appropriate time. In such a case, an exact localization of the plots in course of the vegetation survey is crucial. Thus, we recommend locating the plot with GPS coordinates and additionally, if compatible with the management of the habitat, also with additional signals (e.g. colour signs or sticks) or magnets buried in the soil. In the BDM South Tyrol, the survey of vascular plants and grasshoppers are mostly conducted separately; vegetation survey is conducted from April to August, grasshopper survey from the end of July until the beginning of September.

For expeditions, where a splitting of survey periods is not feasible, we suggest organising the vegetation surveys as late as possible. For alpine habitats for example, a vegetation survey in August is still possible. In Mediterranean habitats, grasshopper phenology is even quicker, and a vegeta-

Table 1: Frequency classes used in the sampling.

\begin{tabular}{ll}
\hline Class & Criteria \\
\hline I & $\begin{array}{l}1 \text { individual. In addition there should be no sign of more individuals of the same species outside of the } \\
\text { plot. } \\
\text { II }\end{array}$ \\
& them individuals in the plot; if you have only one individual in the plot, but you have observed more of \\
III & $6-10$ individuals \\
IV & $11-20$ individuals \\
V & $21-50$ individuals \\
VI & More than 50 individuals \\
\hline
\end{tabular}


tion survey in June, when both grasshoppers and plants are in a stage that allows identification, will be possible without missing a significant number of species. This was confirmed by our experiences during the EDGG Field Workshop in Armenia 2019 (Aleksanyan et al. 2020): In the end of June and in the beginning of July, most species were present with at least some adult individuals that allowed an identification to species level. Of course, in some cases a determination to the species level within every genus was not possible, e.g. Platycleis. However, the option for a delayed joint vegetation survey in favour of a more complete orthopteroid sampling also depends on the type of vegetation surveyed. In annual-dominated grasslands, for example, a late vegetation survey would likely miss a significant number of plant species.

\section{Additional data}

Data from pitfall traps or casual findings can be used to complement species lists. However, we emphasize that the suggested survey methodology is superior to other methods in representatively capturing the species richness of orthopteroid insects. In course of the BDM South Tyrol, findings from sweep-net surveying and from pitfall traps were compared. In most cases, pitfall traps only captured a fraction of the species richness observed via direct surveys. Inversely, in a few cases pitfall traps captured species that were missing in the direct survey data (pers. observation A. Hilpold)

\section{The proposed method at a glance}

\section{General considerations}

- The grasshopper survey includes grasshoppers and locusts (Caelifera), bush crickets and related groups (Ensifera) and mantids (Mantodea).

- The weather conditions are important for a successful survey of orthopteroid insects since most orthoptera species avoid singing at low temperatures. Preferably, surveys should be conducted between 9 a.m. and 5 p.m. However, this is highly dependent on the local climatic conditions and the surveyor has to decide from case to case if a survey is meaningful or not.

- The survey starts with sweep-netting along a transect that is marked by the diagonal of the Biodiversity plot. If the botanical survey is being conducted at the same time, the diagonal that does not include the two $10-\mathrm{m}^{2}$ vegetation plots that should be surveyed. If this is not the case, directionality is not relevant. The transect must be walked at a slow pace (approximately $2 \mathrm{~km} / \mathrm{h}$ ). Sweeping height depends on the height of the vegetation: where vegetation is low sweeping must be done directly at the ground surface; where vegetation is high (e.g. in mesic hay meadows) sweeping is done in the upper part of the vegetation layer.

- If only small $10 \mathrm{~m}^{2}$ vegetation plots are surveyed, orthopteroid sampling might still be conducted. In such a case, the orthopteroid survey should be conducted using the extent of a biodiversity plot, using one corner of the small plot as a starting point for the sweep-net transect. In this case it is important to document transect directionality to ensure reproducibility.

- Ideally, the grasshopper survey should be conducted before the vegetation survey of the $10-\mathrm{m}^{2}$-plots or the $100 \mathrm{~m}^{2}$-plots to prevent some species being chased away. In our experience, this effect was negligible for small and less mobile grasshoppers, but problematic for larger species with good flying ability. Alternatively, the grasshopper survey may be postponed until after the vegetation survey is completed.

- Juveniles caught in the sweep net should also be checked as those of many genera (e.g. Mantis, Gryllus, Oecanthus or Pyrgomorpha) can be identified already at an early stage.

\section{Step 1: Transect}

- Count every individual caught in the net. By opening the net a small cleft you can catch adult individuals first. Once the adult individuals are assessed they can be released or, if identification is doubtful, should be collected and preserved for later identification.

- Count juvenile individuals. If juveniles are very abundant all caught individuals could be transferred to some sort of transparent container that makes counting easier (after having removed the adults).

- Always note the most accurate taxonomic level that can be distinguished. Many groups can be identified in the larval phase, e.g. Calliptamus spp. If you cannot recognise the genus, note the family or sub-family. This could enable species assignment at a later stage after additional specimens have been caught or after examining material collected from the respective site.

\section{Step 2: Exhaustive search}

- $\quad$ Start with an acoustic assessment. Some species groups are much easier to distinguish by their songs than by their morphology (e.g. Chorthippus biguttulus group). The acoustic survey helps to find elusive taxa. Some bush-dwelling Ensifera are cryptic and very mobile and it is hardly possible to detect them with methods other than by song. If you are not familiar with the songs of each species (e.g. in expeditions), a mobile sound device (cell phone) is very helpful and helps to memorise the song (e.g., Roesti \& Rutschmann 2020, for Central European Orthoptera).

- Carefully check patches with bare ground as certain species prefer this microhabitat type, e.g. Oedipoda spp., Tetrix spp.

- Check single shrubs or large herbs and grass tussocks for Ensifera and mantids. 
- Carefully check small patches of short vegetation in the plot, as additional species might be restricted to such patches (e.g. Omocestus haemorrhoidalis, O. petraeus).

- Take no more than 30 minutes and divide this time by the surveyors present (e.g. two surveyors have 15 minutes each).

\section{Step 3: Assigning frequency classes}

- The frequency classes in Table 1 refer to adult and subadult individuals. If specimens are observed in an early larval stage that cannot be identified, it is recommended to assess their frequency class anyway, and on an as accurate taxonomic level as possible (e.g. Acrididae juvenil = IV). Such information could be informative in later analyses, if, for example, total orthopteroid frequencies between plots are compared.

\section{Conclusions and outlook}

With our proposal, we refine a previous proposal for standardized sampling of orthoptera species in EDGG Biodiversity Plots (Dengler et al. 2016; Kühnel et al. 2017). The method has proven to be suited for a wide range of grassland types, is fast and efficient and typically can be conducted during an EDGG Field Workshop or similar sampling campaigns on the same day as the vegetation sampling, thus making it logistically more feasible in remote areas. When the vegetation sampling is phenologically too early, plots need to be marked (nowadays EDGG Biodiversity Plots are marked with magnets by default) to allow for a later survey of orthopteroid species. Since EDGG Biodiversity Plots and EDGG Field Workshops are specifically aimed at standardised multitaxon sampling for analyses of cross-taxon patterns and drivers of biodiversity, adding orthopteroid insects as fourth group next to vascular plants, bryophytes and lichens (Dengler et al. 2016) would be particularly valuable. This adds to previous attempts to integrate spider (Polchaninova et al. 2018) and leafhopper sampling (Filibeck et al. 2018) in a standardised way to the EDGG Biodiversity Plots, which allowed many comparative studies of biodiversity patterns and drivers between vascular plants, bryophytes and lichens (e.g. Kuzemko et al. 2016; Dengler et al. 2020). The joint analysis of multiple taxonomic groups from various trophic levels can be particularly insightful (Zulka et al. 2014).

However, the proposed method is not restricted to be used in conjunction with the EDGG sampling methodology for plant diversity in grassland vegetation, but it can be viewed as an efficient method that is universally applicable in standardised surveys and monitoring of biodiversty. In South Tyrol, the methodology is used for all assessed terrestrial habitats except for urban habitats and lake shores, where transect surveys are applied. In the case of forest sites the plot size is enlarged by a factor of 10. Results of the grasshopper survey of the first BMS field season in 2019 are in favour of the method's efficacy in capturing species diversity: $58 \%$ of known grasshopper diversity of South Tyrol could be captured after surveying 56 Biodiversity Plots that are distribut- ed evenly over the region and represent most of the region's habitats (Hilpold et al. 2020).

\section{Author contributions}

J.D. had the idea of conducting standardised Orthoptera sampling on EDGG Biodiversity Plots and tested it with a student class. A.H. and P.K. implemented and refined the method during the EDGG Field Workshop in Armenia and in the South Tyrolean biodiversity monitoring. A.H. and P.K. led the writing of the article, while J.D. made smaller contributions.

\section{Acknowledgements}

We thank Edy Fantinato and Julia Seeber for valuable comments on an earlier version of this manuscript which improved the manuscript substantially.

\section{References}

Aleksanyan, A., Biurrun, I. ,Belonovskaya, E., Cykowska-Marzencka, B., Berastegi, A., Hilpold, A., Kirschner, P., Mayrhofer, H., Shyriaieva, D., (...) \& Dengler, J. 2020. Biodiversity of dry grasslands in Armenia: First results from the 13th EDGG Field Workshop in Armenia. Palaearctic Grasslands 46: 12-51.

Belovsky, G.E. \& Slade, J.B. 2018. Grasshoppers affect grassland ecosystem functioning: Spatial and temporal variation. Basic and Applied Ecology 26: 24-34.

Belovsky, G.E. \& Slade, J.B. 2000. Insect herbivory accelerates nutrient cycling and increases plant production. Proceedings of the National Academy of Sciences of the USA 97: 14412-14417.

Bhaskar, D., Easa, P.S., Sreejith, K.A., Skejo, J. \& Hochkirch, A. 2019. Large scale burning for a threatened ungulate in a biodiversity hotspot is detrimental for grasshoppers (Orthoptera: Caelifera). Biodiversity and Conservation 28: 3221-3237.

Coray, A. \& Thorens, P. 2001. Heuschrecken der Schweiz: Bestimmungsschlüssel / Orthoptères de Suisse: clé de détermination / Ortotteri della Svizzera: chiave di determinazione [Fauna Helvetica 5]. Centre Suisse de Cartographie de la Faune [Fauna Helvetica], Neuchâtel, $\mathrm{CH}$.

Curry, J.P. 1994. Grassland invertebrates: ecology, influence on soil fertility and effects on plant growth. Chapman and Hall, London, UK.

Dengler, J., Boch, S., Filibeck, G., Chiarucci, A., Dembicz, I., Guarino, R., Henneberg, B., Janišová, M., Marcenò, C., (...) \& Biurrun, I. 2016. Assessing plant diversity and composition in grasslands across spatial scales: the standardised EDGG sampling methodology. Bulletin of the Eurasian Grassland Group 32: 13-30.

Dengler, J., Matthews, T.J., Steinbauer, M.J., Wolfrum, S., Boch, S., Chiarucci, A., Conradi, T., Dembicz, I., Marcenò, C., (...) \& Biurrun, I. 2020. Species-area relationships in continuous vegetation: Evidence from Palaearctic grasslands. Journal of Biogeography 60: 72-86.

Fartmann, T., Krämer, B., Stelzner, F. \& Poniatowski, D. 2012. Orthoptera as ecological indicators for succession in steppe grassland. Ecological Indicators 20: 337-344.

Filibeck, G., Cancellieri, L., Sperandii, M.G., Belonovskaya, E., Sobolev, N., Tsarevskaya, N., Becker, T., Berastegi, A., Bückle, C., (...) \& Biurrun, I. 2018. Biodiversity patterns of dry grasslands in the Central Apennines (Italy) along a precipitation gradient: experiences from the 10th EDGG Field Workshop. Bulletin of the Eurasian Grassland Group 36: 25-41. 
Gardiner, T. \& Dover, J. 2008. Is microclimate important for Orthoptera in open landscapes? Journal of Insect Conservation 12: 705-709.

Gardiner, T. \& Hill, J. 2006. A comparison of three sampling techniques used to estimate the population density and assemblage diversity of Orthoptera. Journal of Orthoptera Research 15: 45-51.

Gardiner, T., Hill, J. \& Chesmore, D. 2005. Review of the methods frequently used to estimate the abundance of Orthoptera in grassland ecosystems. Journal of Insect Conservation 9: 151173.

Hilpold, A., Niedrist, G., Rüdisser, J. \& Tappeiner U. 2020. Biodiversity Monitoring South Tyrol. URL: https:// biodiversity.eurac.edu/ [accessed on 3 June 2020].

Ingrisch, S. \& Köhler, G. 1998. Die Heuschrecken Mitteleuropas. Die Neue Brehm-Bücherei, Westarp Wissenschaften, Magdeburg, DE.

Kühnel, F., Henneberg, B., Bender, J. \& Nágl, L. 2017. Erfassung von Heuschrecken (Orthoptera) auf EDGG-Biodiversitätsplots im Nordosten Brandenburg. In: Dengler, J. \& Gansbühler, S. (eds.) Reader zur Uckermark-Geländeübung 2016 (im Modul Angewandte Vegetationsökologie und Naturschutz der Universität Bayreuth), pp. 212-222. Plant Ecology, University of Bayreuth, Bayreuth, DE. DOI: 10.13140/RG.2.2.21631.10408.
Kuzemko, A., Steinbauer, M.J., Becker, T., Didukh, Y.P., Dolnik, C., Jeschke, M., Naqinezhad, A., Ugurlu, E., Vassilev, K. \& Dengler, J. 2016. Patterns and drivers of phytodiversity of steppe grasslands of Central Podolia (Ukraine). Biodiversity and Conservation 25: 2233-2250.

Marini, L., Fontana, P., Battisti, A. \& Gaston K.J. 2009. Response of orthopteran diversity to abandonment of semi-natural meadows. Agriculture, Ecosystems \& Environment 132: 232-236.

Polchaninova, N., García-Mijangos, I., Berastegi, A., Dengler, J. \& Biurrun, I. 2018. New data on the spider fauna (Araneae) of Navarre, Spain: results from the 7th EDGG Field Workshop. Arachnology Letters 56: 17-23.

Roesti, C. \& Rutschmann, F. 2020. Orthoptera.ch. URL: http:// www.orthoptera.ch. [accessed on 3 June 2020]

Zulka, K.P., Abensperg-Traun, M., Milasowszky, N., Bieringer, G., Gereben-Krenn, B.-A., Holzinger, W., Hölzler, G., Rabitsch, W., Reischütz, A., (...) \& Zechmeister, H. 2014. Species richness in dry grassland patches in eastern Austria: a multi-taxon study on the role of local, landscape and habitat quality variables. Agriculture, Ecosystems \& Environment 182: 25-36.

Zuna-Kratky, T., Landmann, A., Illich, I., Zechner, L., Essl, F., Lechner, K., Ortner, A., Weißmair, W. \& Wöss, G. 2017. Die Heuschrecken Österreichs. Biologiezentrum des Oberösterreichischen Landesmuseums, Linz, AT.

\section{Appendix 1: EDGG Protocol for grasshopper survey (Caelifera, Ensifera, Mantodea)}

Leg.:

Date:__ Plot ID EDGG:

Weather conditions

Alternative plot number

Temperature : ${ }^{\circ} \mathrm{C}$

\begin{tabular}{|c|c|c|c|c|c|}
\hline & \multicolumn{5}{|l|}{ TRANSECT $14.14 \mathrm{~m}$} \\
\hline Nr. ${ }^{1}$ & Species/genus/family & \# adult & \# subad. & \# juv. & Freq. class ${ }^{2}$ \\
\hline & & & & & \\
\hline & & & & & \\
\hline & & & & & \\
\hline & & & & & \\
\hline & & & & & \\
\hline & & & & & \\
\hline & & & & & \\
\hline & & & & & \\
\hline & \multicolumn{5}{|c|}{ EXHAUSTIVE SEARCH (only additional species, not found in transect) } \\
\hline & Species/genus/family & Adult y/n & Subad. $y / n$ & Juv. $y / n$ & Freq. class $^{2}$ \\
\hline & & & & & \\
\hline & & & & & \\
\hline & & & & & \\
\hline & & & & & \\
\hline & & & & & \\
\hline & & & & & \\
\hline & & & & & \\
\hline & & & & & \\
\hline
\end{tabular}

${ }^{1}$ Species richness in the plot. Every species should be counted only once. For example, if you have a subadult Platycleis sp. and an adult Platycleis albopunctata, count it only once, unless it is likely that they are two different species.

${ }^{2}$ Frequency classes: I = 1 individual, II = 2-5 ind.; III = 6-10 ind.; IV = 11-20 ind.; V = 21-50 ind.; VI > 50 ind. 


\title{
Photo Story
}

\section{Summer field work in the Pyrenean valleys of Navarra (Western Pyrenees)}

\author{
Photos and text by Asun Berastegi ${ }^{1}$ and Silvia Zabalza ${ }^{2}$
}

\begin{abstract}
${ }^{1}$ Department of Biodiversity, Environmental Management of Navarre, Padre Adoain 219 Bajo, 31015 Pamplona, Spain; aberastg@gan-nik.es.

${ }^{2}$ Agrodiversity Team, Environmental Management of Navarre, Padre Adoain 219 Bajo, 31015 Pamplona, Spain; szabalza@gan-nik.es.
\end{abstract}

During the summer of 2019 a field study was carried out in the Pyrenean valleys of Navarra, with the aim to characterize the High Nature Value (HNV) system of this area. The final objective was to select some specific indicators enabling qualitative monitoring of this HNV system. To achieve this, 30 farms of the area were randomly selected from amongst all the farms that have at least one plot that met specific criteria. The aim was to relate the nature value of each plot with the characteristics of the plot (slope, size, crop, geographic location, planting pattern...), and the nature value of the whole farm with its characteristics (socioeconomic characteristics, size, number of different crops, management, use of inputs...). The nature value of each plot was defined using a specific scoring sheet. More than 130 fields were visited in total. A transect was set up across each field in order to indentify characteristic species of well conserved hay-meadows. The natural elements (edges, trees, ponds...) and human elements (stone walls, stone buildings) were also evaluated. Finally, impacts and bad practices were measured, resulting in negative points in the evaluation of each field. 144 fields were scored, spending between 1 and 2 hours in each field.

Some hay meadows are particularly rich in species. These are usually far from railways, and quite far from the villages. In these fields biodiversity elements have been kept in the field (pollard trees), but also human traditional structures can be seen (stone walls).

Some hay meadows, particularly in the transition to dry grasslands or when small rocky patches are included in the field, are particularly rich in fauna.

Whilst, high variety in the natural elements have been found in some fields. Curiously there is not always an expected relationship between floristic biodiversity in the field and biodiversity elements. Poor meadows or even seeded meadows can harbour some very interesting diversity elements and, afterwards, quite good landscape structure has been maintained.

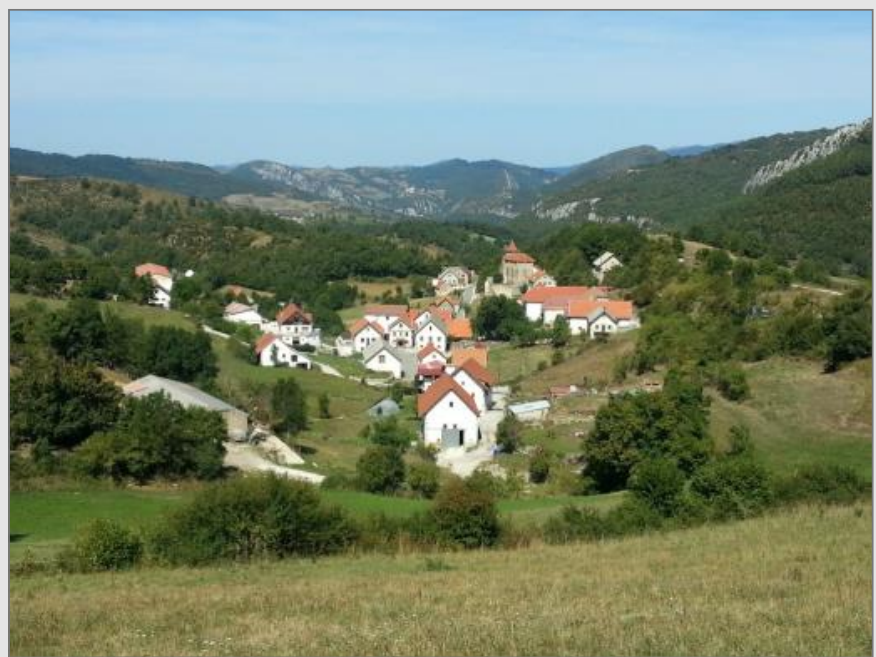

Abaurrepea, in Basque language (Euskera), and Abaurrea baja in Spanish, one of the typical villages of the Pyrenean valleys of Navarra. $855 \mathrm{~m}$ a.s.l. 

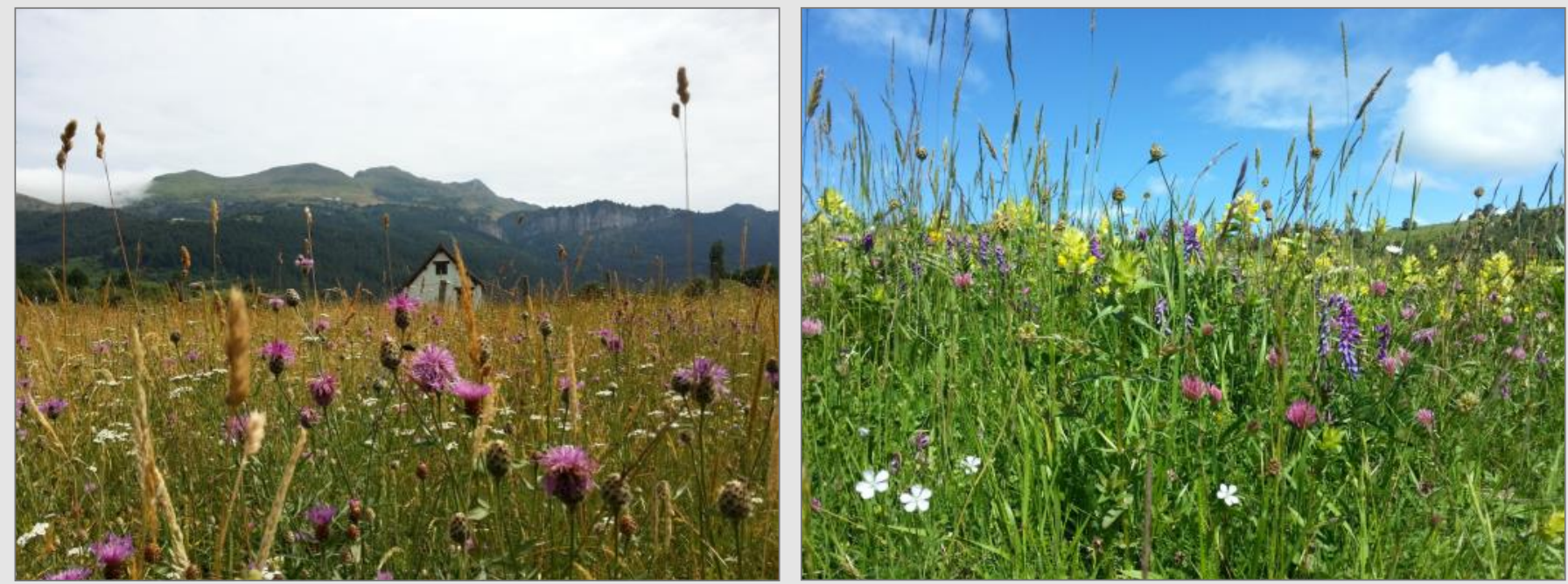

High diversity hay-meadow. 900 m. Isaba.

High diversity hay-meadow. Aintzioa-Erro. 700-800 m a.s.I.

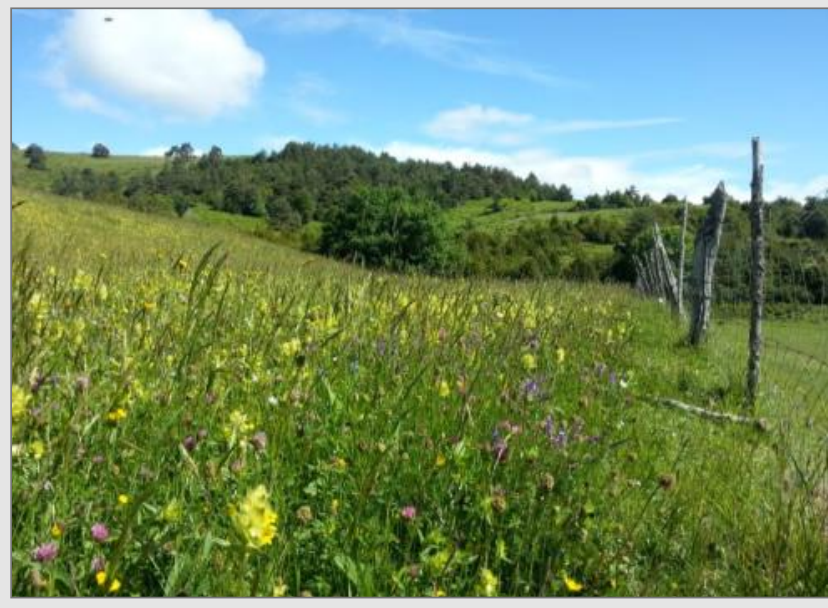

Hay meadows. Aintzioa-Erro.

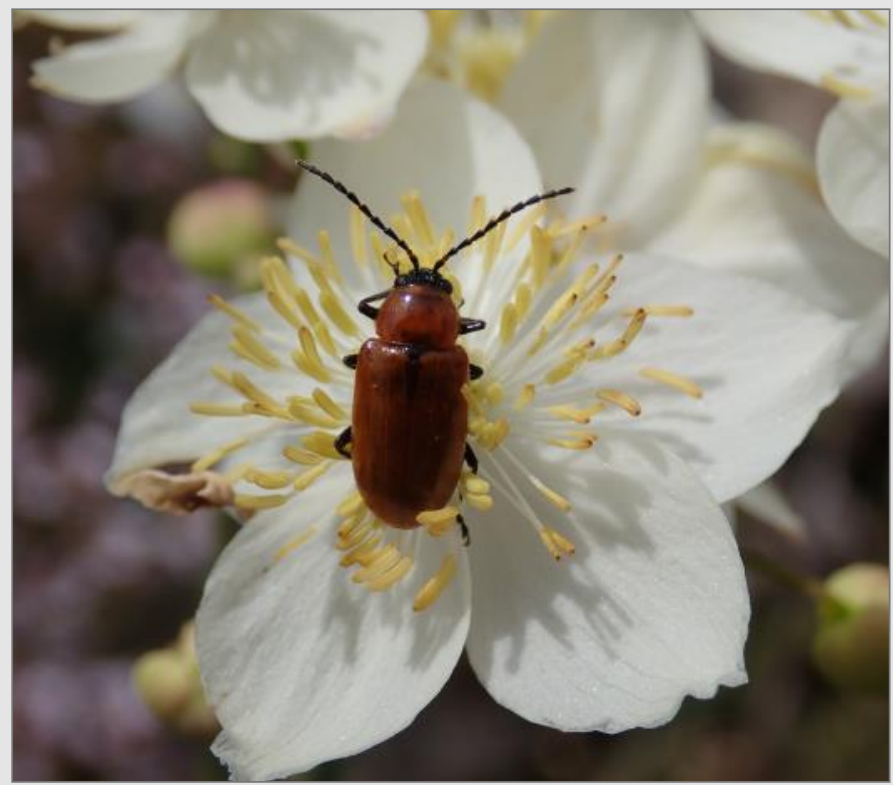

Chrysomelidae beetle.

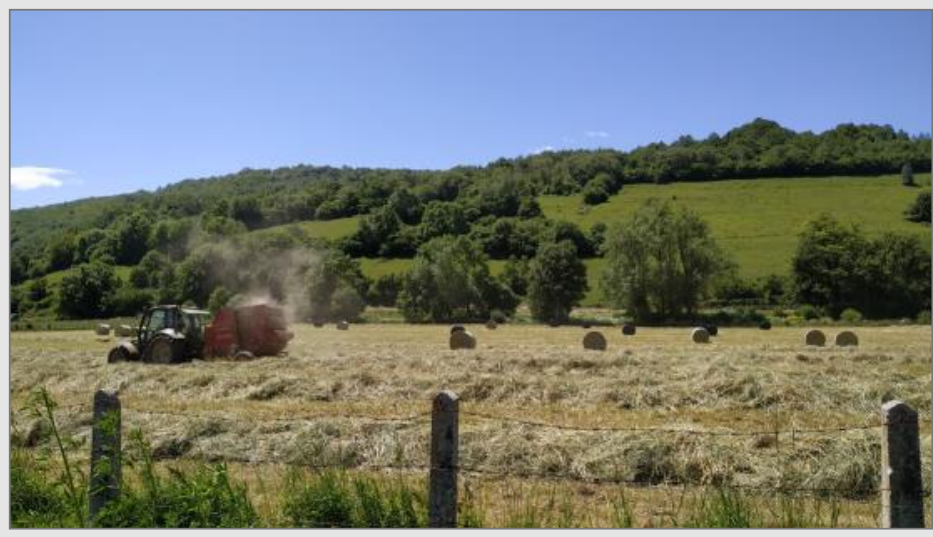

The months of June-July are a very active period for obtaining hay which will be used during winter. Cutting hay meadows near Garralda.

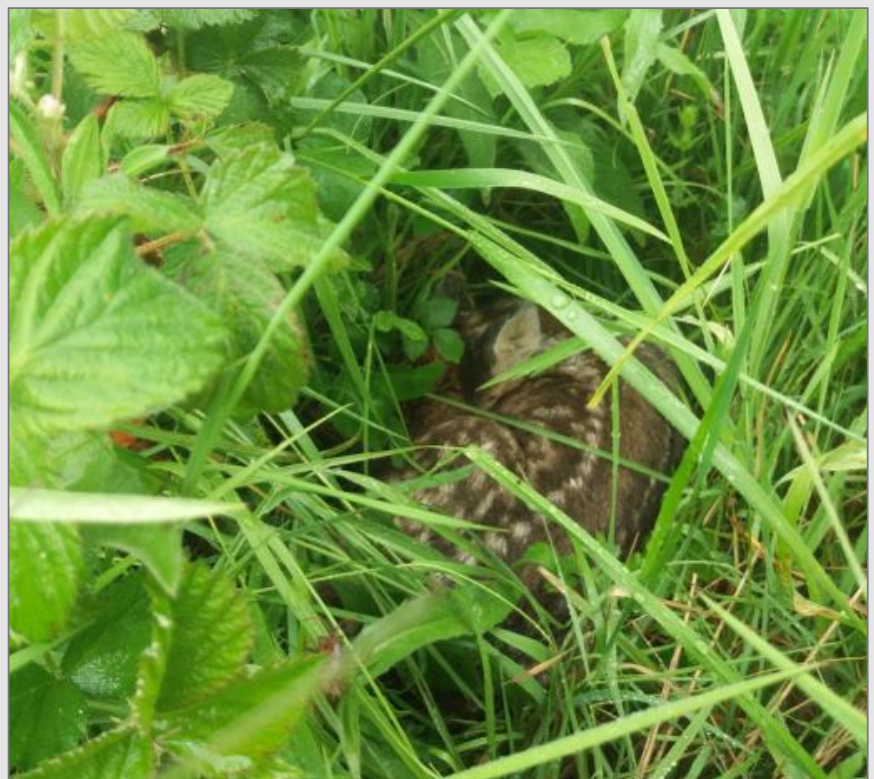

Young roe deer (Capreolus capreolus). 


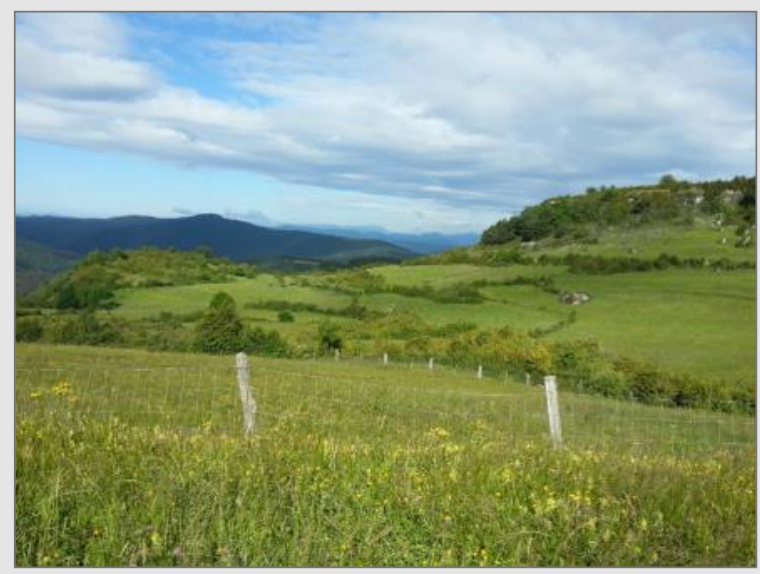

High quality landscape with high diversity in the fields.

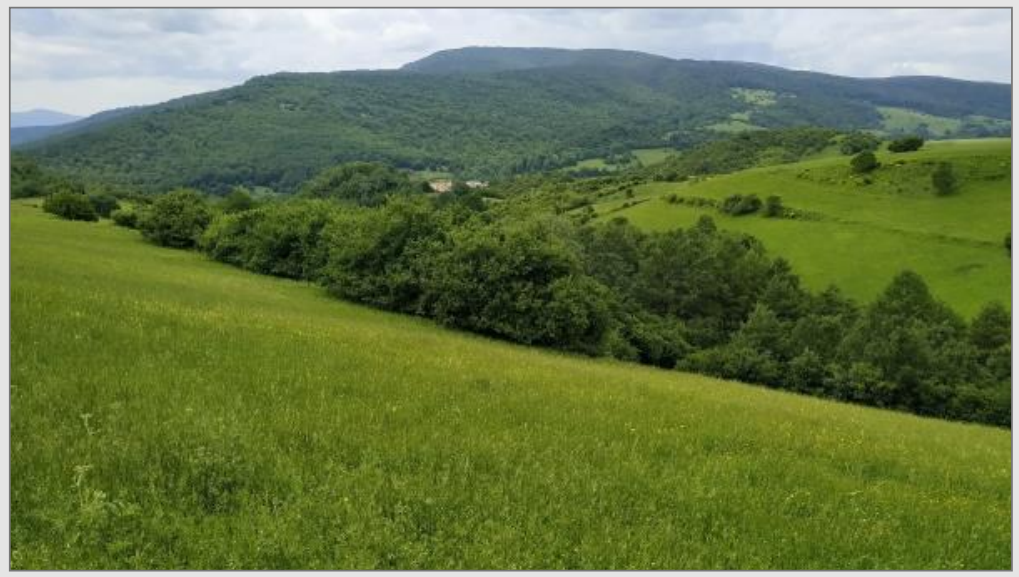

High quality landscape with medium diversity in the fields.
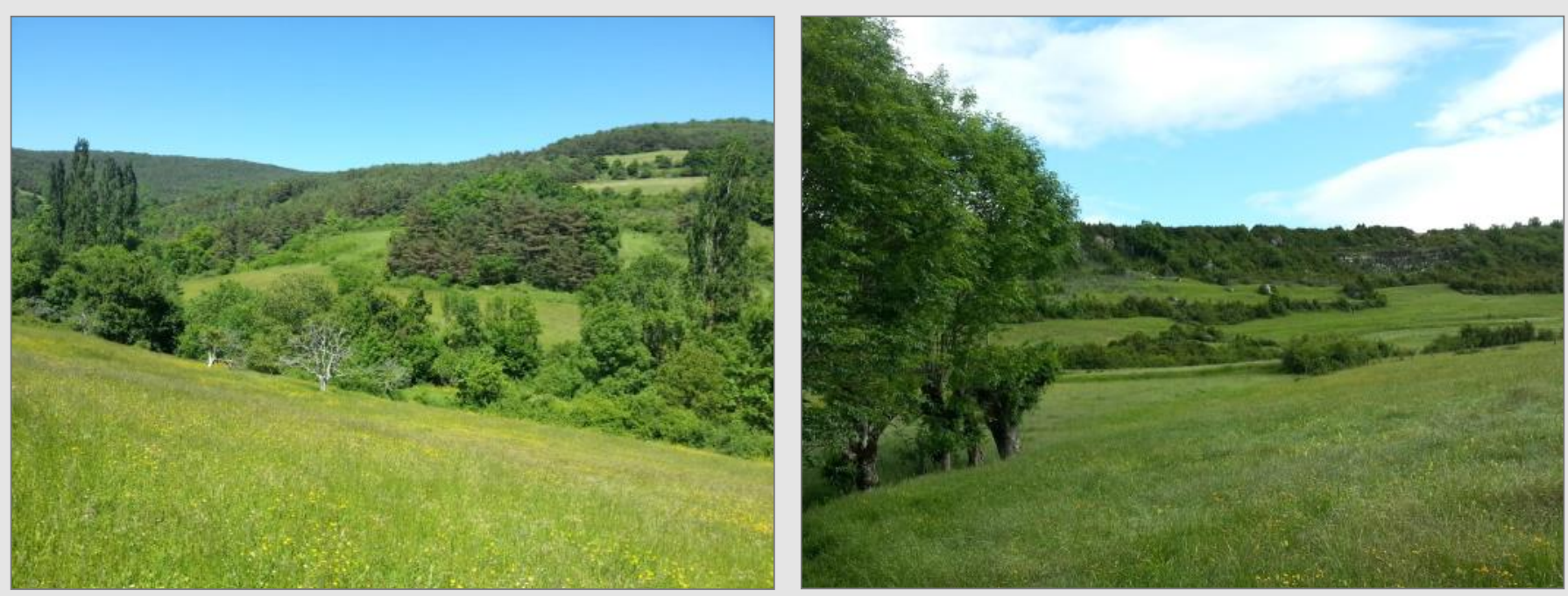

High quality landscapes with high diversity in the fields.

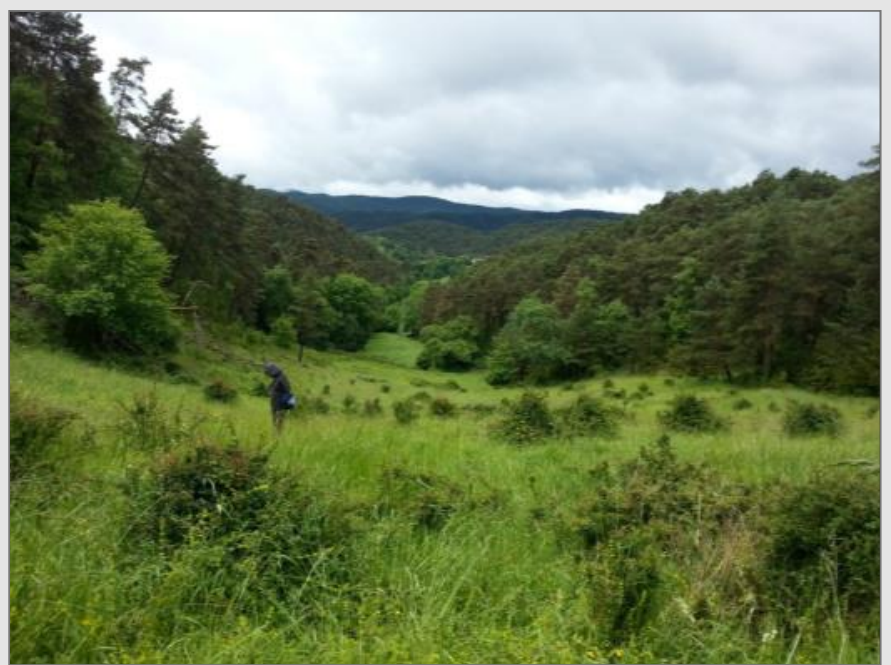

In some areas abandonment is becoming a big problem for the conservation of the hay meadows

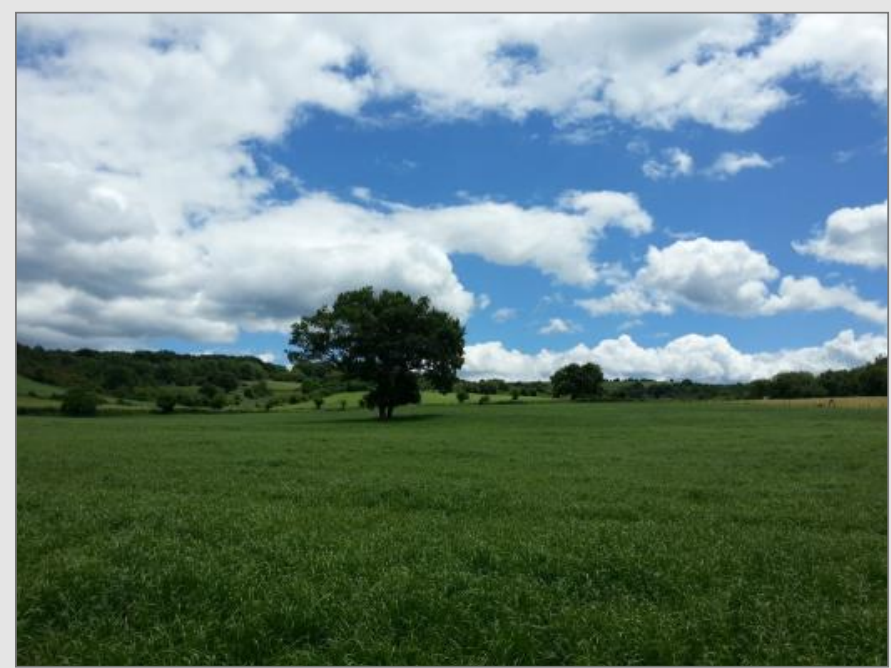

¿High quality landscape? with very poor diversity in the fields. 


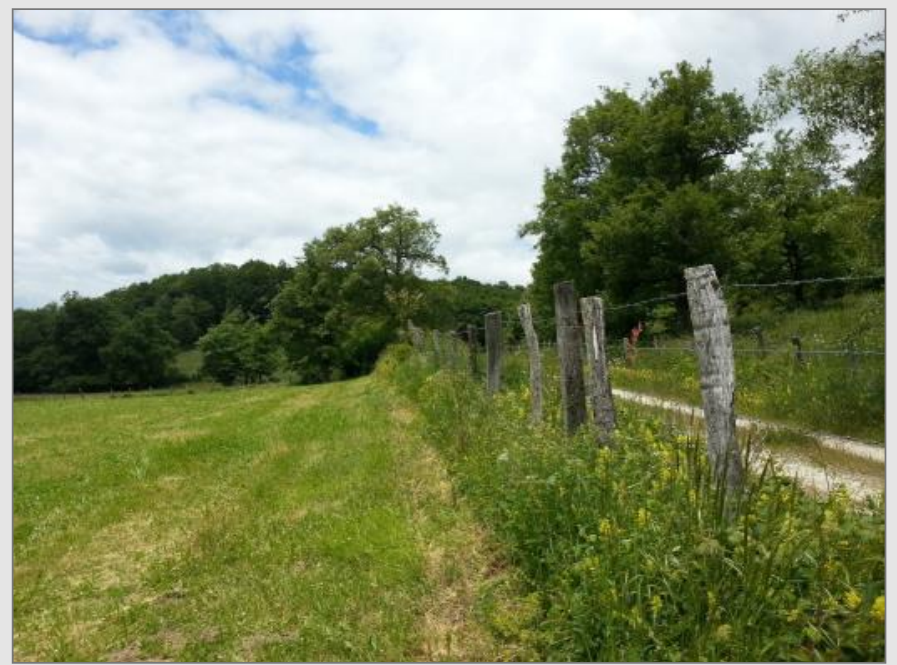

Even in seeded meadows, sometimes very diverse fringes are maintained.

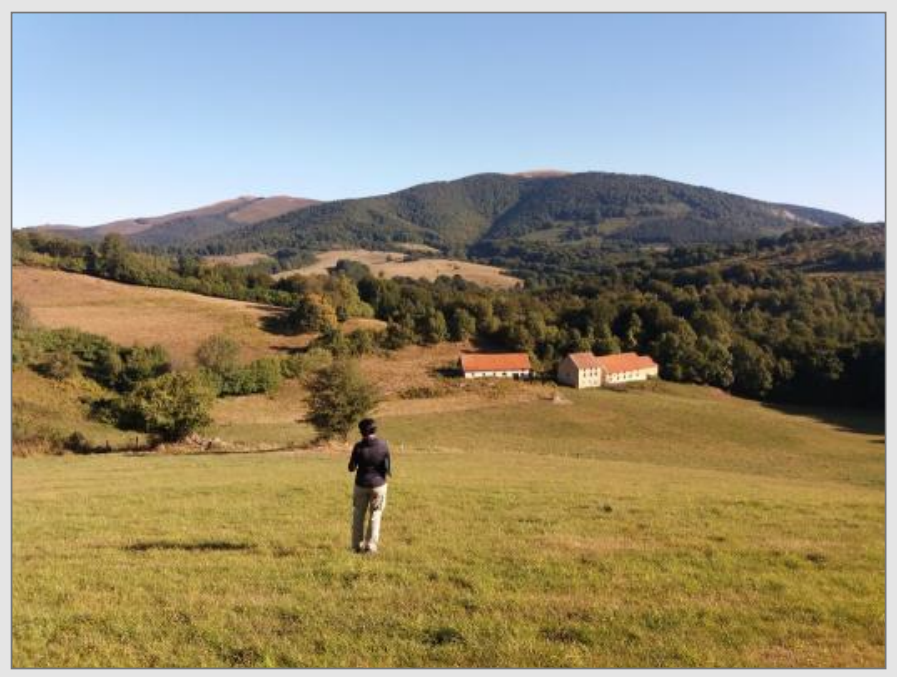

Old houses, sometimes not used anymore.

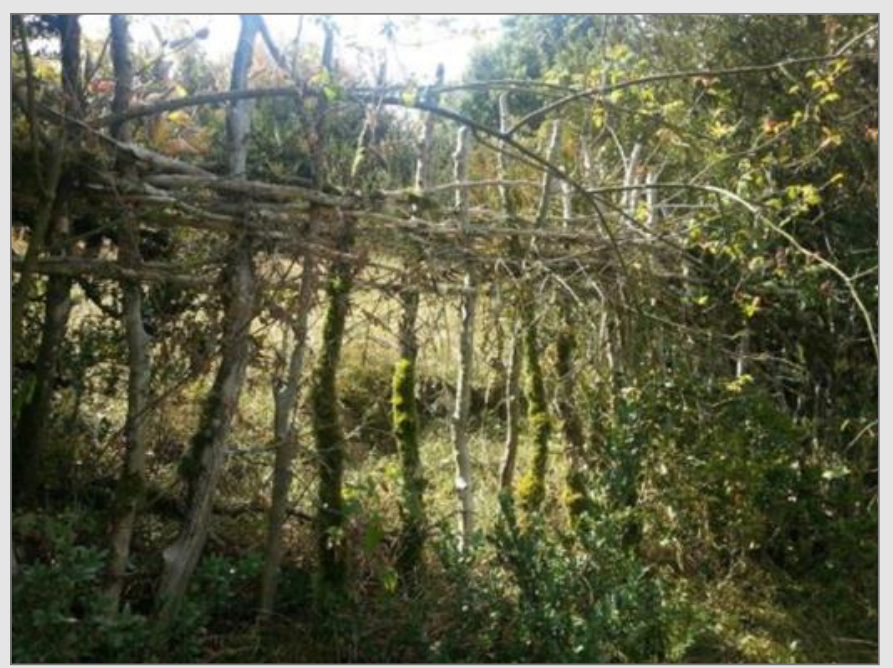

Wicket.

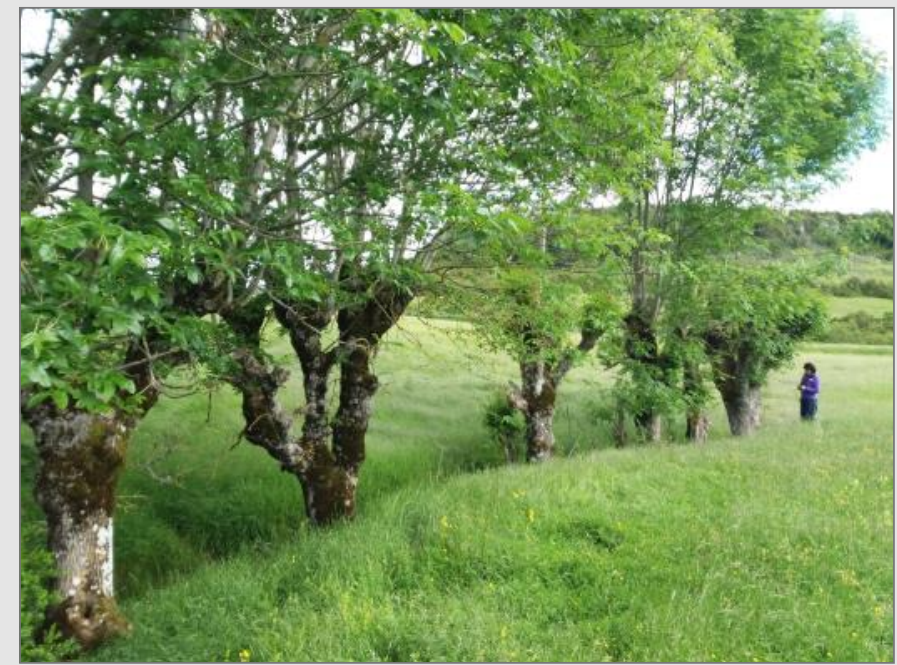

Pollard trees, usually ash tree, are maintained in the border of some hay-meadows.

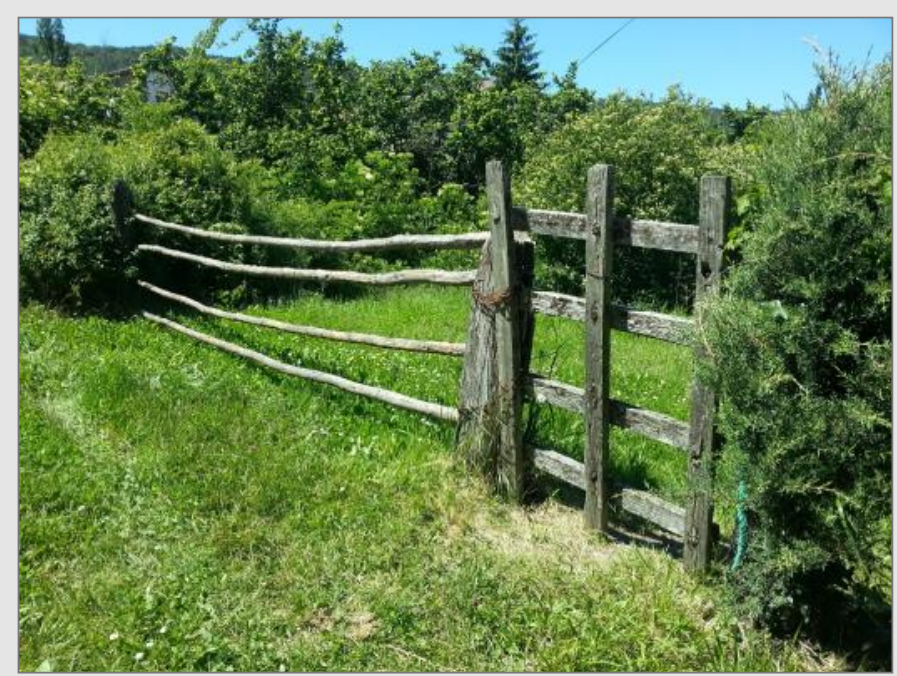

Traditional wicket made of wood.

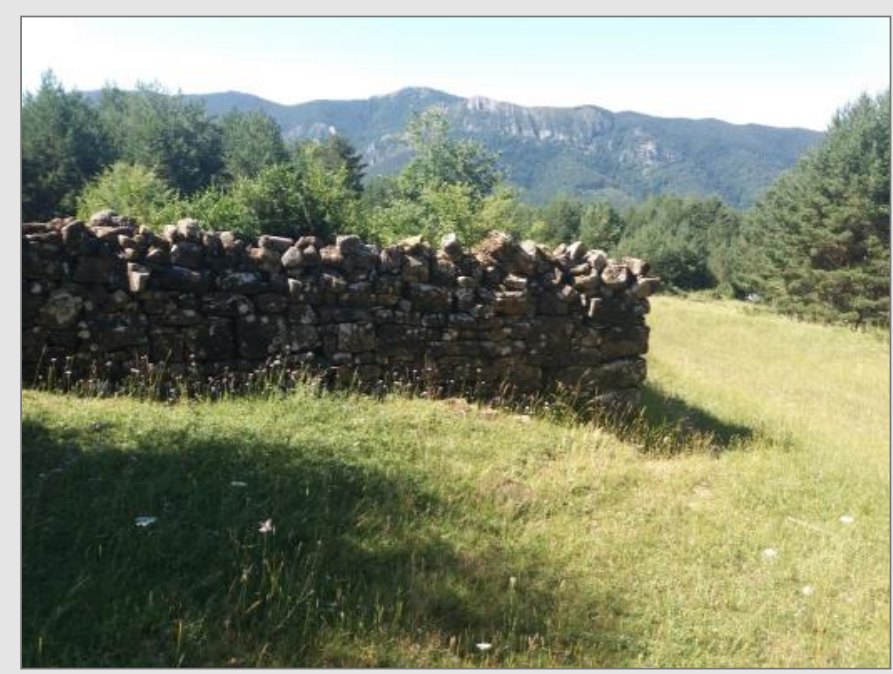

Stone walls are usually covered with vegetation. 

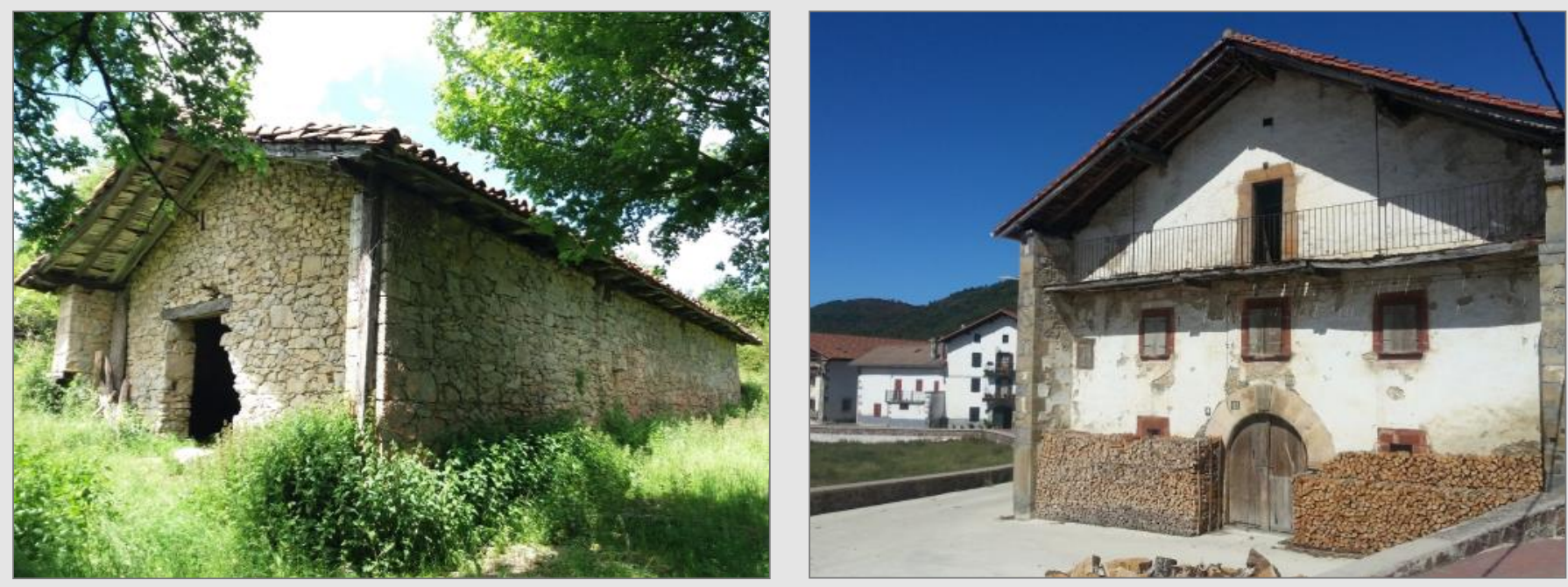

Stone houses.
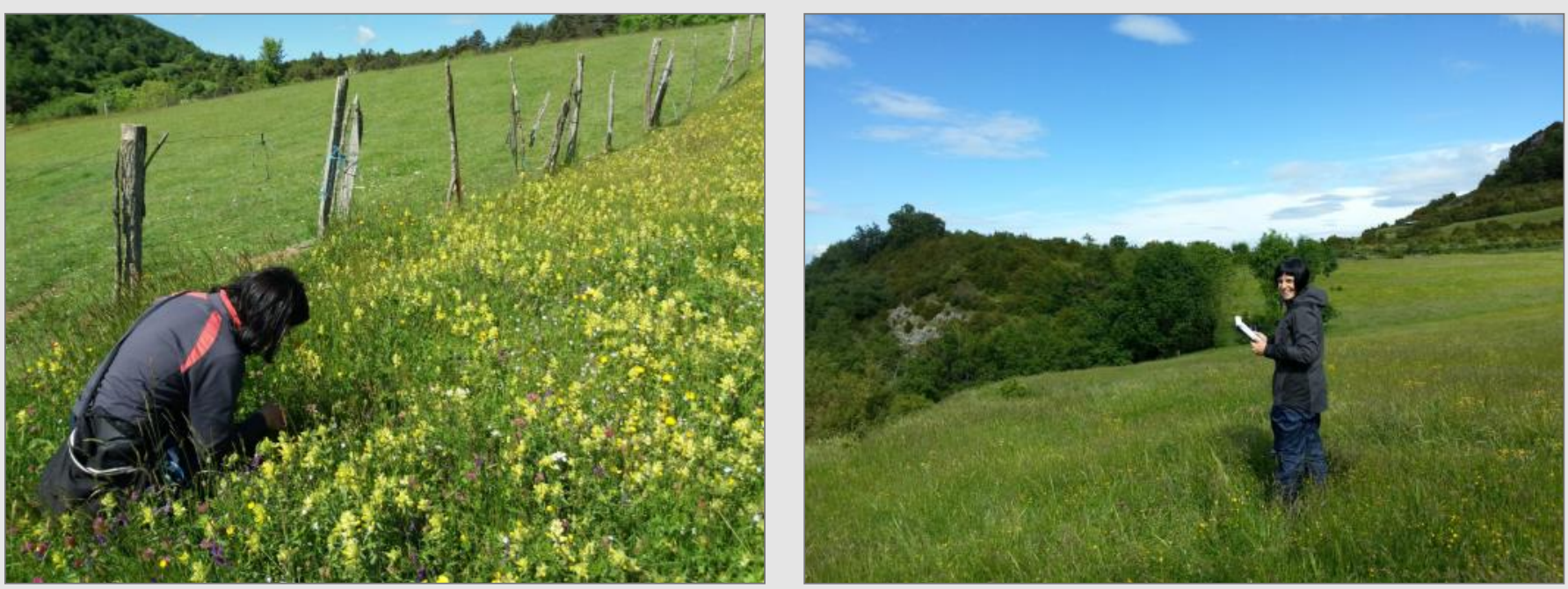

Villages of the area have been losing inhabitants over recent years. Some days, only botanists were seen in the field.
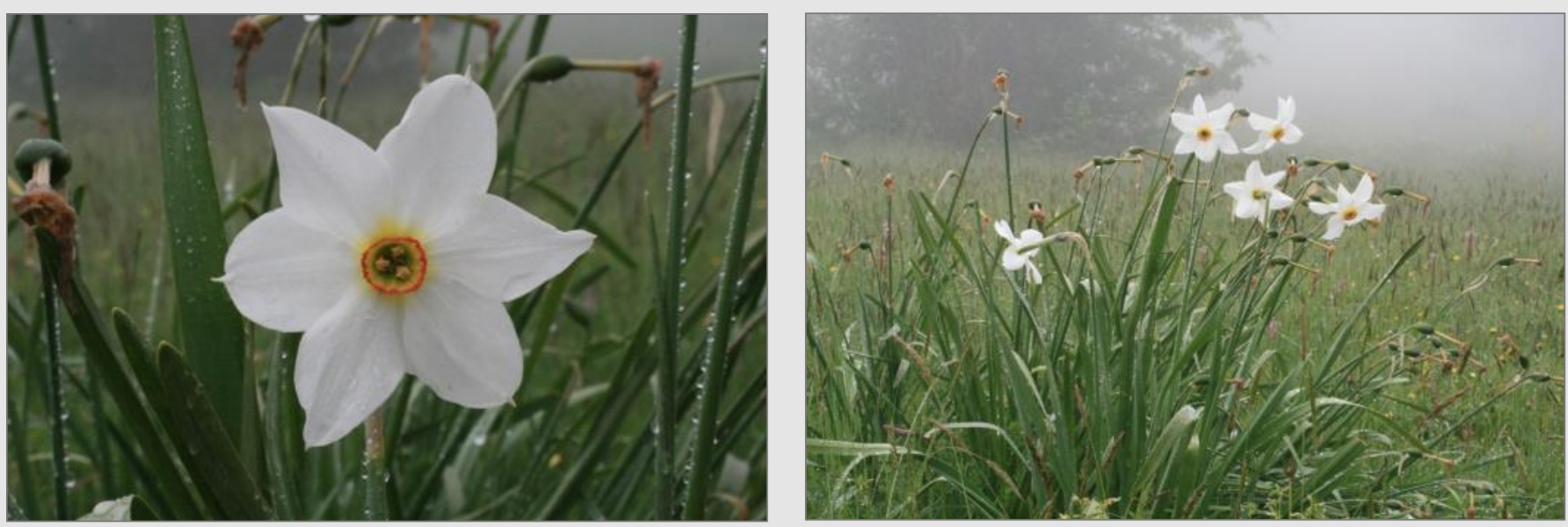

Some endangered plants in Navarra grow in the hay-meadows of the area. Narcissus poeticus. 


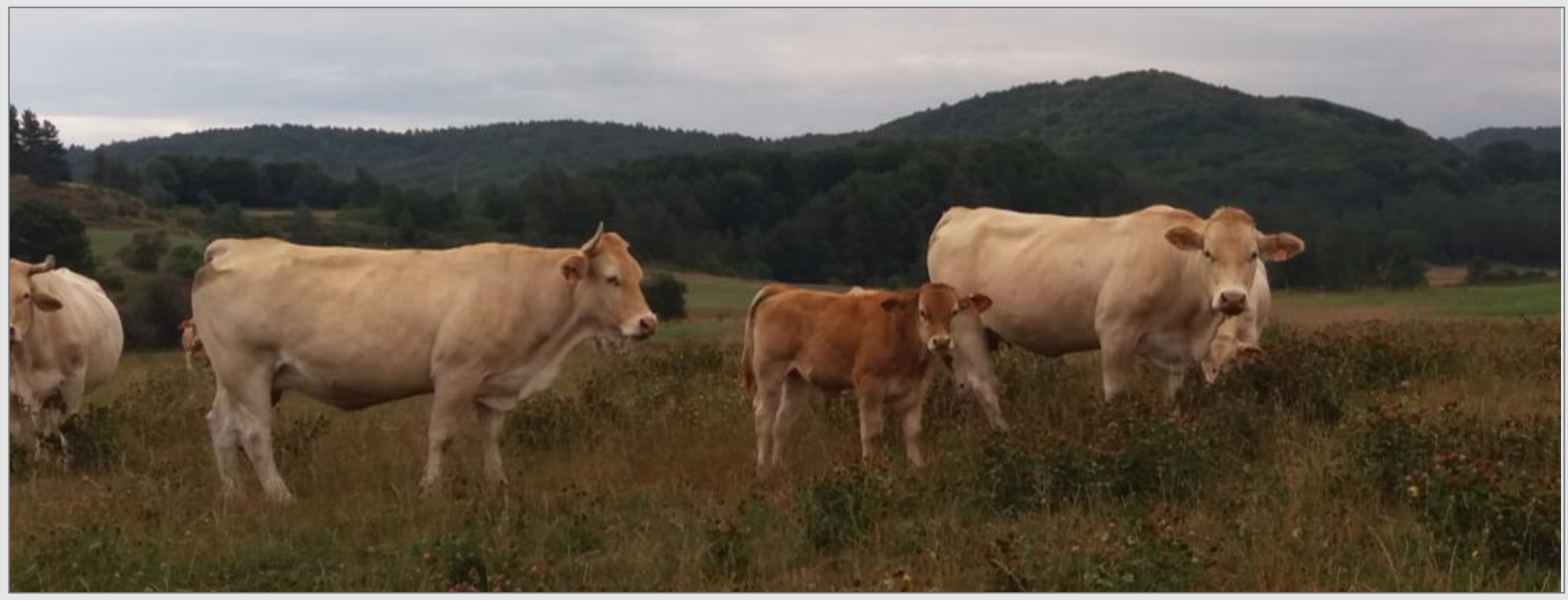

The Pyrenean cow is the typical breed of cattle of this High Nature Value System and its traditional management is linked to grazing.
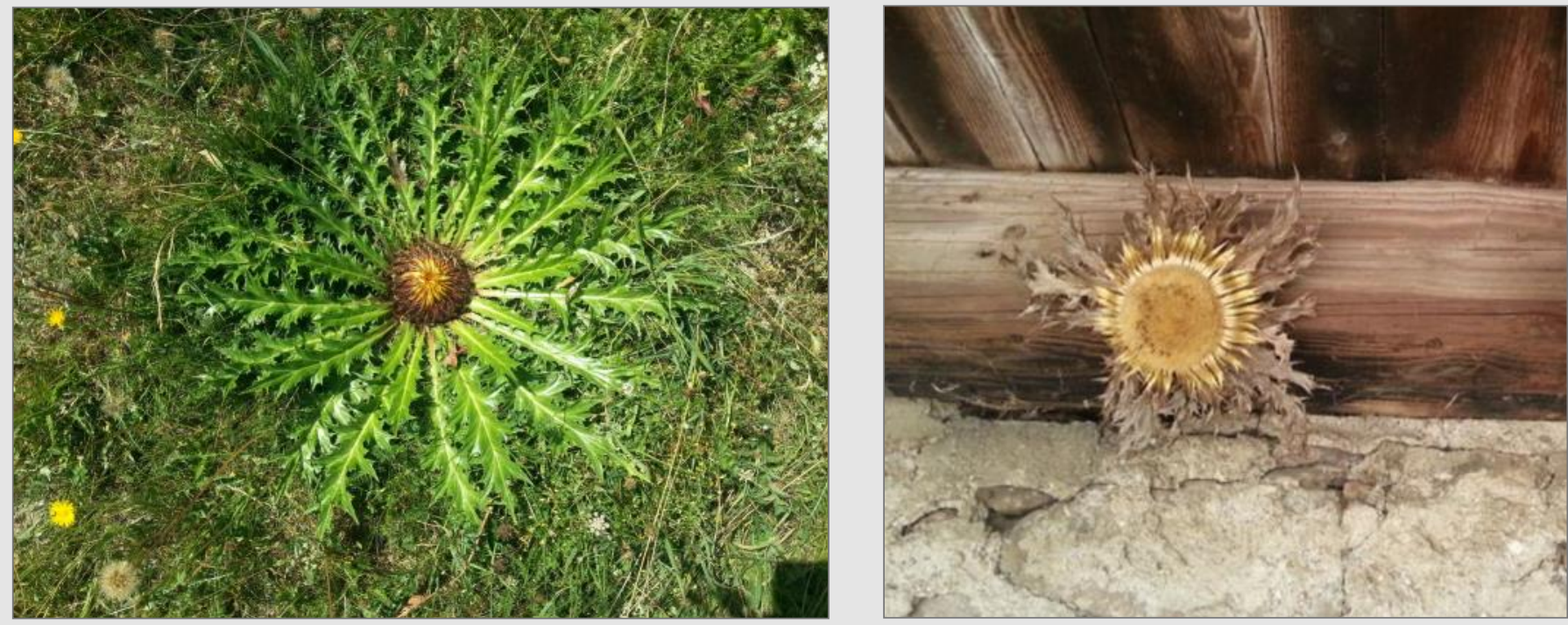

Carlina acanthifolia, sun flower, is used to drive away dangers.

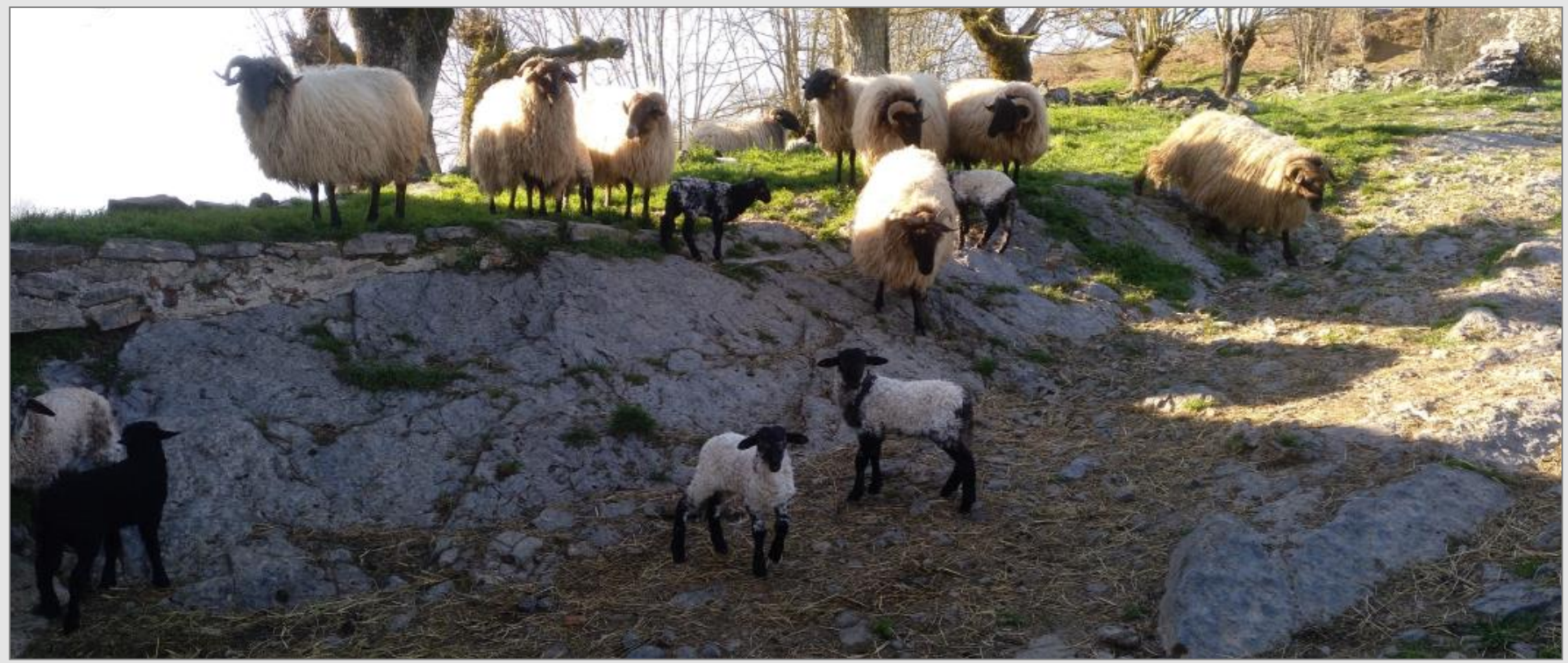

The Latxa is a native breed of sheep very well adapted to the characteristics of the territory and whose milk is used to make traditional cheese of high quality. 


\title{
Photo Story
}

\section{Conservation values of the alkaline grasslands - Hortobágy National Park, East Hungary}

\author{
Photos: Sándor Borza ${ }^{1},{ }^{*}$ Balázs Deák ${ }^{2}$, Laura Godó ${ }^{2}$ text: Orsolya Valkó ${ }^{2}$
}

\author{
${ }^{1}$ Hortobágy National Park Directorate, Debrecen, Hungary \\ ${ }^{2}$ MTA-ÖK Lendület Seed Ecology Research Group, Institute of Ecology and Botany, Centre for Ecological Research, Vácrátót, Hungary \\ *debalazs@gmail.com
}

The Hortobágy National Park, established in 1973, is the oldest, largest and probably the most unique national park in Hungary. The most famous and typical habitat complex of the park is the alkaline grassland and marshland complex situated in the core area, in more than 80,000 hectares, forming one of the largest pristine open landscapes in Europe. It is a flat lowland landscape, typically managed by grazing cattle and sheep (Godó et al. 2017; Kovácsné Koncz et al. 2020). The continental climate and the salt-rich groundwater enabled the formation of extensive alkaline grasslands, which form an extremely heterogeneous habitat complex. Vegetation patterns are driven by the fine scale patterns of abiotic environmental factors such as soil salinity and microtopography (Deák et al. 2014a). On the highest elevated plateaus, species-rich loess grasslands (Salvio nemorosae-Festucetum rupicolae) can be found; they are followed by several types of alkaline dry grasslands (Festucion pseudovinae), open alkaline swards (Puccinellietum limosae), alkaline wet meadows (Beckmannion eruciformis) and alkaline marshes (Bolboschoenetum maritimi) in the deep-lying areas (Deák et al. 2014a,b,c; Valkó et al. 2014). Interestingly, the highest and lowest elevated points of this gradient can be found within one meter of elevation difference (Deák et al. 2014a).

Pannonic salt steppes and marshes of the Hortobágy are considered as priority habitats in the Natura 2000 ecological network of the European Union. They hold several endemic plant species, including Cirsium brachycephalum, Limonium gmelinii subsp. hungaricum and Aster tripolium subsp. pannonicum, which are adapted to the special environmental conditions. Some parts of the landscape are very similar to coastal saline habitats in terms of habitat structure and species composition. The Hortobágy is also a paradise for birdwatchers. Among the nesting species there are the strictly protected Great Bustard (Otis tarda), the Red-Footed Falcon (Falco vespertinus) and the Eurasian Stone-Curlew (Burchinus oedicnemus). The marshes and fishponds provide habitat for several waterbirds, both during the nesting and migration period. Many of these habitats are under the protection of the Ramsar Convention. The National Park is a UNESCO World Heritage Site because of its cultural and natural values. Besides the abovementioned natural values, the 'puszta' still holds several traditions related to ancient animal husbandry, folk art and architecture.

If you are interested in the researches of the MTA-ÖK Lendület Seed Ecology Research Group related to the ecology and conservation of grasslands in the Hortobágy, please visit our research blog at https://deakvalko.blogspot.com/.

\section{References}

Deák, B., Valkó, O., Alexander, C., Mücke, W., Kania, A., Tamás, J. \& Heilmeier, H. 2014a. Fine-scale vertical position as an indicator of vegetation in alkali grasslands - case study based on remotely sensed data. Flora 209: 693-697.

Deák, B., Valkó, O., Török, P. \& Tóthmérész, B. 2014b. Solonetz meadow vegetation (Beckmannion eruciformis) in EastHungary - an alliance driven by moisture and salinity. Tuexenia 34: 187-203.

Deák, B., Valkó, O., Tóthmérész, B. \& Török, P. 2014c. Alkali marshes of Central-Europe - Ecology, Management and Nature Conservation. In: Shao H-B (Ed.) Salt Marshes: Ecosystem, Vegetation and Restoration Strategies, pp. 1-11. Nova Science Publishers, Hauppauge, NY, US.

Godó, L., Valkó, O., Tóthmérész, B., Török, P., Kelemen, A. \& Deák, B. 2017. Scale-dependent effects of grazing on the species richness of alkaline and sand grasslands. Tuexenia 37: 229-246.

Kovácsné Koncz, N., Béri, B., Deák, B., Kelemen, A., Tóth, K., Kiss, R., Radócz, S., Miglécz, T., Tóthmérész, B. \& Valkó, O. 2020. Meat production and maintaining biodiversity: Grazing by traditional and crossbred beef cattle breeds in marshes and grasslands. Applied Vegetation Science 23: 139-148.

Valkó, O., Tóthmérész, B., Kelemen, A., Simon, E., Miglécz, T., Lukács, B. \& Török, P. 2014. Environmental factors driving vegetation and seed bank diversity in alkali grasslands. Agriculture, Ecosystems \& Environment 182: 80-87. 


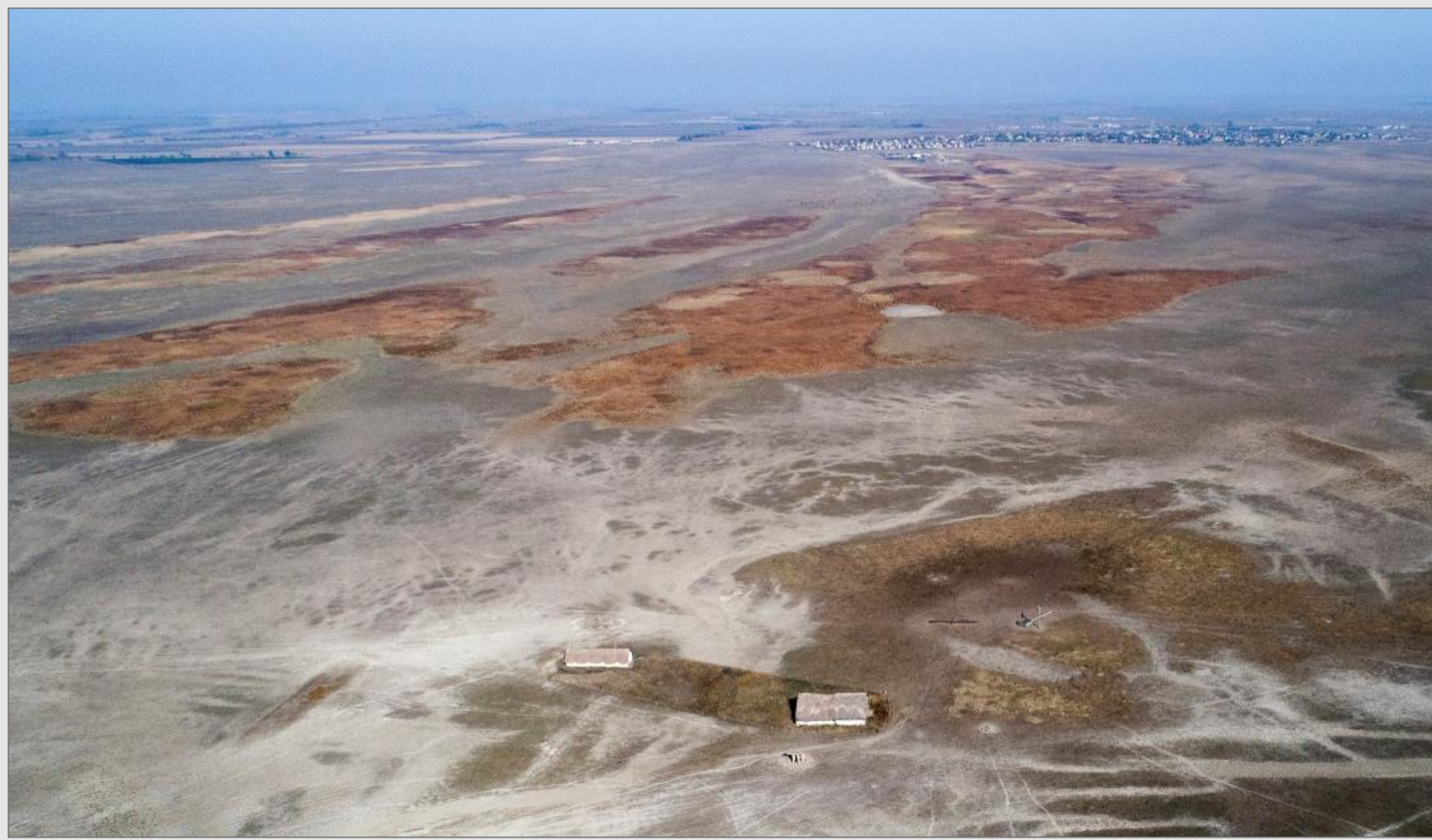

Birdseye view of the extended open landscape (Photo by S.B.).

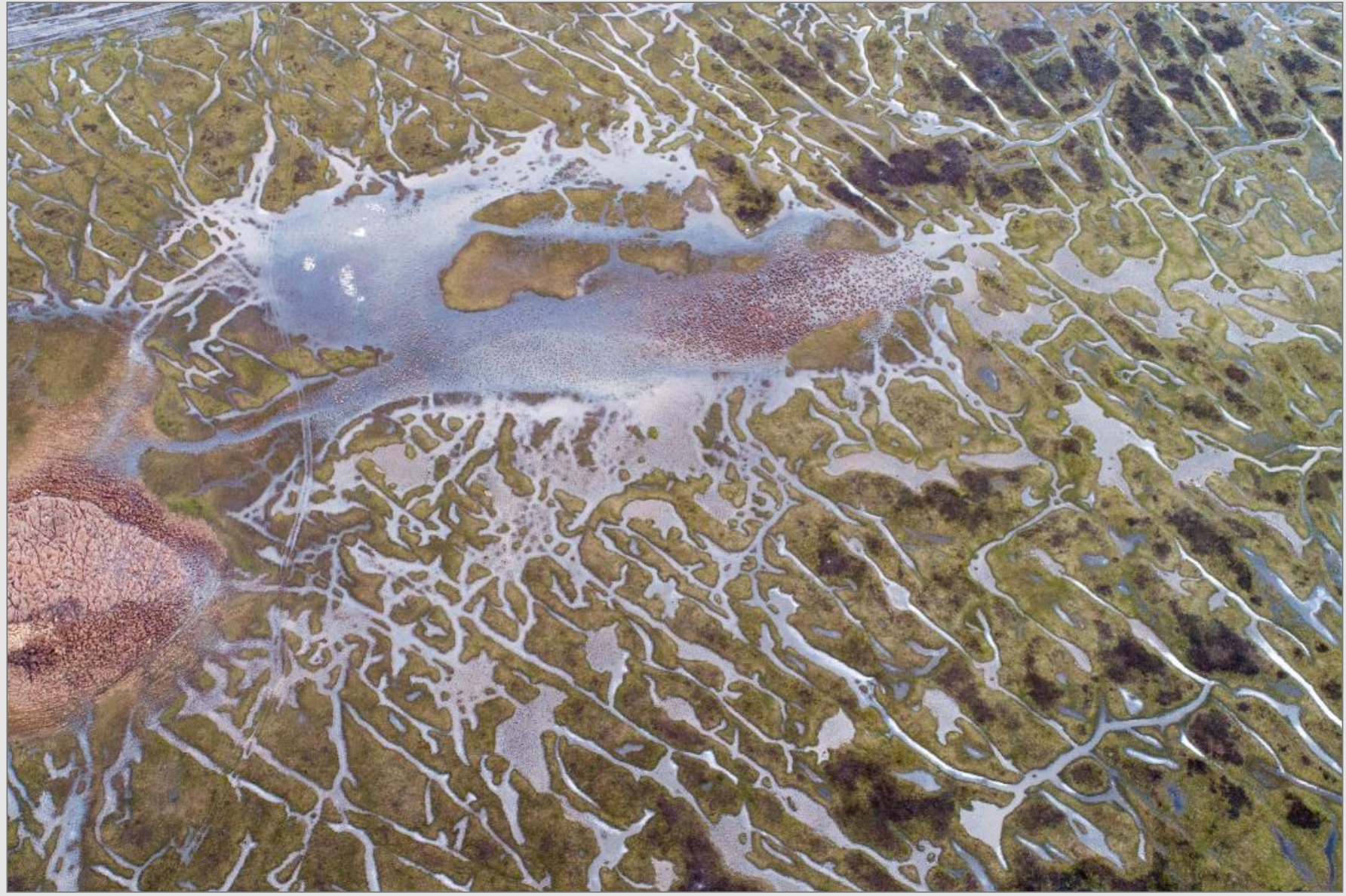

Springtime, the patterns of surface water show perfectly the micro-topographic heterogeneity in the landscape (S.B.). 


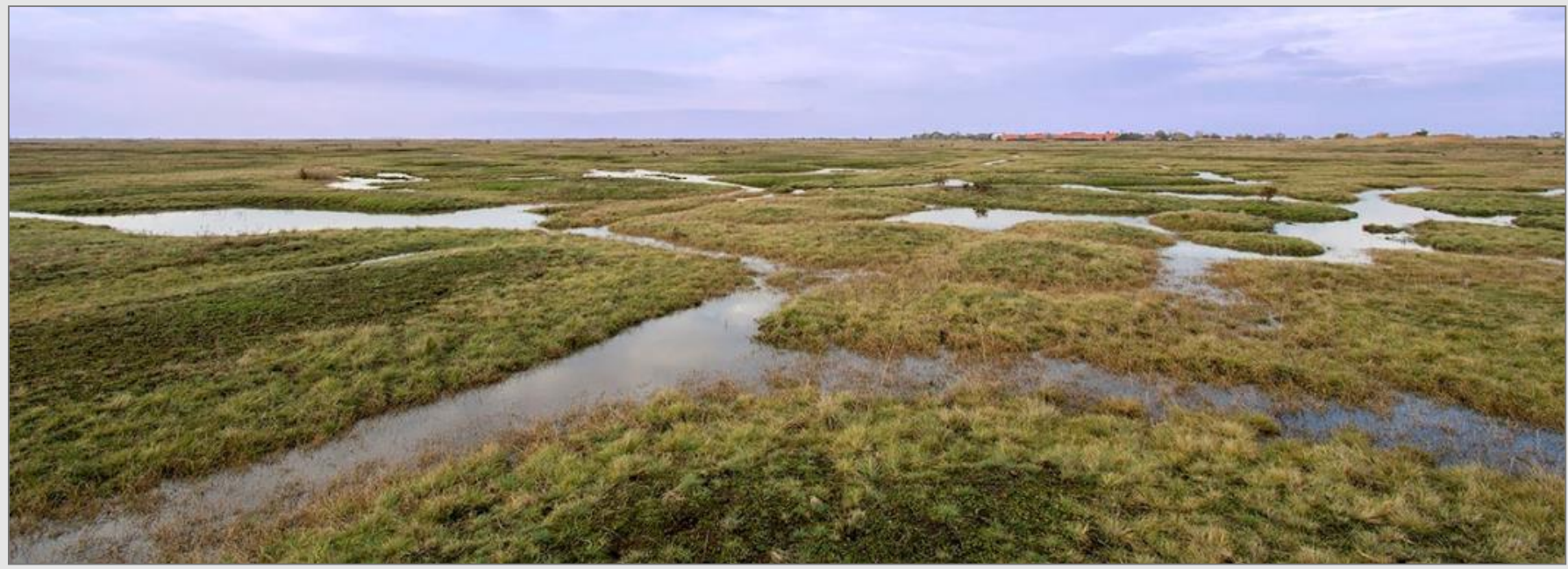

The 'higher-elevated' dry grasslands are separated by surface water in early spring (B.D.).

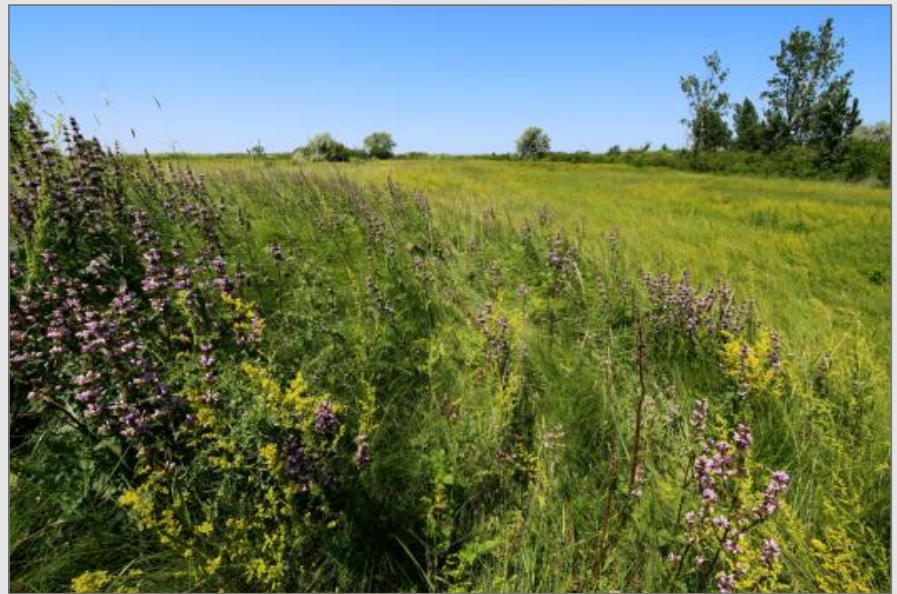

At the 'highest elevations', such as on ancient burial mounds (kurgans), species-rich loess grasslands occur (B.D.).

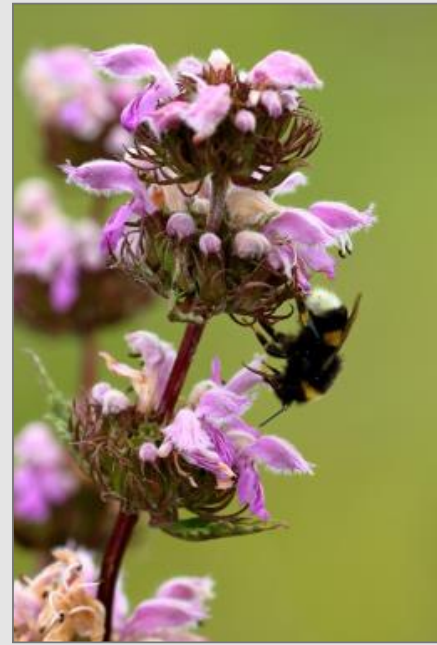

Phlomis tuberosa is a protected species of the loess grasslands (B.D.).

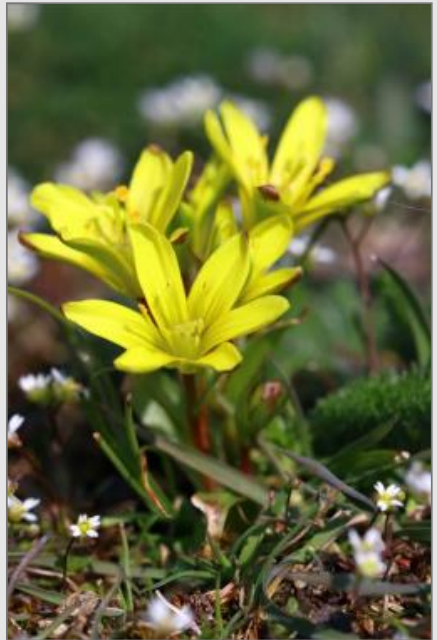

Gagea szovitsii is a protected geophyte which occurs in the most pristine alkaline grasslands (B.D.).

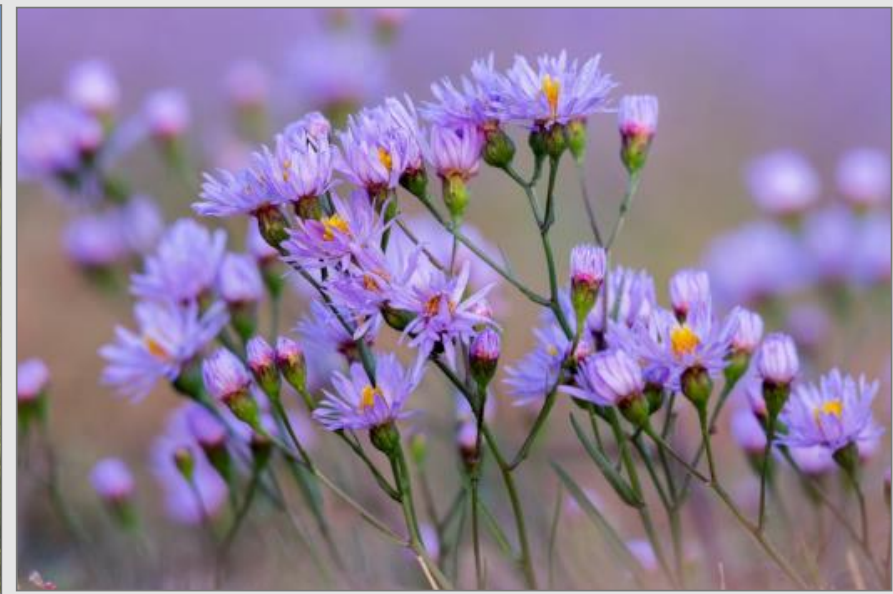

Aster tripolium subsp. pannonicum is an endemic subspecies, typical of alkaline grasslands and meadows (L.G.).

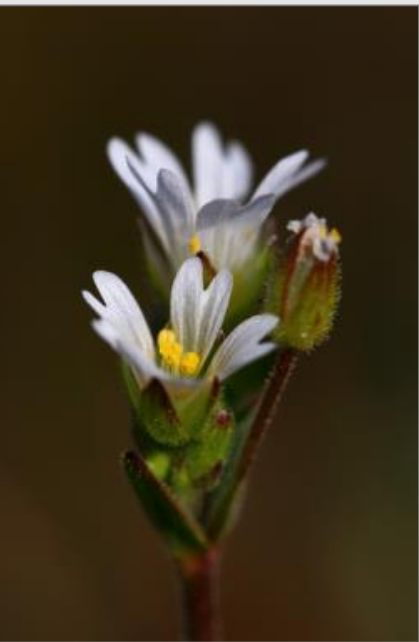

Cerastium dubium is an early-spring annual species typical of alkaline grasslands (B.D.).

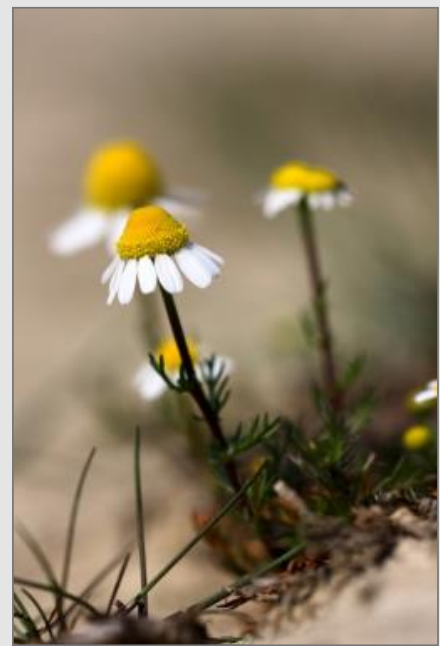

Matricaria chamomilla is a typical species of open alkaline swards and also a well-known medicinal herb (B.D.). 


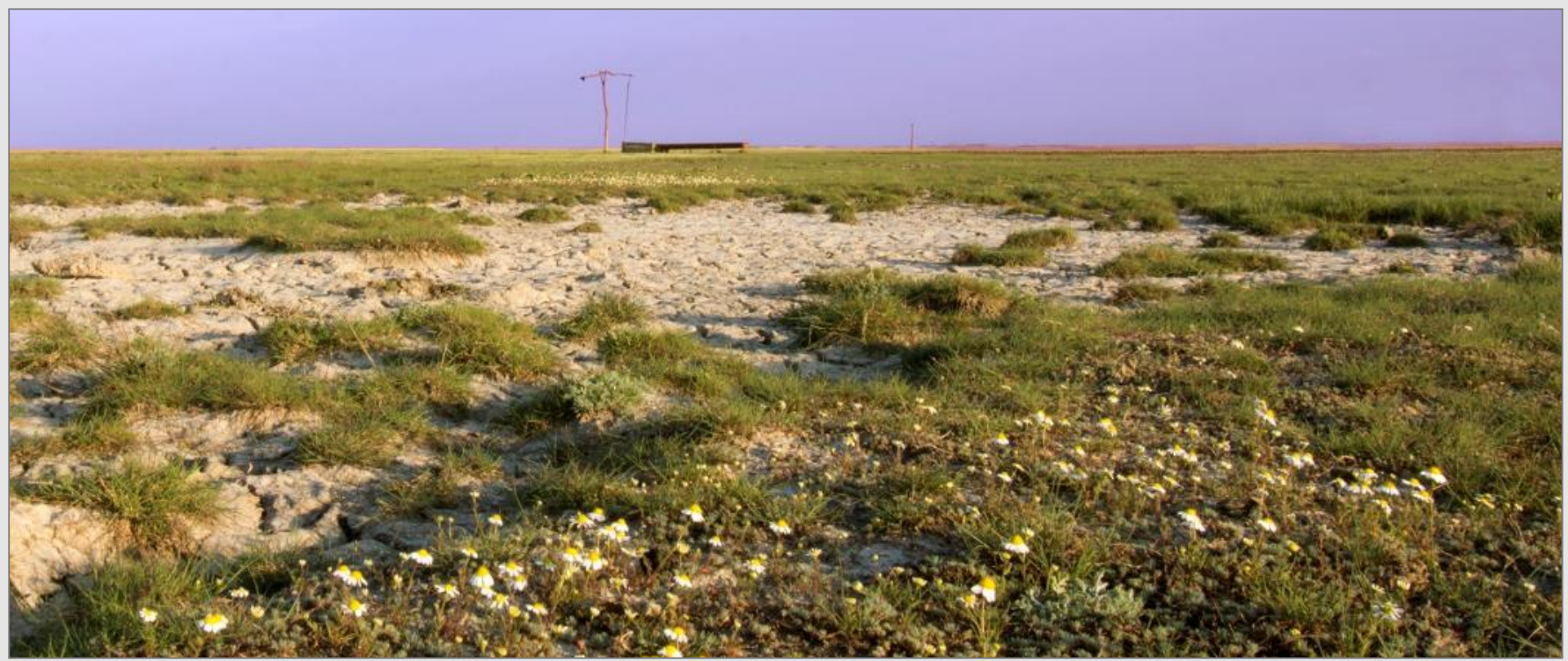

Open alkaline swards in the spring aspect with a traditional sweep-well in the background. Sweep wells are iconic landscape elements in this region protected by the European Landscape Convention (L.G.).

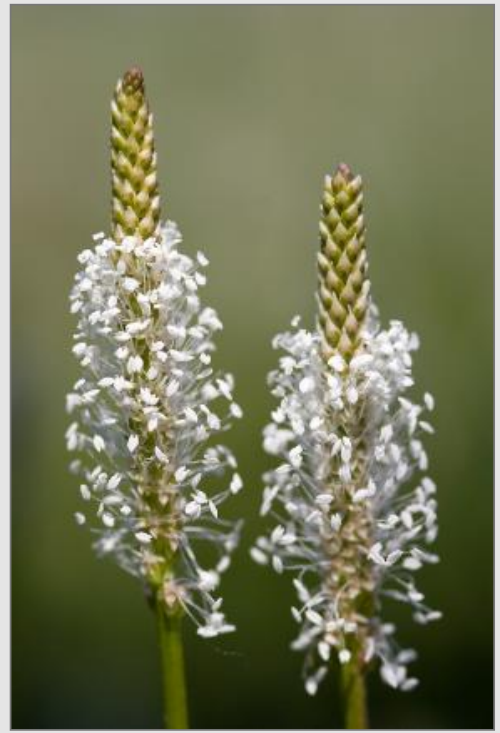

Plantago schwarzenbergiana is a protected endemic species of the alkaline grasslands (B.D.).

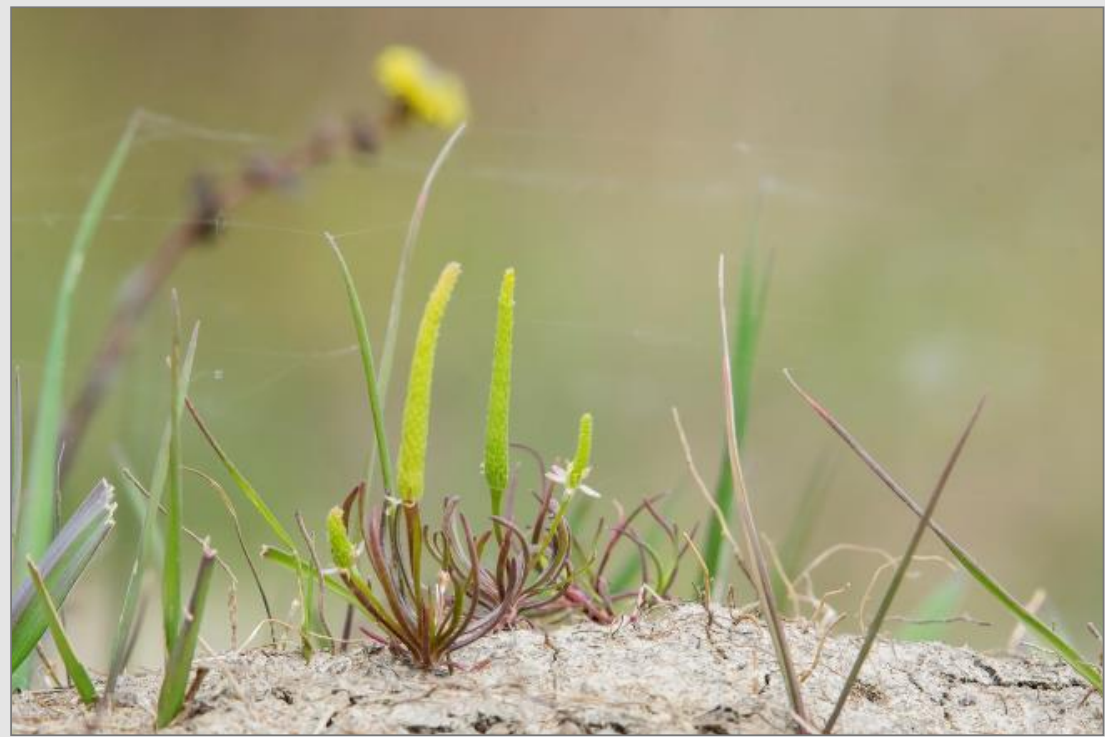

Myosurus minimus is an ephemeral Ranunculaceae species, typical of muddy surfaces (L.G.).

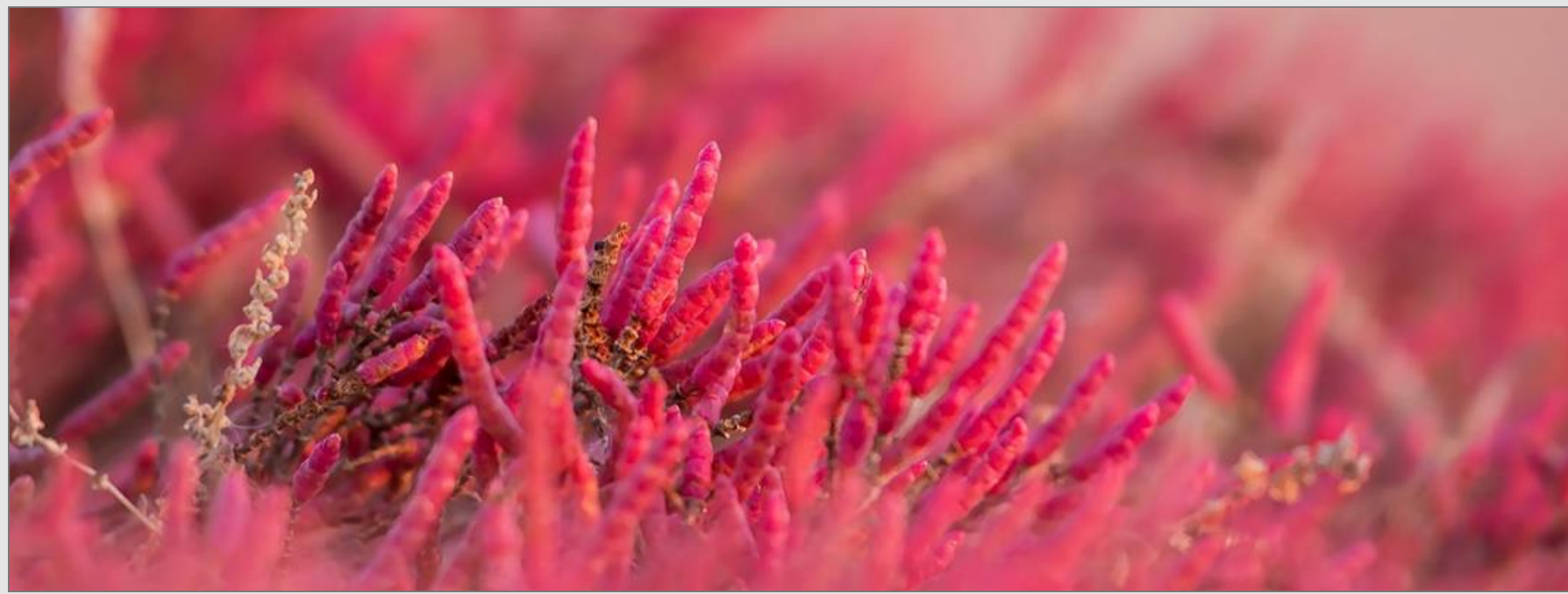

Salicornia prostrata is a halophyte species preferring chloride-rich soil (L.G.). 


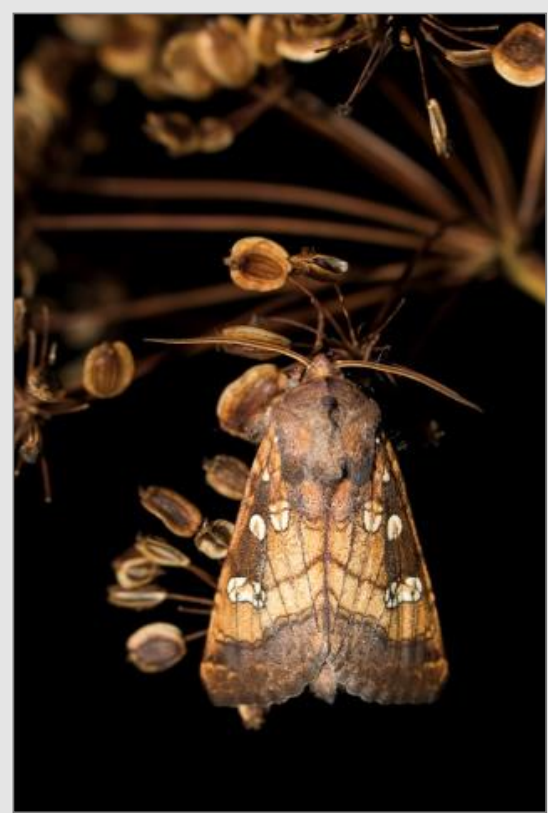

Gortyna borelii lunata is a strictly protected moth species, the caterpillar of which is an oligophagous specialist of Peucedanum officinale (S.B.).

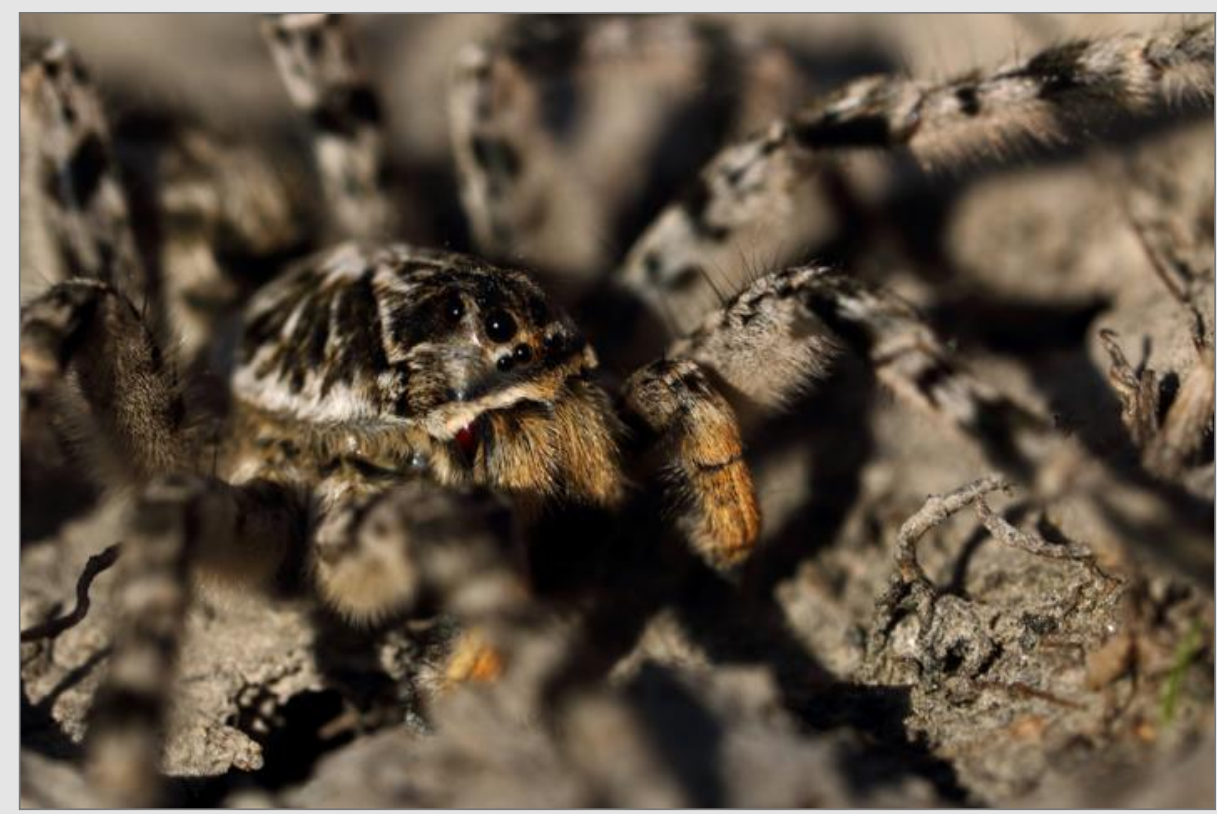

Lycosa singoriensis is a protected spider species. This steppic fauna element reaches its western limit of distribution in Hungary (B.D.).

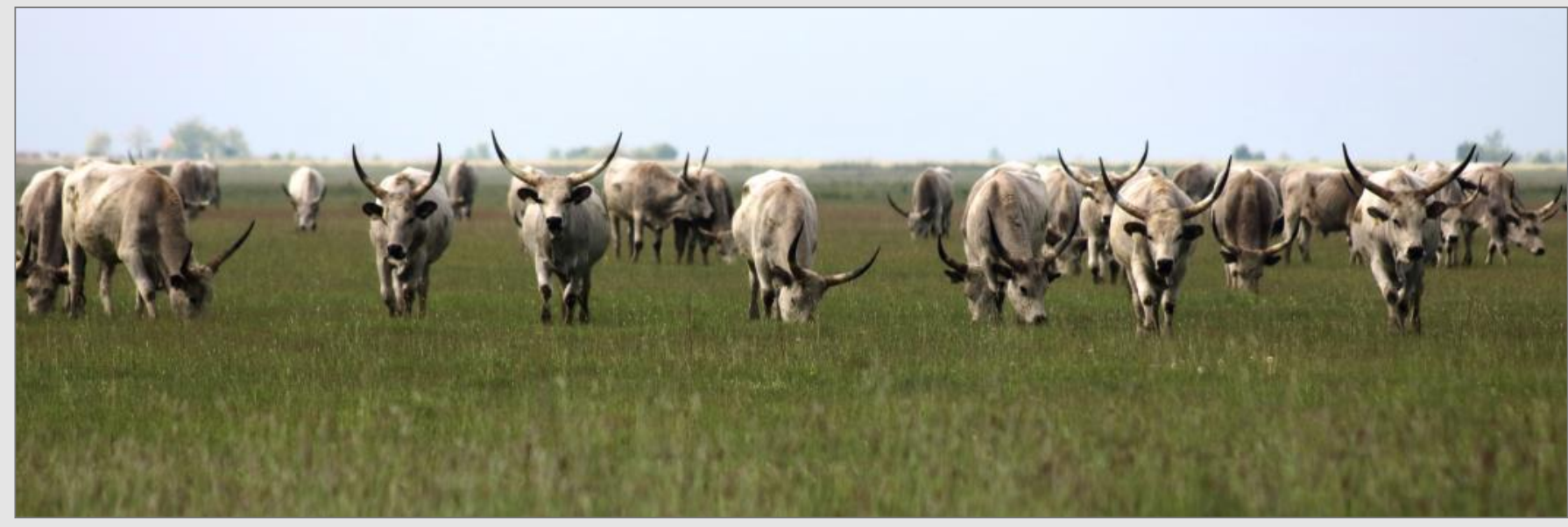

The Hungarian grey cattle is an ancient and robust endemic breed, which is widely used for the conservation management of the alkaline grasslands and wetlands (B.D.).

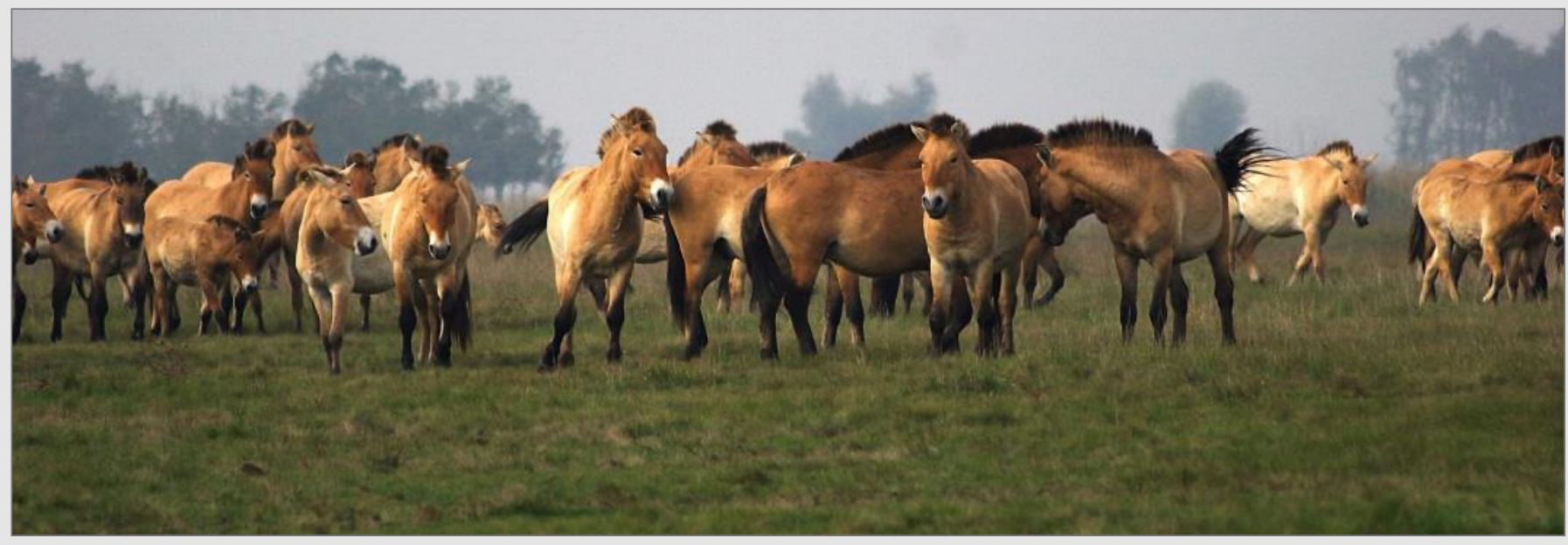

Przewalski horses (Equus caballus przewalskii) are wild horses of the Eurasian steppe. In the Hortobágy, they live in a 4000-hectare large area where the free-ranging grazing mimic the ancient grazing regimes of the Holocene (B.D.). 


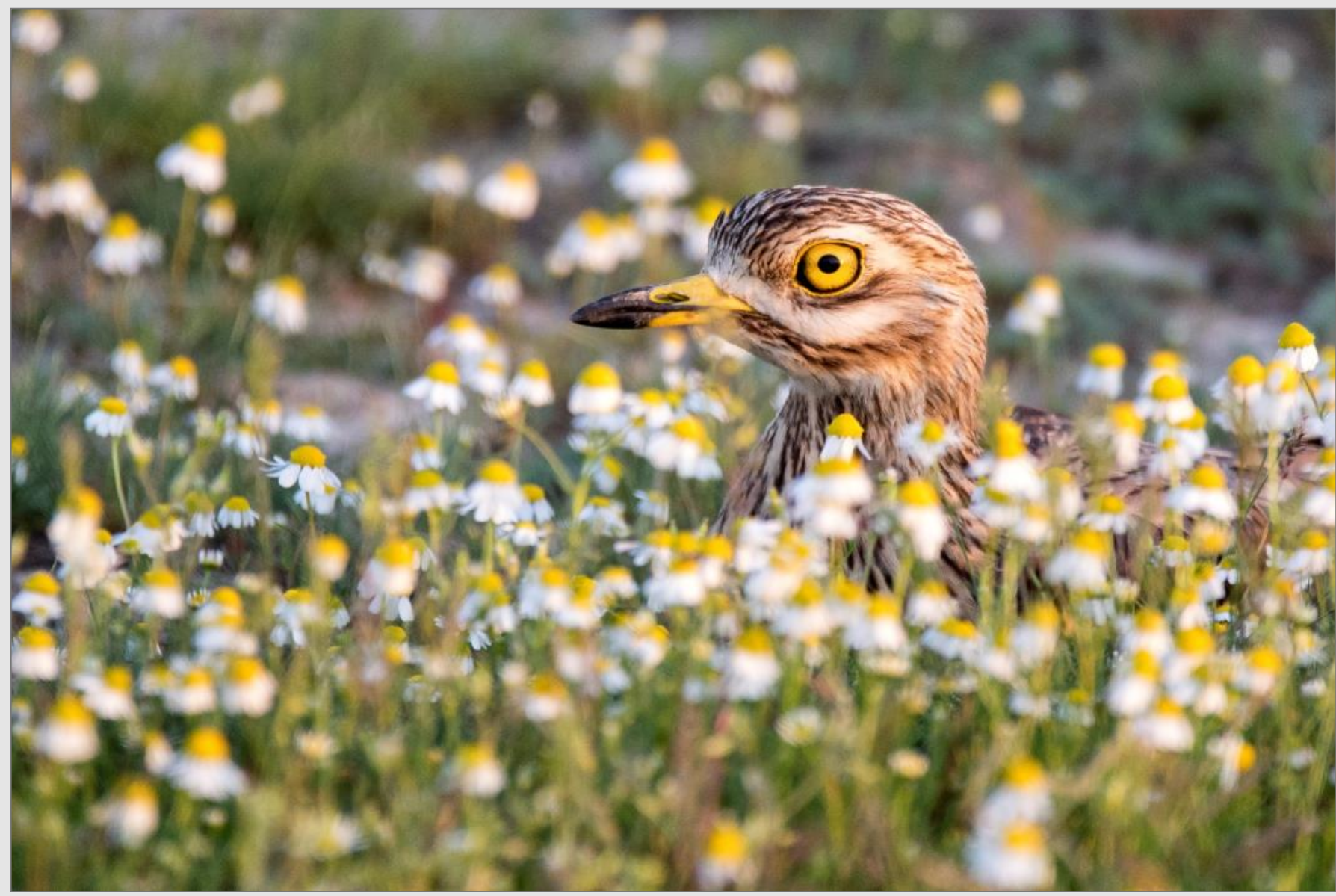

The Eurasian Stone-curlew (Burchinus oedicnemus) prefers the open alkaline swards as its nesting site (S.B.).

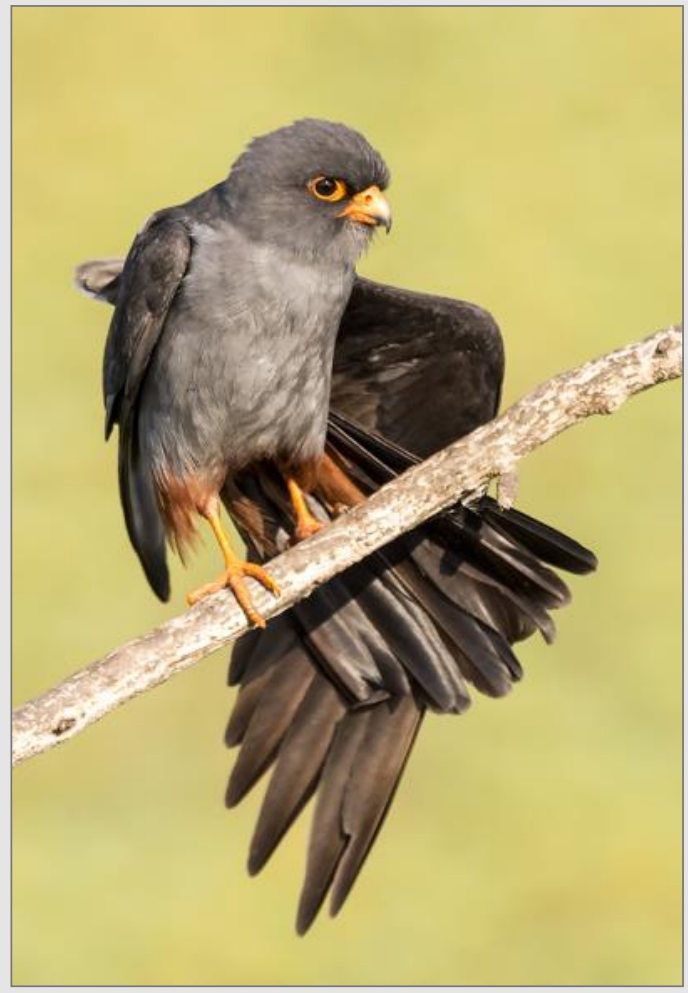

The Red-footed Falcon (Falco vespertinus) is a strictly protected raptor, nesting in colonies in the few forest stands (S.B.).
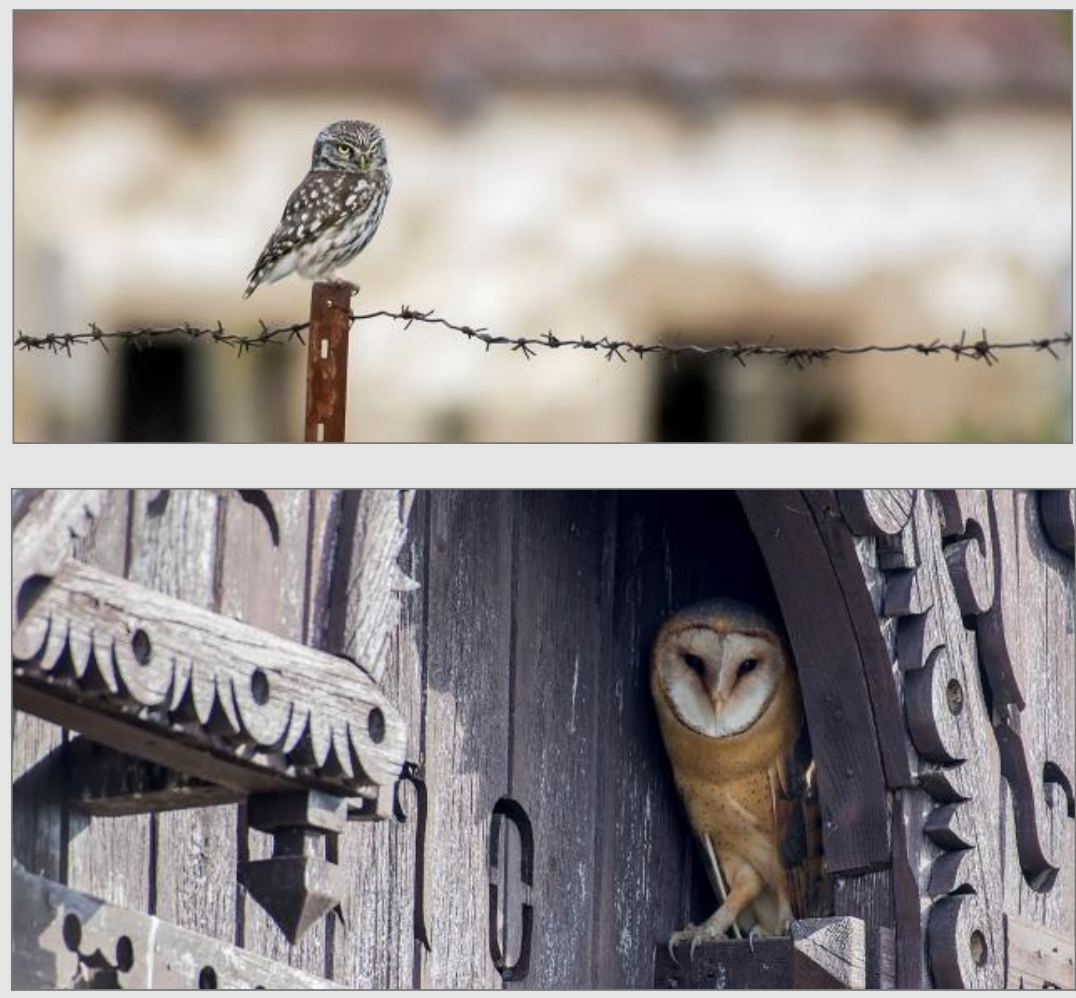

The Little Owl (Athene noctua) (above) and the Barn Owl (Tyto alba) (below) often nest in old farmhouses, and other buildings (L.G.). 


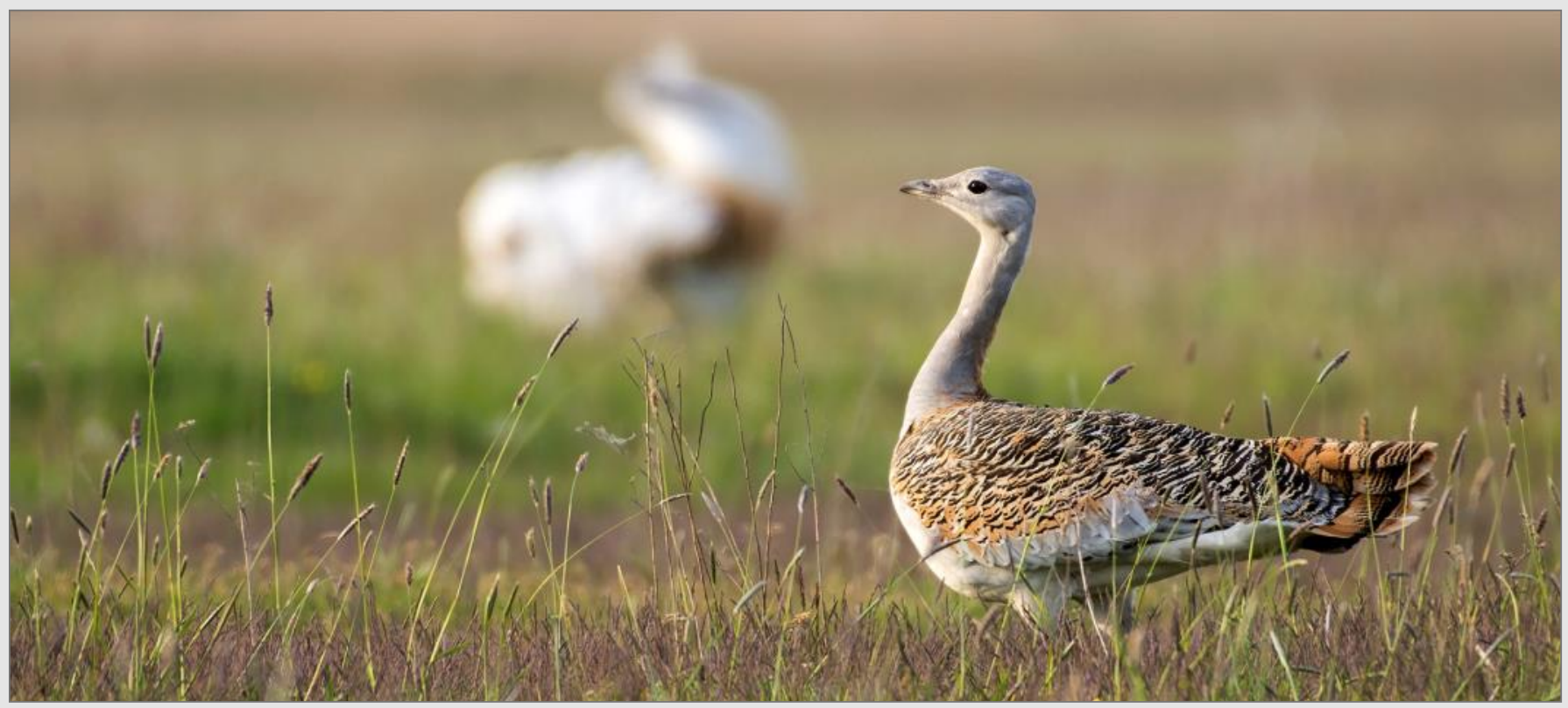

The Great Bustard (Otis tarda) is the largest bird species of Europe. Hortobágy represents one of the last areas where it can occupy its original nesting habitat types, i.e. dry grasslands (L.G.).

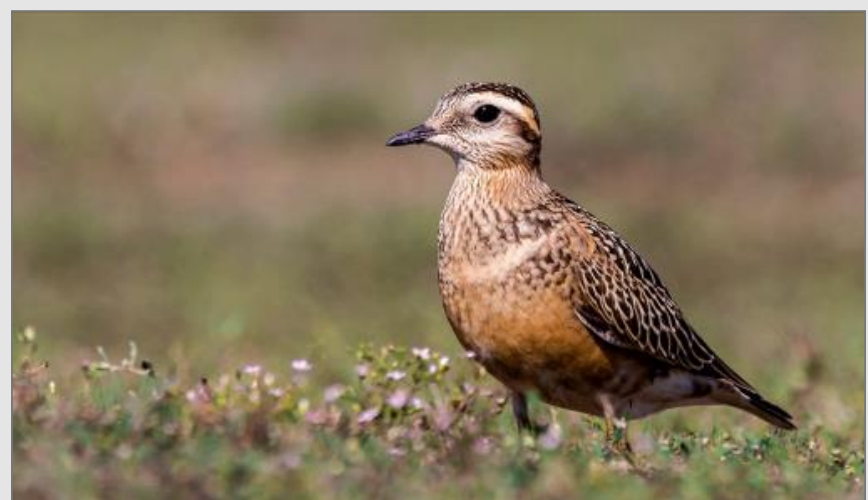

Hortobágy is an important stopover site for bird migration. Eurasian Dotterels (Charadrius morinellus) are present in large numbers on the alkaline grasslands during autumn (S.B.).

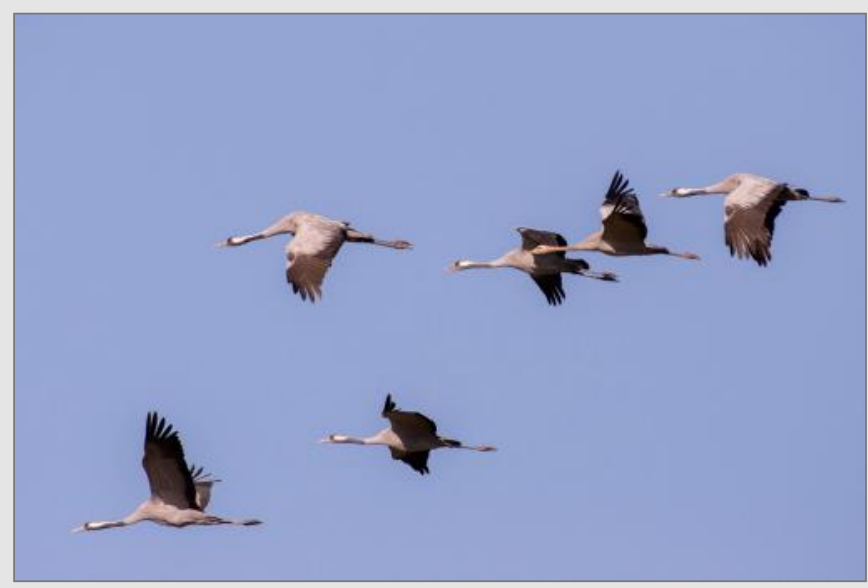

Autumn is a great time for observing the Common Cranes (Grus grus), which spend several weeks in the Hortobágy during their migration. Due to conservation efforts, their number has been steadily increasing in recent years and may reach up to 160,000 individuals at peak season (L.G.).

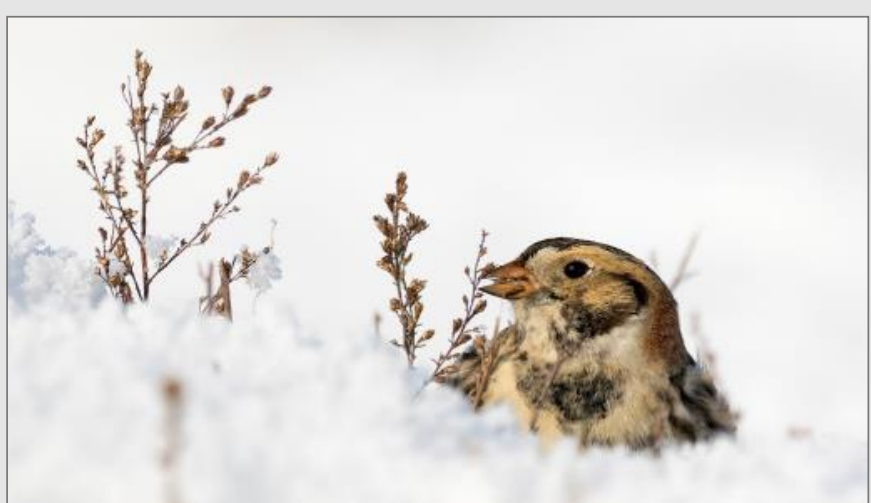

Lapland Buntings (Calcarius lapponicus) often visit the grasslands in wintertime (S.B.).

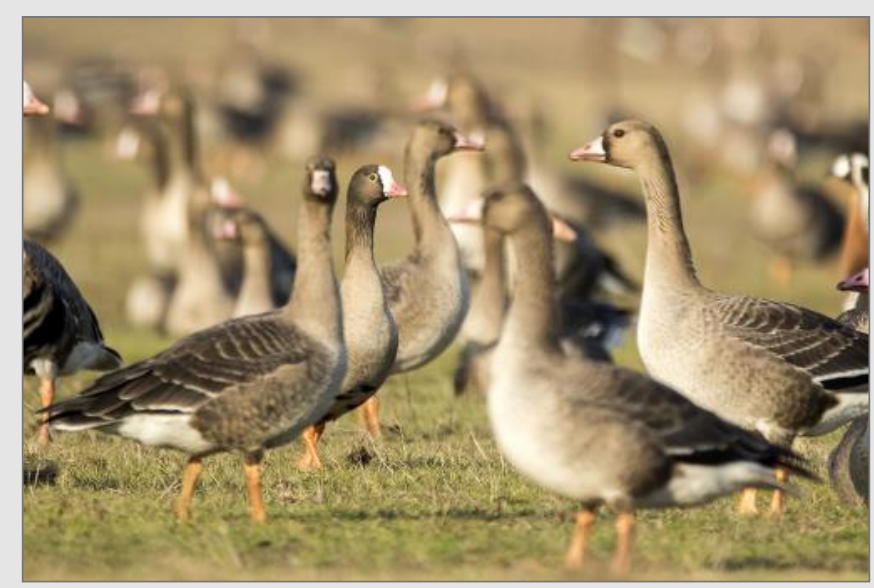

Hortobágy is an important stopover site for migrating geese. In the middle of the picture, the strictly protected and globally endangered Lesser White-fronted Goose (Anser erythropus), with the yellow eye-ring, can be seen (S.B.). 


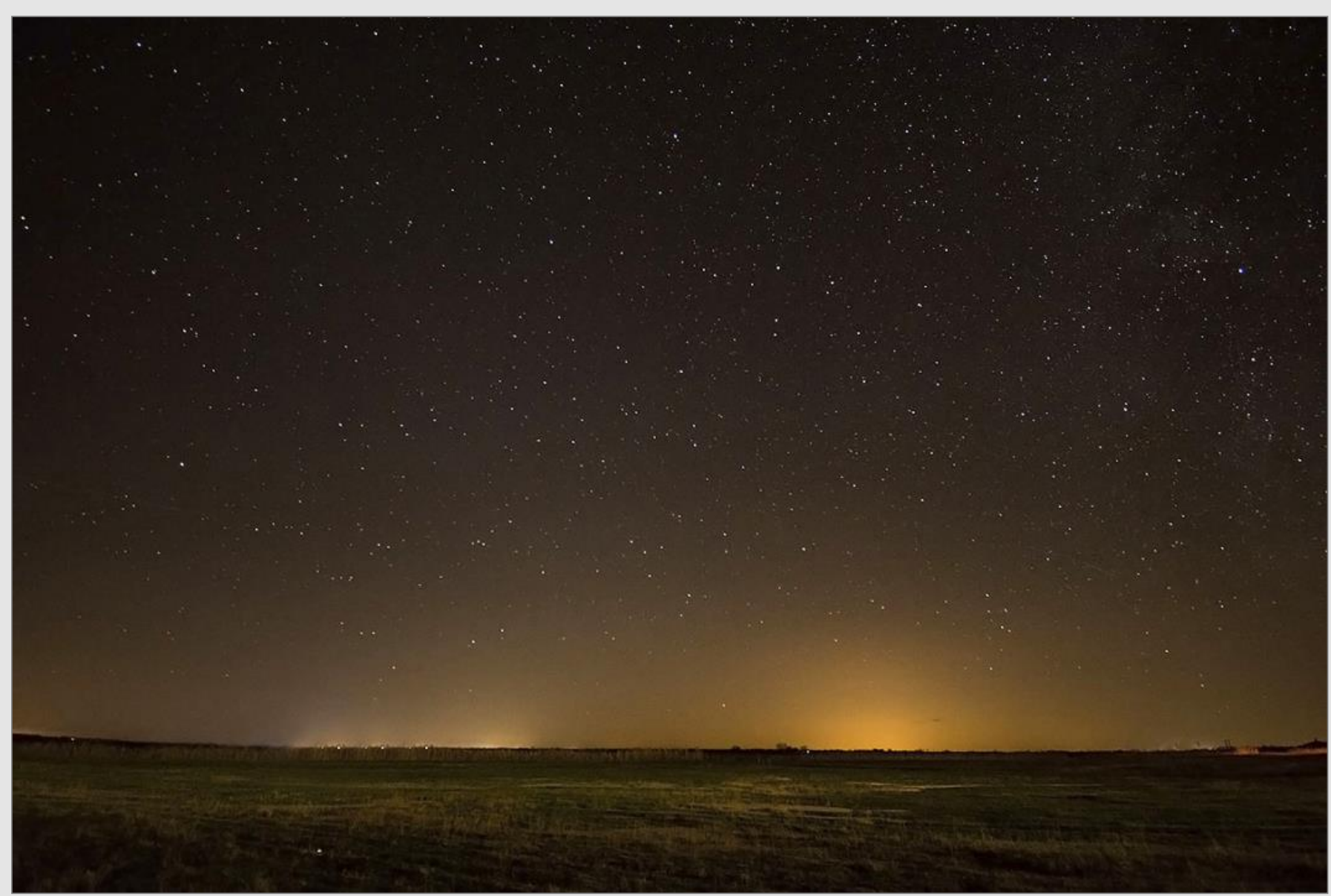

Hortobágy, as one of the largest unpopulated areas in Hungary, has a dark and unpolluted starry sky. As a recognition, the National Park got a silver tier Dark Sky Park designation from the International Dark Sky Association (L.G.).

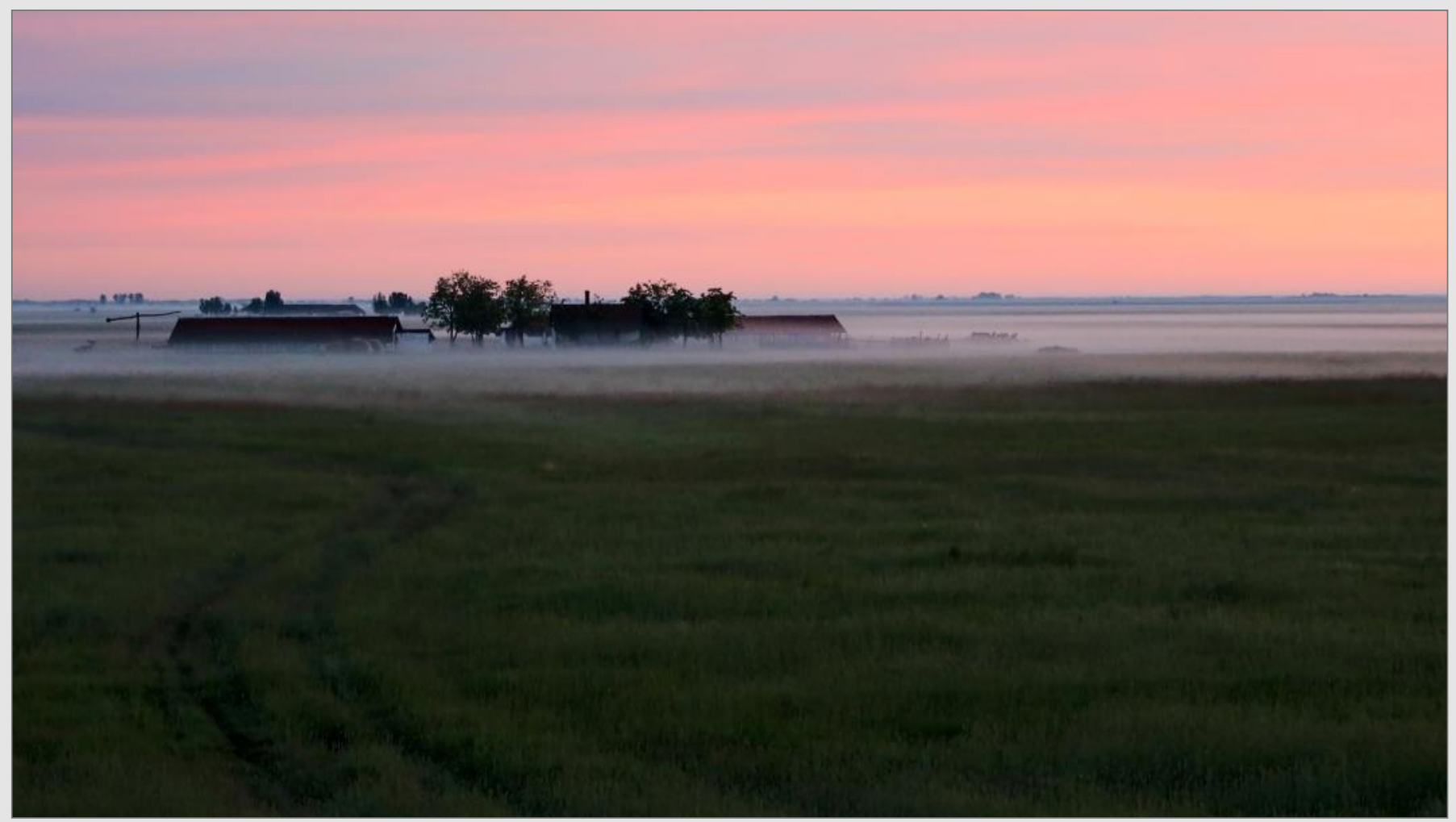

Dawn in the Hortobágy puszta (S.B.). 


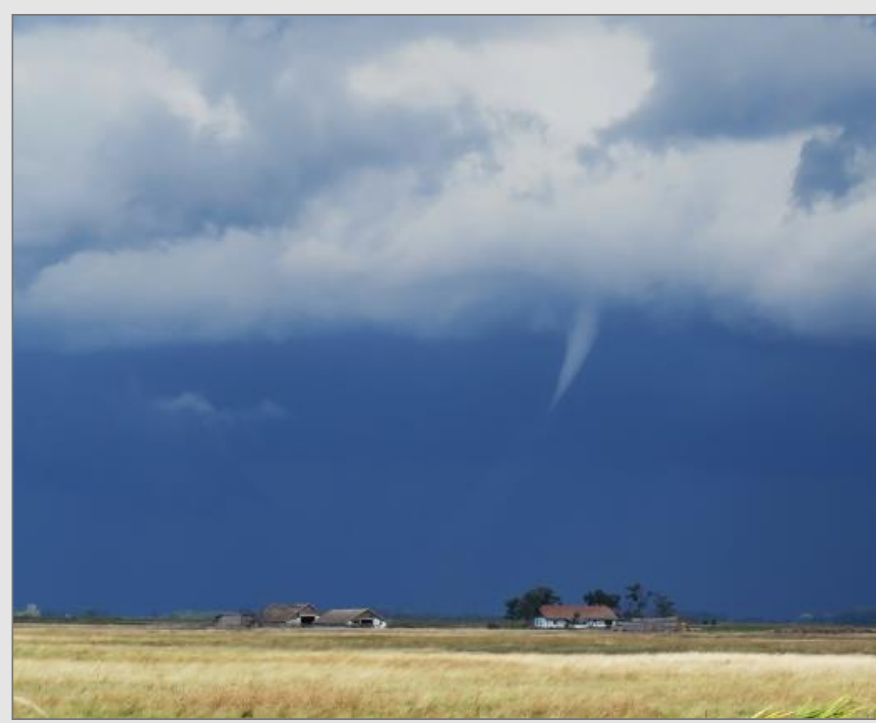

Still life before a thunderstorm (S.B.).

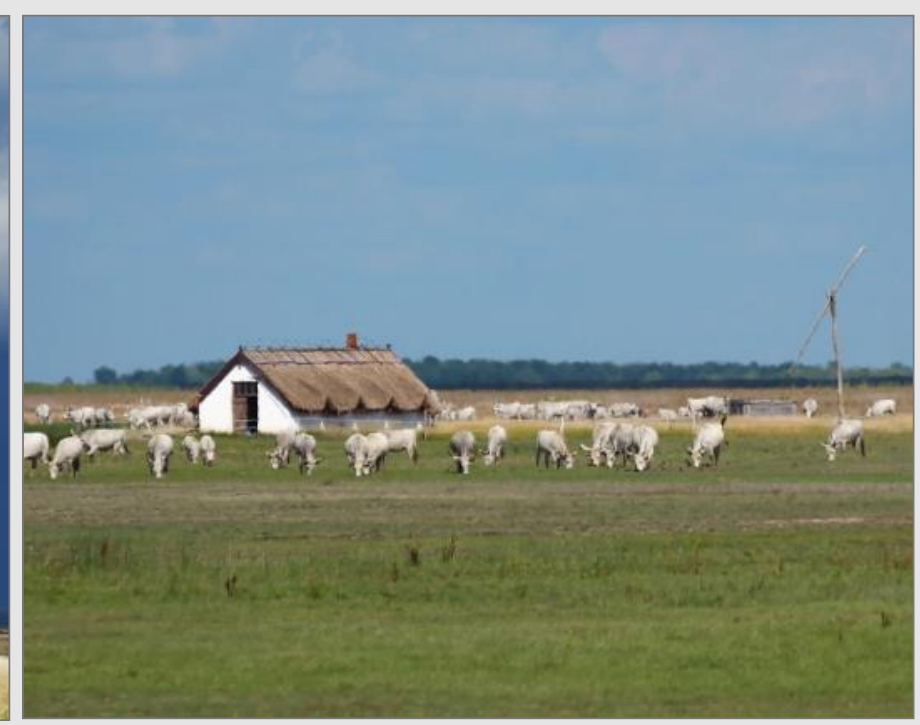

Traditional animal husbandry: Grey cattle, sweep well and traditional architecture (S.B.).

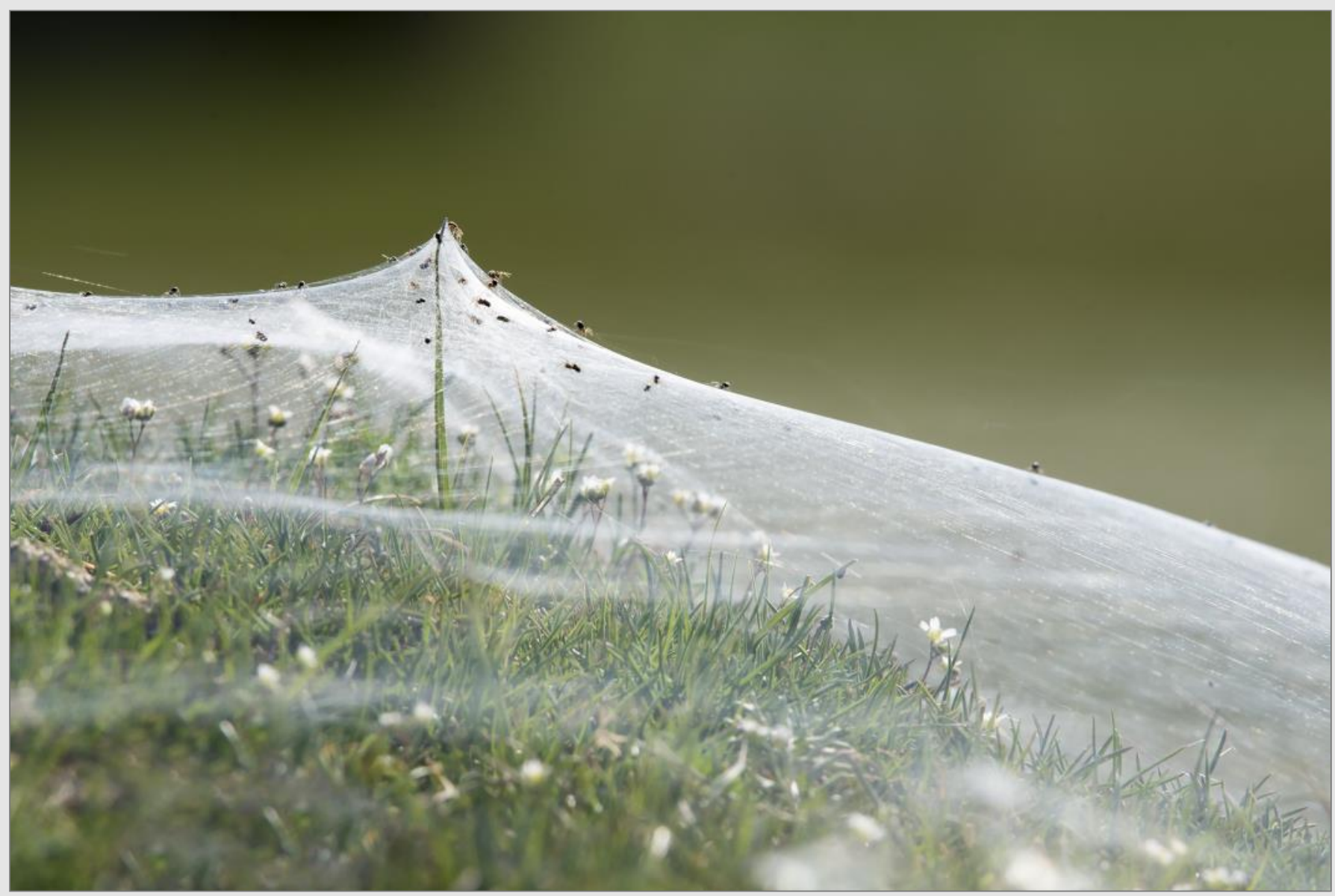

Spider-net veil forming a baldachin above the sward (L.G.). 


\section{Glimpses of a Grassland}

\section{Glimpses of a Grassland - new section in Palaearctic Grasslands}

Probably many of us have been confined to home office due the Corona pandemic. We have missed some of our fieldwork and student classes in spring and early summer when nature in the northern hemisphere and particularly in the Palaearctic grasslands is unfolding its beauty and diversity after the winter break. Therefore, we would like to bring the diversity and beauty of our study objects to you with glimpses of Palaearctic grasslands across the world. This new section titled as "Glimpse of a Grassland" is intended to present short stories and nice photos of grasslands. In this current issue, the section includes 12 grasslands across the Palaearctic (see the Map below). We hope you will enjoy reading it. If you'd like to share your stories, please send them to anyameadow.ak@gmail.com.

Didem Ambarlı \& Chief Editor Team

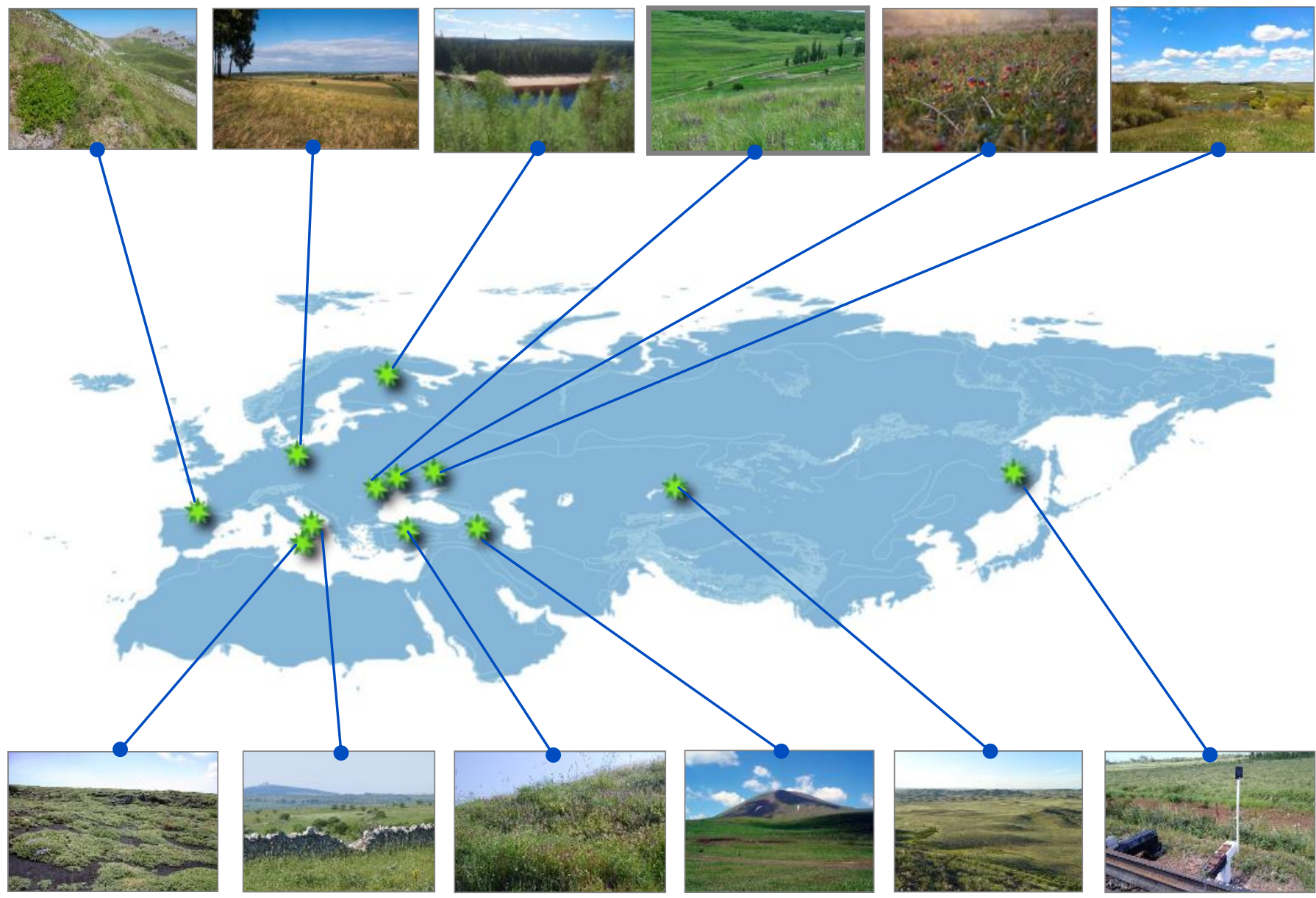




\section{Glimpses of a Grassland}

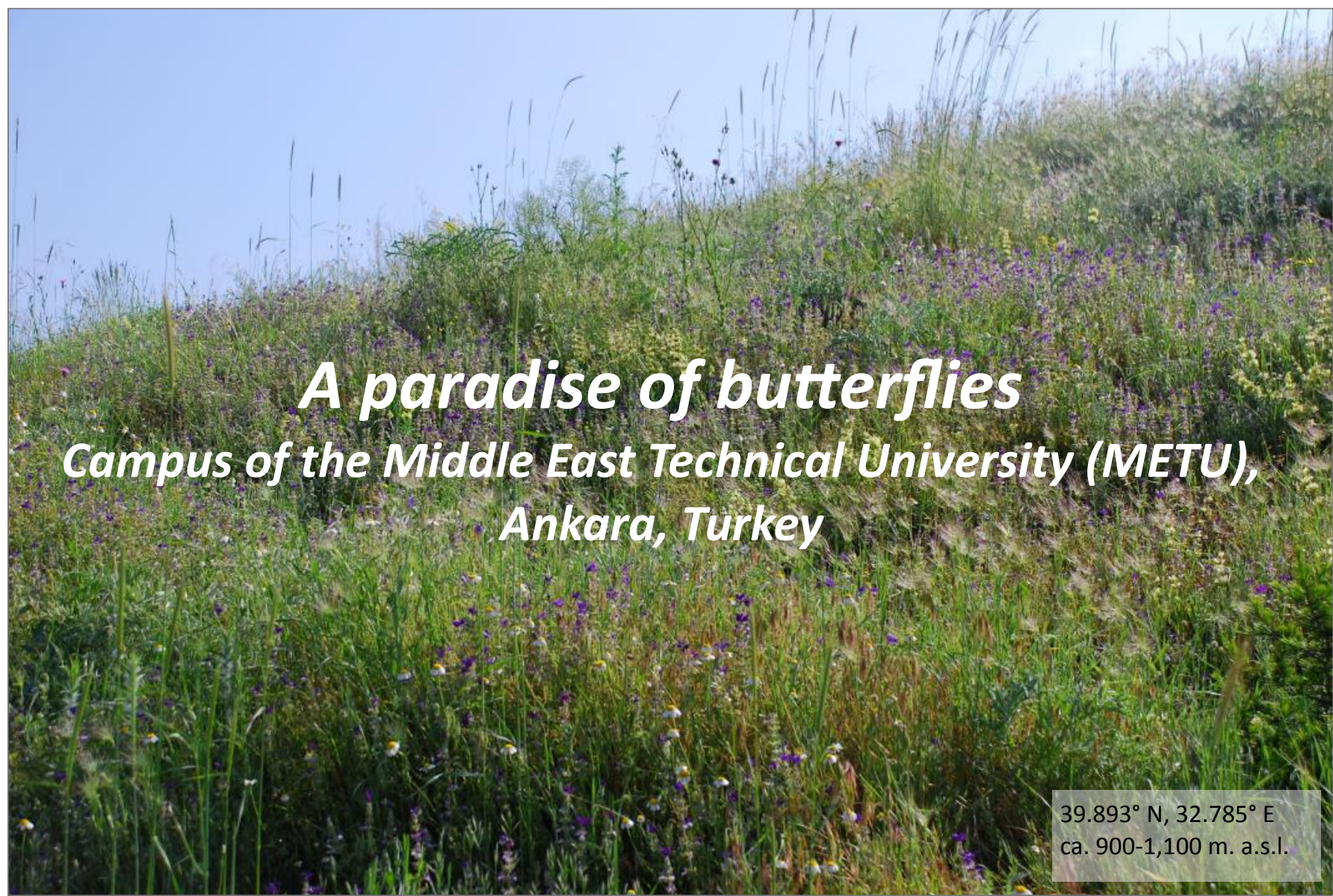

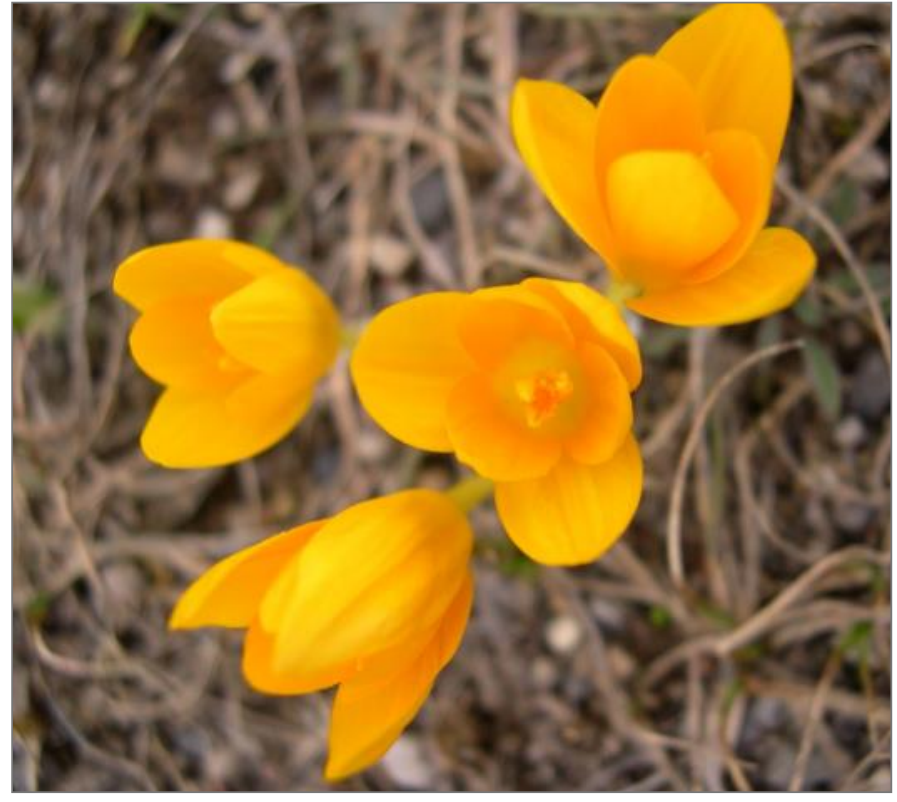

Ankara's Crocus (Crocus ancryensis), Ankara. Photo: D. Ambarlı.
After a very cold and snowy winter, the bloom of Crocus ancryensis between litter and first leaves is the first sign of an approaching beautiful spring. At the same time with this symbol of my city, first butterflies emerge and I find myself in my university's amazing landscape. The very first things I look for in the field are Steppe Ringlet Proterebia afer, False Apollo Archon apollinus and festoons. The steppe ringlet has a challenging contrast for photographers on upper wings which is very dark except for the bright white zones next to its rings. The false apollo is a rare butterfly of this region with transparent parts on the wings. Having seen the two on the same day and with a bit of red skin due to spring sun burn, I return home full of refreshment.

Butterflies flying in May and June diversify with emergence of blues, coppers and nymphalids, and therefore, the observation list extends. The Steppe Fritillary, Euphydryas orientalis, is an endemic and endangered species not to be missed. Flying together with its well-known and widespread sister the Marsh Fritillary Euphydryas aurinia, Steppe Fritillary suffered a lot more from habitat destruction in the recent decades, but found home in the METU campus. 


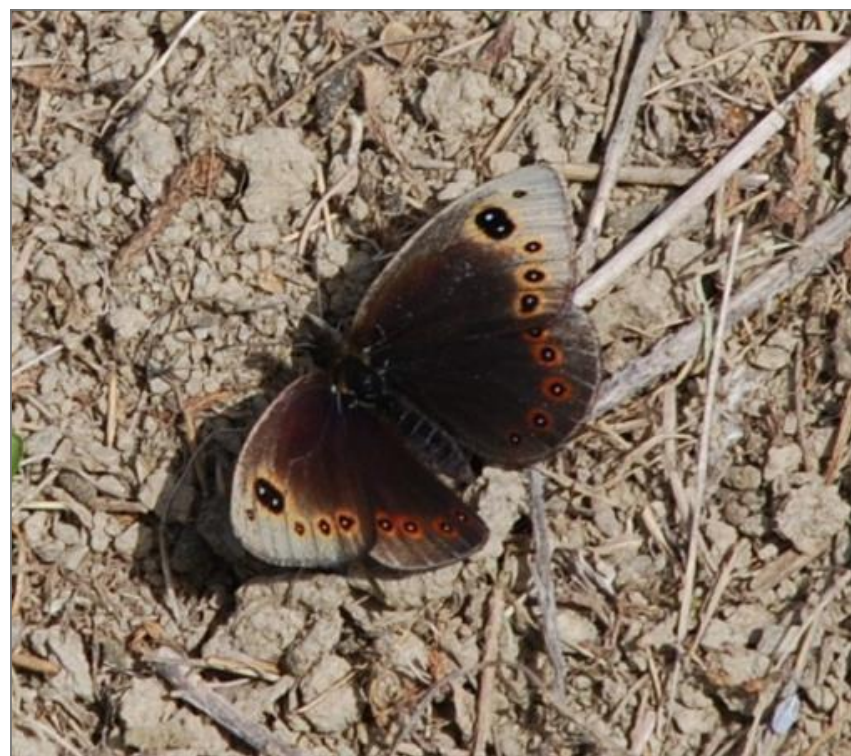

Steppe ringlet (Proterebia afer). Photo: D. Ambarli.

The campus, expanding more than 4000 square $\mathrm{km}$ including the urban areas, is a refuge for steppe species of central Anatolia at the heart of a capital. It hosts more than 700 plant species some of which are endemics. Old fields abandoned for more than 60 years, riverine vegetation, small ponds, a waterfall and woodlands with oaks and almonds add to habitat diversity. As a result, METU hosts more than 100 butterfly species seven of which have high conservation priority. For this reason, the campus is assigned as a prime butterfly area of the country.

The most thrilling observations I have had in the campus were, no doubt, the ones with Sooty Orange Tip, Zegris eupheme. I know that I can find it on roadsides of steppewoodland mosaics rich in flowers, but there is no guarantee as the population size is usually small. Once it appears, you cannot mistake it: the shiny-yellow underwings blind me with flashes like a mirror under sun. Then, I feel my spirit filled with fresh spring air and was walking on air. I stand in wonder with the happiness of seeing a beloved one and sadness of seeing it only for a few seconds. Hope to be back soon...

\section{Further reading}

Karaçetin, E., Welch, H.J., Turak, A., Balkız, Ö. \& Welch, G. 2011. Türkiye'deki Kelebeklerin Koruma Stratejisi [Conservation strategy of Butterflies in Turkey]. Doğa Koruma Merkezi, Ankara, TR. [In Turkish]

Didem Ambarlı, Munich, Germany didem.ambarli@gmail.com

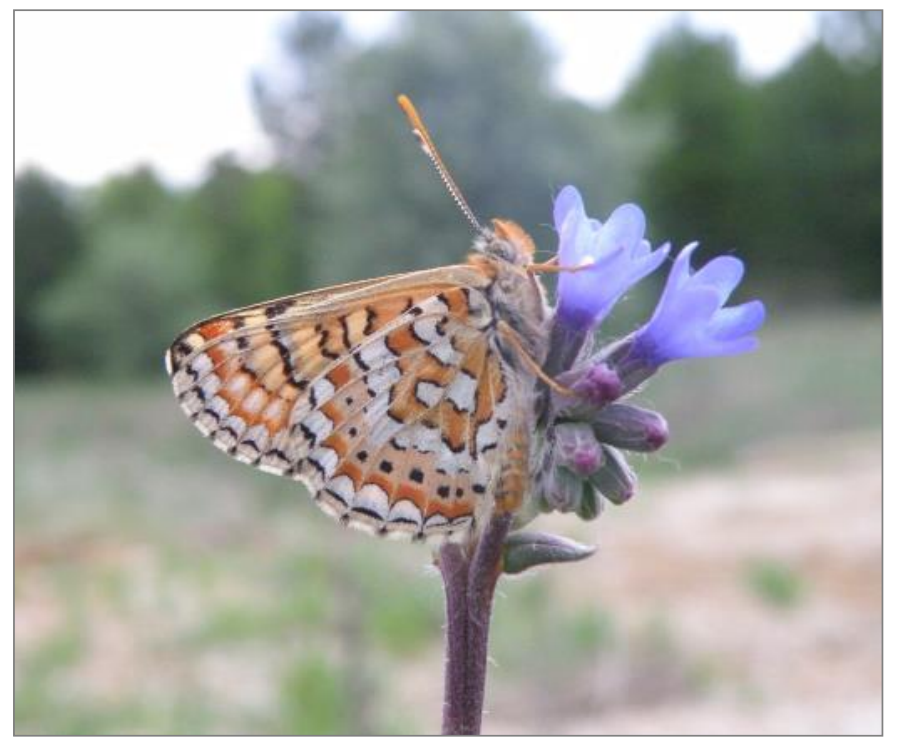

Steppe Fritillary (Euphydryas orientalis), Ankara. Photo: D. Ambarlı.

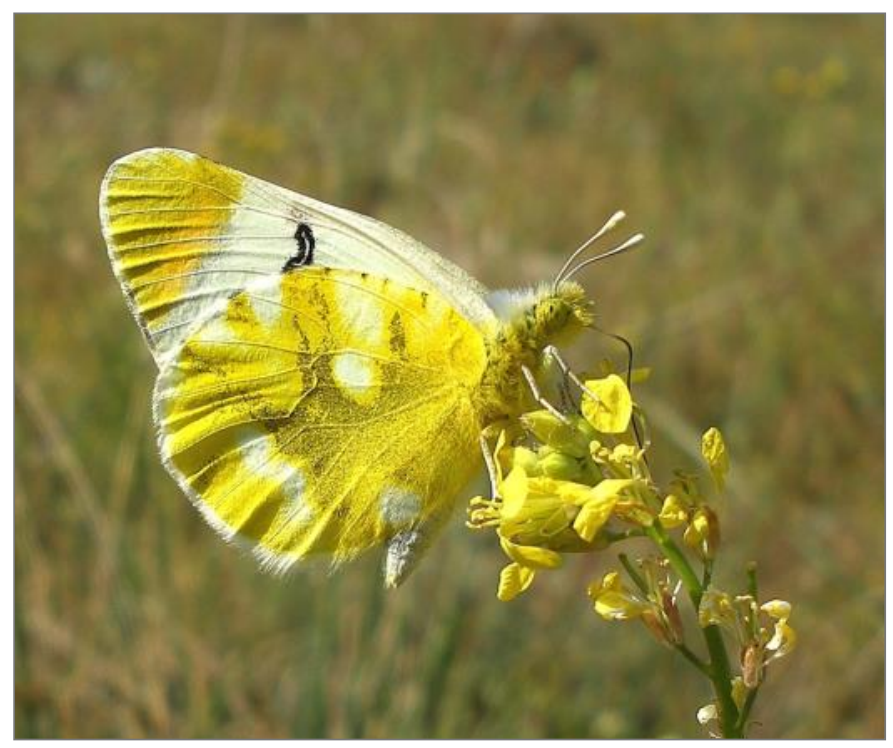

Sooty Orange Tip (Zegris eupheme), Ankara. Photo: S. Ekşioğlu. 


\section{Glimpses of a Grassland}

\section{Amazing grassland near crowded city}

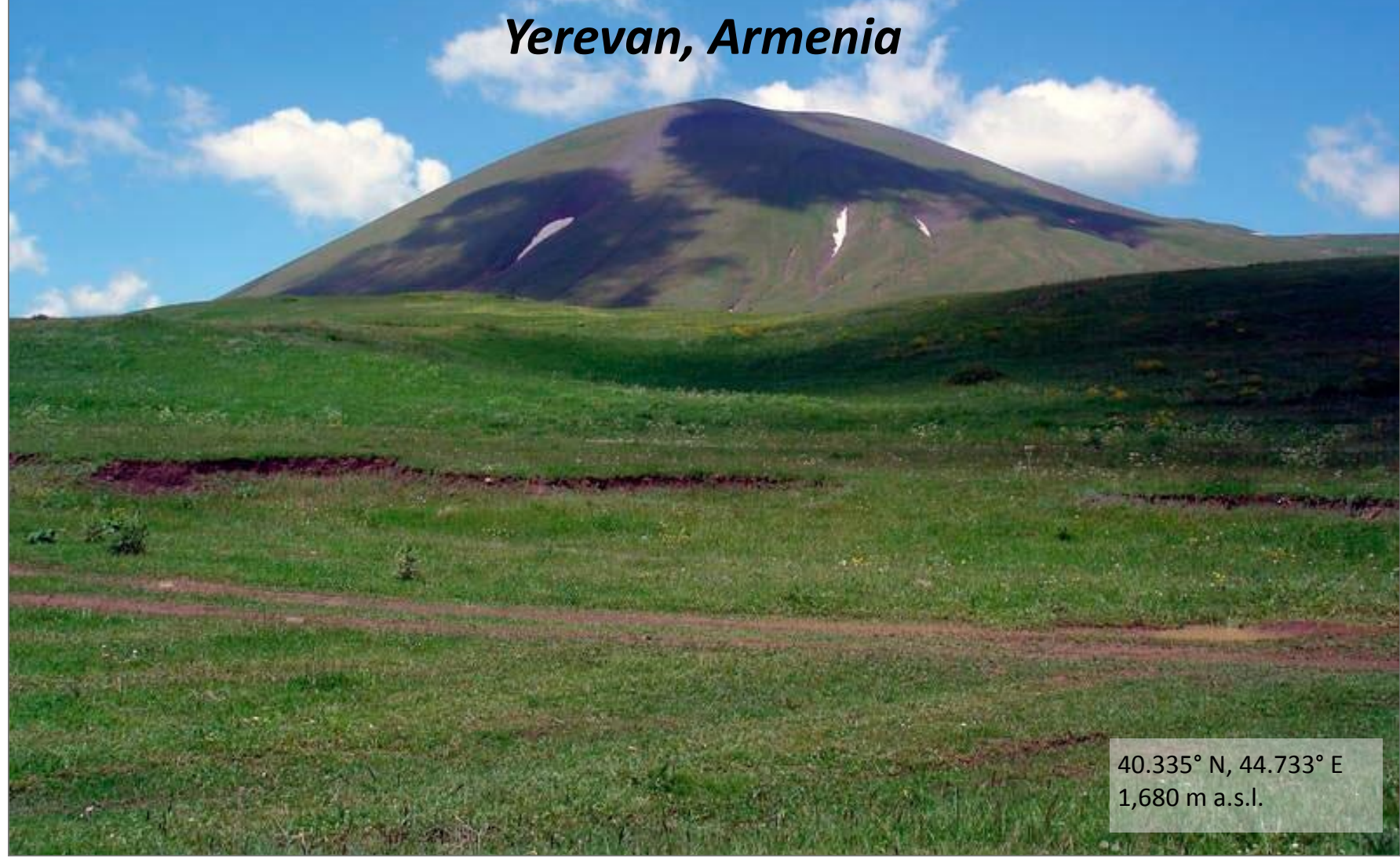

Armenia is a small mountainous country in the South Caucasus with a very small territory (less than $30,000 \mathrm{sq}$. $\mathrm{km}$ ). It is striking, with a variety of landscapes, the richness of flora and fauna, and the representation of diverse ecosystems from the sandy desert to alpine meadows and carpets, from steppes to broad-leaved forests, from arid open forests to swamps, rivers and lakes. If we assume that systematic study of the flora and vegetation of Armenia began at the very beginning of the XVIII century, it would seem that over the past 300 years all ecosystems of the country should have been thoroughly studied, all corners should have been investigated and described, in any case no worse than in the countries of Central Europe. However, reality surprises and continues to amaze botanists and ecologists. Every year researchers have amazing findings - new species, genus of plants or new ecosystems are discovered - new for science, the region or country - even near urban and well investigated areas.

Not far from Yerevan (about $20 \mathrm{~km}$ ) in a well studied area, at the foot of the dormant Hatis volcano there is a small ecosystem which we assign to the category E2.161 - Grassmeadow-steppes, highlighting the category E2.1611 -Grassmeadow-steppes with an abundant representation of Acanthus dioscoridis. The entire area occupied by this ecosystem is about 2 hectares at an altitude of about 1,700 $\mathrm{m}$ above sea level. The dominant species in this ecosystem are Festuca valesiaca, Koeleria macrantha and Dactylis glomerata, also rather plentiful are Hordeum bulbosum, Eremopoa persica, Stipa tirsa, and a very rare plant in Armenia, Acanthus dioscoridis, relatively abundant in rocky areas.

Acanthus dioscoridis was found in 1988 and identified as a new species for Armenia and the Soviet Union. The population includes about 1,000 individuals. The closest known 
population of this species is in Turkey, in the vicinity of Bitlis, about $300 \mathrm{~km}$ away from this population. Such a disjunction is interesting by itself but the ecosystem in which this species is represented is even more interesting. It is included in the Red Book of Armenia as a critically endangered species. It should be mentioned that this ecosystem is the only area of occupancy for Acanthus dioscoridis.

Rosa spinosissima and Cerasus incana are found in this ecosystem as separate shrubs. In grass cover can be found Scutellaria orientalis, Stachys atherocalyx, Phlomis tuberosa, Cerinthe minor, Crambe orientalis, Coronilla varia, Verbascum pyramidatum, Vinca grossheimii. In total, we've recorded about 120 species of vascular plants. Taxonomic and chorological analysis of the flora showed that the ecosystem is relict, preserved from at least the last glaciation. The appearance of Acanthus dioscoridis here is not a recent invasion; most likely, the species and the ecosystem were preserved in a kind of refuge at the foot of the volcano during the last glaciation. Obviously, this was facilitated by Hatis volcano, which, according to geologists, is dormant, as evidenced by its geothermal activity.

George Fayvush, Yerevan, Armenia gfayvush@yahoo.com

Alla Aleksanyan, Yerevan, Armenia alla.alexanyan@gmail.com

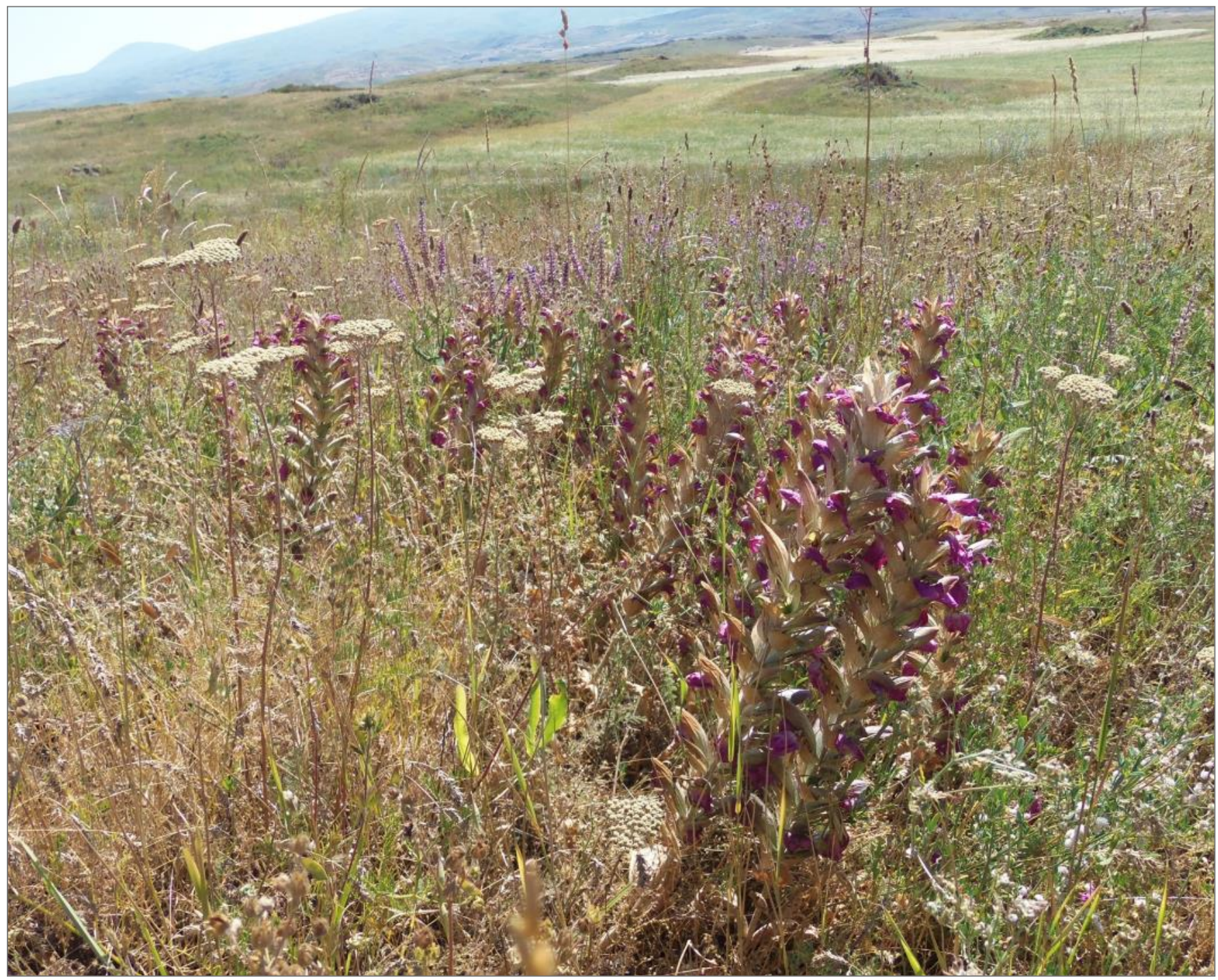

Acanthus dioscoridis at the foot of the dormant Hatis volcano. Photo: A. Aleksanyan. 


\section{Glimpses of a Grassland}

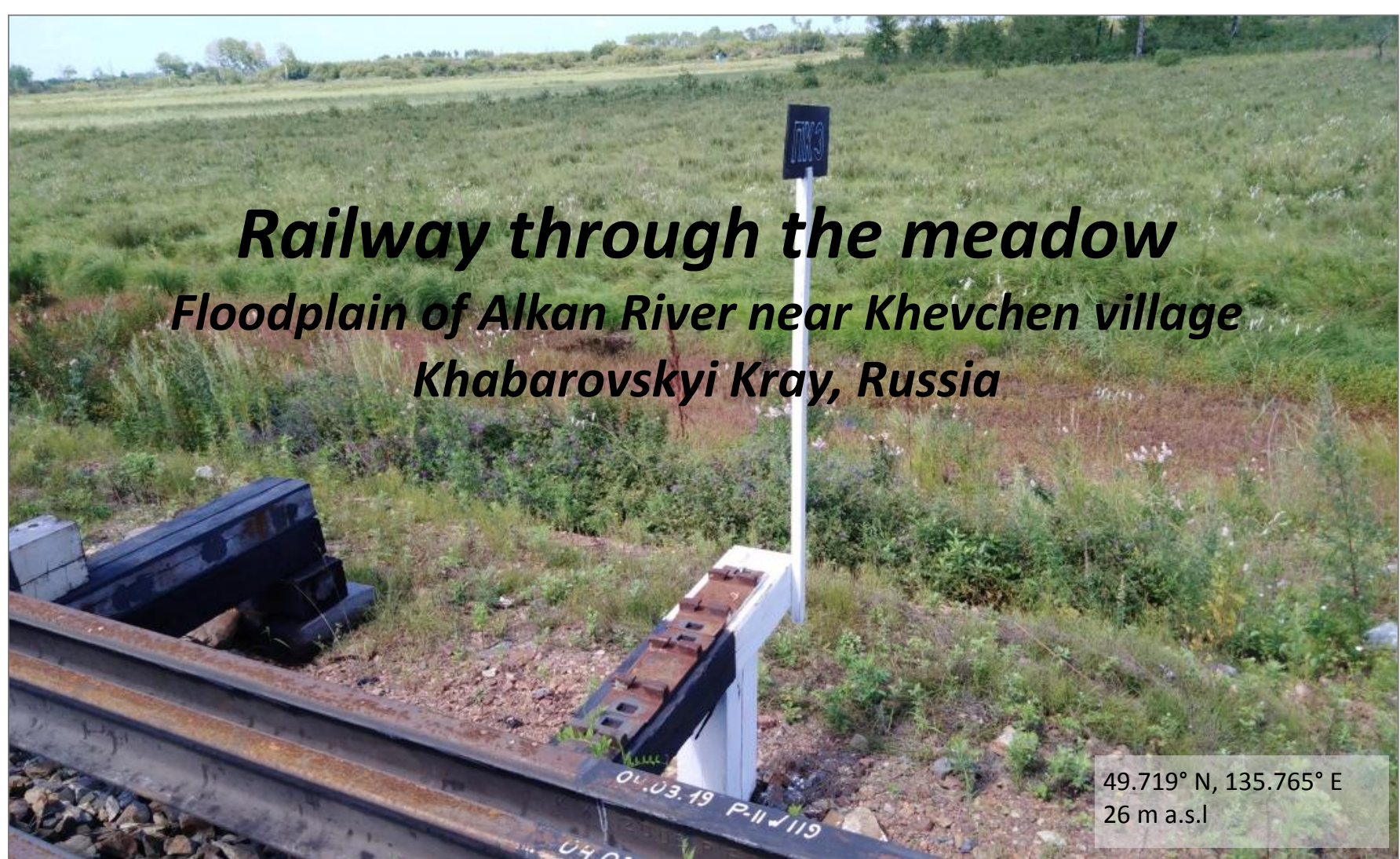

In August 2019, we had a trip to the Khabarovsk Kray (Far activities, but, as expected at present, a certain human imEast) for field verification of remote sensing data. This was pact is necessary for their existence.

carried out under a project mapping the Great Eurasian Natural Backbone as an integrated range of natural communities stretching from the Pacific Ocean to the Green Belt of Fennoscandia through the Arctic, tundra, forests and partially forest-steppe (Grant of Russian Fund for Basic Researches and Russian Society of Geographers No 17-05-41204 and the State Task No 0148-2019-0007). This huge natural massif is under various human impact. The case of grasslands is especially complicated, since they can be destroyed by human

On August 12, 2019, we arrived at the Khevchen railway station to examine briefly the wet meadow in the floodplain of the Alkan River. The railway has existed here since 1940. It separates the meadow from the same meadows of the Ramsar site 'Lake Bolon and the mouths of the Selgon and Simmi River' and the related IBA, the core of which is the Bolon Reserve (10 km from Khevchen). The upper part of the Alkan River is protected as an ichthyological preserve $(12 \mathrm{~km}$ from Khevchen). Unlike many meadows of the Amur Valley, the

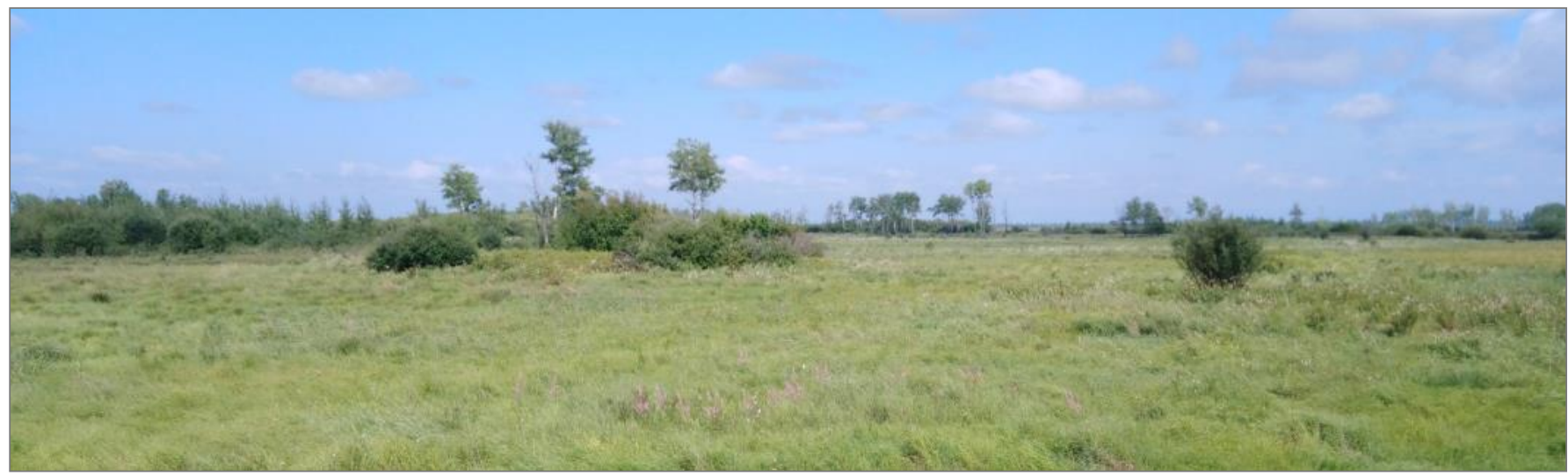

The wet meadow in the floodplain of the Alkan River. Photo: N. Sobolev. 
studied meadow has never been exposed to fires for the entire period of daily fire monitoring since 2010: the only fire closer than $500 \mathrm{~m}$ from Khevchen occurred on May 11, 2017 on the opposite bank of the Alkan River.

Calamagrostis langsdorffii dominates in this wet flood meadow. The grass layer is characterized by considerable height (maximum more than $150 \mathrm{~cm}$ ), high density (100\%) and huge litter. Among other species, Pedicularis grandiflora and Sanquisorba parviflora are most vivid and visible. Spiraea salicifolia sparce bushes bloomed with them. We were even dressed in the tone of flowering plants, taking in mind the possibilities of remote sensing. The studied floodplain meadow is a natural intrazonal community formed on alluvial soils annually enriched with silt. Annual spills prevent meadows from overgrowing with shrubs. Various types of meadows with Calamagrostis langsdorffii are widespread east of the Yenisei and especially in the Amur-Ussuri interfluve. They belong to the alliance Calamagrostion langsdorffii, order Calamagrostetalia langsdorffii of the class Calamagrostetea langsdorffii. Calamagrostis langsdorffii and Sanguisorba parviflora are, among others, character species of this class. Communities of this class occupy here biotopes similar to those of communities of the MolinioArrhenatheretea class west of the Yenisei.

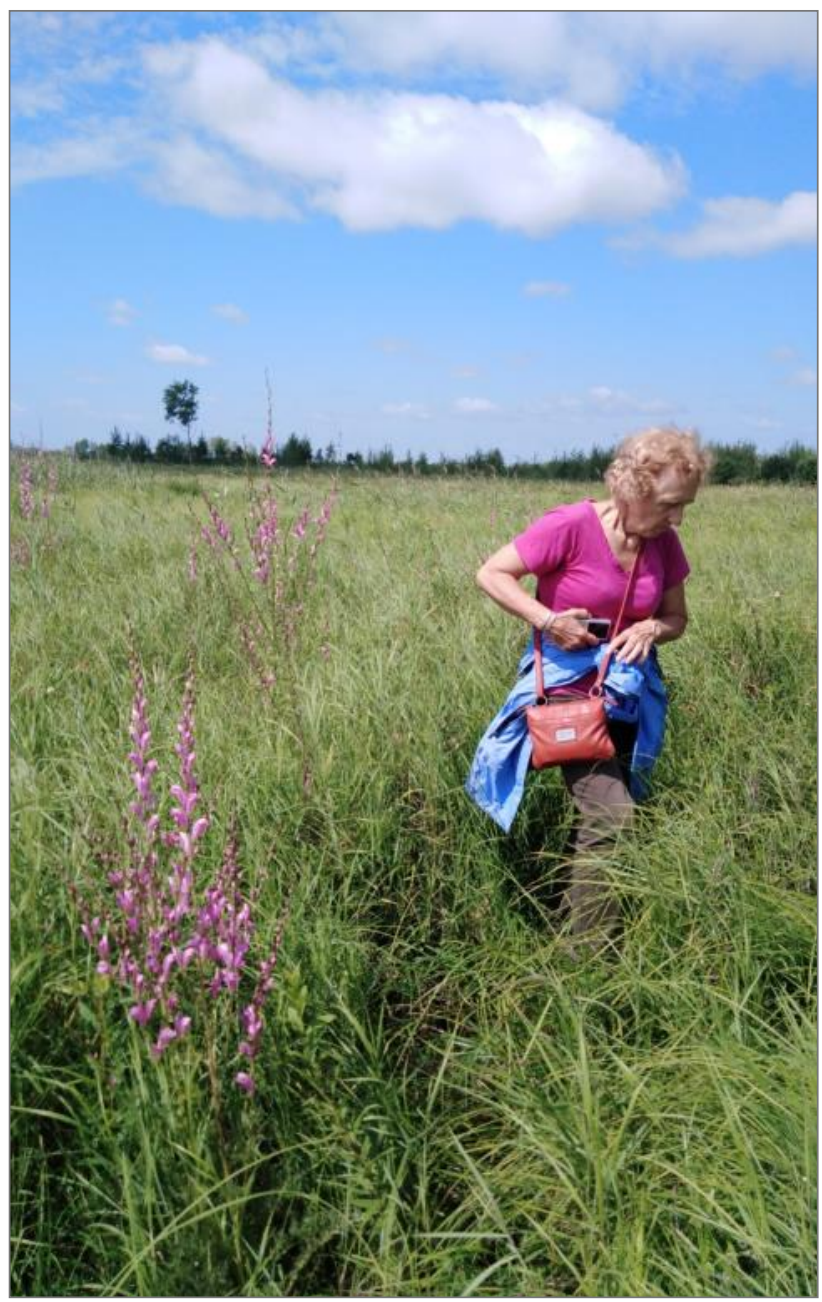

Pedicularis grandiflora and Dr. Elena Belonovskaya. Photo: N. Sobolev.
Communities with Phragmites australis, formed on floodplain lakes near the river, also occupy small humid plots along the railway.

Xerophytic habitats formed on the slopes of the railway. Here we see, among others, Lespedeza bicolor typical for Far Eastern meadow steppes and Corydalis speciosa inhabiting well insolated open dry biotopes. Among them there is also a species of European significance - Agrimonia pilosa.

Ruderal plants (Achillea alpina, Setaria viridis, etc.) grow on and near the railroad tracks. An alien species, Commelina communis, is also noted here. However, neither they, nor Impatiens glandulifera, not uncommon near railways and in settlements, penetrate the natural community due to its well-preserved composition.

In fact, the railway does not threaten the integrity of the Great Eurasian Natural Backbone here. However, it is important to pay attention for conservation of this meadow.

Elena Belonovskaya, Moscow, Russian Federation ebelonovskaya.0709@gmail.com

Nikolay Sobolev, Moscow, Russian Federation sobolev.nicolas@gmail.com

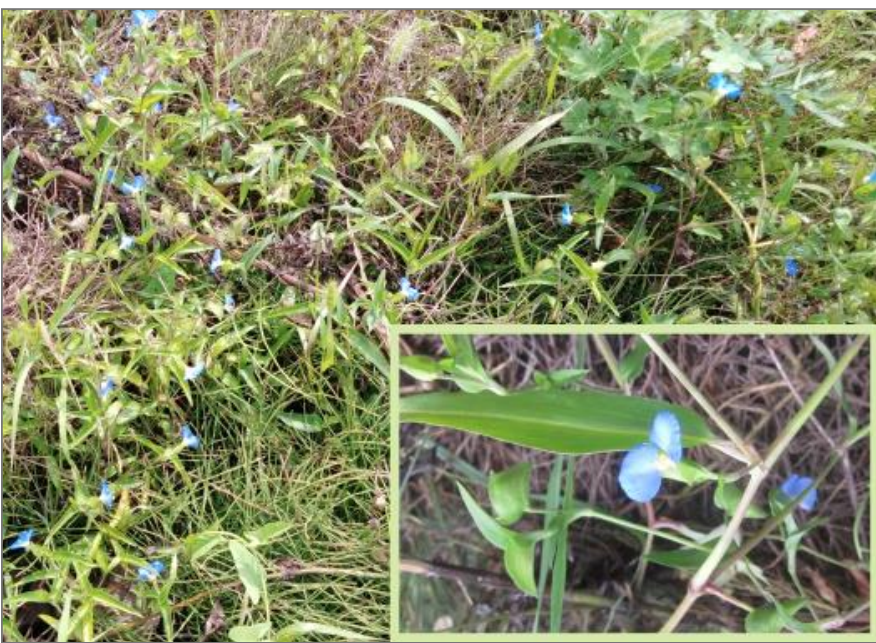

Commelina communis. Photo: N. Sobolev, E. Belonovskaya (box).

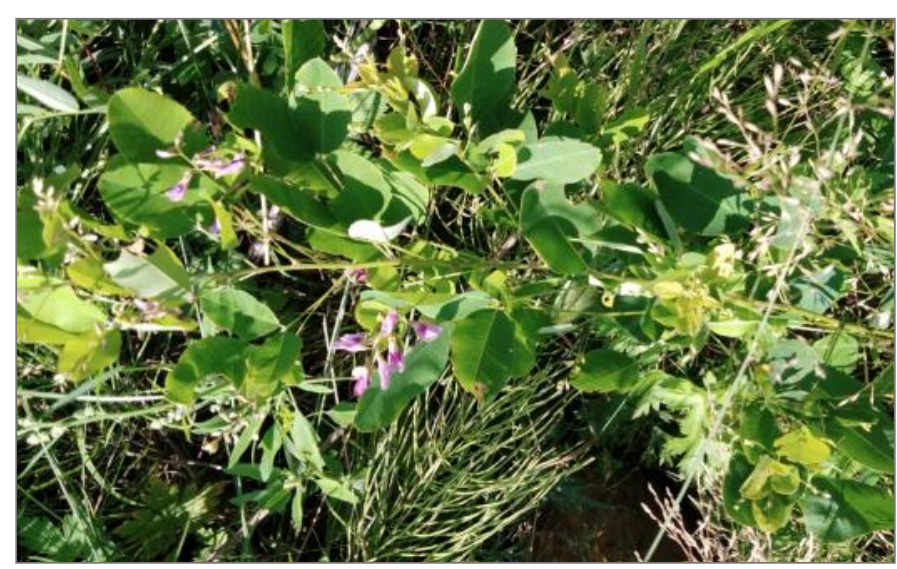

Lespedeza bicolor. Photo: N. Sobolev. 


\section{Glimpses of a Grassland}

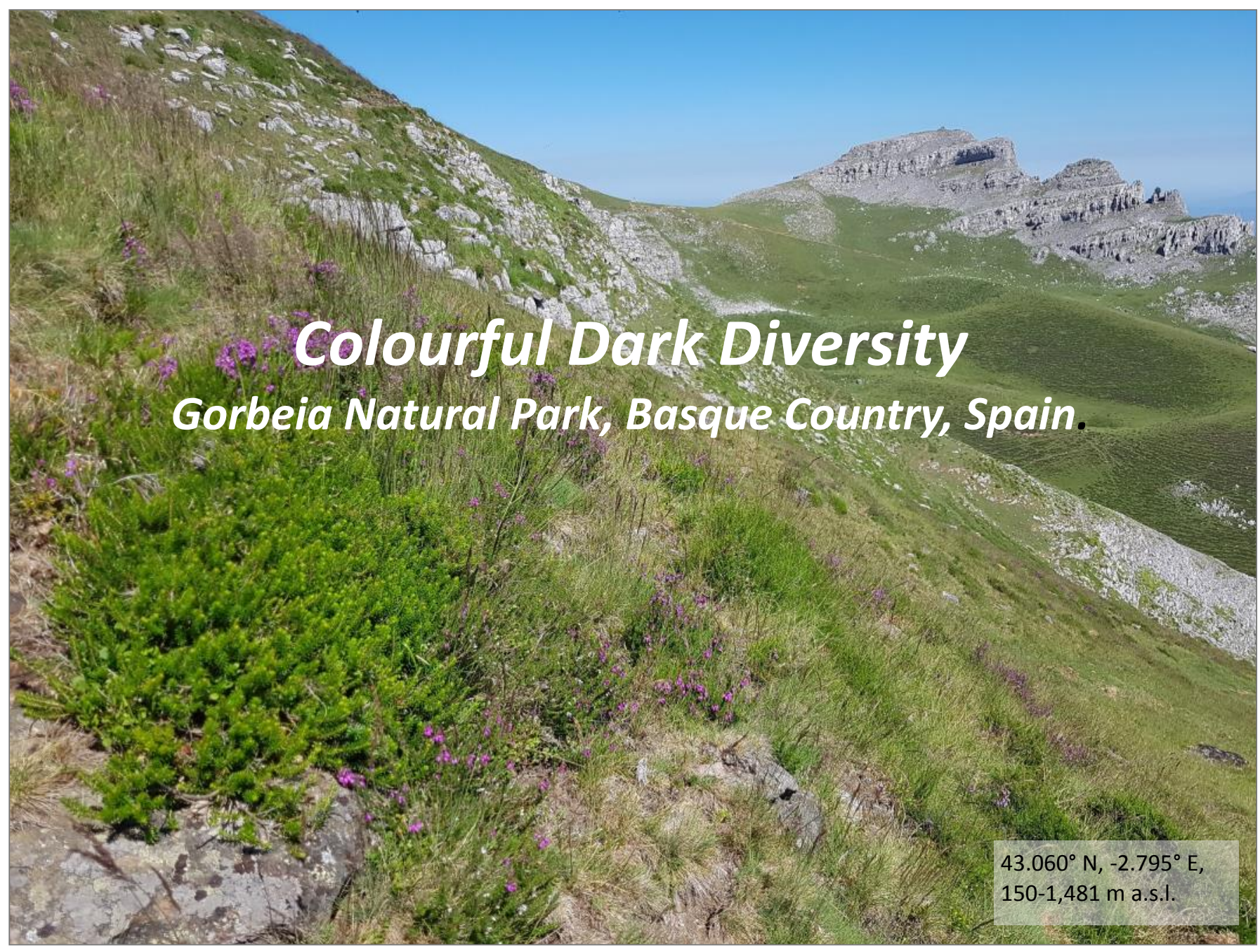

Every year Gorbeia mountain welcomes in May flocks of sheeps, cattle and horses coming from the surrounding valleys and filling the air with the sounds of their bells. Sheeps, mares and cows give birth to their babies, and spend the long summer days grazing and watching the hikers that everyday climb to the top of the mountain. I imagine this scene in my mind, and I wonder if this year is the same. Daffodils are already gone, as many other bulbs, and nobody was there to enjoy their colour.

I miss enjoying nature, and I miss our sampling in Gorbeia, where our research group from the University of the Basque Country has a study area for the DarkDivNet Project. Gorbeia mountain is part of the Basque-Cantabrian watershed, that divides the Cantabrian and Mediterranean Basins. The mountain top, at 1,481 m a.s.l., is only $43 \mathrm{~km}$ away from the Bay of Biscay, but southern foothills already show submediterranean features. In our study area of 10 $\mathrm{km}$ radius we have siliceous rocks, such as the sandstones of the Gorbeia Summit, but also limestone peaks and karstic landscapes, and flysch and marl in the foothills.

Natural zonal vegetation is mostly formed by deciduous forests with Fagus sylvatica, Quercus robur, Q. pyrenaica, $Q$. petraea and $Q$. faginea. Small patches of evergreen sclerophyllous forests with Quercus ilex and Arbutus unedo also occur in sunnny limestone outcrops. But everything is not forest in Gorbeia! Basque mountains have been used for millenia for animal husbandry, and this is evident if we look around the mountain and admire the extensive grasslands and heathlands. Heathlands draw the mountain with colour during summer, when heaths and gorses bloom.

Traditional land use combined burning and grazing, but heathland is now frequently ploughed to favoure grasslands of the alliance Violion caninae. On elevations higher than $1,300 \mathrm{~m}$ they host endangered species such as Diphasiastrum alpinum, Ranunculus ampexicaulis and Meum athamanticum, one of the reasons why every 


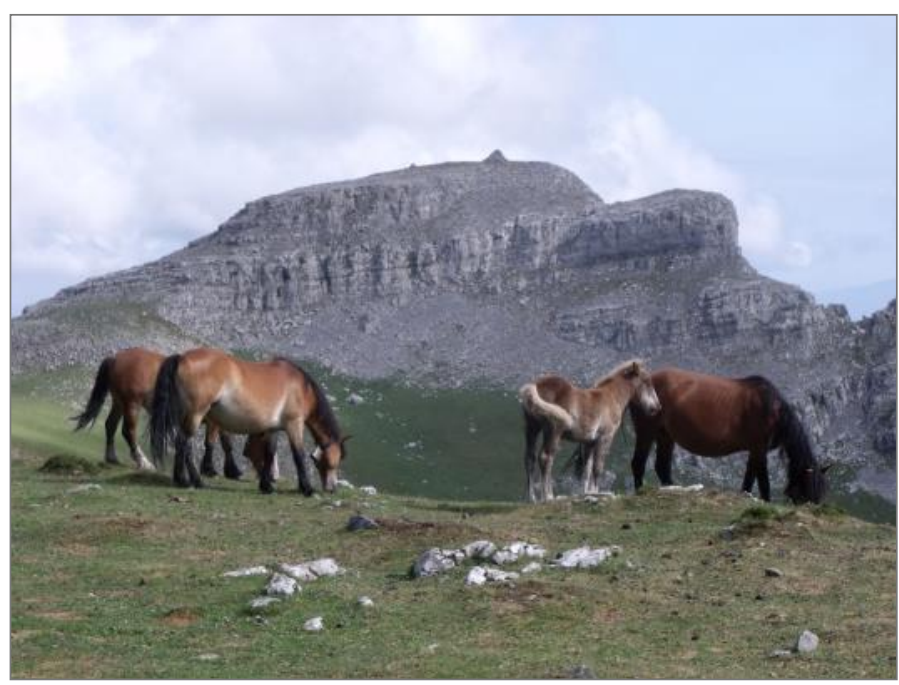

Mares and foul grazing in Agrostis curtisii grasslands, with Aldamin on the background. Photo: J.A. Campos.

summer our research group spends time in Gorbeia monitoring their populations. Small fens are common in these sandstone areas, with communities of the alliances Hyperico elodis-Sparganion, Anagallido-Juncion and Ericion tetralicis arranged along the hydrological gradient, along with rush communities (Molinion caeruleae). There was also a bog in Saldropo Plateau, which was totally destroyed due to peat extraction during 1970 s and 1980 s. A sad story that hopefully will always remind us that we really need to protect our natural heritage.

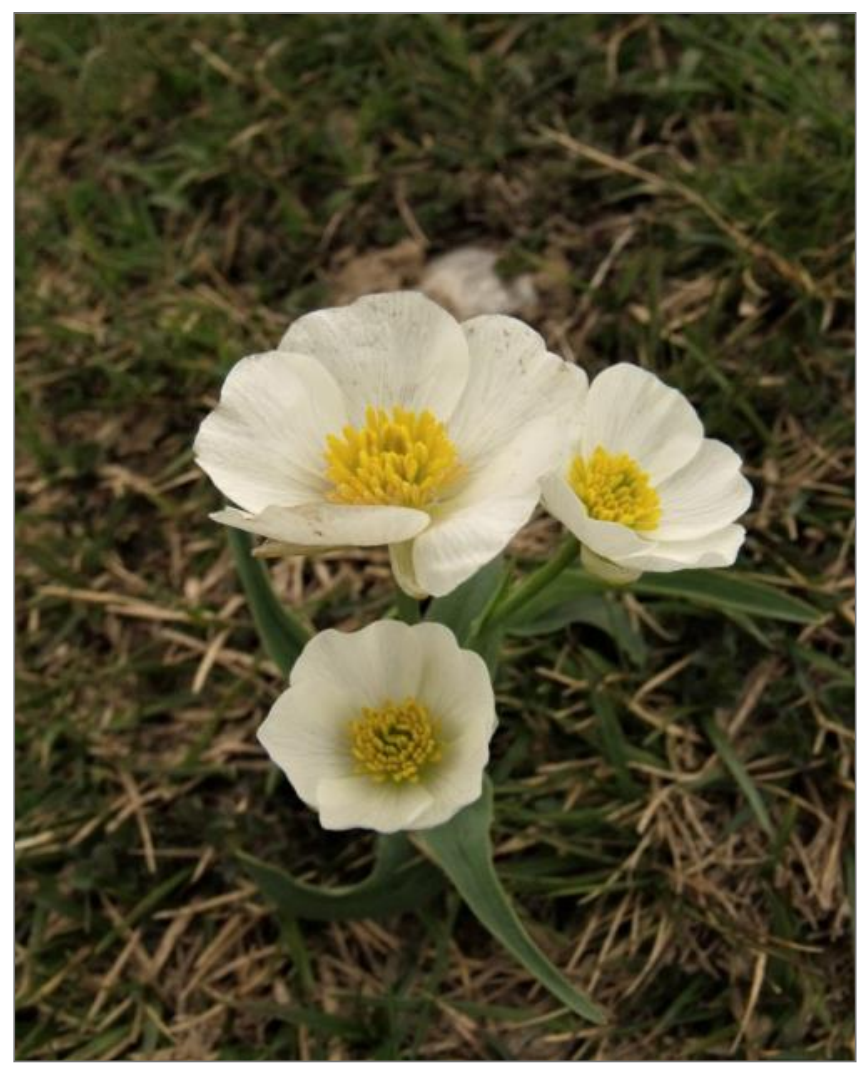

Ranunculus amplexicaulis. Photo: J.A. Campos.
On the limestone areas dry grasslands show us their beauty; both rocky grasslands (Bromo-Teucrion pyrenaici) and meso -xeric grasslands (Potentillo-Brachypodion pinnati) are often mixed with thorn-chusion scrubs (Genistion occidentalis). In the north-faced steep slopes of Aldamin, the highest limestone peak, subalpine grasslands of Primulion intricatae give shelter to scattered individuals of the protected orchid Gymnadenia gabasiana. On the foothills meadows of the alliance Brachypodio-Centaureion nemoralis are managed by combined mowing and grazing. On the southernmost area submediterranean rocky grasslands paint the eroded marl with colourful dots with flowers of Aphyllantes monspeliensis, Helianthemum apenninum, Coris monspeliensis, many other chamaephytes, and, of course, orchids.

I hope to return soon to Gorbeia and, together with my colleagues, whom I also miss so much, continue sampling the high habitat diversity that makes us happy!

\section{Further reading}

Darquistade, A., Berastegi, A., Campos, J.A. \& Loidi, J. 2004. Pastizales supratemplados Cántabro-Euskaldunes de Agrostis curtisii: caracterización y encuadre fitosociológico. Silva Lusitana 12: 135-149.

García-Mijangos, I., Biurrun, I., Campos, J.A., García-Magro, D., Herrera, M. \& Loidi, J. 2017. Seguimiento de las poblaciones de Ranunculus amplexicaulis, Diphasiastrum alpinum, Meum athamanticum y Nigritella gabasiana en el Monte Gorbeia (Bizkaia). Technical Report. Bizkaia Provincial Council, Bilbao, ES.

Idoia Biurrun, Bilbao, Spain idoia.biurrun@ehu.es

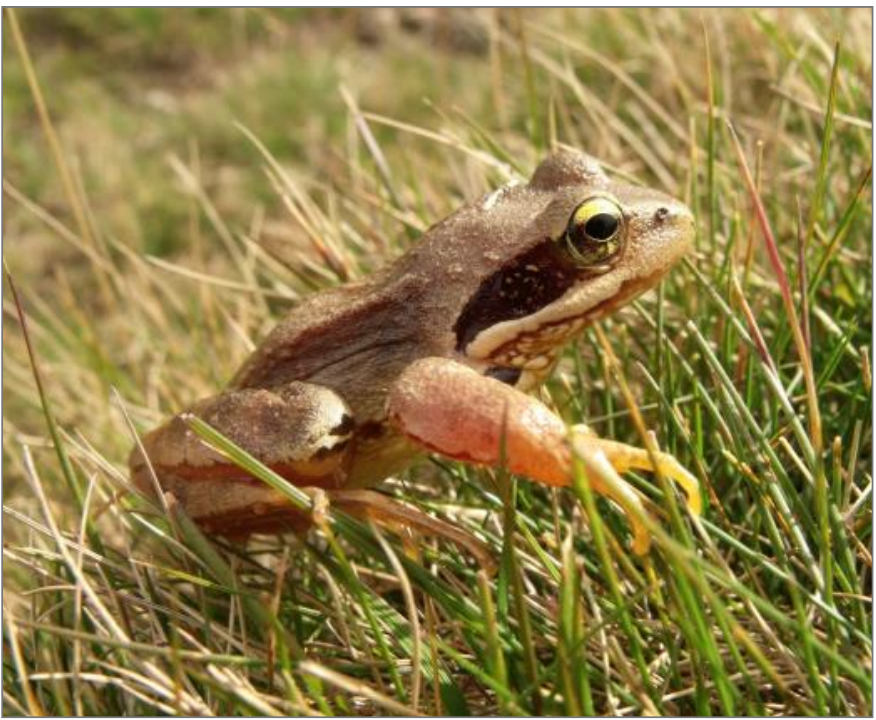

Rana temporaria in Nardus stricta, Gorbeia mountain, Basque Country. Photo: J.A. Campos. 


\section{Glimpses of a Grassland}

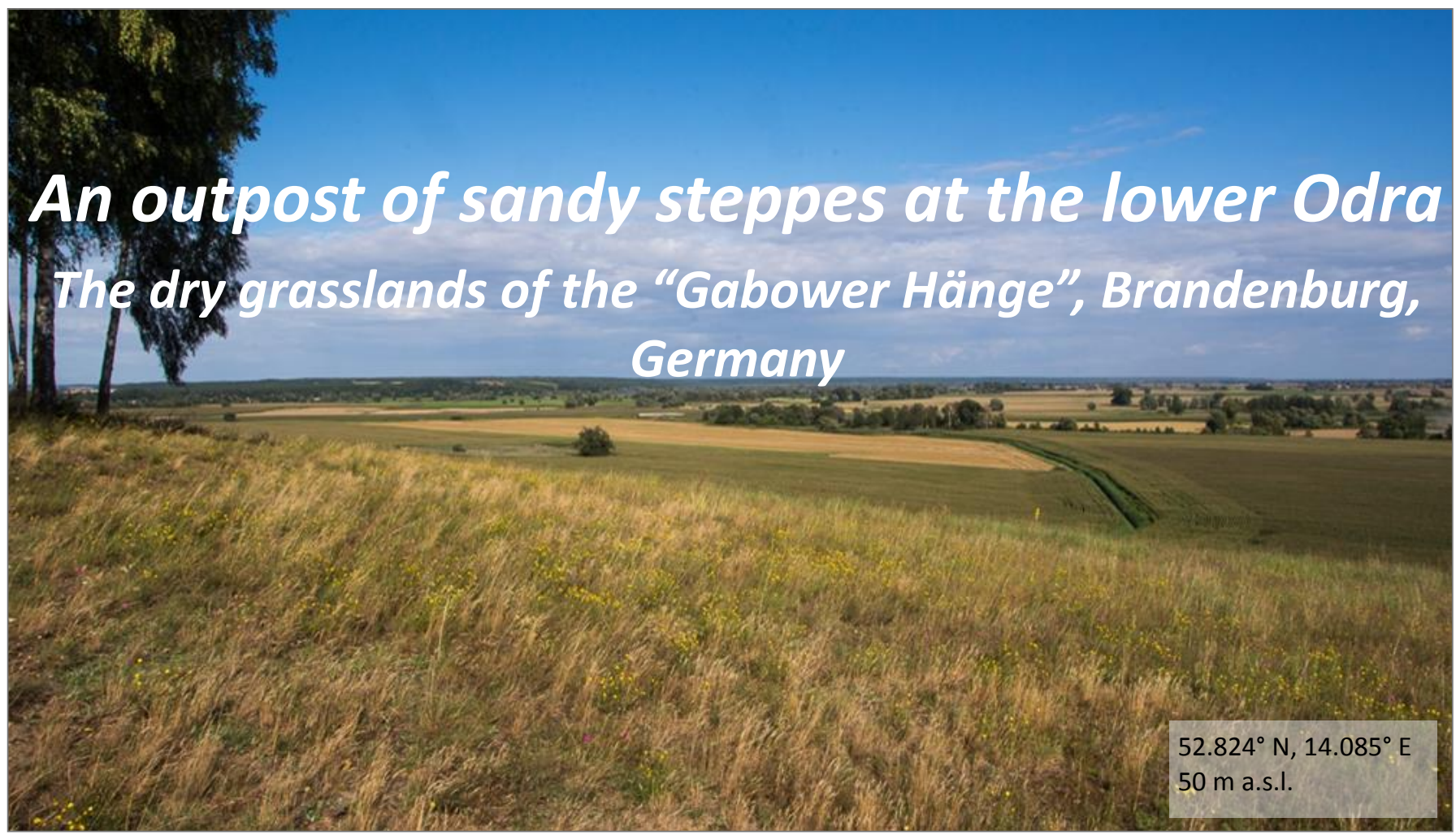

In 1993, I did my Diploma thesis on the "Flora and vegetation of dry grasslands and related plant communities in the Biosphere Reserve Schorfheide-Chorin" in NE Brandenburg. I stayed for half a year in a building of the Biosphere Reserve in a settlement of only a handful of houses amidst a big forest. I explored about 100 dry grassland sites in this conservation area of approx. $1250 \mathrm{~km}^{2}$ in size just by bicycle. While the main reasons for the proclamation of this Biosphere Reserve had been its extensive forests, lakes and mires with their large avifauna, actually also the dry grass-

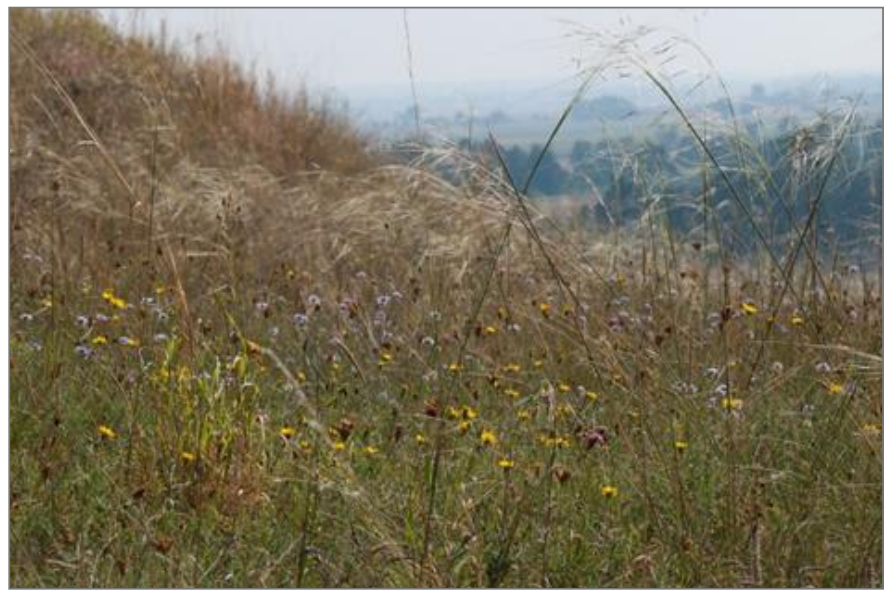

Potentillo arenariae-Stipetum capillatae with Stipa capillata, Scabiosa canescens and Hieracium umbellatum. Photo: J. Dengler. lands there are quite diverse, covering wide edaphic gradients from loamy to sandy and from basic to acidic.

Among all the studied grassland sites, the "Gabower Hänge" was one of the most fascinating ones for me. In the following years, I regularly organized vegetation ecology field courses in the Biosphere Reserve, and always this site was one of the highlights. During one of the classes conducted in 2015 we resampled some of my more than 20 year old plots. Interestingly, we found hardly any vegetation change; if at all to the better.

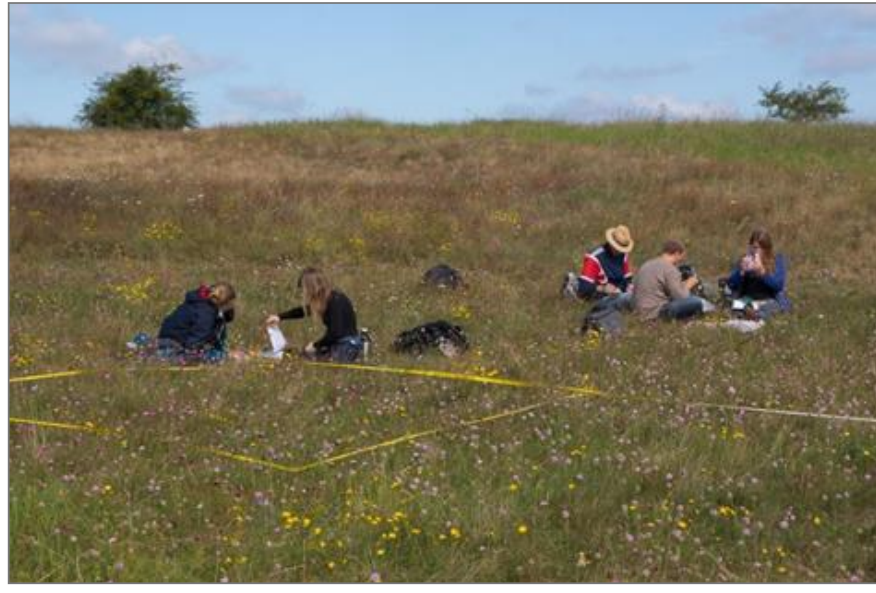

Students of the University of Bayreuth sampling EDGG Biodiversity Plots in an extensive stand of the Armerion elongatae. Photo: J. Dengler. 
So, what makes the "Gabower Hänge" so special that I would count it among the ten most important dry grassland sites in Germany? The site is located just $3 \mathrm{~km}$ from the Odra river, in one of the driest parts of Germany, with less than $500 \mathrm{~mm}$ of annual precipitation. It is an isolated lobe of a terminal moraine of the Weichselian glaciation that falls steeply towards the former flood plain of the Odra river, nowadays intensively used as arable fields. What a contrast the marginal slopes are with their diverse xerothermic vegetation! While most of them are composed of marl, the "Gabower Hänge" is an exception as it is largely composed of sand. Due to the origin of the sand and the subcontinental climate, the sand has largely a high $\mathrm{pH}$, often above 7 . Therefore, one can encounter here some of the largest and best developed stands of the alliance Koelerion glaucae as well as of the psammophytic subassociation of the Potentillo arenariae-Stipetum capillatae (Festucion valesiacae) within Germany here. There are also well-developed stands of the Armerion elongatae and dry subtypes of the Arrhenatherion elatioris, and locally the Cirsio-Brachypodion and the Corynephorion canescentis. For some rare subcontinental to continental plant species, the "Gabower Hänge" hosts one of largest populations within Germany, e.g. Silene chlorantha and Scabiosa canescens. Throughout the seasons, the slopes are full of flowers, from various small annu- al Veronica and Myosotis species in spring to Aster linosyris and Dianthus carthusianorum in autumn. In total, at least 333 vascular plant species as well as 42 bryophyte and 40 lichen species are known from the 80 ha large area. The fauna is also diverse: there are many xerothermic orthopterans, the Sand lizard (Lacerta agilis) is common, and one might see the Eurasian hoopoe (Upupa epops). While the site is still not formally protected as a nature reserve and the grassland management via sheep grazing did not always work out during the last decades, the "Gabower Hänge" has maintained most of its peculiarity and beauty during the 27 years I have known it. It is certainly an insider tip for grassland lovers!

\section{Further reading}

Hüllbusch, E., Brandt, L.M., Ende, P. \& Dengler, J. 2016. Little vegetation change during two decades in a dry grassland complex in the Biosphere Reserve Schorfheide -Chorin (NE Germany). Tuexenia 36: 395-412.

Kratzert, G. \& Dengler, J. 1999. Die Trockenrasen der „Gabower Hänge" am Oderbruch. Verhandlungen des Botanischen Vereins zu Berlin und Brandenburg 132: 285 -329 .

Jürgen Dengler, Wädenswil, Switzerland juergen.dengler@uni-bayreuth.de

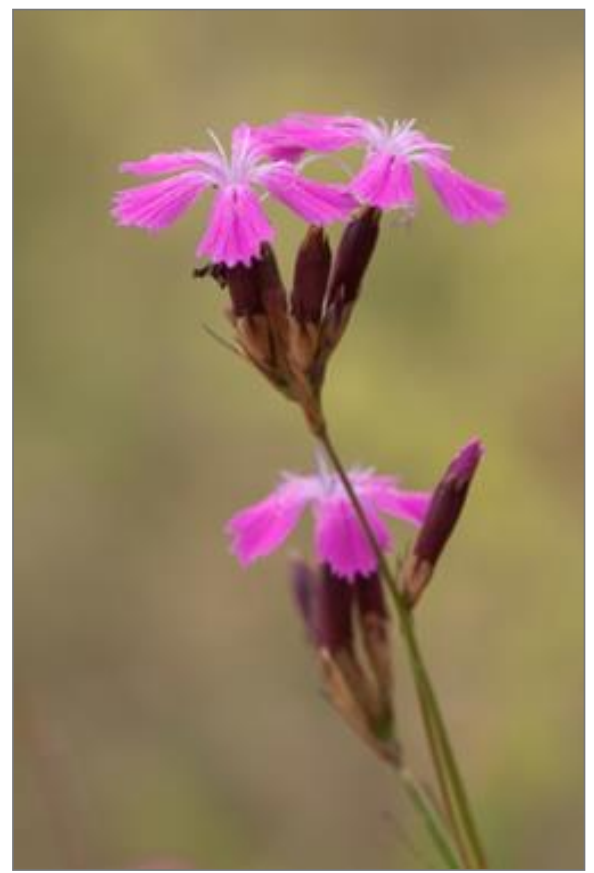

Dianthus carthusianorum. Photo: J. Dengler.

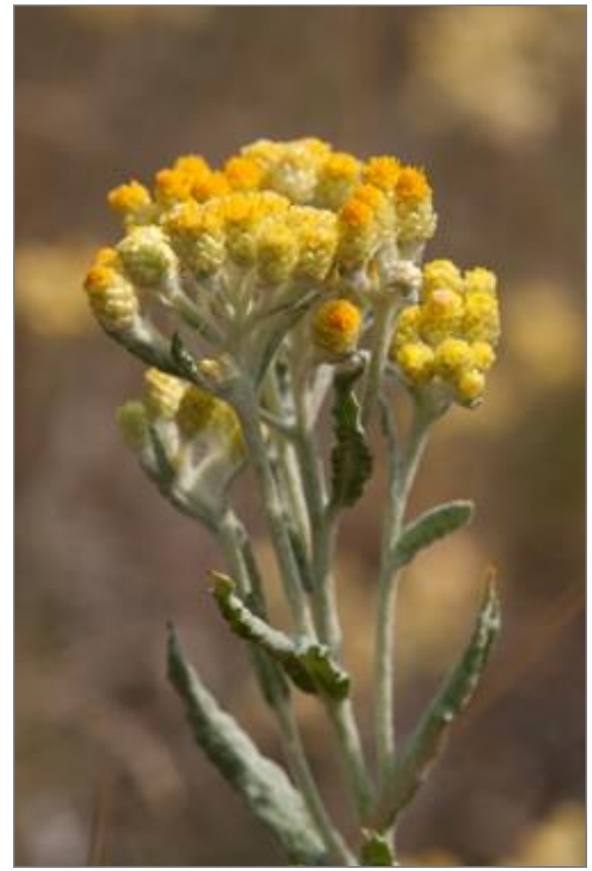

Helichrysum arenarium. Photo: J. Dengler.

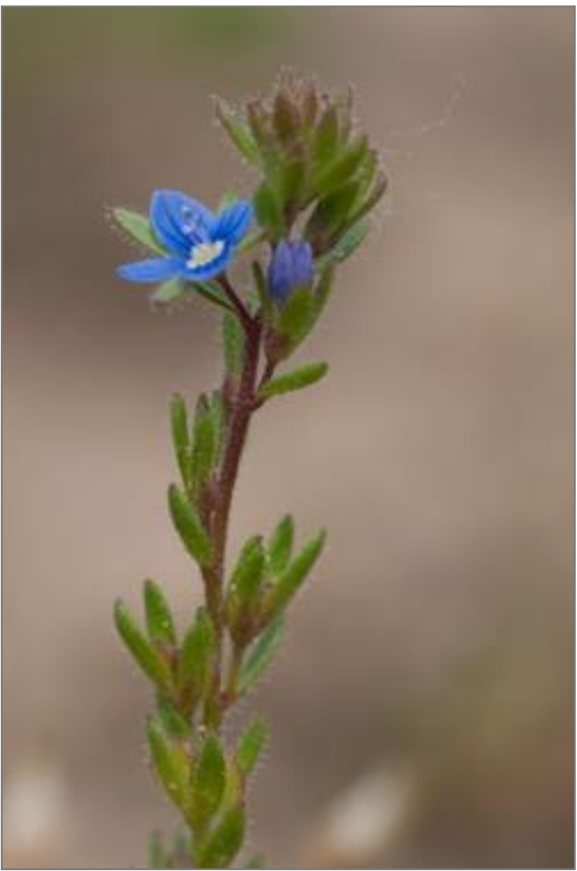

Veronica dillenii. Photo: J. Dengler. 


\section{Glimpses of a Grassland}

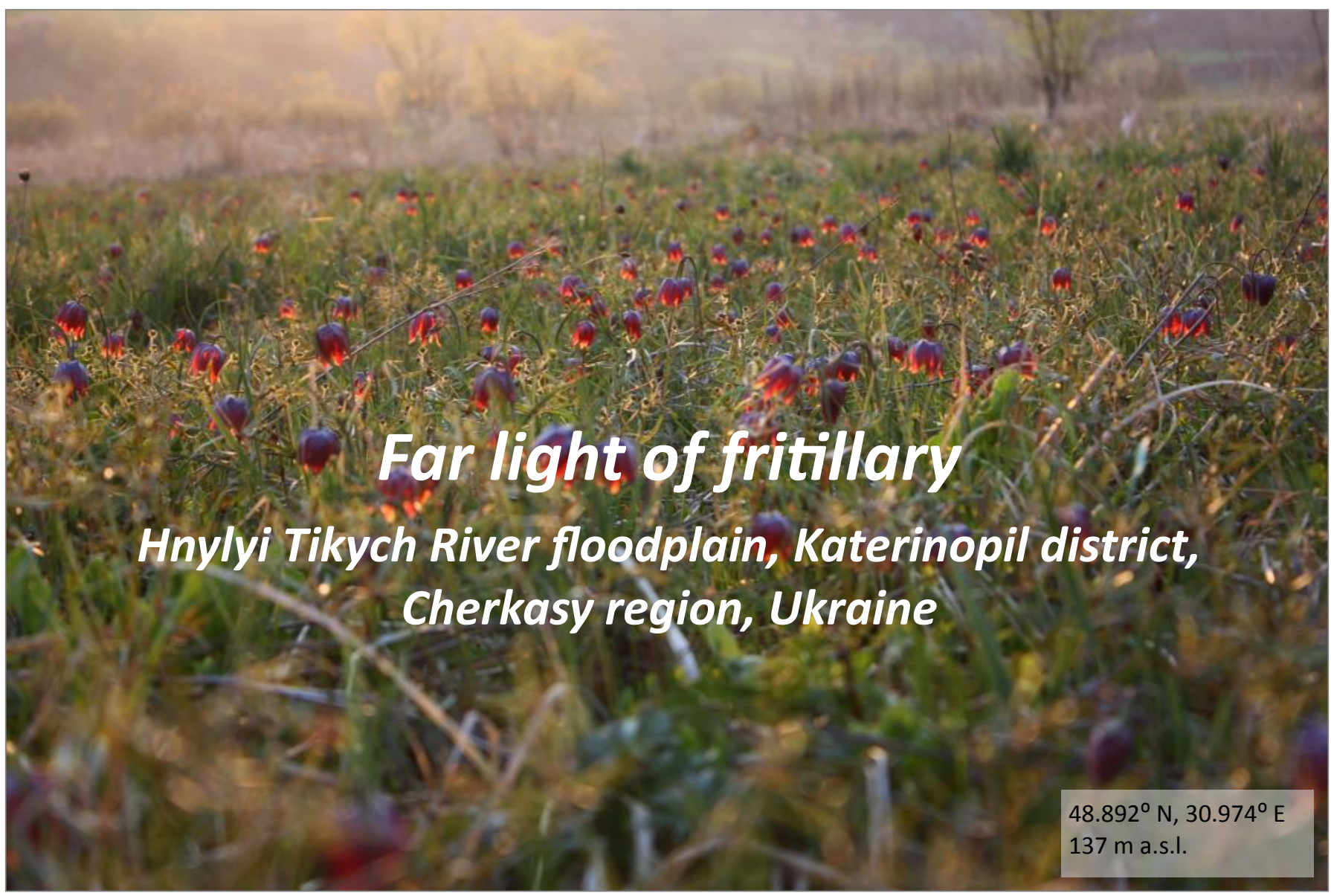

Despite the fact that I studied grasslands since the end of the 1990s, for a long time I could not see one of the most beautiful grassland flowers - a snake's head fritillary also known as chess flower. When I was preparing my Ph.D. thesis, I once saw this plant at the fruiting stage, but I first saw flowering fritillary only in 2007, when I moved from Kiev to Uman, my hometown. My colleagues from the National Dendrological Park "Sofiyivka" showed it to me. This scene stunned me, because it was not one or two flowers, as I expected, but a huge population with no less than several hundred thousand individuals and had such a high density that the floodplain was painted a dark purple color from the flowers. This plant was introduced to me as Fritillaria meleagroides. This location was already mentioned in several literary sources, and even in the Red Data Book of Ukraine. Since I had never seen other species of fritillary, except for the non-native imperial fritillary in flower beds, it never occurred to me to doubt the identification. The second time I visited this place after 5 years. I got there in the evening, at sunset and in the rays of the setting sun we saw an unusual picture - each flower seemed to absorb a piece of sunset and looked like a small lantern. Fortunately, I was able to capture this fantastic sight in the pictures. After some time, I posted my drawing of this plant on Facebook, of course, indicating that it is Fritillaria meleagroides. What a surprise when, soon, my colleague from Kharkiv Natalia Saidakhmetova wrote to me that my picture depicts a different species - Fritillaria meleagris. At first I did not believe her, because judging by the map in the Red Data Book of Ukraine, this species is distributed mainly in the western regions of Ukraine and has never been reported from Cherkasy region. However, Natalia was able to convince me that her identification was correct. The fact is that in the eastern regions of Ukraine Fritillaria meleagroides is quite widespread. However, just a year before the appearance of my Facebook drawing, Natalia found an unusual fritillary in Slobozhansky National Nature Park, but to confirm that it was Fritillaria meleagris, she did a lot of research into differences between the two species. This story showed that the generally accepted ideas about the range of Fritillaria meleagris and Fritillaria meleagroides in Ukraine are not entirely true and this should be corrected in the next edition of the Red Data Book of Ukraine. Since this population is located within the reserve of local importance, for some time I was 
sure that it was under protection. Later, I found out that this reserve belongs to the category of 'hydrological'. Taking this into account, I prepared a justification for a botanical reserve called "Dzinziry" (the local name for fritillary). It should be noted that the locals know that this species is listed in the Red Book and indignantly reported that some people dig it up and pick it for bouquets for sale. Over the past several years, in the second half of April, I have been trying to visit this magical place and I try also to show this unique beauty to all my friends and colleagues. This year I was not able to visit this place during the fritillary flowering, but I hope that for many years I will have the opportunity to admire the magical light of these beautiful flowers in the rays of the setting sun.

Anna Kuzemko, Kyiv, Ukraine anyameadow.ak@gmail.com
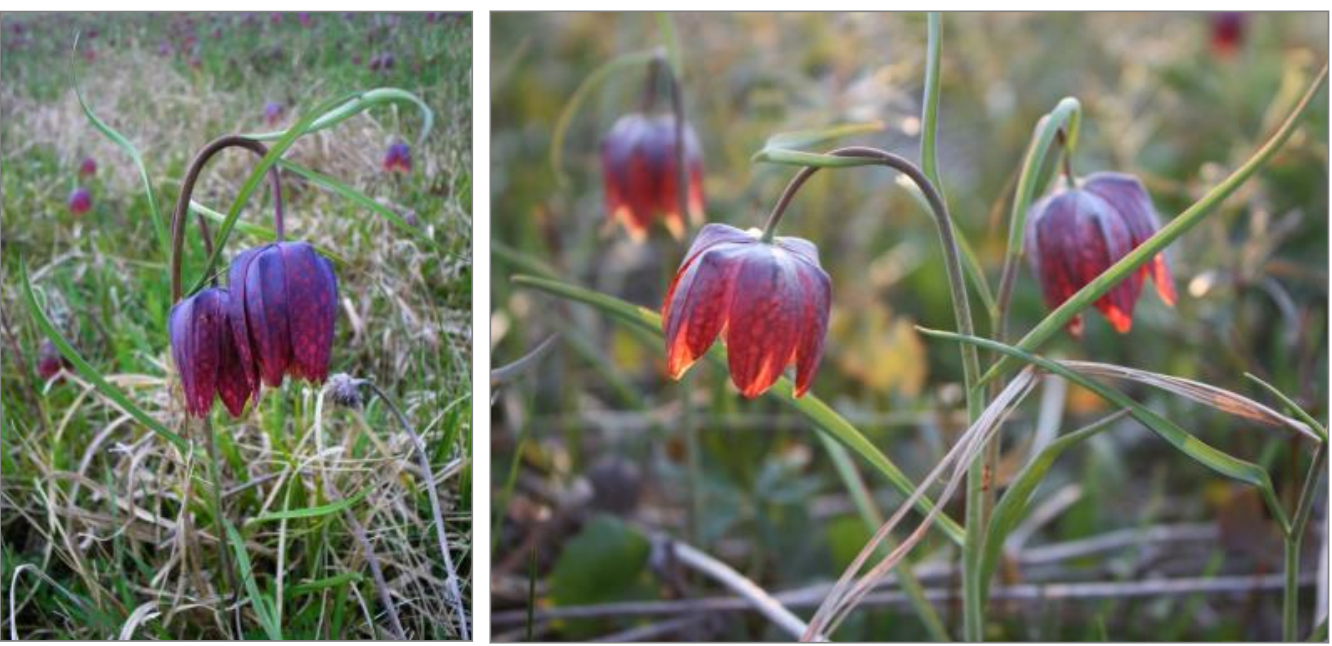

21 April, 2007.

27 April, 2011. Photo: A. Kuzemko.

Photo: A. Kuzemko.
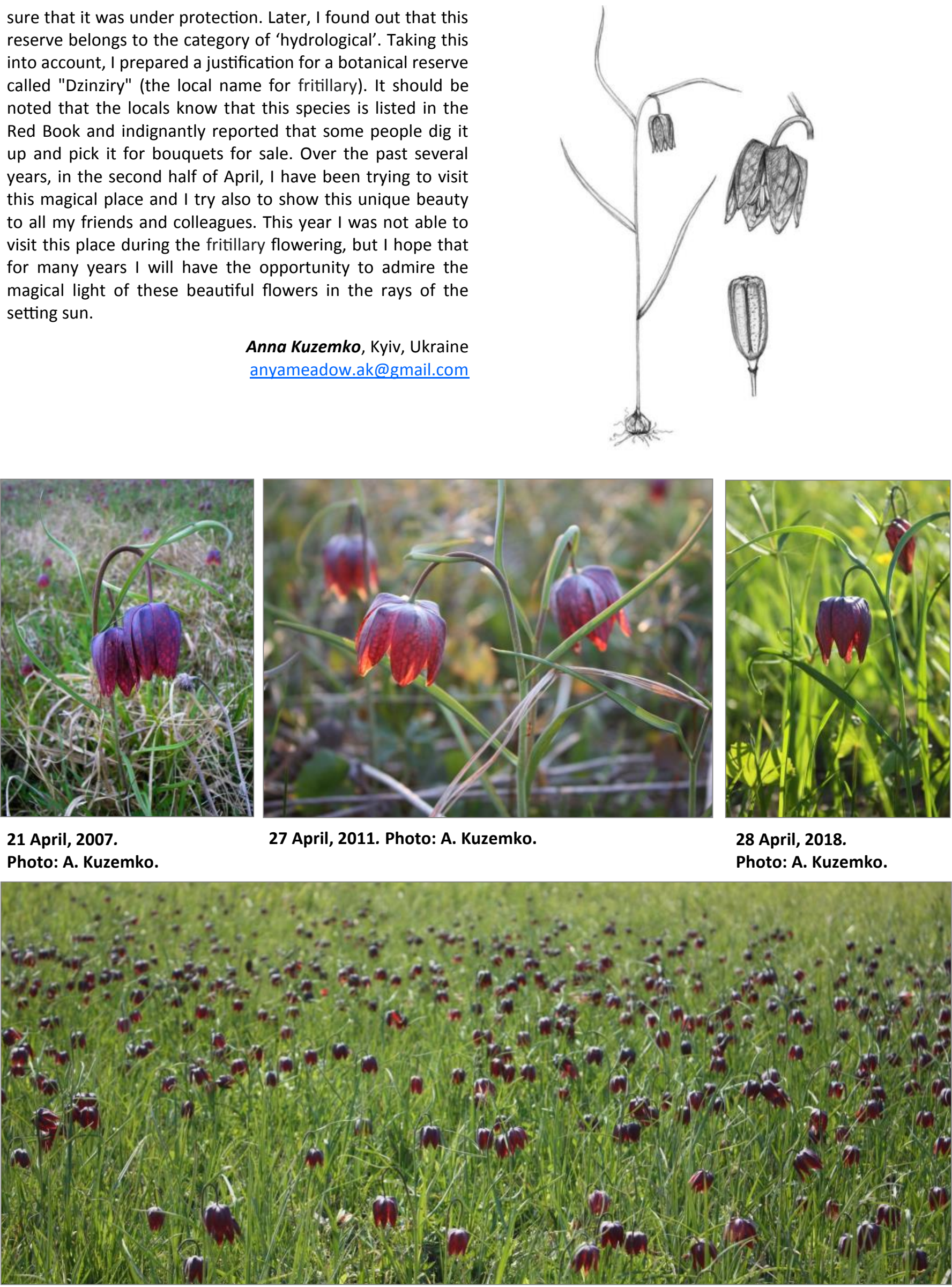


\section{Glimpses of a Grassland}

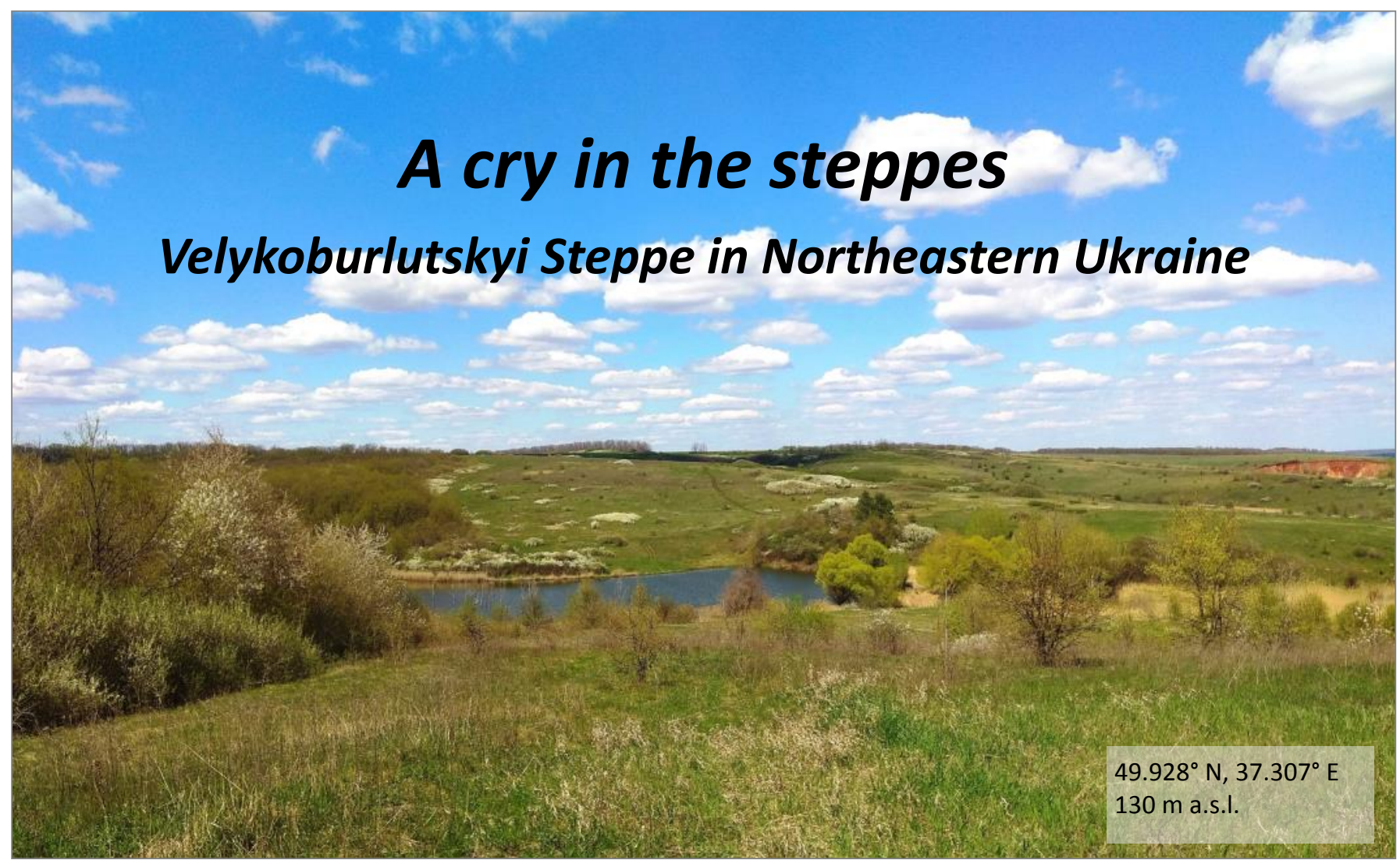

A large area of forest-steppe lies in the northeast of Ukraine. It was formerly covered with meadow and forbfescue-feather grass steppes on the upper interfluves and gully slopes; natural forests grew in ravines, and the floodplains hosted rich meadows.

We launched research in the Velykoburlutskyi Steppe in 1991 and focused on marmot (Marmota bobak) ecology and the vegetation of its habitats. At that time, the area in question had been transformed by human activity. All lands available for ploughing were converted into crop fields. Natural grasslands survived on the steep slopes, some gully bottoms and mesic meadows. They were used for intensive grazing that promoted development of a specific pasture community. Only small spots left somehow intact hosted the typical steppe plants: Stipa capillata, S. pennata, Salvia nutans, Adonis vernalis, Centaurea orientalis, Inula hirta, Galatella villosa, Trifolium montanum, Vinca herbacea, Iris pumila, Amygdalus nana, Caragana frutex, Chamaecytisus ruthenicus.

An area of intensive cattle grazing became an ecological center of the marmot settlement. Year in, year out we watched a lawn thoroughly trimmed by cows. In spring, it was emerald green, later the summer heat made it faded and grayish but it always revived after rains. The marmots shared the pastures with the wheatear (Oenanthe oenan- the) that nested in their burrows, and a number of birds. Of these, the most common was the skylark (Alauda arvensis). The steppe met us with a choir of voices, melodic in birds, alarming in marmots. Seeing us, the adult animals rushed to their burrows, but curious juveniles were not scared. They accompanied us with sonorous cries, ignored by their adults.

Since 2005, stall-fed cattle rearing has been replacing traditional pastoralism. Rich grasses and forbs returned to the pastures, but did not profit their inhabitants. High grass quickly turns coarse and senescent, lacking nutrients. Without a wide view, the marmots become easy prey for foxes and dogs. Young animals hardly grow up nor gain fat for wintering. In the new conditions, the young marmots did not survive; the adults gradually died, and the settlement was doomed to vanish.

In 2012, when the entomologists joined us to study the pasture invertebrates, there was only one gully left where intensive grazing maintained the marmot families. We found out that the spiders preferred ungrazed gullies while the true bugs did not care and chose the gully slopes. The carabid beetles were more abundant at the bottoms. The dung beetles, surely, thrived on the pasture and weevil beetles followed them. The variety of arthropod responses needed thorough investigation. Alas, we were late. The grazing was 
finally ceased in 2015. Since then we have been forced just to observe the life of abandoned steppe gullies and their inhabitants.

Early morning in May, we are walking along the steppe. The feather grasses and forbs are blossoming. The skylark is still singing its lovely song in the sky, but near the ground, it is quiet. Just one old marmot is spying on us from the high grass. He has nobody to address his alarm call so he is silent. "Hey, old man! Will we ever see your family back again?"

\section{Further reading}

Polchaninova, N., Savchenko, G., Drogvalenko, A., Ronkin, V. \& Shabanov, D. 2016. The impact of cattle grazing on cursorial spiders (Aranei) and true bugs (Heteroptera) in steppe gullies of northeastern Ukraine. Agriculture, Ecosystems \& Environment 234: 65-71.

Savchenko, G. \& Ronkin, V. 2018. Grazing, abandonment and frequent mowing influence the persistence of the steppe marmot, Marmota bobak. Hacquetia 17: 25-34.

Nina Polchaninova, Kharkiv, Ukraine polchaninova n@ukr.net

Galina Savchenko, Kharkiv, Ukraine savchgala5@gmail.com

Vladimir Ronkin, Kharkiv, Ukraine ronkinvl@discover-ua.com

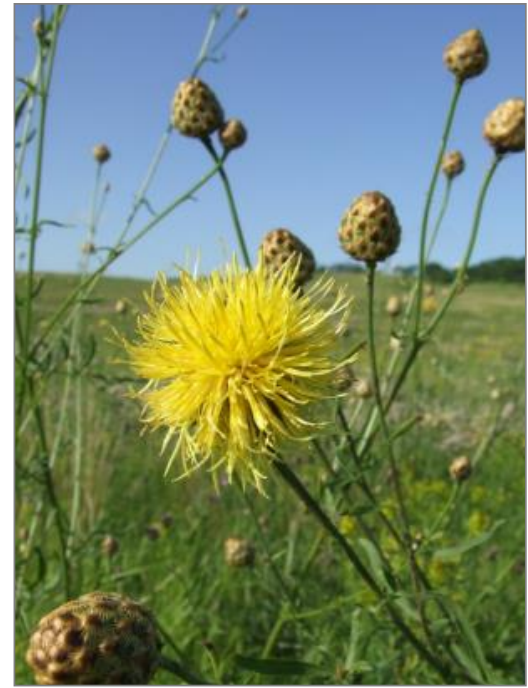

Centaurea orientalis.

Photo: V. Ronkin.

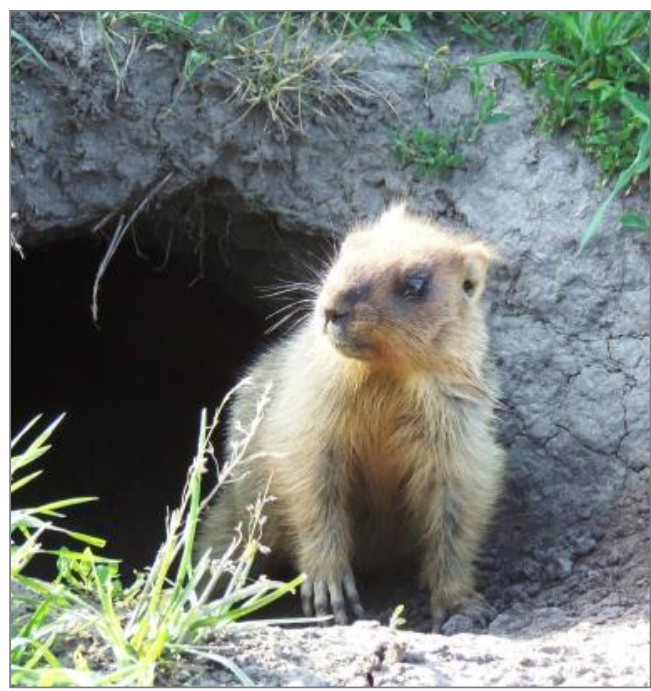

Marmota bobak. Photo: V. Ronkin.

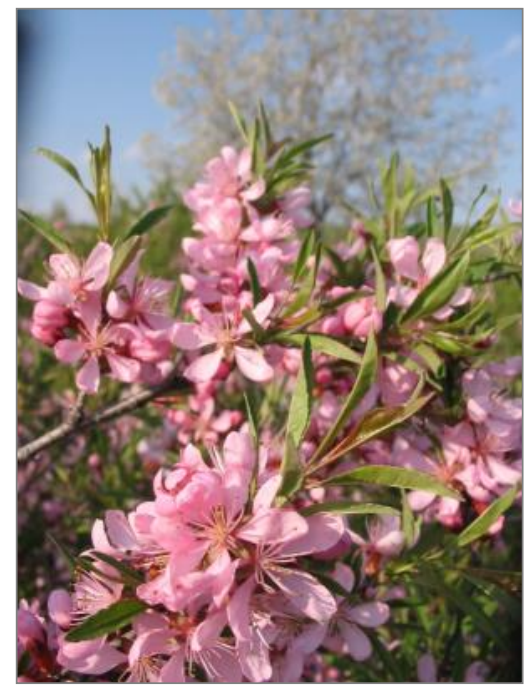

Prunus tenella. Photo: V. Ronkin.

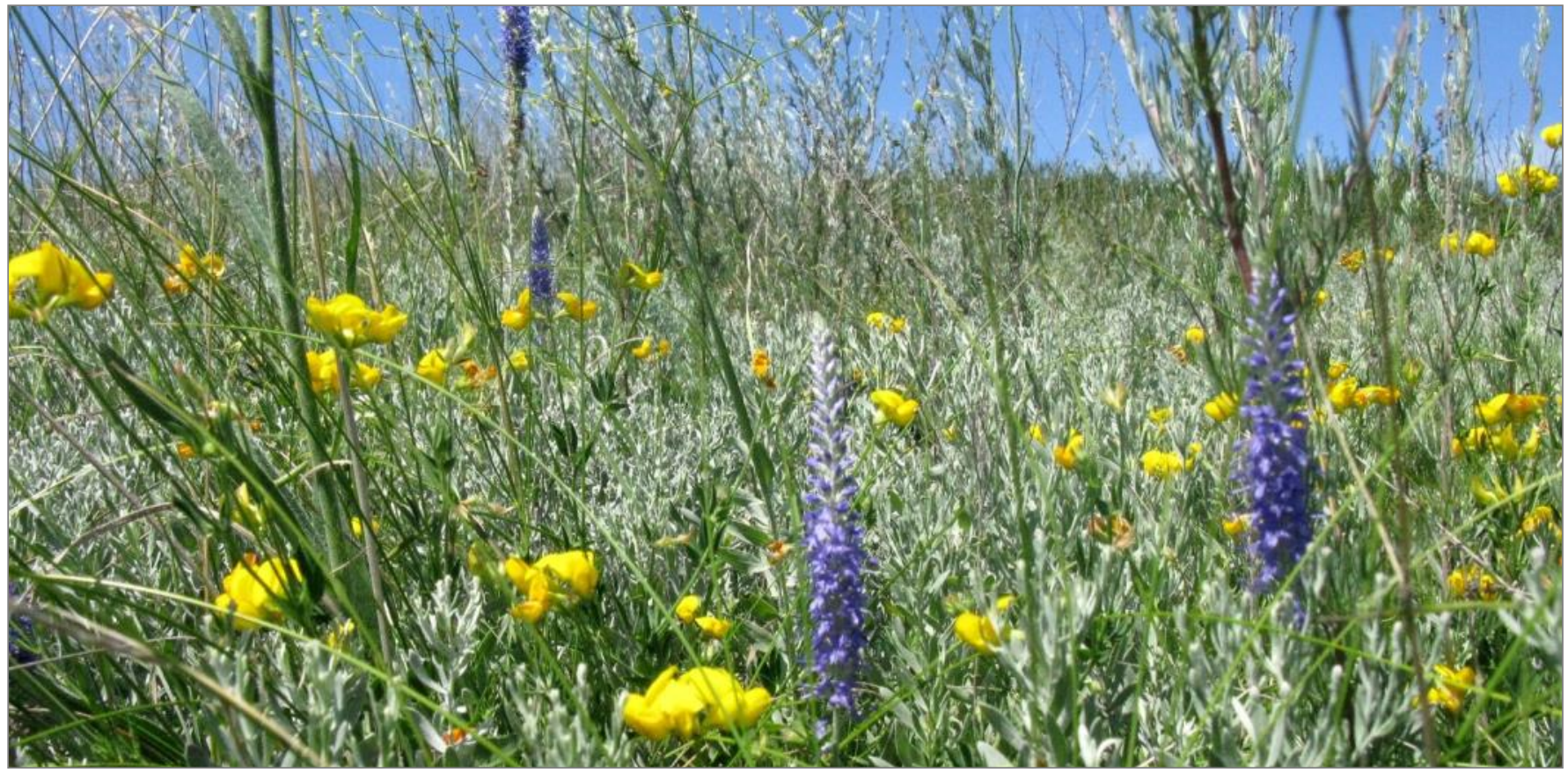

Blossom of a steppe forbs. Photo: N. Polchaninova. 


\section{Glimpses of a Grassland}

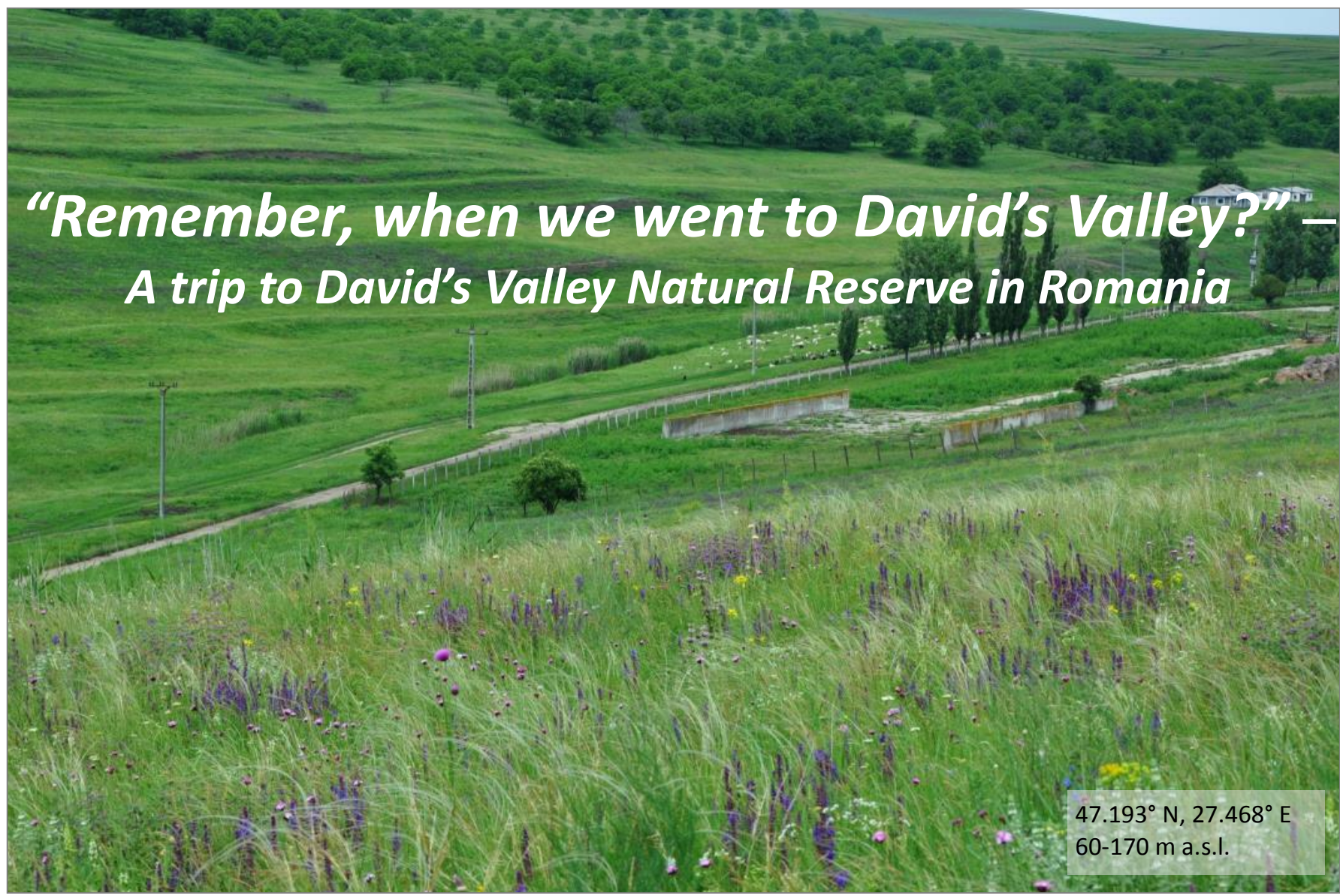

Sometimes, especially now, in the lockdown, we go back to the memories from our past trips. One of the lovely memories is our "steppe hunting" trip to Romania in early June 2013. It is the memory of the Carpathian landscapes, the endless horizon of the Danube Delta, the people we met on the way and most of all the beauty of the Romanian meadows and the wildflowers. I went there to learn more about steppe vegetation and to find inspiration for my planting design projects and Tim for his passion for plants.

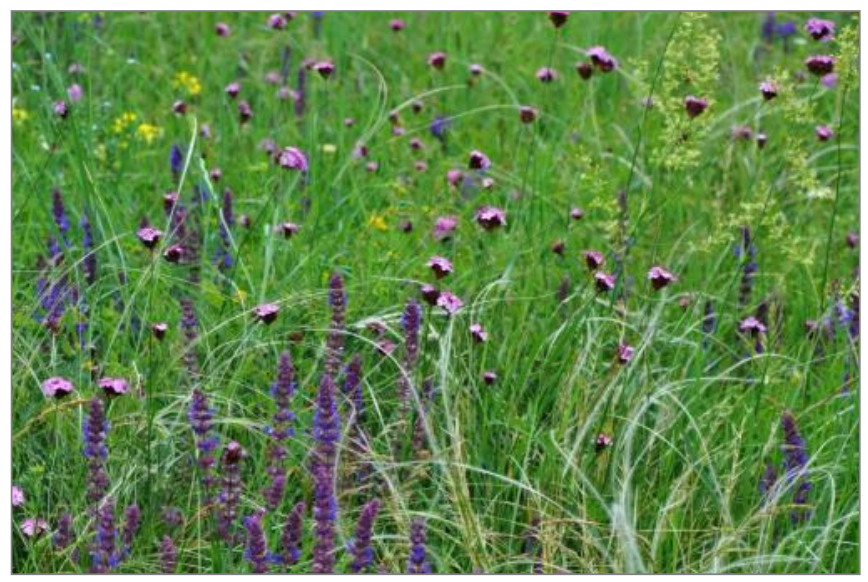

One of the most incredible places we visited was David's Valley Hay Fields Natural Reserve (Rezervaţia naturală "Fanetele seculare Valea lui David"). The reserve is located just West of the city of laşi and covers an area of 46.36 hectare. It is located on the western slope of the hill Coşeri (La Coşări).

David's Valley Reserve is listed as IUCN Category IV (Habitat/Species Management Area) for having an important role in preserving the flora and fauna adapted to

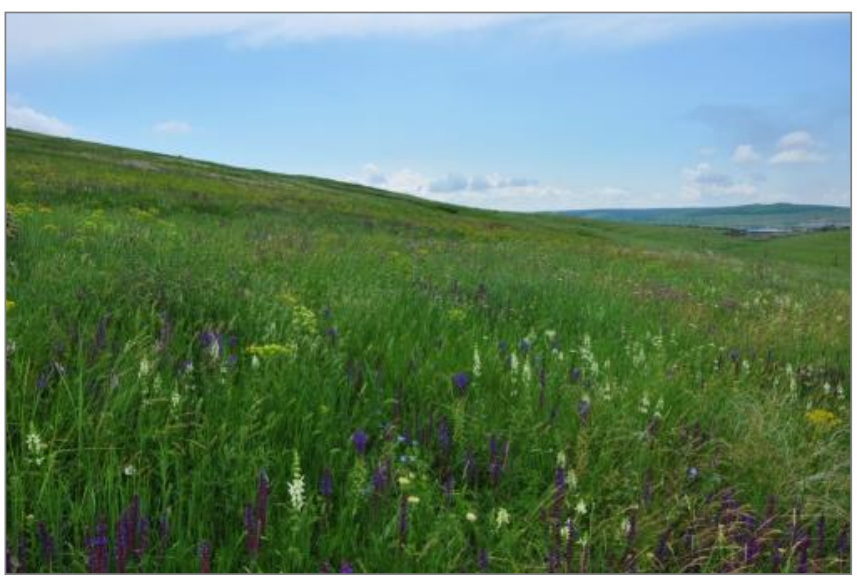

Colourful xerothermic grasslands. Photos: M. Firganek-Fulcher. 
steppic conditions. The reserve is part of the Natura 2000 site ROSCI0265 "Valea lui David" protecting the following habitats: Ponto-Sarmatic steppes, Ponto-Sarmatic deciduous shrubs and Pannonian and Ponto-Sarmatic salt meadows and marshes.

We were astonished by the beauty of this place, as well as the diversity of plants and insects. The surroundings of the reserve, the denuded pasture, just a few meters away on the other side of the valley and the agricultural field immediately above it emphasised the fragility of this ecosystem.

Romania has left us with many beautiful memories and David's Valley is one most enduring.

\section{Further reading:}

Popescu, I.E. 2014. Unicitatea patrimoniului natural din Rezervaţia de fâneţe seculare de la Valea lui David laşi. https://

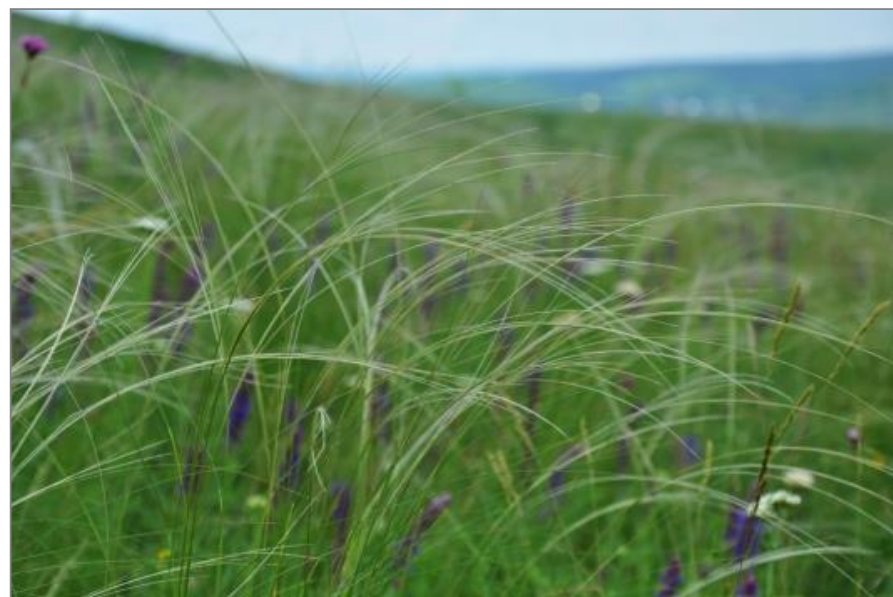

Stipa pennata agg. and Salvia nemorosa community. Photo: T. Fulcher.

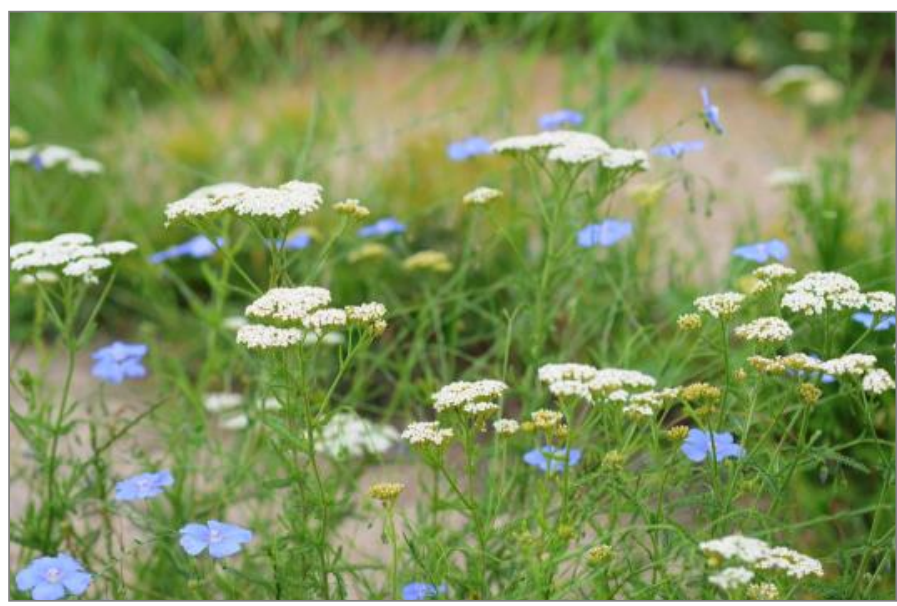

Achillea millefolium agg. and Linum austriacum. Photo: T. Fulcher. aliantapentruconservareabiodiversi-

tatii.wordpress.com/2014/10/31/unicitatea-

patrimoniului-natural-din-rezervatia-de-fanete-secularede-la-valea-lui-david-iasi/ accessed on 22.05.2020

Sjöman, H., Bellan, P., Hitchmough, J. \& Oprea, A. 2015. Herbaceous plants for climate adaptation and intensely developed urban sites in northern Europe: a case study from the eastern Romanian steppe. Ekológia (Bratislava) 34: 39-53.

Magdalena Firganek-Fulcher, London, United Kingdom Tim Fulcher, London, United Kingdom tkf.mbf@gmail.com

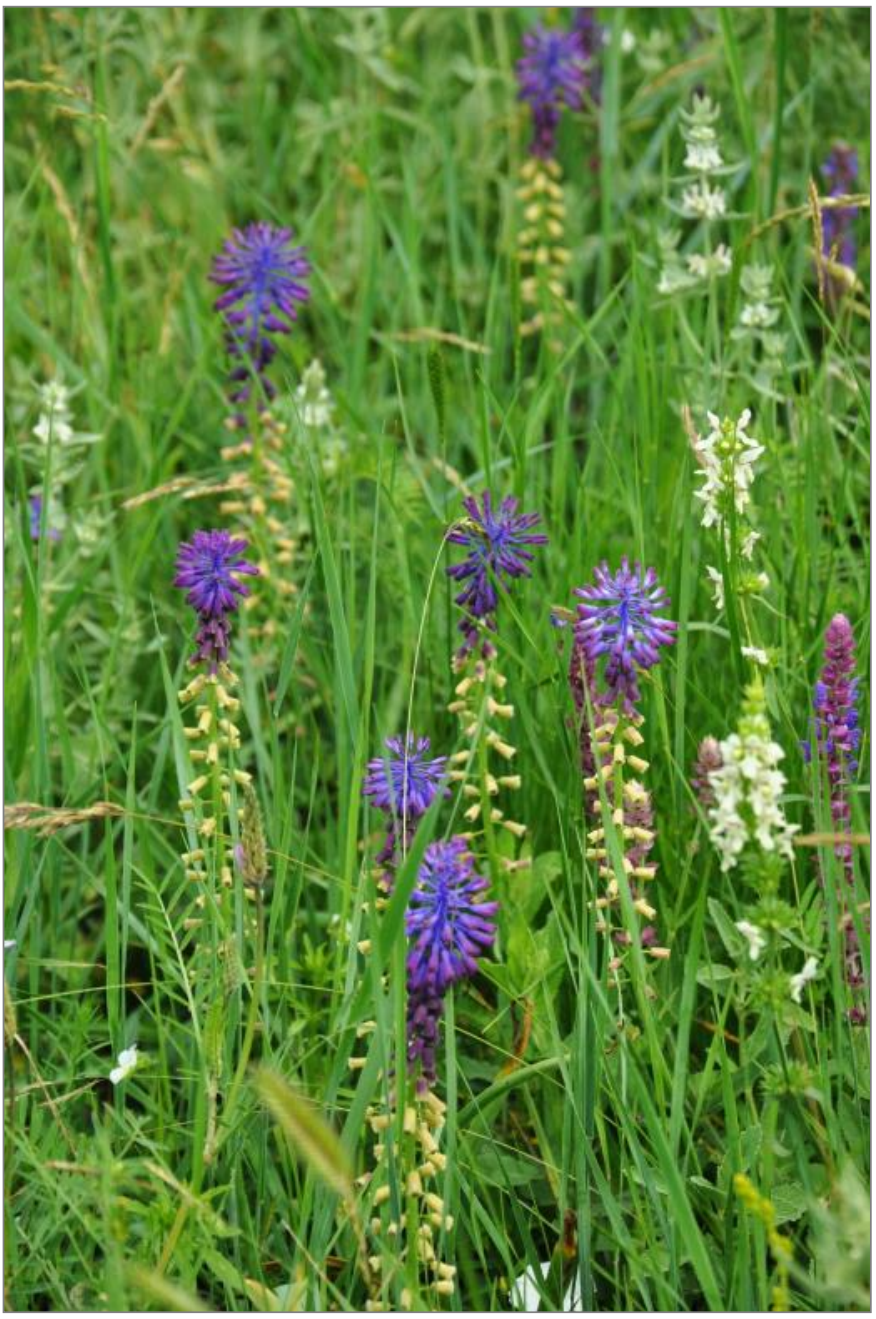

Leopoldia tenuiflora. Photo: M. Firganek-Fulcher. 


\section{Glimpses of a Grassland}

\section{The hedgehog heaths of Mt. Etna - a mix of strength and delicacy}

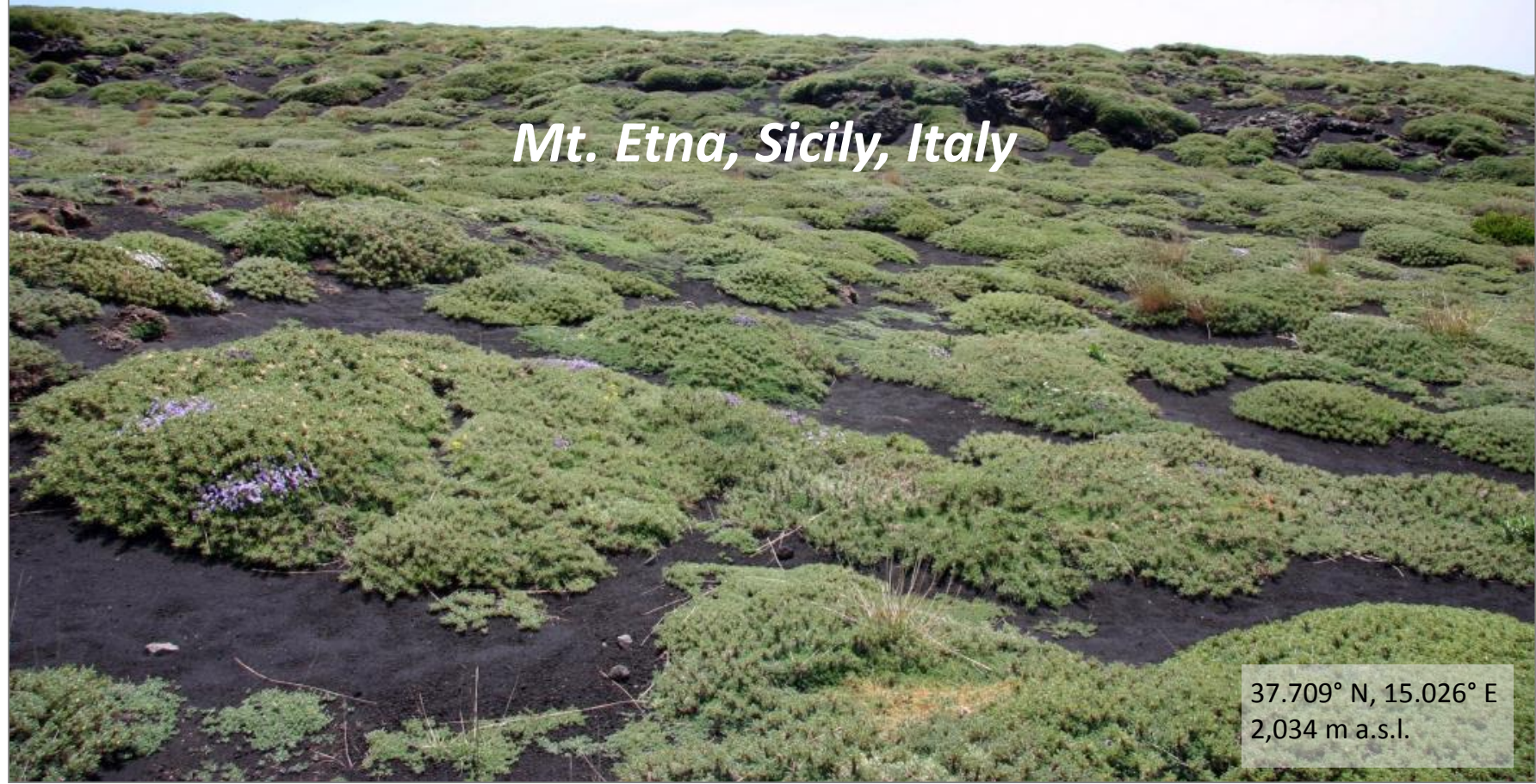

RICCARDO - Pink flowers of Saponaria sicula crowning Astragalus siculus in the dark background of volcanic pyroclasts. There is no more effective way to evoke the stunning beauty of the oro-mediterranean hedgehog heaths of Mt. Etna.

In 1992, the first time I went to Sicily, it was to meet Etna. Since then, every year I make at least one excursion to Etna. Usually I go there alone, for some days. I put somewhere an adequate supply of water, which becomes the centre of my

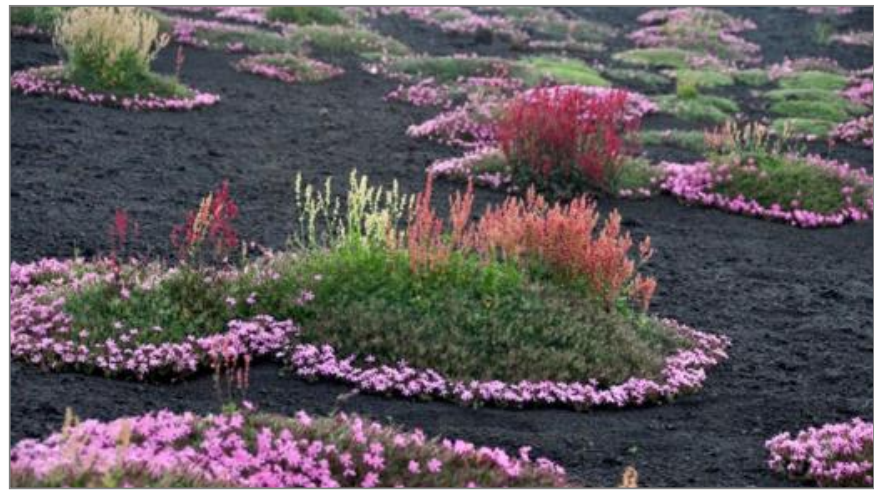

Astragaletum siculi with Astragalus siculus, Saponaria sicula, Rumex scutatus subsp. aetnensis. Photo: C. Giuffrida. silent well-being. From there, I move every day in a different direction, without a precise destination. I go just looking around, to enjoy the reward of an aesthetic catharsis, the intoxication of meditative wonder. Mt. Etna has a calming influence; its immensity helps us to appraise ourselves and, consequently, to put our problems into perspective.

On Mt. Etna, the Astragaletum siculi is my favourite vegetation: it is an extraordinary mix of strength and delicacy, resistance and resilience, isolation and symbiosis. Each thorny

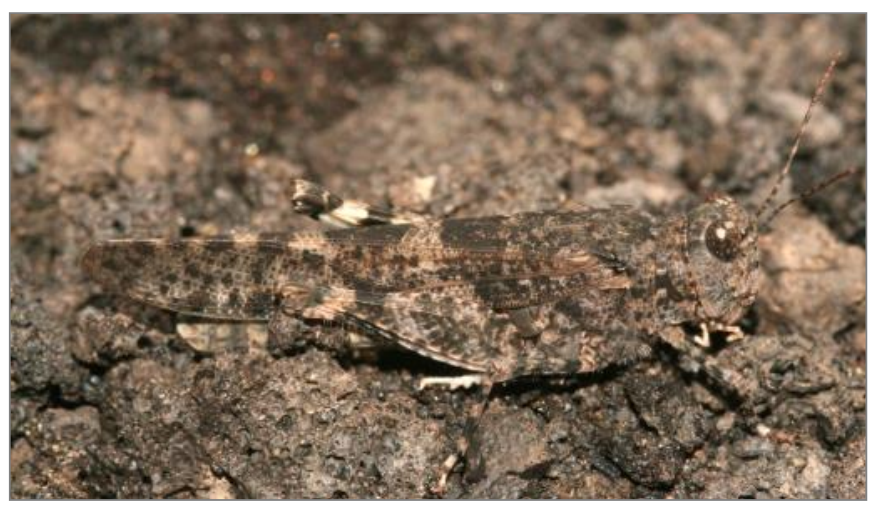

Sphingonotus caerulans exornatus. Photo: C. Giuffrida. 
cushion is a microcosm on its own, a shelter to many other plant species, whose presence is manifested with brilliant colours at flowering time. For their strategy, these plants have been defined "Polstergäste" (literally: the guests of the cushion), a pun for the word Poltergeist, that is a ghost supposed to manifest its presence by occasional noises. But the only noise, up there, are the calling songs produced by males of the about 40 species of Orthoptera recorded on Mt. Etna. It was during one of my annual contemplative sessions in the Astragaletum that I met Calogero, the entomologist co-author of this short note, to whom I give the floor.

CALOGERO - For any naturalist, wandering around Etna's paths is like strolling in a candy factory for a child. Even more so if he is an entomologist. You don't even have to do exhausting hikes to conquer the beauty enclosed in the entomological daily party of an Astragaletum in full blossom. It is enough to tiptoe next to one of the cushions, sit and wait.

Then, almost by magic, what was not seen before begins to appear. The brown colours of Mt. Etna impose several adaptations to the invertebrate fauna, the most evident of which is melanism. And so, while an almost invisible Sphingonotus caerulans exornatus takes off with its iridescent wings, you'll see here many small hemiptera of the genus Cercopis, with elytra entirely coloured in black and not in red, as usual.

On sheltered rocks, up to the top of Etna, it is not uncommon to find large groups of ladybugs, Coccinella sep-

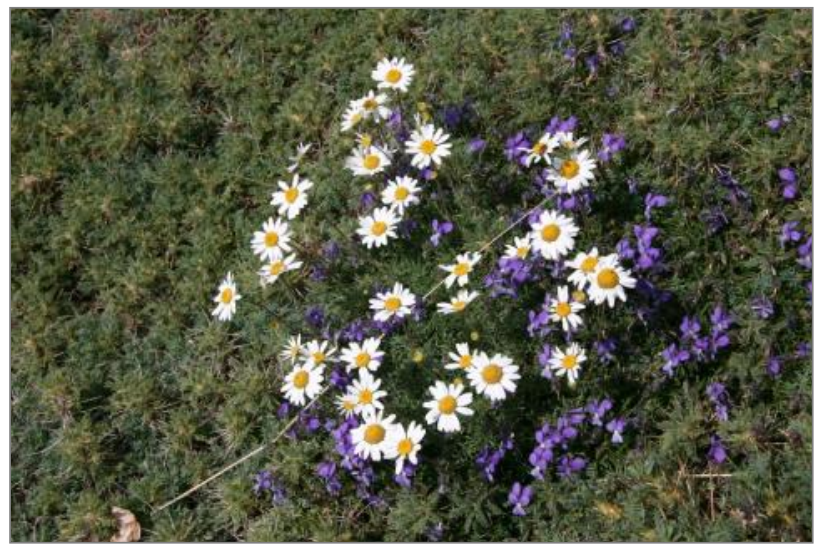

Astragalus siculus, with Anthemis aetnensis and Viola aethnensis as Polstergäste. Photo: R. Guarino.

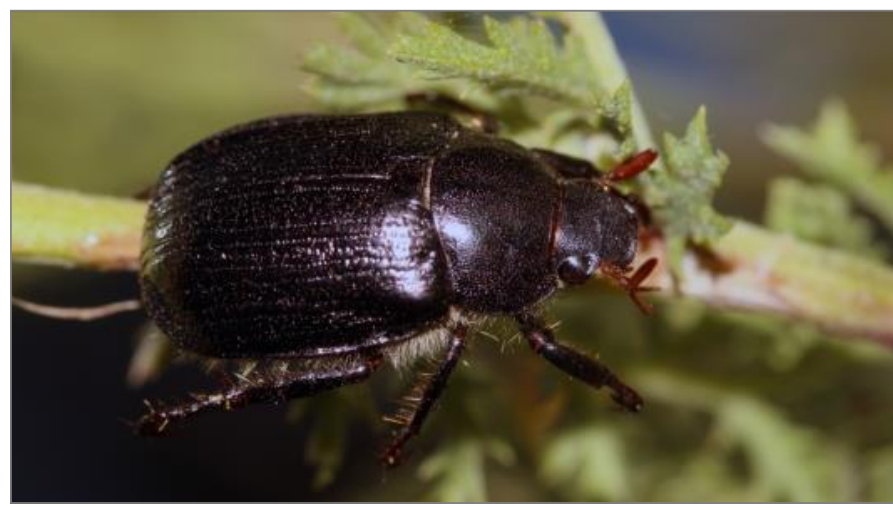

Mimela junii miksici. Photo: C. Muscarella. tempunctata and Adalia bipunctata, driven from lower elevations by upward currents causing impressive vertical migrations of flying invertebrates. A similar vertical migration also affects some Lepidoptera, such as the showy Vanessa cardui. In the late afternoon of summer days, our entomologist will come across the bombastic flight of Mimela junii miksici, one of the many endemic insects of Etna, a Rutelidae with lively metallic glare.

All this, just sitting and waiting. If we had actively searched we would have met at least a part of the approximately 800 species of beetles recorded from Etna. Coleoptera, in turn, are just a small part of the entomological fauna living amidst apparently inhospitable black volcanic scoriae dotted with dwarf, cushion-like shrubs, that every year reawaken the desire to go back to Etna.

\section{Further reading}

Guarino, R. \& Pasta, S. 2017. Botanical excursions in central and western Sicily. Field Guide for the 60th IAVS Symposium. Palermo University Press, 606 pp.

Massa, B. 2011. Gli Ortotteri di Sicilia: check-list commentata. Biogeographia 30: 567-626.

Riccardo Guarino, Palermo, Italy riccardo.guarino@unipa.it

Calogero Muscarella, Palermo, Italy calogero@silenecoop.org

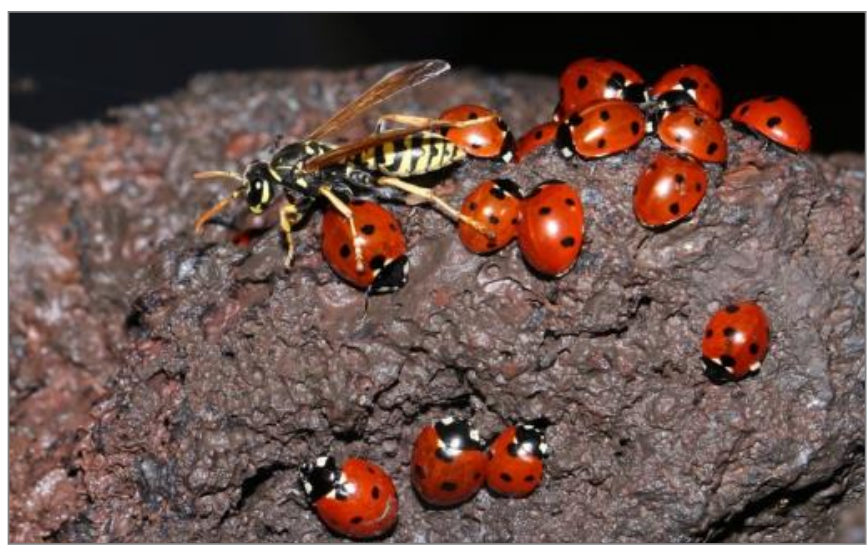

Coccinella septempuctata and Polistes gallicus.

Photo: C. Muscarella.

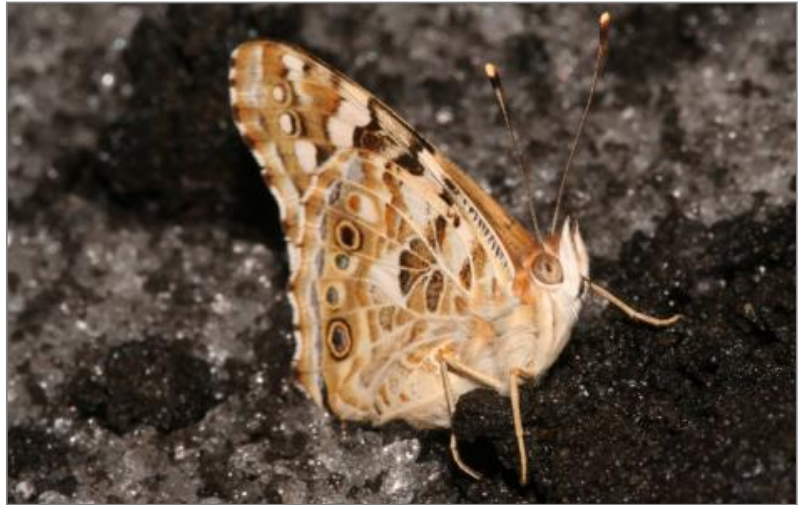

Vanessa cardui. Photo: C. Muscarella. 


\section{Glimpses of a Grassland}

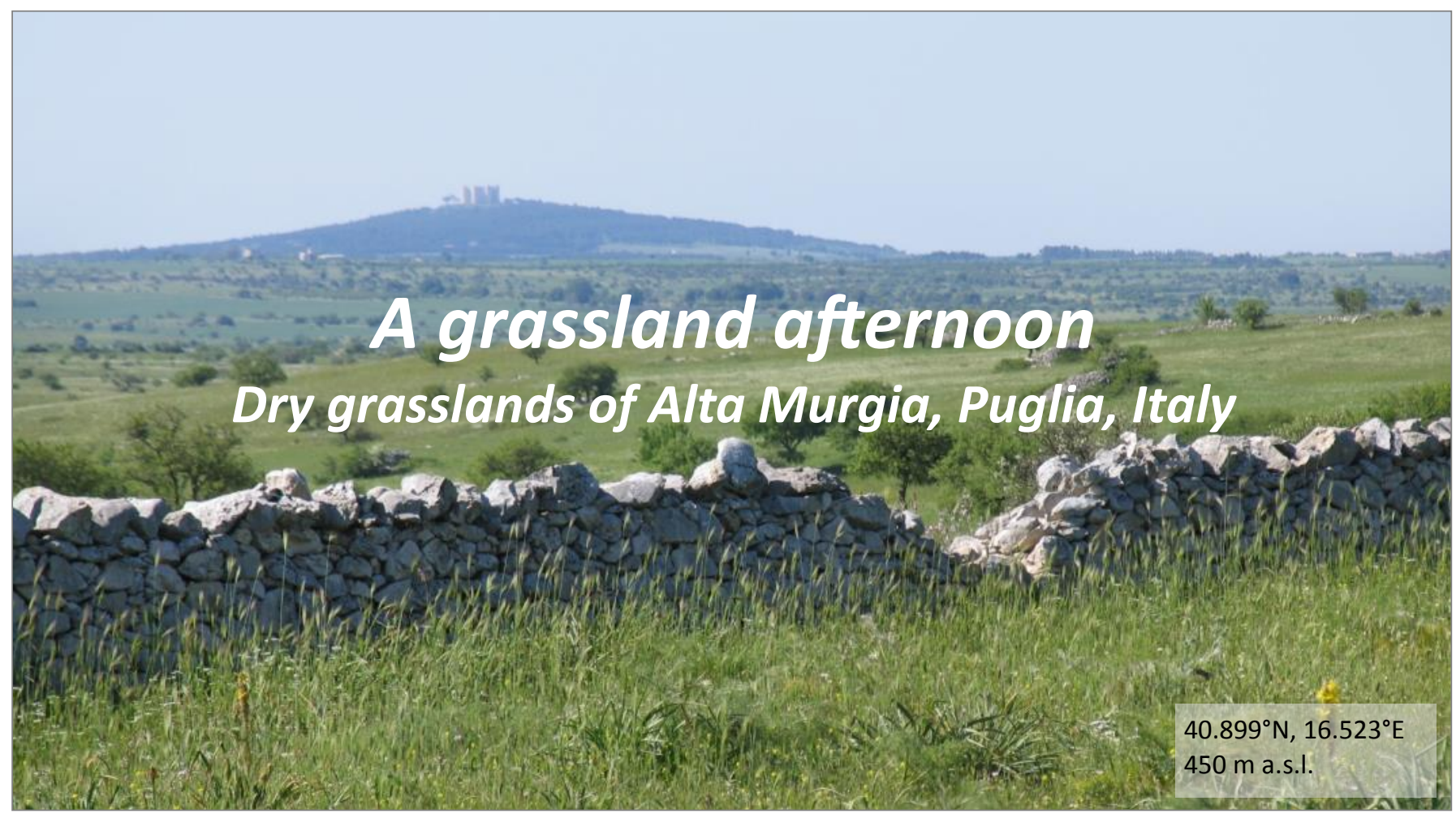

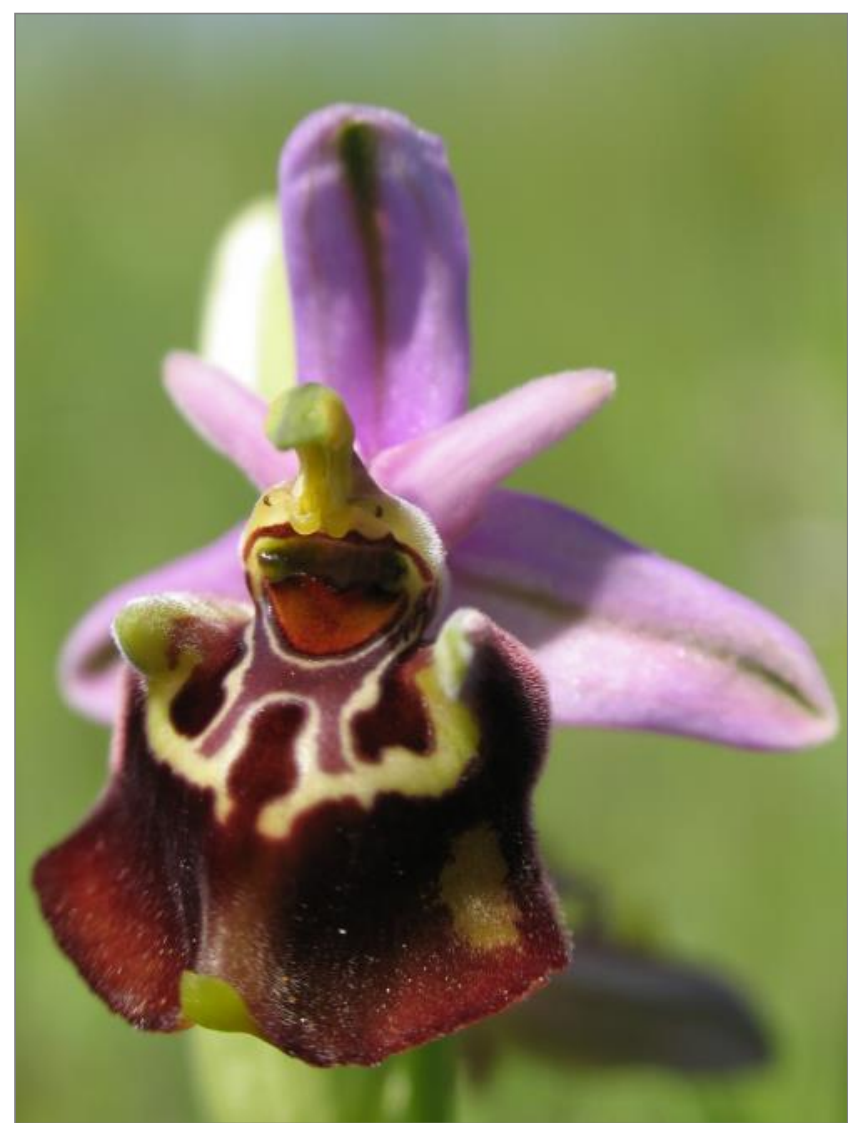

Ophrys apulica, just one of the approximately $\mathbf{5 0}$ orchid species flowering in Alta Murgia. Photo: R. Labadessa.
The vast calcareous plateau of Alta Murgia has been my main work place for about ten years. I would say it is no less than a second home for me; a familiar place made of a hundred-thousand hectares of sheep, rocks and wind.

However - I shall be honest - it's not the kind of luxuriant and cozy nature that we usually expect to find in a National Park. It is rather a harsh dry landscape, with no watercourses and very few remnants of tree vegetation, where you can feel how hard life can be. Probably it is something you would rather hate. Actually, people hate this rough territory since those ancient times when Murgia was named after the Latin 'Murex', the land of sharp rocks. And this is also my very first impression.

Then it happens that I get lost in a warm spring afternoon, surrounded by a sea of feathergrass (Stipa austroitalica), under the stunt flying of Lesser kestrels (Falco naumanni) and the restless voice of a Calandra lark (Melanocorypha calandra).

This is how the secret beauty of Alta Murgia grasslands unfolds, beneath the dominant grasses and beyond the dull limestone rocks, when I lose count of the flowering plants and orchids between my feet, or when I feel like being invited to the amazing shows of hunting raptors and courting snakes. Or when my eyes fall on the small, intricate ornaments built by spiders and insects on the grass. Or even when I simply walk along one of those ancient herding paths, trying to imagine how many grazing sheep and shepherds had walked the same steps. 
Alta Murgia is one of those powerful landscapes that melt together the history of our planet with that of our people, and stick tight to the most hidden part of our memory. Every time spent there sounds like an adventure, and a spring afternoon can turn into a millennium-long journey.

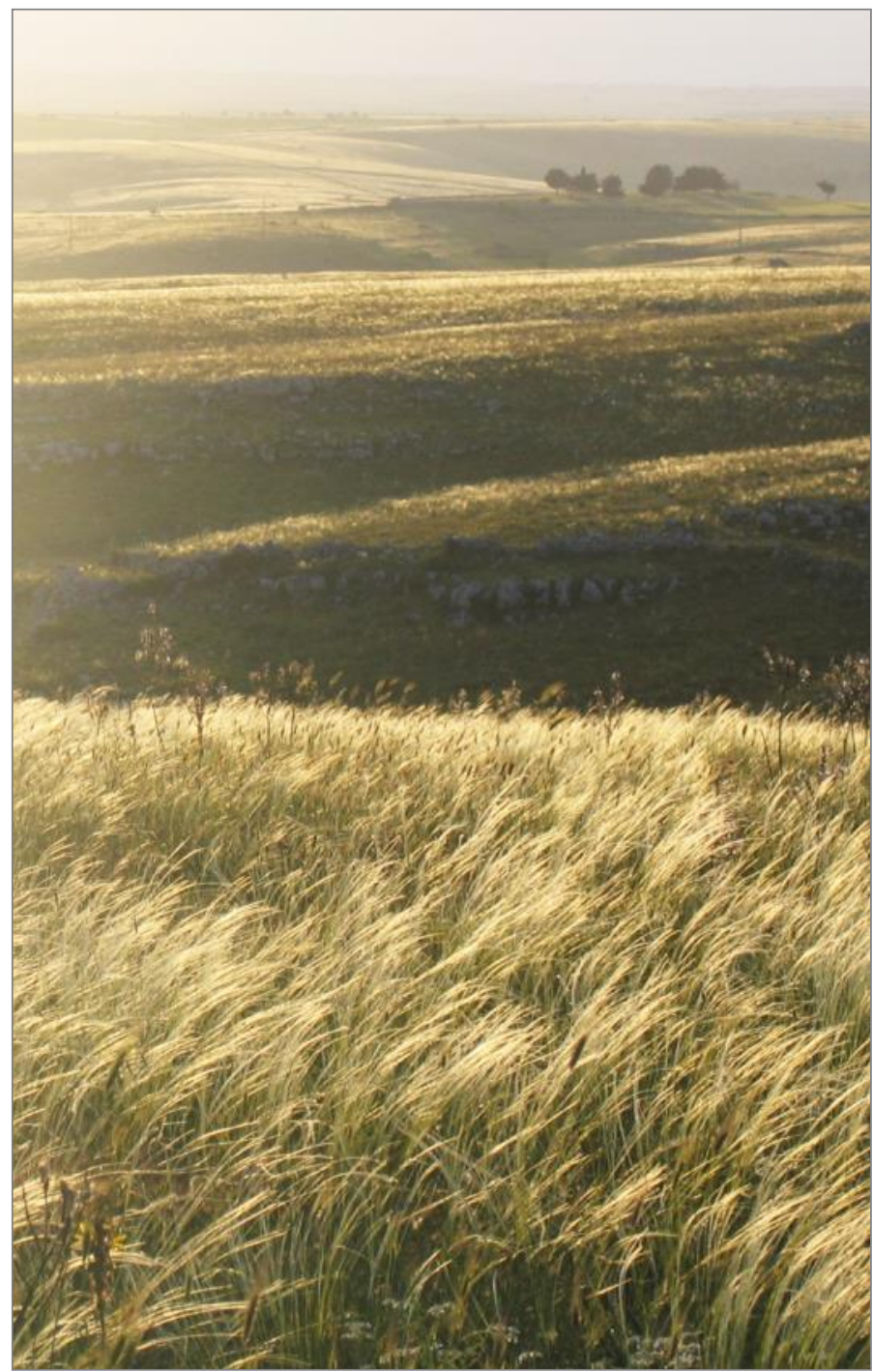

Endemic grassland communities of Hippocrepido glaucaeStipion austroitalicae with Stipa austroitalica. Photo: R. Labadessa.
And this is why, when I get back in town with my senses still full of surprise, I always feel a bit sick like being far from my heart. Even if Alta Murgia is only an hour away.

Rocco Labadessa, Bari, Italy rocco.labadessa@gmail.com

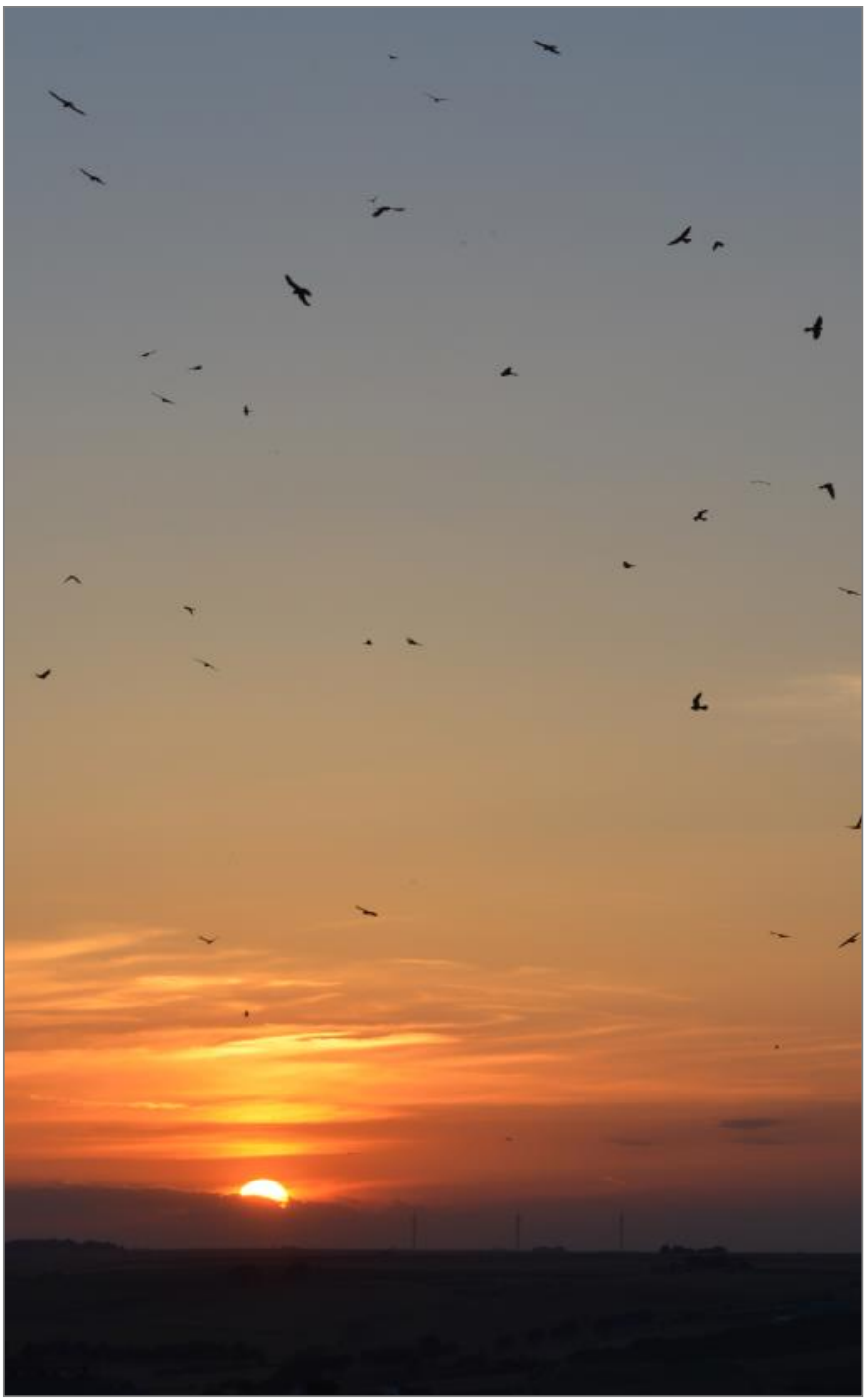

The show of Lesser kestrels (Falco naumanni) getting back to their roosting colony at sunset. Photo: $R$. Labadessa. 


\section{Glimpses of a Grassland}

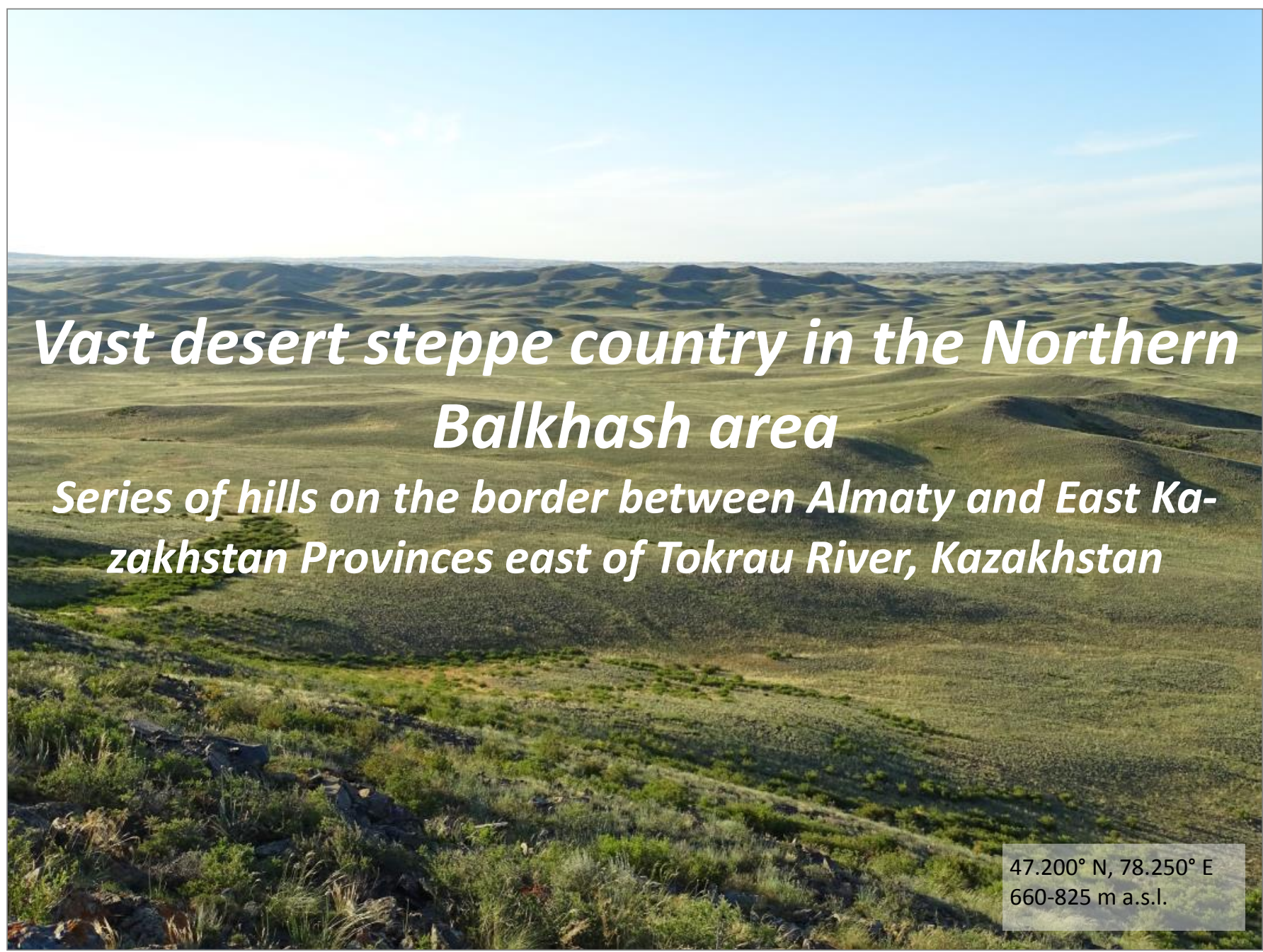

Vast semiarid wilderness lies to the north of the eastern half of Balkhash Lake, the largest lake inside Kazakhstan. The landscape is arranged as giant stairs from the crest of Shyngystau Ridge to the Balkhash shore line, running 200 kilometers north to south and almost 1,000 meters altitude drop, from 1,304 to $341 \mathrm{~m}$ a.s.l. The lowest benches are two lake terraces, flat red-clay plains covered with xerophytic dwarf shrub vegetation of the northern Turan desert (Artemisia spp., Anabasis salsa, Atriplex cana, etc.). The next bench up is hill country stretching for 300 kilometers east to west, between the Bakanas and Tokrau Rivers. Its rugged topography is formed by blocks of low rolling hills and small rocky ridges subdivided one from another by wide flat-bottom valleys and salty depressions. Desert steppe grasslands, mostly petrophytic, added to shrub thickets, cover the hills, outcrops, and flats; saline steppes, salt meadows, and salt desert vegetation occupy valleys and depressions.

Staying on the high ground and looking over the country, we see endless running hills covered with short grass. From April to June the grassland is pale green with a silvery veil of feather-grass, dotted with blue-gray patches of Artemisia sublessingiana and dark green patches of low shrubs (mainly Salsola arbusculiformis and Spiraea hypericifolia). Reddish brown and dark straw colours dominate in other months, except the snow time. No tree, no running water is commonly visible. Hot sunshine, blue sky with light clouds, and ever present wind are important features of the scenery too.

Formerly, before the 1990s, the whole area was a spacious rangeland. Almost every valley and depression had a stockbreeding farm or summer camp with their own wells for watering livestock. The grassland was grazed with numerous cattle, sheep, horses, and camels. Local overgrazing was common around farms and watering points.

We visited the area for the first time in 2009 when we traveled to north of Balkhash, surveying steppe raptors. We found the rangeland abandoned but not unproductive. The steppe in early June was in bloom and full of different animals, including vertebrates. We have recorded many nesting pairs of Steppe Eagle and Long-legged Buzzard, nesting colonies of Lesser Kestrel, and even a few pairs of 
Saker Falcon (quickly disappearing in Kazakhstan). Studying the area, we found all the stock-breeding farms abandoned and ruined, their wells dried and vegetation restored.

We were astonished to see so large a tract of the (re)wild steppe in such good condition and impressed with such total abandonment of a vast steppe area. No wonder after that we visited the area several times to get to know it better.

Our last visits (2016-2017) were for collecting data on mammals. Specifically, the target was the Manul, or Pallas's Cat, Otocolobus manul, a wild cat species which can be treated really as a steppe inhabitant. We used trail cameras to reveal the species presence. Our set of 22 cameras worked for 15 months and, surprisingly, proved the area is one of the

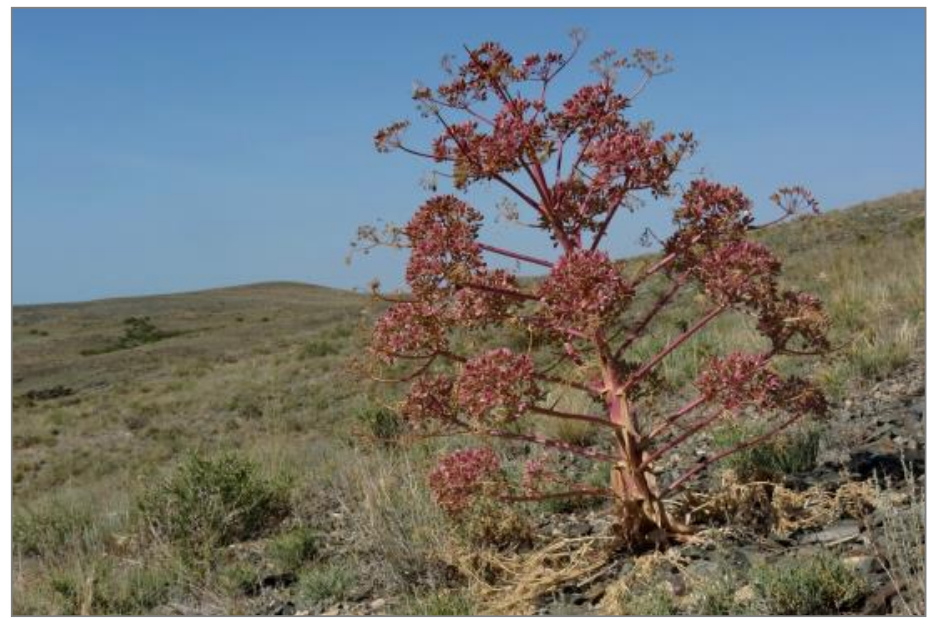

Ferula teterrima, an endemic of Balkhash-Alakol Depression. Giant umbellate herbs like this species and another, Ferula ferulioides, visually play a role of trees in the treeless desert steppe landscape. Photo: I. Smelansky.

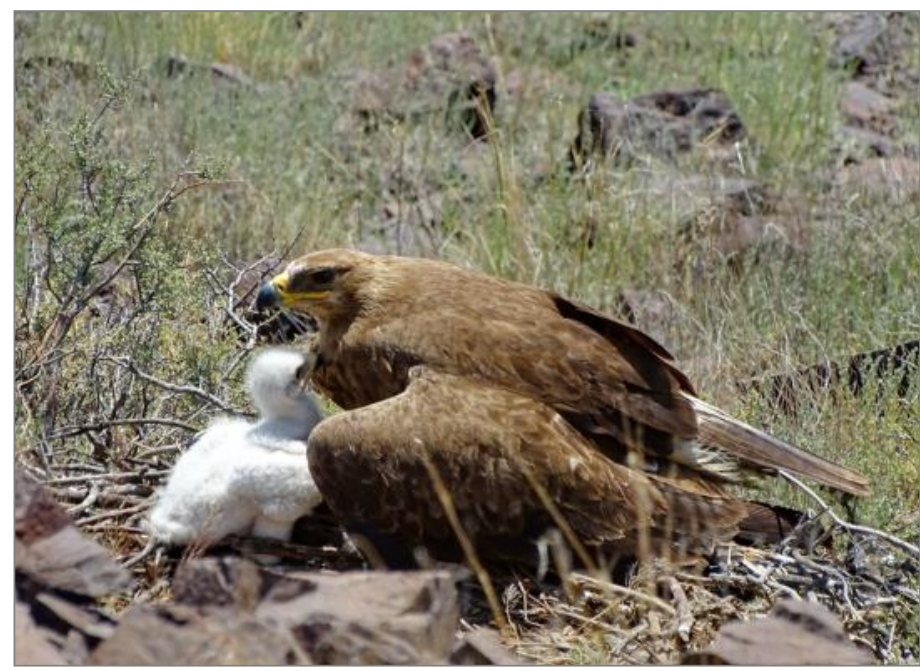

Steppe Eagle, Aquila nipalensis, female with nestlings in their nest on the ground (only one nestling is visible while another is hidden under mother's wing from hot sunshine and wind). Photo: I. Smelansky. main hotspots for the Manul in Kazakhstan. Eight cameras recorded the cats, which is a high occurrence. Moreover, in these hills we were fortunate to discover a Manul den with small kittens, and this is the only confirmed finding in Kazakhstan in recent decades.

Now, we are about to initiate organizing a new protected area here to conserve the desert steppe as a living landscape. Formal protection is especially needed as we have a growing concern that the area could become subject to mining development.

Ilya Smelansky, Novosibirsk, Russia oppia@yandex.ru

Anna Barashkova, Novosibirsk, Russia yazula@yandex.ru

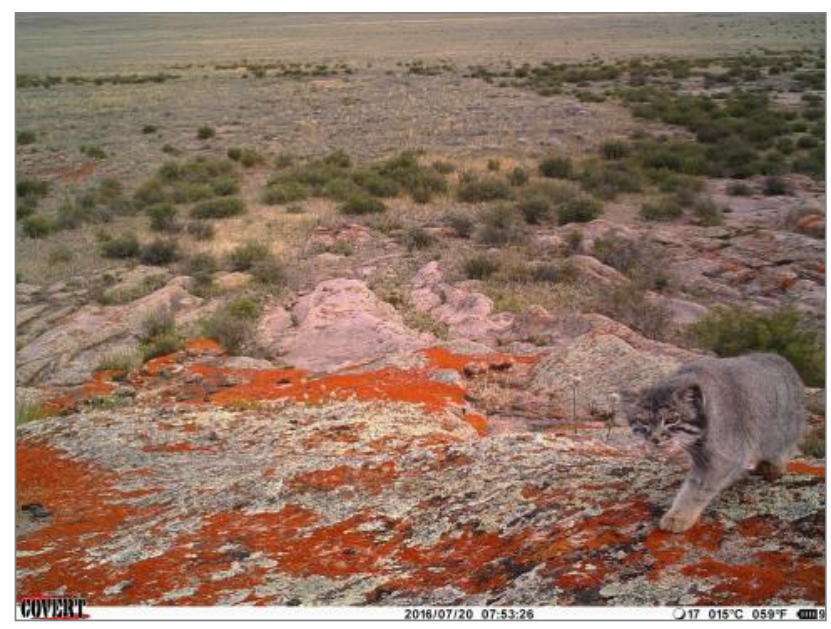

Manul crossing the foot of granite outcrop. Two or three individual cats visited this place at least 8 times from June 2016 to September 2017.

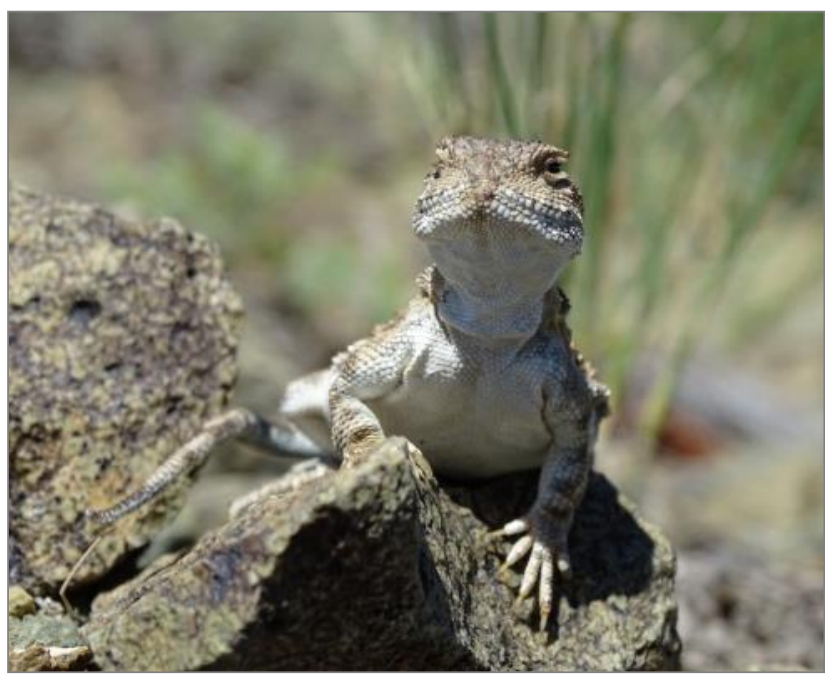

Phrynocephalus helioscopus, an agamid lizard common in the deserts and xeric (desert and dry) steppes of Central Asia. Photo: I. Smelansky. 


\section{Glimpses of a Grassland}

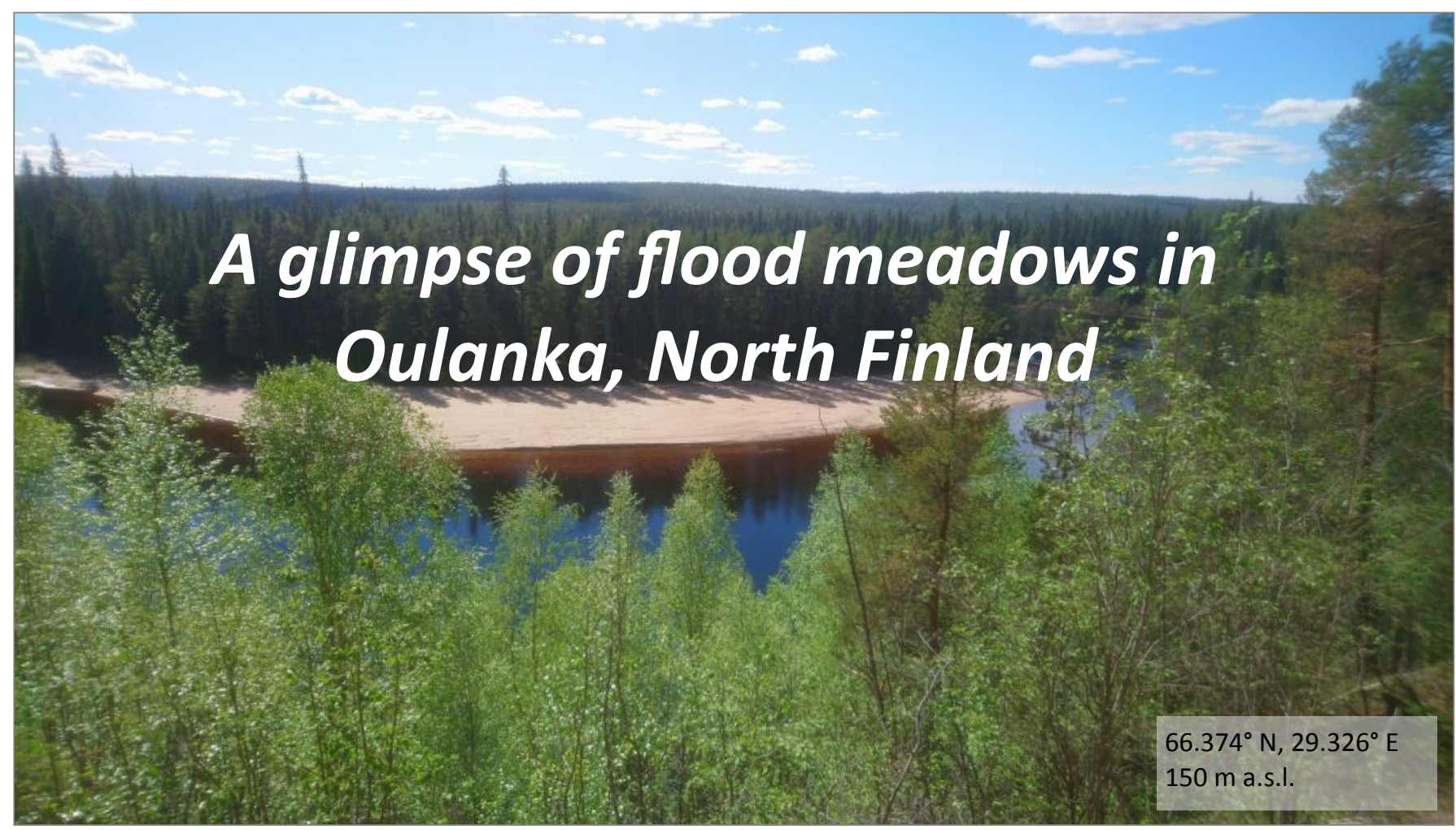

The Oulanka river runs through the Oulanka National Park in northern Finland, until it crosses the border into NW Russia. The river cuts through steep gorges, and its course is followed by a popular hiking trail called the Bear's Ring. The park contains many valuable grassland habitats, most of which are flood meadows along the course of the river. This year, thirty years after my previous visit to the region, I returned to study these meadows for Metsähallitus, as part of a national project to survey semi-natural grasslands, peatlands and bird wetlands throughout Finland.

Last winter was one of the snowiest in living memory in northern Finland, whilst the south of the country had virtually no snow. I arrived in Oulanka in June when there was still snow in places. As these last remnants disappeared, the spring floods were rising in low-lying areas and the river was tumultuous, it's water-level rising by $1.5 \mathrm{~m}$. Over the following couple of weeks, the water level fell, exposing the meadows I will be surveying this summer.

Most of the flood meadows are low-lying and close to the river, with a topography of low ridges, gulleys and pits. As the floodwater withdraws, many of these remain flooded, some as inlets of the river, others as stagnant ponds. Here and there are patches of freshly deposited sand. One unexpected effect of the floodwater is to move vast fallen tree trunks.

Despite the major influence of flooding, these meadows are mostly very dry, from the moment the flood withdraws. Much of the vegetation is that of dry meadow habitats.

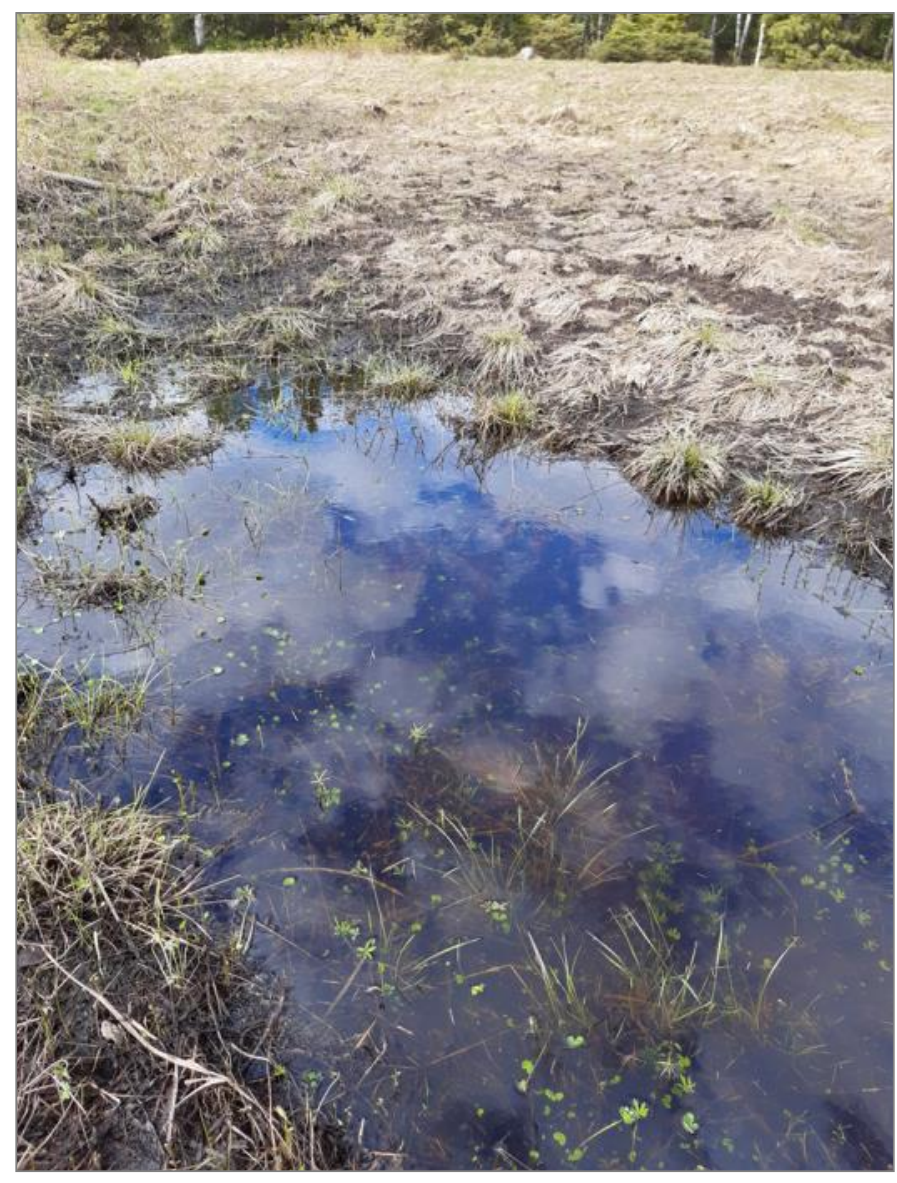

The ground shortly after the flood has withdrawn. 
Amongst the first noteworthy species to appear are moonworts, particularly Botrychium boreale, B. lanceolatum, B. lunaria and $B$. multifidum. As I made my first site visits after the floods, the orchid Calypso bulbosa was flowering in many places. Catsfoot Antennaria dioica is one of the main indicator species of these habitats, though it is easier to detect when it flowers. One species which in Finland is more or less unique to this region is Erigeron decoloratus. A number of its close relatives occur in isolated parts of northern Lapland. Other regionally characteristic plant species of these meadows are Astragalus alpinus and $A$. frigidus.

Two weeks later, the vegetation is very different, with globeflower Trollius europeus flowering abundantly, followed by wood cranesbill Geranium sylvaticum. Now there starts to be an abundance of hoverflies and some bees, particularly bumble bees. Other plant-visiting insects include longhorn beetles (Cerambycidae) and the Eurasian bee beetle Trichius fasciatus. More inconspicuous plant species begin to appear, such as coralroot Corallorhiza trifida, Dianthus superbus and Silene tatarica. The carabid beetle
(Coleoptera, Carabidae) fauna is dominated by typical dry grassland species of the genera Harpalus and Amara, as well as hygrophilic communities of the receding water margins. Due to the proximity of water, there is an abundant community of dragonflies (Odonata). These meadows also contain deadwood, in the form of fallen trees and hay barns constructed of logs which, together with patches of bare soil, are valuable as potential nesting sites for bees. These hay barns are also fascinating due to the ingenuity shown in fashioning door hinges and fastenings from novel-shaped pieces of wood. One topic that has aroused my curiosity is how arthropods overcome the flood. Do bees whose larvae develop in such patches of bare soil survive the week or two of inundation? Also species that develop in logs have the same situation; can they survive a week or two of inundation? These are questions I hope to shed some light on in my research during the coming season.

Stephen Venn, Helsinki, Finland stephen.venn@helsinki.fi

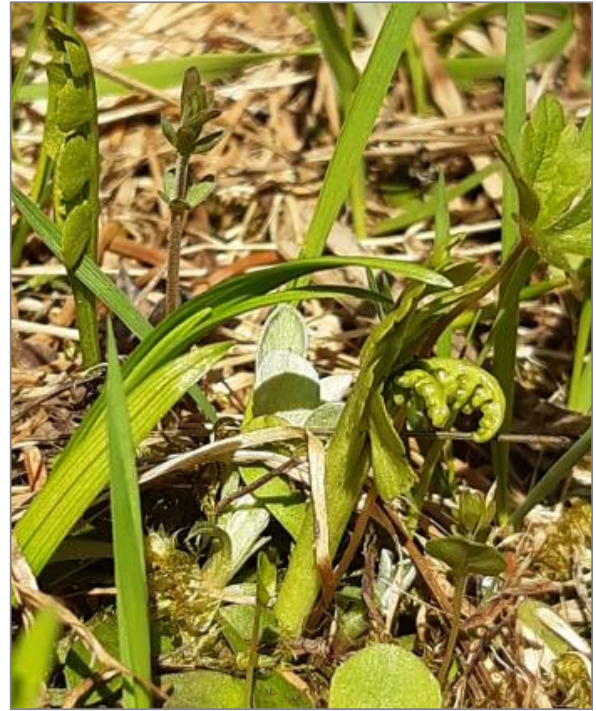

Botrychium lunaria. Photo: S. Venn.

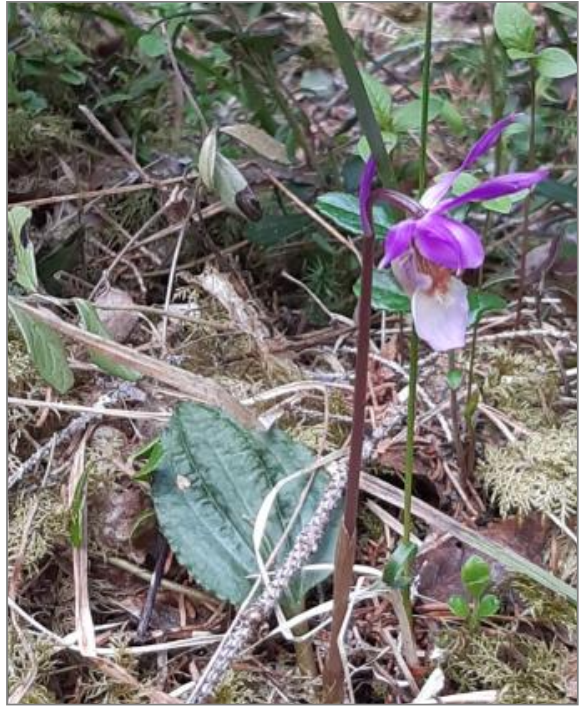

Calypso bulbosa. Photo: S. Venn.

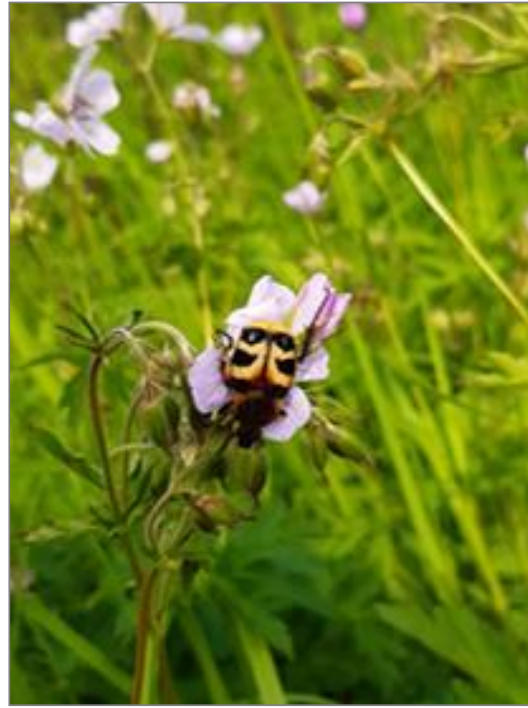

Eurasian bee beetle (Trichius fasciatus). Photo: S. Venn.

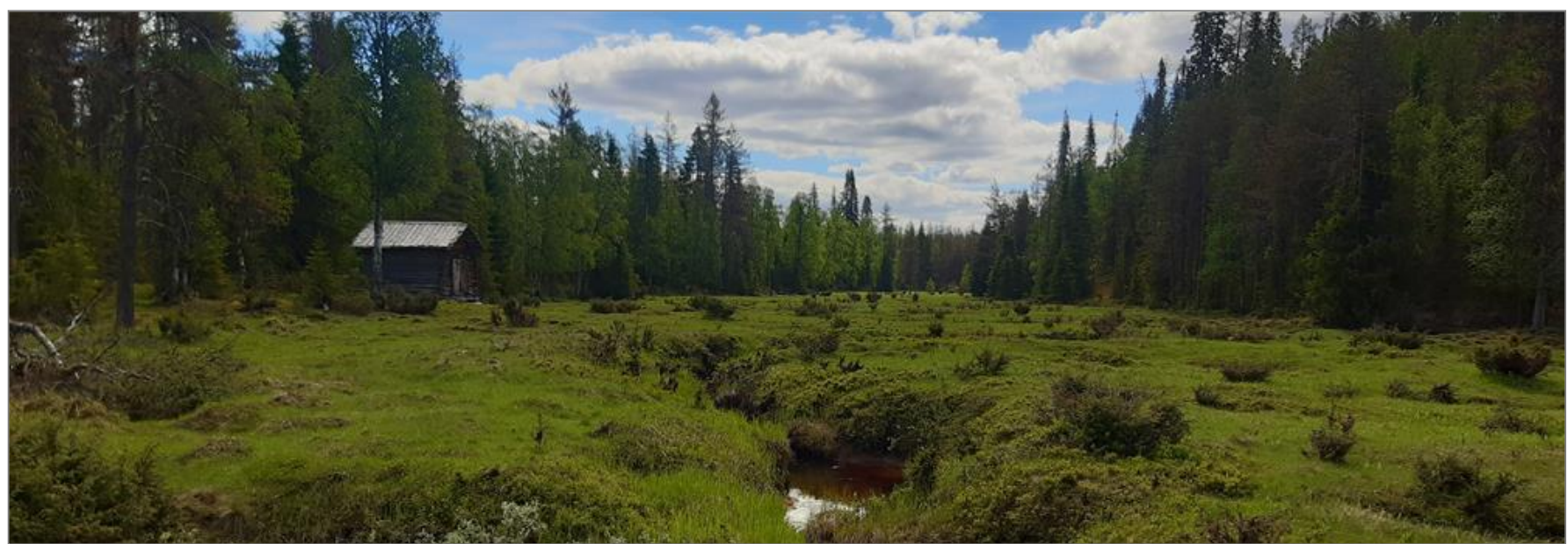

Hay barn in meadow. Photo: S. Venn. 


\section{Photo Competition}

\section{Best Shots on "Managing grasslands"}

Here the three winners of the EDGG Photo Competition!

The Jury of the Photo Competition comprised Edy Fantinato, Magdalena Firganek-Fulcher, Rocco Labadessa, Jim Martin, Jalil Noroozi \& Salza Palpurina.

\section{$1^{\text {st }}$ place}

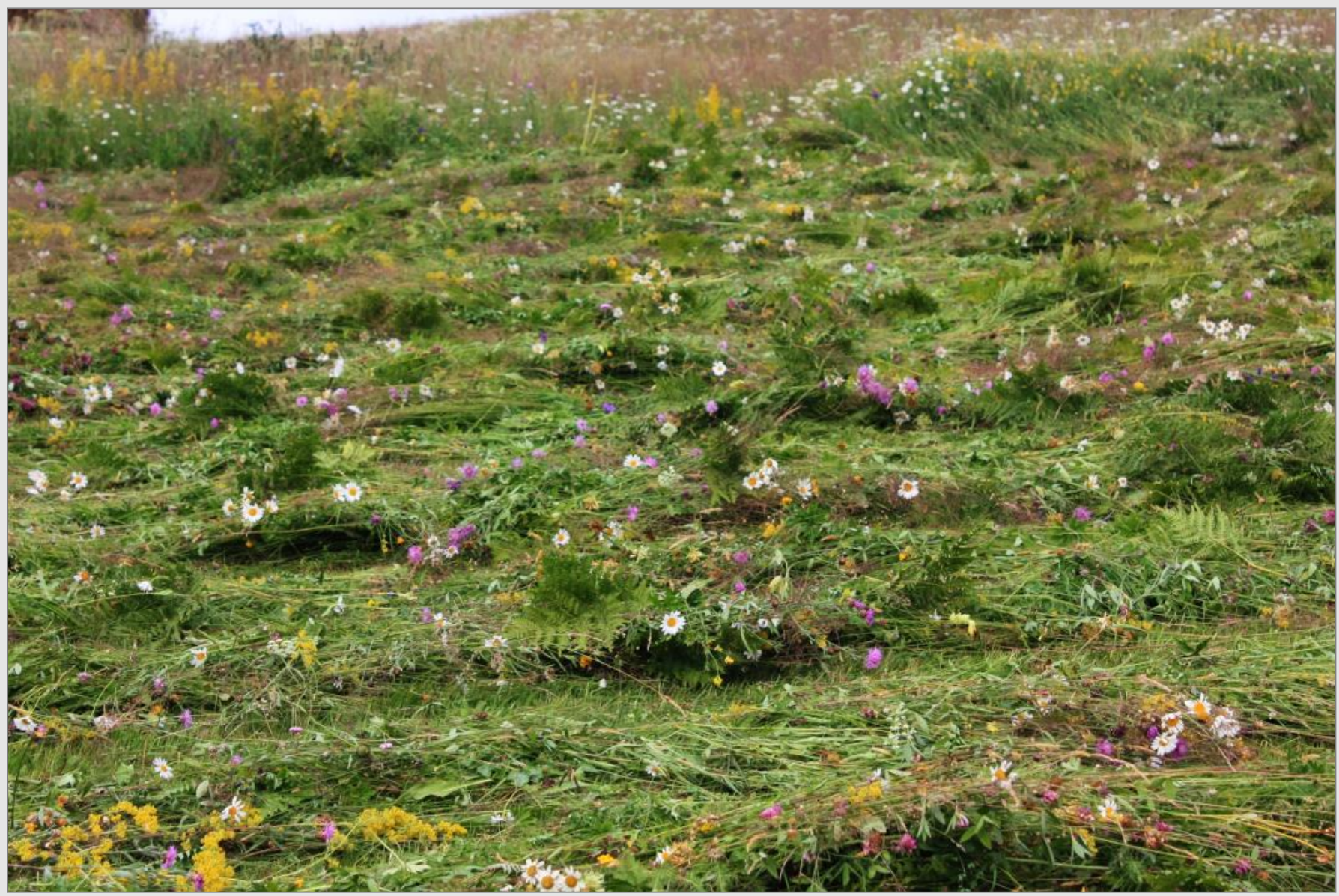

Fresh hay of the Carpathian grasslands, Putyla district, Chernivtsi oblast, Ukraine.

Camera Canon EOS 450 D, aperture f/8, exposure time $1 / 80$ s. Author: Anna Kuzemko, Ukraine, anyameadow.ak@gmail.com.

Reviews from the Jury:

"The fresh hay is very charming."

"Extensive management practices support grassland biodiversity. How wonderful to think that the diversity of colours and shapes portrayed in the present picture is maintained by human work."

"The setting of the traditional meadows within the steep valley serve to highlight the isolated nature of the site." 


\section{$2^{\text {nd }}$ place}

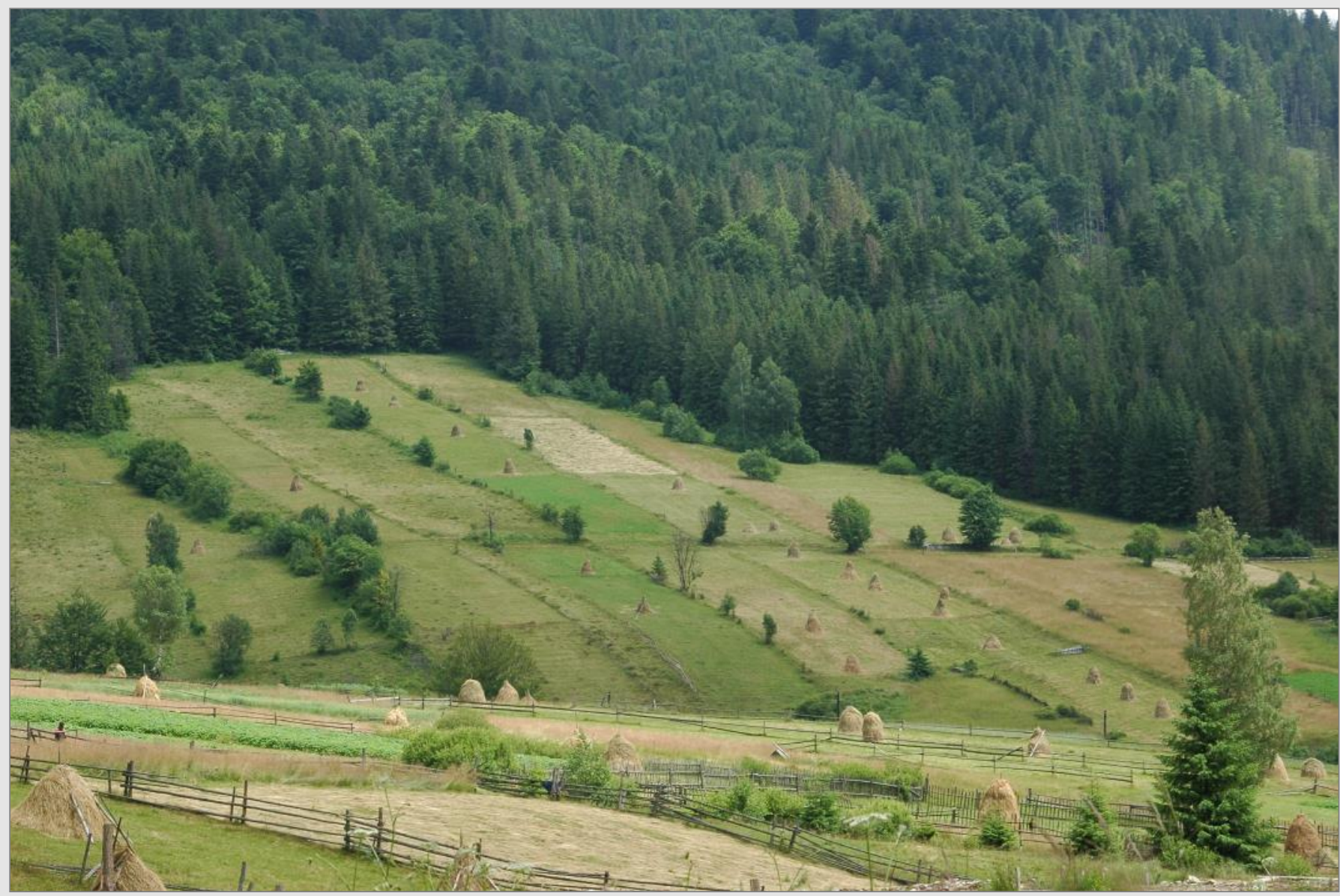

Meadows in a deforested place with a dominance of Festuca pratensis, F. rubra, Cynosurus cristatus, Briza media and the presence of some orchids, altitude $600 \mathrm{~m}$ a.s.I. near Dolyna village, Ivano-Frankivsk oblast, Ukrainian Carpathians.

Author: Ihor Sirenko, Ukraine, i.sirenko@gmail.com.

Reviews from the Jury:

"An interesting patchwork of traditional meadows, with the forestry looming on the edge."

"I love this picture because of the agricultural mosaic showing the diversity of small plots for hay and the hedges between plots."

"A landscape shaped by traditional haymaking is like a dress trimmed with lace." 
$3^{3 d}$ place:

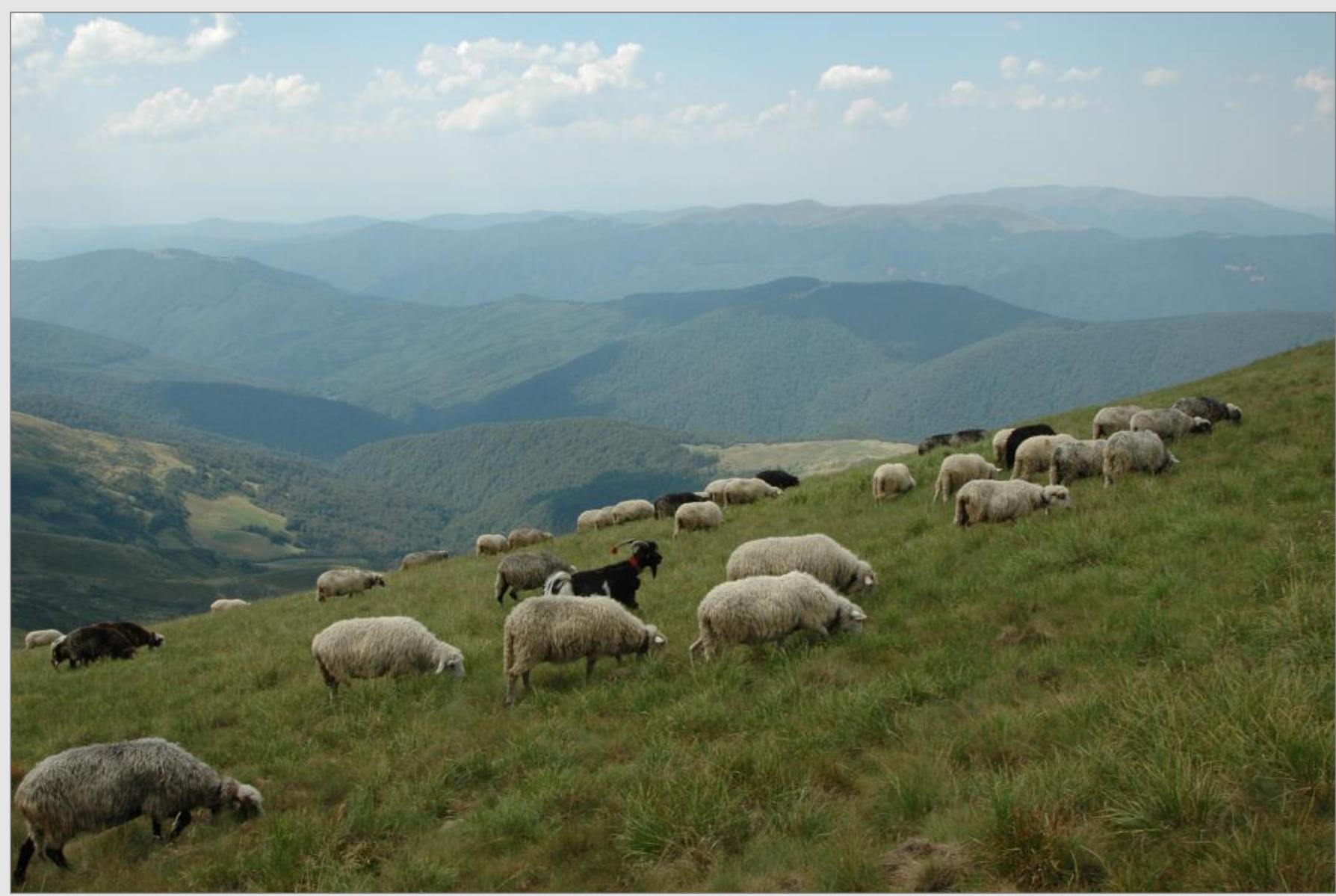

Nardus stricta grasslands at Blyznytsia mountain in the Ukrainian Carpathians, altitude 1350 m a.s.l., moderate grazing, Carpathian Biosphere Reserve. Author: Ihor Sirenko, Ukraine, i.sirenko@gmail.com.

\section{Reviews from the Jury:}

"This photo nicely captures the movement of the herd as it grazes the pasture, set against a spectacular landscape in the background."

"Does the picture portray a pasture or the most iconic sense of freedom?" 


\section{Short Contributions}

\section{European extrazonal steppes are of disproportionately large value for the conservation of the Eurasian Steppe biome}

The disjunct distribution of extrazonal steppe biota has fuelled speculations on their origin for over a century (Jännicke 1892). While it has been emphasized that extrazonal steppe biota have split from zonal steppe biota ever since, their spatiotemporal dynamics have so far not been explored. It has not been clear, for example, if today's extrazonal steppe biota have persisted in European refugia throughout the Pleistocene, or if they are young remnants of the steppe expansions during the last cold stage. Both scenarios have direct implications for the conservation of European steppes. In a recent article published in the journal Nature Communications, Kirschner et al. (2020) addressed this topic by applying a combination of molecular genetic methods and ecological niche modelling on six typical steppe species, from over 300 steppe localities in Europe and Asia (three insect species: an ant, Plagiolepis taurica, two grasshoppers, Omocestus petraeus and Stenobothrus nigromaculatus; and three vascular plant species: AstragaIus onobrychis, Euphorbia seguieriana and Stipa capillata).

The study showed a largely congruent evolutionary history of steppe biota in Europe. Divergent phylogenetic lineages that exclusively occur in the extrazonal steppes of Europe were found in all six species. These extrazonal lineages have evolved in the extrazonal steppes independently from zonal lineages and in long-term isolation. The initial separation of extrazonal and zonal lineages was explicitly dated to the mid-Pleistocene period in two cases. This strongly contrasts with the view that extrazonal steppe biota are young relics of the steppe belt that covered Europe during the last cold stage of the Pleistocene. Long-term isolation of extrazonal lineages implies the presence of suitable habitat in Europe

in both cold and warm stage conditions. Ecological niche models based on present-day and Last Glacial Maximum climatic data suggest wide availability of stable habitats for these lineages during Pleistocene cold and warm stage conditions in Central and Western Europe.

From a conservation perspective, these findings significantly raise the conservation value of European extrazonal steppes. Extrazonal steppes are not only the cradle of exclusively extrazonal lineages, but also their only habitat. In addition to these "endemic" extrazonal lineages, European extrazonal steppes are also inhabited by lineages that have their main distribution in the zonal steppes. This is reflected by the large phylogenetic diversity (a biodiversity measure based on phylogenetic trees) found in European steppes. In conclusion, the conservation of the European extrazonal steppes is key in preserving the genetic heritage of the Eurasian steppe biome.

\section{References}

Jännicke, W. 1892. Die Sandflora von Mainz, ein Relict aus der Steppenzeit. Gebrueder Knauer, Frankfurt, DE.

Kirschner, P., Záveská, E., Gamisch, A., Hilpold, A., Trucchi, E., Paun, O., Sanmartín, I., Schlick-Steiner, B.C., Frajman, B., (...) \& Schönswetter, P. 2020. Long-term isolation of European steppe outposts boosts the biome's conservation value. Nature Communications 11: Article 1968.

\section{Philipp Kirschner, Innsbruck, Austria} philipp.kirschner@gmail.com

Andreas Hilpold, Bozen/Bolzano, Italy andreas.hilpold@eurac.edu
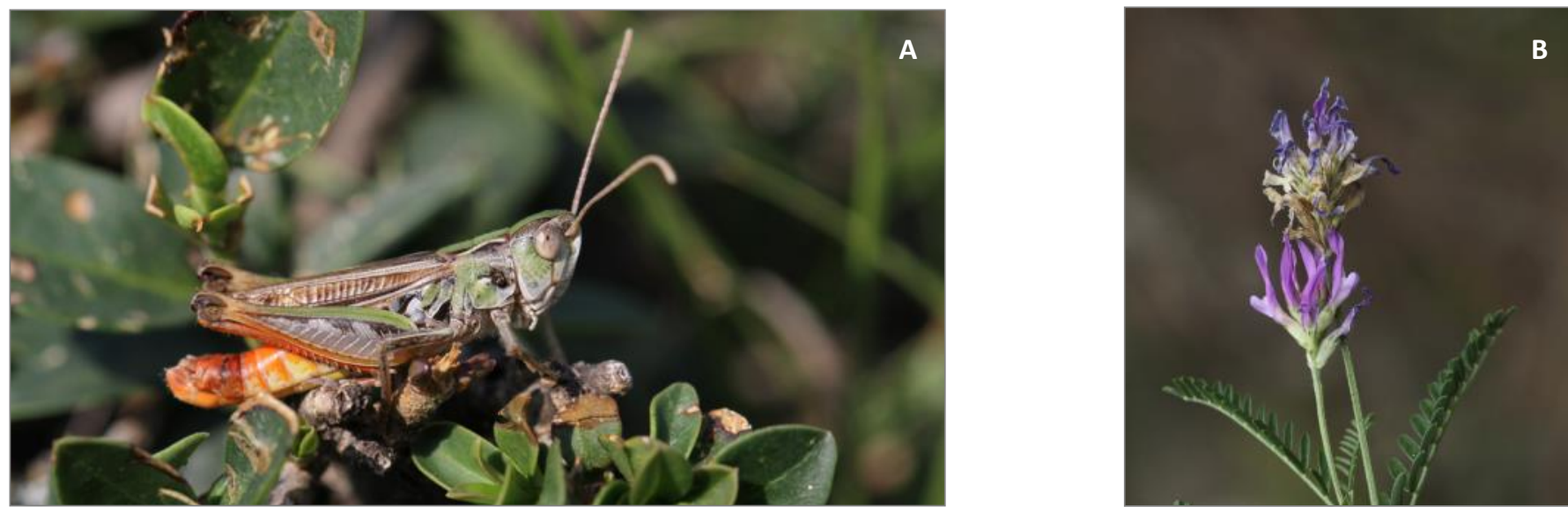

Extrazonal steppes such as the "Vinschger Sonnenberg" (South Tyrol, Italy) harbor divergent genetic lineages of steppe biota that have evolved in long-term isolation from the zonal steppes. This was shown by Kirschner et al. (2020) using genetic data and environmental niche models from six typical steppe insect and plant species (A: Stenobothrus nigromaculatus, by P. Kirschner, B: Astragalus onobrychis, by A. Hilpold). 


\section{Global campaigns of afforestation do not necessarily serve smaller-scale conservation objectives - the case of sandy drylands}

Woody plants in water-limited ecosystems, such as tropical savannas, Mediterranean open woodlands and foreststeppes, affect their environment in multiple ways. Compared to open grasslands, the canopy of woody species moderates temperature extremes by reducing insolation during the day and trapping heat during the night (Tölgyesi et al. 2018). Humidity is also retained under the canopy, while litter turnover and increased atmospheric nutrient deposition contribute to increased fertility of sub-canopy habitats. As a result, woody species of arid habitats can offer shelter for sensitive herb layer plants and epigeic animals (Scholes \& Archer 1997). However, considering larger spatial scales, increasing woody cover at the expense of grasslands can have contrasting effects. The high water consumption of woody species can reduce regional water bal- ance, as evidenced by decreasing groundwater levels and stream flows, which can compromise the water supply of downstream wetlands and agricultural production systems (Farley et al. 2005).

Local effects of woody species have mostly been studied in natural forest-grassland mosaics, while regional effects have been studied in conjunction with exotic afforestation. Local and regional scale effects of woody species have not been linked into a multi-scale model; thus, it is not known whether and to what extent local and regional effects can co-occur in the same systems. To establish this link across scales, we simultaneously monitored environmental parameters of local (microclimate and topsoil moisture) and regional relevance (deep soil moisture) in grasslands and patches of woody species in a dry sandy region of Central Hungary.

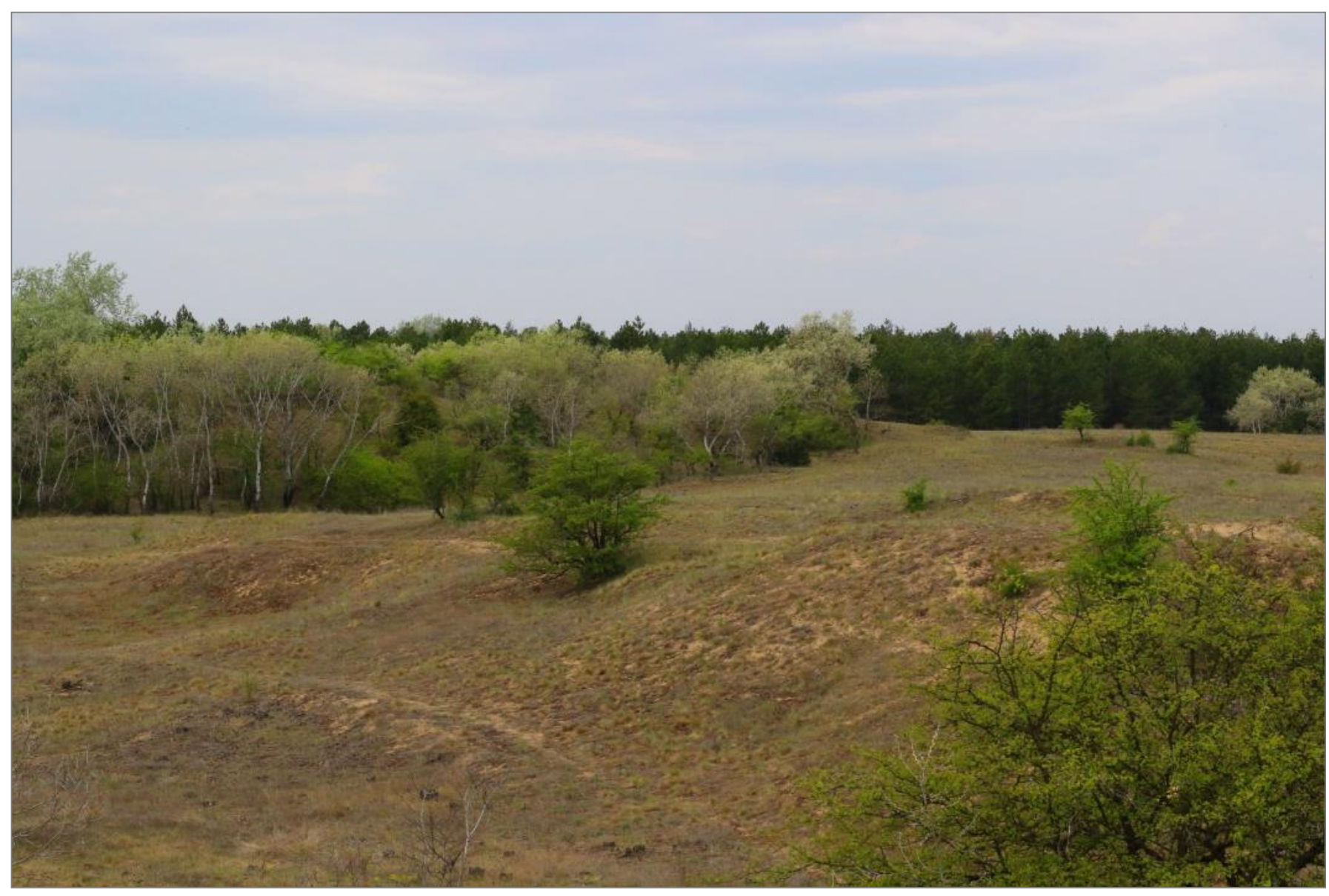

Fig. 1. Vegetation of the study region dominated by bunchgrass steppe (foreground) and poplar groves (left side). Large areas have been afforested by non-native species, such as Pinus nigra (background). 
Macroclimatic and edaphic conditions are at the limit of tolerance for woody vegetation in the study region, allowing for only small native poplar (Populus alba) groves in a matrix of bunch-grass steppe, dominated by Festuca vaginata and Stipa borysthenica (Fig. 1).

There has also been large-scale afforestation in the region with mostly non-native species, such as Robinia pseudoacacia and Pinus nigra. Thus, trees with diverse life history traits, including annual canopy cycles, are available in the region. Being evergreen, pines have the longest active canopy cover during the year, while Robinia has the shortest, as its leaves emerge in May, approximately one month later than those of poplar.

We measured microclimate (temperature and relative humidity) and soil moisture down to $120 \mathrm{~cm}$ in eight locations in all four habitat types (poplar, Robinia and pine forests, and grassland) eight times over the course of a year.

We found that all forested habitats moderated temperature extremes, and the effect correlated closely with canopy cover. Even the leafless canopy of the Robinia and poplar forests had this effect to some extent outside the vegetation period. Relative humidity was higher in the forests during the day but this was not always the case at night, due to the sharp temperature decline in the grassland sites after sunset. Topsoil moisture was also mostly higher in the forests than in the grassland.

Conversely, deep soil moisture was stable in grasslands throughout the year. Pine forests started significantly tapping on deep soil moisture from early April. Declining deep soil moisture became detectable in the deciduous forests somewhat later but they had caught up with the pine forests by summer. In summer, we barely detected any trace of water in the 50 to $120 \mathrm{~cm}$ section of the soil. Deep soil moisture after the active period of the canopy started to recharge but this was rather delayed in pine forests and became complete only by January.

Our results suggest that the cost of micro-environmental moderation is an inevitable desiccation of deep soil layers, inhibiting groundwater recharge. The direction of the effects is consistent across tree species, but its magnitude correlates positively with annual canopy lifetime. Our findings should be considered during the conservation and restoration of dry forest-grassland mosaic ecosystems, the planning of profit-oriented forestry activities and, in particular, afforestation schemes to sequestrate atmospheric carbon dioxide (Bastin et al. 2019). The decline of regional wa- ter balance can reduce overall regional productivity and the carbon-sink capacity of low-lying wetlands, hence potentially offsetting carbon gain in the afforested areas. Land managers may need to favour grasslands instead of forests in such regions, despite that this may, at first sight, contradict the global trends of afforestation to mitigate climate change. For further details please check our recent paper in Ecography (Tölgyesi et al. 2020).

\section{References}

Bastin, J.-F., Finegold, Y., Garcia, C., Mollicone, D., Rezende, M., Routh, D., Zohner, C.M. \& Crowther, T.W. 2019. The global tree restoration potential. Science 375: 76-79.

Farley, K.A., Jobbágy, E.G. \& Jackson, R.B. 2005. Effects of afforestation on water yield: a global synthesis with implication for policy. Global Change Biology 11: 1565-1576.

Scholes, R.J. \& Archer, S.R. 1997. Tree-grass interactions in savannas. Annual Reviews of Ecology and Systematics 28: 517-544.

Tölgyesi, C., Valkó, O., Deák, B., Kelemen, A., Bragina, T.M., Gallé, R., Erdős, L. \& Bátori, Z. 2018. Tree-herb co-existence and community assembly in forest-steppe transitions. Plant Ecology and Diversity 11: 465-477.

Tölgyesi, C., Török, P., Hábenczyus, A.A., Bátori, Z., Valkó, O., Deák, B., Tóthmérész, B., Erdős, L. \& Kelemen, A. 2020. Underground deserts below fertility islands - woody species desiccate lower soil layers in sandy drylands. Ecography 43: 848-859.

Csaba Tölgyesi, Szeged, Hungary festuca7@yahoo.com

Péter Török, Debrecen, Hungary molinia@gmail.com

Alida Anna Hábenczyus, Szeged, Hungary alidaanna@gmail.com

Zoltán Bátori, Szeged, Hungary zbatory@gmail.com

Orsolya Valkó, Vácrátót, Hungary valkoorsi@gmail.com

Balázs Deák, Vácrátót, Hungary debalazs@gmail.com

Béla Tóthmérész, Debrecen, Hungary tothmerb@gmail.com

László Erdős, Vácrátót, Hungary erdos.laszlo@okologia.mta.hu

András Kelemen, Vácrátót, Hungary kelemen.andras12@gmail.com 


\section{László Erdős: Green Heroes. From Buddha to Leonardo DiCaprio. Springer. e-book: ISBN 978-3-030- 31806-2, 21,39 €. Hardcover: ISBN 978-3-030-31805- $5,29,95 €$}

"What kind of story can start with Buddha and conclude with Leonardo DiCaprio? Well, a story of a movement that unites animal advocates, nature conservationists, and environmentalists, a movement that ranges from an ancient religious leader to a contemporary movie star. In this book I want to tell some of the most important, most exciting, and most inspiring parts of that story (...). The personalities you will read about in this book form a quite eclectic group: saints and scientists, philosophers and activists, writers and filmmakers, indigenous leaders and clergymen, movie stars and politicians, women and men, humans and nonhumans." - László Erdős begins his book with these words. Therefore he presents a lot of influential people who no doubt had and have an enormous role in shaping the world view of young and adult people.

From the age of seven when I was a kid and later an adolescent, I had a budding and deep interest in Nature. Because of this, I constantly read the fantastic books of David Attenborough, Gerald Durrell, Joy Adamson and Dian Fossey. I also watched the documentaries of Attenborough and Durrell on our black and white television. These writings and films had a definite impact on my career in becoming a biologist and an expert of science popularization. The work of Gerald Durrell was inspirational in dealing with the reintroduction of endangered animals in my scientific research. I still remember from my early years the odour of a freshly published David Attenborough book full of amazing pictures, mainly on wild animals. At home, I still have the collection of almost all of his books published in Hungarian. Later I knew about the work of Jane Goodall and recently I attended her presentation in Budapest together with a full hall. It was a very special moment to see her so close and to photograph the event.

In my childhood I also read the book Doctor Dolittle and the Russian version of this story (both books translated to Hungarian). At that time I thought these were only tales for children and talking with animals is not possible. The section "Talking Apes - Ambassadors of the Animal Kingdom in the Human World" tells us that in fact it is possible. Gorillas, chimpanzees and bonobos can learn more than a thousand words with sign language and talk with their educators and other people. That is a fantastic accomplishment in my eyes.

Darwin, who also has his own chapter in the book, started to demolish the mental wall between men and animals. The research on the cognitive capacities of animals follows this path and shows that primates can also have intelligent ideas to discuss. In this way the difference between Mankind and the Animal Kingdom is perceived to be much smaller today than some centuries ago.

The 223 page book of László Erdős contains three main parts: "Heroes for Animals", "Heroes for Nature" and "Heroes for the Environment". The biographies are arranged in 36 chapters - most of them are the stories of well-known people. However, some units are more broad in scope: for example the

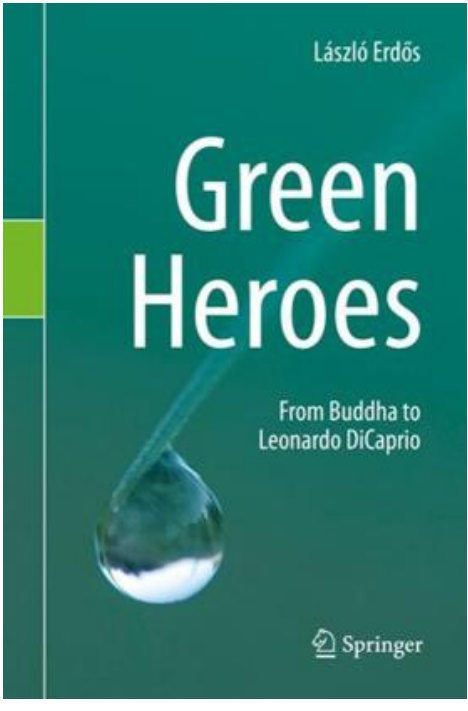
one about the beginnings of the conservation movement and another about the Greenpeace-story. Instead of conventional biographies, Erdős wrote portraits based on biographical data, scientific facts, celebrity stories, historical circumstances, ethical principles, green strategies and tactics, and thought-provoking quotes.

Today there are many people working in the nature conservation and environmental area. They are faced day-to-day to problems which are difficult to solve. Environmental problems are often global and one person can feel too small to have an impact on these processes. People working in other areas also know about these problems and can have the same negative feelings and fear. Many people from both groups mentioned here feel an anxiety about climate which can even affect their mental health. This is why it is so important and reassuring to have idols who have enormous achievements in the field. Reading this book "Green Heroes" and seeing their example tell us that change is possible and there is hope that things can go in the right direction.

Who would be interested in this book? Adolescents with fresh enthusiasm for environmental protection. Professionals working in the nature conservation area who want to be inspired by big achievements, plus anybody interested in nature and environmental conservation. Fortunately, the book avoids jargon, so it is probably accessible to the general public also.

To sum it up, the concept of the book is very interesting this is a work worth reading. It would be interesting to have a similar book for vegetation scientists introducing personalities who shaped botany and vegetation science in the rather long history of botany from the ancient Greeks to the modern era.

Bálint Bajomi, Budapest, Hungary bb@bajomi.eu 


\section{Recent Publications of our Members}

In this section, the contents of which will also be made available via our homepage, we want to facilitate an overview of grassland-related publications throughout Eurasia and to improve their accessibility. You are invited to send lists of such papers from the last three years following the format below to Iwona Dembicz, i.dembicz@gmail.com. We will include your e-mail address so that readers can request a pdf. For authors who own full copyright, we can also post a pdf on the EDGG homepage.

\section{Conservation and restoration}

Boch, S., Dengler, J., Hoderegger, R., Keller, C. \& Bergamini, A. 2020. Verbuschung gefährdet spezialisierte Arten in Felsensteppen. N+L Inside 2020(1): 21-21.

Deák, B., Valkó, O., Nagy, D.D., Török, P., Torma, A., Lőrinczi, G., Kelemen, A., Nagy, A., Bede, Á., (...) \& Tóthmérész, B. 2020. Habitat islands outside nature reserves - threatened biodiversity hotspots of grassland specialist plant and arthropod species. Biological Conservation 241: 108254.

Kiss, R., Deák, B., Tóthmérész, B., Miglécz, T., Tóth, K., Török, P., Lukács, K., Godó, L., Körmöczi, Zs., (...) \& Valkó, O. 2020. Establishment gaps in species-poor grasslands: artificial biodiversity hotspots to support the colonization of target species. Restoration Ecology. doi: $10.1111 /$ rec.13135

Kovácsné Koncz, N., Béri, B., Deák, B., Kelemen, A., Tóth, K., Kiss, R., Radócz, Sz., Miglécz, T., Tóthmérész, B. \& Valkó, O. 2020. Meat production and maintaining biodiversity: Grazing by traditional and crossbred beef cattle breeds in marshes and grasslands. Applied Vegetation Science 23: 139-148.

Valkó, O., Deák, B., Török, P., Tóth, K., Kiss, R., Kelemen, A., Miglécz, T., Sonkoly, J. \& Tóthmérész, B. 2020. Dynamics in vegetation and seed bank composition highlight the importance of post-restoration management in sown grasslands. Restoration Ecology. doi: 10.1002/rec.13192

Kirschner, P., Záveská, E., Gamisch, A., Hilpold, A., Trucchi, E., Paun, O., Sanmartín, I., Schlick-Steiner, B.C., Frajman, B., (...) \& Schönswetter, P. 2020. Long-term isolation of European steppe outposts boosts the biome's conservation value. Nature Communications 11: 1968.

\section{Biodiversity}

Vetter, V., Kreyling, J., Dengler, J., Apostolova, I., Arfin Khan, M.A.S., Berauer, B.J., Berwaers, S., De Boeck, H., Nijs, I., (...) \& Jentsch, A. 2020. Invader presence disrupts the stabilizing effect of species richness in plant community recovery after drought. Global Change Biology 26: 3539 -3551 .

\section{Ecology}

Li, Z., Li, Z., Tong, X., Zhang, J., Dong, L., Zheng, Y., Ma, W., Zhao, L., Wang, L., (...) \& Li, F.Y. 2020. Climatic humidity mediates the strength of the species-richness-biomass relationship on the Mongolian Plateau steppe. Science of the Total Environment 718: Article 137252.

Wang, Y., Niu, X., Hhao, L., Liang, C., Miao, B., Zhang, Q., Zhang, J., Schmid, B. \& Ma, W. 2020. Biotic stability mechanisms in Inner Mongolian grassland. Proceedings of the Royal Society B 287: Article 20200675.

\section{Methodology, classification, databases}

Bruelheide, H., Jansen, F., Jandt, U., Bernhardt-Römermann, M., Bonn, A., Bowler, D., Dengler, J., Eichenberg, D., Grescho, V., (...) \& Lütt, S. 2020. Using incomplete floristic monitoring data from habitat mapping programmes to detect species trends. Diversity and Distributions 26: 782-794.

Jansen, F., Biurrun, I., Dengler, J. \& Willner, W. 2020. Vegetation classification goes open access. Vegetation Classification and Survey 1: 1-6.

\section{Contact persons:}

Steffen Boch: steffen.boch@wsl.ch

Balázs Deák: debalazs@gmail.com

Jürgen Dengler: juergen.dengler@uni-bayeruth.de

Orsolya Valkó: valkoorsi@gmail.com

Jinghui Zhang: xzhn@zhaw.ch

Philipp Kirschner: philipp.kirschner@gmail.com

Andreas Hilpold: andreas.hilpold@eurac.edu 


\section{Forthcoming Events}

$11^{\text {th }}$ International Conference on Ecological Informatics (ICEI:2020)

17-21 November 2020, Thiruvnanthapuram, India

Event website: https://www.iiitmk.ac.in/cvrlei/icei2020/ index.html

\section{$29^{\text {th }}$ Workshop of the European Vegetation Survey (EVS)}

Spring 2021, Roma, Italy

$14^{\text {th }}$ EDGG Field Workshop:

May 2021 South Ukraine

FW webpage https://edgg.org/fieldworkshop2020

$64^{\text {th }}$ Symposium of the International Association for Vegetation Science (IAVS)

28 June - 3 July 2021, Madrid, Spain

$30^{\text {th }}$ International Congress for Conservation Biology (ICCB) 2021

18-22 July 2021, Kigali, Rwanda

Conference website:https://conbio.org/mini-sites/iccb-2021 $17^{\text {th }}$ Eurasian Grassland Conference: Grassland dynamics and conservation in a changing world

September 2021, Tolosa, Spain

Conference webpage https://edgg.org/egc2020

$30^{\text {th }}$ Workshop of the European Vegetation Survey (EVS) Spring 2022, Bratislava, Slovakia

$15^{\text {th }}$ EDGG Field Workshop:

Summer 2022, South Tyrol (Vintschgau, Veltlin, etc.), Italy

$18^{\text {th }}$ Eurasian Grassland Conference

Summer 2022, Hungary

$16^{\text {th }}$ EDGG Field Workshop

Summer 2023, Picos de Europa, Northern Spain

$19^{\text {th }}$ Eurasian Grassland Conference

Late summer 2023, Bolzano, Italy

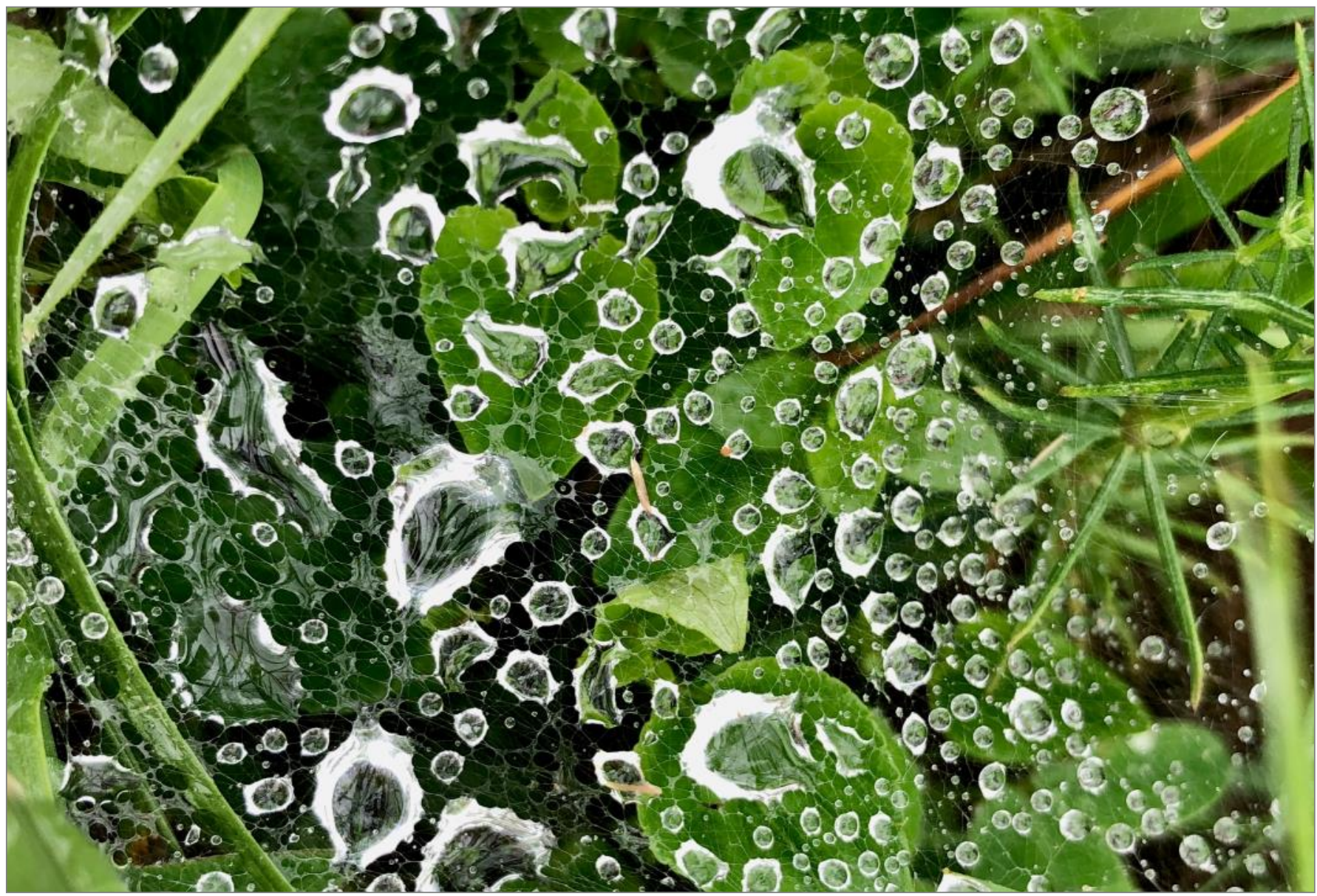

Cobweb after rain, Nova Sedlica village, Romania. Photo: M. Janišová. 


\section{eDGG}

Grass|ลกd] research and conservation
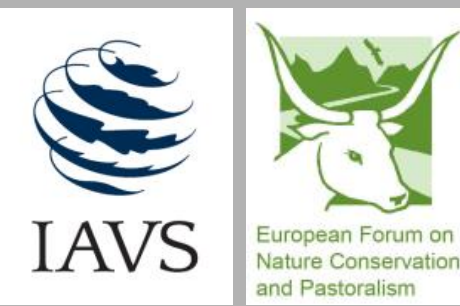

EDGG on the web:

http://www.edgg.org

EDGG in Facebook:

https://www.facebook.com/groups/938367279561202

EDGG on the ResearchGate

https://www.researchgate.net/project/EDGG-Eurasian-

DryGrassland-Group

The Eurasian Dry Grassland Group (EDGG), founded in 2008, is a working group of the International Association for Vegetation Science (IAVS) and member of the European Forum on Nature Conservation and Pastoralism (EFNCP). On 15 July 2020 , it had 1337 members from 64 countries.

The Eurasian Dry Grassland Group (EDGG) is a network of researchers and conservationists interested in any type of Palaearctic natural and semi-natural grasslands. It is an official subgroup of IAVS (http://www.iavs.org) but one can join our group without being an IAVS member. We live from the activities of our members. Everybody can join the EDGG without any fee or other obligation.

The EDGG covers all aspects related to grasslands, in particular: plants - animals - fungi - microbia - soils - taxonomy - phylogeography - ecophysiology - population biology - species' interactions - vegetation ecology - syntaxonomy - landscape ecology - biodiversity - land use history - agriculture - nature conservation - restoration - environmental legislation - environmental education.

\section{EDGG Executive Committee and responsibilities of its members}

Alla Aleksanyan, Armenia, alla.alexanyan@gmail.com Chief Editor of the Website; Deputy Conference Coordinator; member of the Editorial Board of Palaearctic Grasslands

Didem Ambarlı, Turkey \& Germany, didem.ambarli@gmail.com

Conference Coordinator; Deputy Chief Editor of the Website; member of the Editorial Board of Palaearctic Grasslands

Idoia Biurrun, Spain, idoia.biurrun@ehu.es

Membership Administrator; Deputy Chief Editor of Palaearctic Grasslands; Deputy Field Workshop Coordinator

Jürgen Dengler, Switzerland, juergen.dengler@uni-bayreuth.de

Secretary-General; Coordinator for Special Features; Deputy Chief Editor of Palaearctic Grasslands
Iwona Dembicz, Poland, i.dembicz@gmail.com

Field Workshop Coordinator; member of the Editorial Board of Palaearctic Grasslands

Anna Kuzemko, Ukraine, anyameadow.ak@gmail.com Chief Editor of Palaearctic Grasslands; Deputy Facebook Group Administrator

Péter Török, Hungary, molinia@gmail.com IAVS Representative and Treasurer; Deputy Coordinator for Special Features; Deputy Secretary-General; member of the Editorial Board of Palaearctic Grasslands

Stephen Venn, Finland, stephen.venn@helsinki.fi Facebook Group Administrator; member of the Editorial Board of Palaearctic Grasslands; Deputy Conference Coordinator

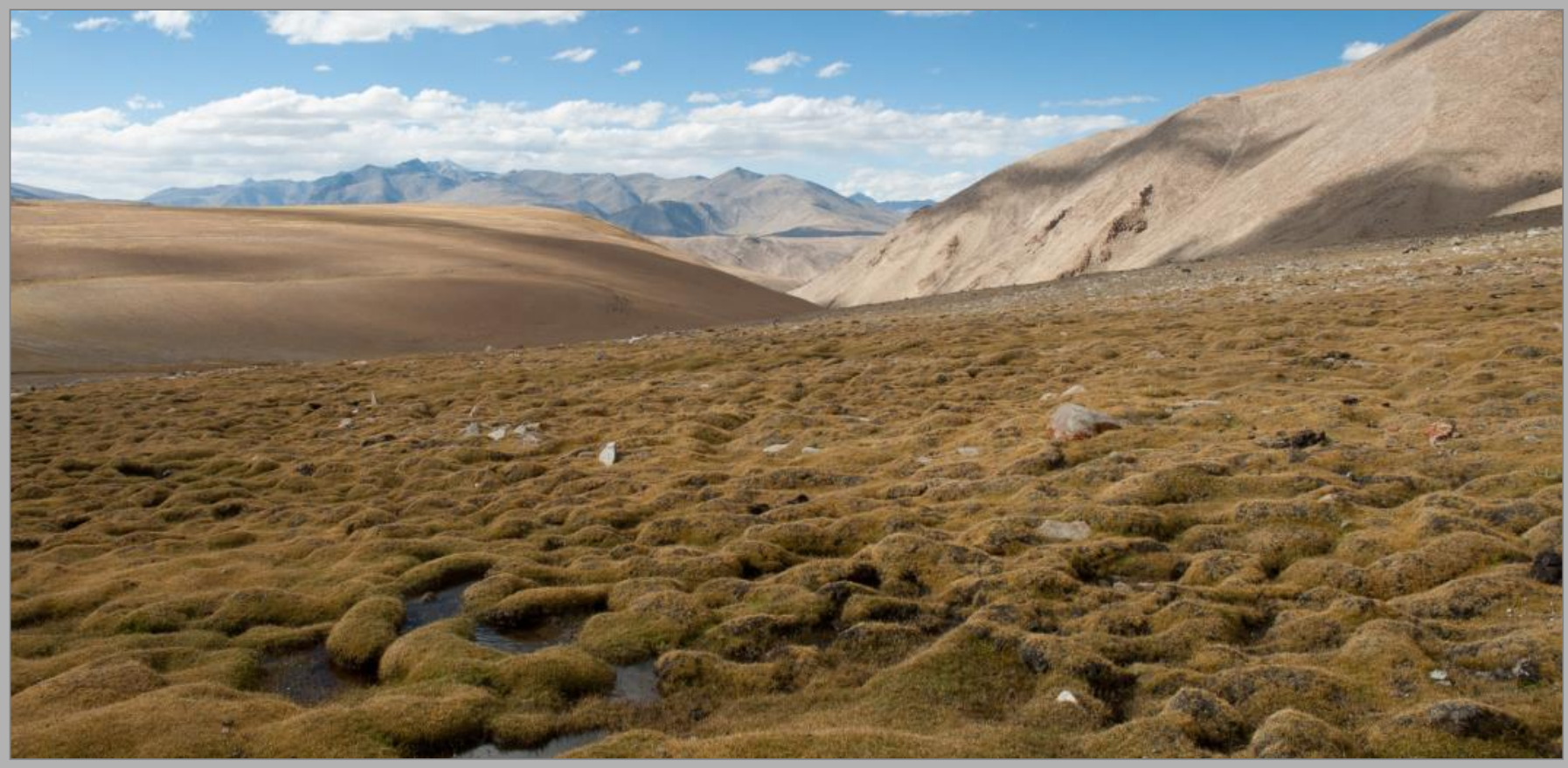

